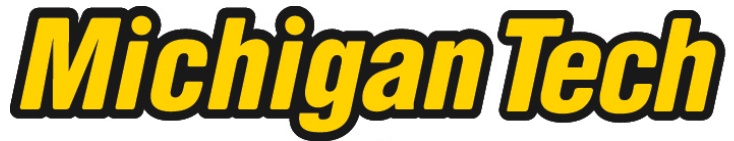 \\ Michigan Technological University Create the Future Digital Commons @ Michigan Tech
}

2006

Development and modeling of thermally conductive resins for fuel cell bipolar plate applications

Michael G. Miller

Michigan Technological University

Follow this and additional works at: https://digitalcommons.mtu.edu/etds

Part of the Chemical Engineering Commons

Copyright 2006 Michael G. Miller

\section{Recommended Citation}

Miller, Michael G., "Development and modeling of thermally conductive resins for fuel cell bipolar plate applications", Dissertation, Michigan Technological University, 2006.

https://doi.org/10.37099/mtu.dc.etds/3

Follow this and additional works at: https://digitalcommons.mtu.edu/etds

Part of the Chemical Engineering Commons 


\title{
Development and Modeling of Thermally Conductive Resins for Fuel Cell Bipolar Plate Applications
}

By

\author{
Michael G. Miller
}

Bachelor of Science, Michigan Technological University, May 2003

\author{
A Dissertation \\ Submitted to the Graduate Faculty \\ Of The \\ Michigan Technological University \\ In partial fulfillment of the requirements \\ For the degree of \\ Doctor of Philosophy \\ In \\ Chemical Engineering \\ Houghton, Michigan \\ September 2006 \\ (C) 2006 Michael G. Miller
}




\section{Chapter 0: Prequel}

\section{Section 0.1: Signatures Page}

This dissertation, "Development and Modeling of Thermally Conductive Resins for Fuel Cell Bipolar Plate Applications,” is hereby approved in partial fulfillment of the requirements for the degree of DOCTOR OF PHILOSPHY in the field of Chemical Engineering.

\section{DEPARTMENT - Chemical Engineering}

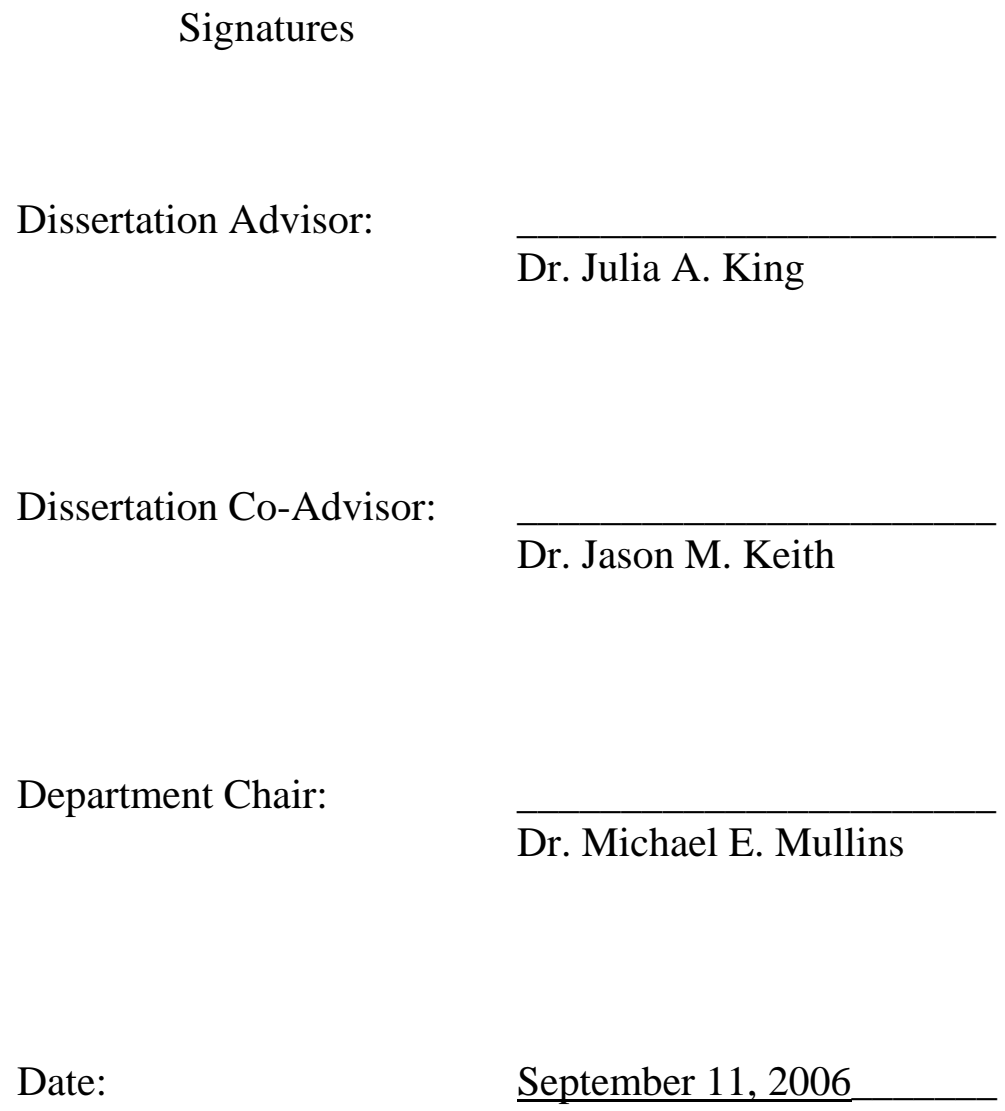




\title{
Section 0.2: Abstract Development and Modeling of Thermally Conductive Resins for Fuel Cell Bipolar Plate Applications
}

\author{
By: Michael G. Miller \\ Committee Chair: Dr. Julia A. King \\ Committee Co-Chair: Dr. Jason M. Keith \\ Chemical Engineering
}

Thermally conductive resins are a class of material that show promise in many different applications. One growing field for their use is in the area of bipolar plate technology for fuel cell applications. In this work, a LCP was mixed with different types of carbon fillers to determine the effects of the individual carbon fillers on the thermal conductivity of the composite resin. In addition, mathematical modeling was performed on the thermal conductivity data with the goal of developing predictive models for the thermal conductivity of highly filled composite resins. 


\section{Section 0.3: Acknowledgements}

First and foremost, I would like to thank my committee (co-advisors Dr. Julia A. King and Dr. Jason M. Keith, committee members Dr. Joseph H. Holles and Dr. Ibrahim Miskioglu) for their continued guidance and support as I proceeded with this project.

Funding for my research was graciously provided by the U.S. Department of Education (GAANN grant via Dr. S. Komar Kawatra), the U.S. Department of Energy and the National Science Foundation.

Without the support and understanding of my family, none of this would have been possible. My parents, Chris and Cheryle Miller, and my sister, Catherine, have always been there for me during all my years at Michigan Tech. Their words of inspiration and support have kept me going even through the toughest times.

Over the years, the people who have shared the office I worked in have been wonderful to be around and work with. Nick Janda and Carrie Majkrzak, your verbal jousts never failed to keep my spirits high - and you always made sure I was keeping the proper perspective on things. Cho Hui Lim, Rodwick Barton and Rebecca Hauser, you were all joys to work with - your assistance on various portions of our mutual projects was invaluable.

All the undergraduate assistance I received over the course of this project made the work go a lot more smoothly and a lot more enjoyably. Many thanks go out to Megan Donaldson, Rachel Wright, Rebecca Hauser, Angela Moran, James Simoneau, Kelly Griffioen, Teresa Savaloja, Connie Gherna, Samuel Kosiara, Hiram Witkop, Lemayian Kimojino, Carl Hingst, Ryan Smith, Amanda Neuhalfen, Anthony Michalski,

Nils Klinkenberg, Marianna Cruz, Stephanie Nattrass, Kelly Griffioen, Amanda Tomson, 
Brian Edwards, Matt Hedlund, Juan Morinelly, Leslie Brown, Andrew Cole, Kara Lenhart, Katherine Lindahl, Jacob Lundmark, Terrence Mazure, Troy Tambling, Samuel Roache, Elaine Venema, Joan Wierzba, Amanda Zalud, Peter Grant, Bryan Klett, and Matt Ponkey.

I'd also like to thank some of my high school teachers for guiding me into chemical engineering along the way. Of particular note are Harlan Larson (chemistry), Dawn Bassuener and Mary Pardun (biology) and Gerry Pardun (physics) for helping me narrow down which field of science I wanted to specialize in and Cindy Goll, Lori Kotarba and John Kriegl (mathematics) for firing my interest in the mathematical side of the sciences. 
Section 0.4: Table of Contents

Chapter 0: Prequel.................................................... 0-2

Section 0.1: Signatures Page............................................... 0-2

Section 0.2: Abstract ............................................................... 0-3

Section 0.3: Acknowledgements ........................................... 0-4

Section 0.4: Table of Contents.................................................... 0-6

Section 0.5: List of Figures ....................................................... 0-10

Section 0.6: List of Tables................................................... 0-14

Section 0.7: Table of Nomenclature...................................... 0-20

Chapter 1: Introduction ............................................ 1-1

Section 1.1: Background ............................................................ 1-1

Section 1.2: Thermal Conductivity ........................................... 1-3

Section 1.3: Motivation ................................................................... 1-4

Section 1.4: Fuel Cells .................................................................... 1-5

Section 1.5: Bipolar Plates ......................................................... 1-7

Section 1.6: Research Objectives ............................................. 1-9

Section 1.7: References ............................................................... 1-10

Chapter 2: Fundamentals of Polymers, Heat Transfer and Fuel Cell Bipolar Plates......................................... 2-1

Section 2.1: Polymeric and Composite Materials.................. 2-1

Section 2.2: Thermal Conductivity Background ................... 2-4

Section 2.3: Thermal Conductivity Models............................ 2-8

Section 2.3.1: Basic Thermal Conductivity Models ............................ 2-9

Section 2.3.2: Advanced Thermal Conductivity Models .................... 2-10

Section 2.4: Current Bipolar Plate Technology ................... 2-18

Section 2.5: References .............................................................. 2-20

Chapter 3: Materials and Experimental Procedures . 3-1

Section 3.1: Materials..................................................................... 3-1

Section 3.1.1: Matrix Materials................................................................. 3-1

Section 3.1.1.1: Vectra A950RX LCP.......................................................... 3-1

Section 3.1.2: Filler Materials............................................................... 3-2

Section 3.1.2.1: Ketjenblack ............................................................................................ 3-2

Section 3.1.2.2: Asbury Thermocarb Synthetic Graphite..................................... 3-6

Section 3.1.2.3: Asbury Synthetic Graphite 4012 ............................................. 3-8

Section 3.1.2.4: Asbury Natural Flake Graphite 3160 .................................. 3-10 
Section 3.1.2.5: Asbury Calcined Needle Coke F108A ................................... 3-12

Section 3.1.2.6: Fortafil 243 Carbon Fiber................................................... 3-14

Section 3.2: Experimental Design .......................................... 3-15

Section 3.3: Methods .................................................................. 3-16

Section 3.3.1: Fabrication Methods............................................... 3-16

Section 3.3.1.1: Drying .................................................................................... 3-16

Section 3.3.1.2: Extrusion.......................................................................16

Section 3.3.1.3: Injection Molding ..............................................................3-21

Section 3.3.2: Test Methods.................................................................... 3-24

Section 3.3.2.1: TCA Analysis (Transverse Thermal Conductivity) (ASTM

F433-98) ...........................................................................................3-24

Section 3.3.2.2: HotDisk Analysis (Specific Heat, Transverse / Longitudinal

Thermal Conductivity) .....................................................................................3-25

Section 3.3.2.3: Density (ASTM D792-98)......................................................3-29

Section 3.3.2.4: Solvent Digestion (ASTM D5526-98) ..................................... 3-30

Section 3.3.2.5: Filler Length and Aspect Ratio..............................................3-32

Section 3.3.3: Determination of Particle Orientation in the Composite

Section 3.3.3.1: Sample Preparation ................................................................. 3-35

Section 3.3.3.2: Polishing .............................................................................3-36

Section 3.3.3.3: Optical Imaging Methods....................................................... 3-37

Section 3.3.3.4: Image Processing...............................................................3-39

Section 3.3.3.5: Image Analysis and Measurements .....................................3-39

Section 3.4: References ........................................................... 3-41

Chapter 4: Carbon Black and Carbon Particle Studies

4-1

Section 4.1: Materials............................................................. 4-1

Section 4.2: Experimental Method............................................... 4-2

Section 4.3: Sample Fabrication .............................................. 4-3

Section 4.4: Sample Testing........................................................ 4-3

Section 4.5: Results............................................................................ 4-4

Section 4.5.1: Thermal Conductivity Results......................................... 4-4

Section 4.5.1.1: Carbon Black Thermal Conductivity Results.......................... 4-5

Section 4.5.1.2: Carbon Particle Thermal Conductivity Results......................... 4-5

Section 4.5.2: Filler Orientation Results ........................................ 4-6

Section 4.6: Summary ..................................................................... 4-7

Section 4.7: References ........................................................ 4-8

Chapter 5: Thermocarb TC-300 Study........................ 5-1

Section 5.1: Materials........................................................ 5-1

Section 5.2: Experimental Method............................................. 5-2 
Section 5.3: Sample Fabrication ........................................... 5-3

Section 5.4: Sample Testing......................................................... 5-3

Section 5.5: Results.......................................................................... 5-4

Section 5.5.1: Thermal Conductivity Results........................................ 5-4

Section 5.5.2: Thermal Conductivity Model Results........................... 5-7

Section 5.5.3: Filler Orientation Results .............................................. 5-8

Section 5.6: Summary ............................................................ 5-9

Section 5.7: References ....................................................... 5-10

Chapter 6: Fortafil 243 Carbon Fiber Study .............. 6-1

Section 6.1: Materials............................................................... 6-1

Section 6.2: Experimental Method....................................... 6-2

Section 6.3: Sample Fabrication ........................................ 6-3

Section 6.4: Sample Testing................................................ 6-3

Section 6.5: Results............................................................. 6-4

Section 6.5.1: Heat Capacity Results .................................................... 6-4

Section 6.5.2: Thermal Conductivity Results....................................... 6-4

Section 6.5.3: Thermal Conductivity Model Results........................... 6-7

Section 6.6: Summary ......................................................... 6-9

Section 6.7: References .............................................................. 6-10

Chapter 7: Modeling................................................... 7-1

Section 7.1: Basic Modeling..................................................... 7-2

Section 7.1.1: Rule of Mixtures................................................................ 7-3

Section 7.1.2: Inverse Rule of Mixtures .................................................. 7-3

Section 7.1.3: Geometric Rule of Mixtures............................................. 7-3

Section 7.1.4: Basic Modeling Results................................................... 7-4

Section 7.1.4.1: Carbon Black Basic Model Results ............................................ 7-4

Section 7.1.4.2: Synthetic Graphite Basic Model Results ................................... 7-6

Section 7.1.4.3: Carbon Fiber ...................................................................... 7-8

Section 7.2: Nielsen's Model and Variants.......................... 7-10

Section 7.3: Nielsen's Model and Variants Results ............ 7-12

Section 7.3.1: Carbon Black Advanced Model Results..................... 7-12

Section 7.3.2: Synthetic Graphite Advanced Model Results............. 7-13

Section 7.3.3: Carbon Fiber Advanced Model Results ..................... 7-15

Section 7.4: Modeling Summary ............................................. 7-17

Section 7.5: References ............................................................... 7-18

Chapter 8: Summary and Future Work....................... 8-1 
Section 8.1: Impact of Carbon Black on Thermal

Conductivity..................................................................................... 8-1

Section 8.2: Impact of Carbon Particle on Thermal

Conductivity.................................................................................... 8-1

Section 8.3: Impact of Carbon Fiber on Thermal

Conductivity.......................................................................... 8-2

Section 8.4: Summary of Model Results................................. 8-2

Section 8.5: Contributions ................................................... 8-3

Section 8.6: Recommendations for Future Work................. 8-4

Section 8.7: References ............................................................ 8-5

Chapter 9: Appendices ................................................9-1

Section 9.1: Extrusion Screw Designs.................................... 9.1-1

Section 9.2: Extrusion Conditions......................................... 9.2-1

Section 9.3: Injection Molding Conditions.......................... 9.3-1

Section 9.4: TCA Through-Plane Thermal Conductivity 9.4-1

Section 9.5: Specific Heat Data ............................................. 9.5-1

Section 9.6: Hot Disk Thermal Conductivity Data............ 9.6-1

Section 9.7: Density Data ....................................................... 9.7-1

Section 9.8: Orientation Data ..................................................... 9.8-1

Section 9.9: Through-Plane Micrographs ........................... 9.9-1

Section 9.10: In-Plane Micrographs ................................... 9.10-1

Section 9.11: Modeling Results ............................................ 9.11-1 


\section{Section 0.5: List of Figures}

Figure 1.5-1: Cross Section of Polymer Electrolyte Fuel Cell [13] ...............................1-7

Figure 2.1-1: Representation of Polymer Chains in an Amorphous Polymer [1-2] ....... 2-1

Figure 2.1-2: 2D Representation of Polymer Chains in a Semi-Crystalline Polymer [1,3]

Figure 2.2-1: Two-Dimensional Array of Atoms Connected by Springs.......................2-5 Figure 2.2-2: Fiber Configurations [(a) carbon fiber in a vacuum, (b) carbon fiber in

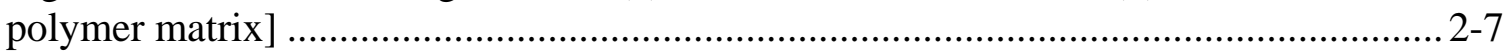

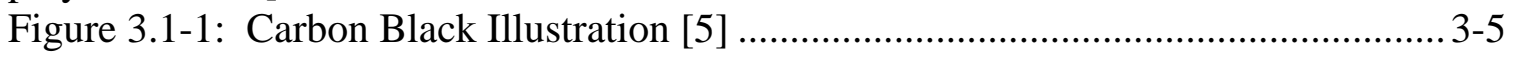

Figure 3.1-2: Thermocarb TC-300 SEM image..........................................................

Figure 3.1-3: Asbury Synthetic Graphite 4012 SEM image ........................................... 3-9

Figure 3.1-4: Asbury Natural Flake Graphite 3160 SEM Image ................................. 3-11

Figure 3.1-5: Asbury Calcined Needle Coke F108A SEM Image.............................. 3-13

Figure 3.1-6: Fortafil 243 Carbon Fiber SEM Image ............................................... 3-14

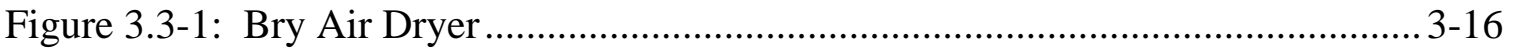

Figure 3.3-2: 27mm Twin Screw American Leistritz Extruder................................... 3-18

Figure 3.3-3: AccuRate Flexwall Feeder ................................................................. 3-18

Figure 3.3-4: AccuRate Conisteel Feeder.............................................................. 3-18

Figure 3.3-5: Water Bath and Pelletizer ................................................................... 3-20

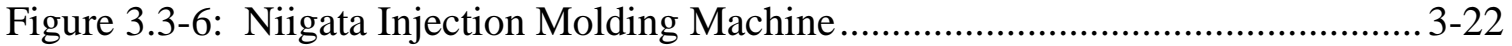

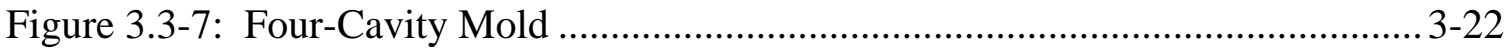

Figure 3.3-8: Diagram of Thermal Conductivity Test Method [21] ............................. 3-24

Figure 3.3-9: Image of TCA 300 ............................................................................ 3-25

Figure 3.3-10: Schematic of Samples and Sensor. The inset at the lower left shows the

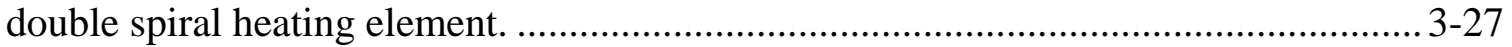

Figure 3.3-11: Solvent Digestion Filtration Apparatus...............................................3-32

Figure 3.3-12: Fiber Dispersion Apparatus ............................................................... 3-33

Figure 3.3-13: Image of Microscope Setup used for Filler Length and Aspect Ratio.. 3-34

Figure 3.3-14: Polishing Apparatus ....................................................................... 3-36

Figure 3.3-15: Olympus BX60 Microscope.......................................................... 3-38

Figure 3.3-16: Top View of Sample Pucks used in Image Analysis (Through-Plane and

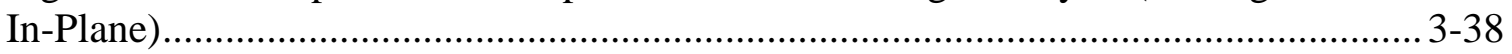

Figure 4.5-1: Through-Plane Thermal Conductivity Results ..................................... 4-4

Figure 4.5-2: Through -Plane Thermal Conductivity Sample Containing $40 \mathrm{wt} \%$

Calcined Needle Coke F108A in Vectra A950RX at 100X Magnification.....................4-6

Figure 5.5-1: Through-Plane Thermal Conductivity (W/mK) vs. Volume Fraction Filler

for Synthetic Graphite / Vectra Composite, TCA........................................................5-5

Figure 5.5-2: Through-Plane Thermal Conductivity (W/mK) vs. Volume Fraction Filler

for Synthetic Graphite / Vectra Composite, HotDisk ..................................................5-5

Figure 5.5-3: In-Plane Thermal Conductivity (W/mK) vs. Volume Fraction Filler for

Synthetic Graphite / Vectra Composite, HotDisk ........................................................5-5

Figure 5.5-4: Combined Thermal Conductivity (W/mK) vs. Volume Fraction Filler for

Synthetic Graphite / Vectra Composite (Exponential Fit).............................................5-8

Figure 6.5-1: Through-Plane Thermal Conductivity (W/mK) vs. Volume Fraction

Fortafil 243 Carbon Fiber, TCA ......................................................................... 6-5 
Figure 6.5-2: Through-Plane Thermal Conductivity (W/mK) vs. Volume Fraction Fortafil 243 Carbon Fiber, HotDisk.

Figure 6.5-3: In-Plane Thermal Conductivity (W/mK) vs. Volume Fraction Fortafil 243

Carbon Fiber, HotDisk

Figure 6.5-4: Combined Thermal Conductivity (W/mK) vs. Volume Fraction Fortafil

243 Carbon Fiber (Exponential Fit).

Figure 7.1-1: Basic Mixing Rule Model Results - Carbon Black Composites .............. 7-5

Figure 7.1-2: Basic Mixing Rule Model Results - Synthetic Graphite Composites ...... 7-7

Figure 7.1-3: Selected Basic Mixing Rule Model Results - Synthetic Graphite

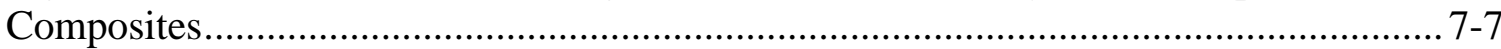

Figure 7.1-4: Basic Mixing Rule Model Results - Carbon Fiber Composites ............... 7-9

Figure 7.1-5: Selected Basic Mixing Rule Model Results - Carbon Fiber Composites. 7-9

Figure 7.3-1: Advanced Model Results - Carbon Black Composites ......................... 7-13

Figure 7.3-2: Advanced Model Results - Synthetic Graphite Composites .................. 7-14

Figure 7.3-3: Advanced Model Results - Carbon Fiber Composites ........................... 7-16

Figure 9.1-1: 5-12-2004 Screw Design (Used for extrusion in this work prior to May

2005)

9.1-1

Figure 9.1-2: 5-12-2004 Screw Design (Used for extrusion in this work prior to May 2005)

Figure 9.9-1: Optical Micrograph by reflected light of a through-plane thermal conductivity sample containing $40 \mathrm{wt} \%$ Thermocarb TC-300 synthetic graphite in Vectra A950RX LCP at 100x magnification.

Figure 9.9-2: Optical Micrograph by reflected light of a through-plane thermal conductivity sample containing $60 \mathrm{wt} \%$ Thermocarb TC-300 synthetic graphite in Vectra A950RX LCP at 200x magnification. 9.9-2

Figure 9.9-3: Optical Micrograph by reflected light of a through-plane thermal conductivity sample containing $70 \mathrm{wt} \%$ Thermocarb TC-300 synthetic graphite in Vectra A950RX LCP at 100x magnification.

Figure 9.9-4: Optical Micrograph by reflected light of a through-plane thermal conductivity sample containing $40 \mathrm{wt} \%$ Asbury 4012 synthetic graphite in Vectra A950RX LCP at 100x magnification.

Figure 9.9-5: Optical Micrograph by reflected light of a through-plane thermal conductivity sample containing $60 \mathrm{wt} \%$ Asbury 4012 synthetic graphite in Vectra A950RX LCP at 100x magnification.

Figure 9.9-6: Optical Micrograph by reflected light of a through-plane thermal conductivity sample containing $70 \mathrm{wt} \%$ Asbury 4012 synthetic graphite in Vectra A950RX LCP at 100x magnification.

Figure 9.9-7: Optical Micrograph by reflected light of a through-plane thermal conductivity sample containing $40 \mathrm{wt} \%$ Asbury 3160 natural flake graphite in Vectra A950RX LCP at 200x magnification.

Figure 9.9-8: Optical Micrograph by reflected light of a through-plane thermal conductivity sample containing $60 \mathrm{wt} \%$ Asbury 3160 natural flake graphite in Vectra A950RX LCP at 200x magnification.

Figure 9.9-9: Optical Micrograph by reflected light of a through-plane thermal conductivity sample containing $70 \mathrm{wt} \%$ Asbury 3160 natural flake graphite in Vectra A950RX LCP at 200x magnification. 
Figure 9.9-10: Optical Micrograph by reflected light of a through-plane thermal conductivity sample containing $40 \mathrm{wt} \%$ Asbury F108A CNC in Vectra A950RX LCP at 100x magnification.

Figure 9.9-11: Optical Micrograph by reflected light of a through-plane thermal conductivity sample containing $60 \mathrm{wt} \%$ Asbury F108A CNC in Vectra A950RX LCP at 100x magnification. 9.9-11

Figure 9.9-12: Optical Micrograph by reflected light of a through-plane thermal conductivity sample containing 70 wt\% Asbury F108A CNC in Vectra A950RX LCP at 100x magnification. 9.9-12

Figure 9.9-13: Optical Micrograph by reflected light of a through-plane thermal conductivity sample containing $10 \mathrm{wt} \%$ Fortafil 243 carbon fiber in Vectra A950RX LCP at $100 \mathrm{x}$ magnification. 9.9-13

Figure 9.9-14: Optical Micrograph by reflected light of a through-plane thermal conductivity sample containing $20 \mathrm{wt} \%$ Fortafil 243 carbon fiber in Vectra A950RX LCP at $100 \mathrm{x}$ magnification. 9.9-14

Figure 9.9-15: Optical Micrograph by reflected light of a through-plane thermal conductivity sample containing $40 \mathrm{wt} \%$ Fortafil 243 carbon fiber in Vectra A950RX LCP at 100x magnification. 9.9-15

Figure 9.9-16: Optical Micrograph by reflected light of a through-plane thermal conductivity sample containing 60 wt\% Fortafil 243 carbon fiber in Vectra A950RX LCP at 100x magnification. 9.9-16 Figure 9.10-1: Optical Micrograph by reflected light of an in-plane electrical resistivity sample containing $40 \mathrm{wt} \%$ Thermocarb TC-300 synthetic graphite in Vectra A950RX LCP at 200x magnification.

Figure 9.10-2: Optical Micrograph by reflected light of an in-plane electrical resistivity sample containing $60 \mathrm{wt} \%$ Thermocarb TC-300 synthetic graphite in Vectra A950RX LCP at 200x magnification. 9.10-1 Figure 9.10-3: Optical Micrograph by reflected light of an in-plane electrical resistivity sample containing $70 \mathrm{wt} \%$ Thermocarb TC-300 synthetic graphite in Vectra A950RX LCP at 200x magnification. 9.10-1

Figure 9.10-4: Optical Micrograph by reflected light of an in-plane electrical resistivity sample containing $40 \mathrm{wt} \%$ Asbury 4012 synthetic graphite in Vectra A950RX LCP at 100x magnification.

Figure 9.10-5: Optical Micrograph by reflected light of an in-plane electrical resistivity sample containing $60 \mathrm{wt} \%$ Asbury 4012 synthetic graphite in Vectra A950RX LCP at 100x magnification.

Figure 9.10-6: Optical Micrograph by reflected light of an in-plane electrical resistivity sample containing $70 \mathrm{wt} \%$ Asbury 4012 synthetic graphite in Vectra A950RX LCP at 100x magnification.

Figure 9.10-7: Optical Micrograph by reflected light of an in-plane electrical resistivity sample containing $40 \mathrm{wt} \%$ Asbury 3160 natural flake graphite in Vectra A950RX LCP at 200x magnification. 9.10-3

Figure 9.10-8: Optical Micrograph by reflected light of an in-plane electrical resistivity sample containing $60 \mathrm{wt} \%$ Asbury 3160 natural flake graphite in Vectra A950RX LCP at 200x magnification. 9.10-3 
Figure 9.10-9: Optical Micrograph by reflected light of an in-plane electrical resistivity sample containing $70 \mathrm{wt} \%$ Asbury 3160 natural flake graphite in Vectra A950RX LCP at 100x magnification. 9.10-3

Figure 9.10-10: Optical Micrograph by reflected light of an in-plane electrical resistivity sample containing $40 \mathrm{wt} \%$ Asbury F108A CNC in Vectra A950RX LCP at 100x magnification.

Figure 9.10-11: Optical Micrograph by reflected light of an in-plane electrical resistivity sample containing $60 \mathrm{wt} \%$ Asbury F108A CNC in Vectra A950RX LCP at 100x magnification. 9.10-4

Figure 9.10-12: Optical Micrograph by reflected light of an in-plane electrical resistivity sample containing $40 \mathrm{wt} \%$ Asbury F108A CNC in Vectra A950RX LCP at 100x magnification.

Figure 9.10-13: Optical Micrograph by reflected light of an in-plane electrical resistivity sample containing $10 \mathrm{wt} \%$ Fortafil 243 carbon fiber in Vectra A950RX LCP at 100x magnification. 9.10-5

Figure 9.10-14: Optical Micrograph by reflected light of an in-plane electrical resistivity sample containing $20 \mathrm{wt} \%$ Fortafil 243 carbon fiber in Vectra A950RX LCP at 100x magnification. 9.10-5

Figure 9.10-15: Optical Micrograph by reflected light of an in-plane electrical resistivity sample containing $40 \mathrm{wt} \%$ Fortafil 243 carbon fiber in Vectra A950RX LCP at 100x magnification. 9.10-5 Figure 9.10-16: Optical Micrograph by reflected light of an in-plane electrical resistivity sample containing $60 \mathrm{wt} \%$ Fortafil 243 carbon fiber in Vectra A950RX LCP at 100x magnification. 9.10-6 


\section{Section 0.6: List of Tables}

Table 1.2-1: Thermal Conductivity of Common Materials [10].....................................1-3

Table 2.3-1: Shape Factor 'A' for Common Filler Types [11] ..................................... 2-14

Table 2.3-2: Maximum Packing Fraction of Selected Fillers [11] ……........................2-15

Table 3.1-1: Properties of Ticona's Vectra A950RX LCP [1] ........................................ 3-1

Table 3.1-2: Classification of Manufacturing Processes, Feedstocks, and Uses of Carbon

Black [3]......................................................................................................... 3-3

Table 3.1-3: Properties of Akzo Nobel Ketjenblack EC-600 JD Carbon Black [5]........3-5

Table 3.1-4: Properties of Conoco's Thermocarb TC-300 [10] ..................................... 3-7

Table 3.1-5: Properties of Asbury Synthetic Graphite 4012 [10] .................................... 3-9

Table 3.1-6: Properties of Asbury Natural Flake Graphite 3160 [10] ........................... 3-11

Table 3.1-7: Properties of Asbury Calcined Needle Coke F108A [10]......................... 3-13

Table 3.1-8: Properties of Akzo Nobel Fortafil 243 PAN based 3.2mm Chopped and

Pelletized Carbon Fiber [13].................................................................................. 3-14

Table 3.3-1: Polishing Procedure [30] ...................................................................3-37

Table 3.3-2: Polishing Procedure [31] ......................................................................3-37

Table 4.2-1: Single Filler Loading Levels in Vectra A950RX ....................................... 4-2

Table 5.2-1: Single Filler Loading Levels of Thermocarb TC-300 in Vectra A950RX

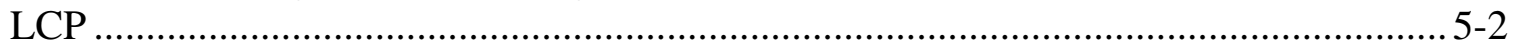

Table 5.5-1: Thermal Conductivity Results................................................................5-6

Table 6.2-1: Single Filler Loading Levels of Fortafil 243 Carbon Fiber in Vectra

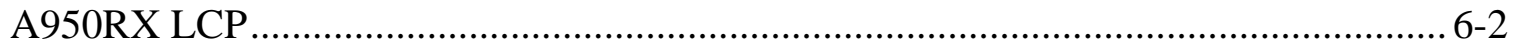

Table 6.5-1: Thermal Conductivity Results.............................................................. 6-7

Table 7.1-1: Thermal Conductivity of Constituents [1-4] ............................................. 7-2

Table 7.1-2: Error Analysis - Basic Mixing Rules, Carbon Black Composite................ 7-5

Table 7.1-3: Error Analysis - Basic Mixing Rules, Synthetic Graphite Composite........7-6

Table 7.1-4: Error Analysis - Basic Mixing Rules, Carbon Fiber Composite................. 7-8

Table 7.2-1: Nielsen Model Parameters [9-10]........................................................... 7-11

Table 7.3-1: Error Analysis - Nielsen's Model, Carbon Black Composites................... 7-12

Table 7.3-2: Error Analysis - Nielsen’s Model, Synthetic Graphite Composites..........7-14

Table 7.3-3: Error Analysis - Nielsen’s Model, Carbon Fiber Composites....................7-15

Table 9.2-1: Extrusion Conditions, EAV Composites................................................. 9.2-2

Table 9.2-2: Extrusion Conditions, EAV Composites............................................... 9.2-3

Table 9.2-3: Extrusion Conditions, EBV Composites ................................................. 9.2-4

Table 9.2-4: Extrusion Conditions, EBV Composites ................................................. 9.2-5

Table 9.2-5: Extrusion Conditions, EBV Composites .................................................. 9.2-6

Table 9.2-6: Extrusion Conditions, EBV Composites ................................................. 9.2-7

Table 9.2-7: Extrusion Conditions, EBV Composites ................................................... 9.2-8

Table 9.2-8: Extrusion Conditions, ECV Composites .............................................. 9.2-9

Table 9.2-9: Extrusion Conditions, EDV Composites................................................ 9.2-10

Table 9.2-10: Extrusion Conditions, EEV Composites ............................................. 9.2-11

Table 9.2-11: Extrusion Conditions, EHV Composites.............................................. 9.2-12

Table 9.2-12: Extrusion Conditions, EHV Composites........................................... 9.2-13

Table 9.2-13: Extrusion Conditions, EHV Composites............................................... 9.2-14

Table 9.2-14: Extrusion Conditions, EHV Composites............................................... 9.2-15 
Table 9.3-1: Injection Molding Conditions for EVRR and EAV Composites ............ 9.3-2

Table 9.3-2: Injection Molding Conditions for EVRR and EAV Composites ........... 9.3-3

Table 9.3-3: Injection Molding Conditions for EBV Composites ............................... 9.3-4

Table 9.3-4: Injection Molding Conditions for EBV Composites ............................. 9.3-5

Table 9.3-5: Injection Molding Conditions for EBV Composites ............................... 9.3-6

Table 9.3-6: Injection Molding Conditions for ECV Composites ............................... 9.3-7

Table 9.3-7: Injection Molding Conditions for EDV Composites..............................9.3-8

Table 9.3-8: Injection Molding Conditions for EEV Composites ............................... 9.3-9

Table 9.3-9: Injection Molding Conditions for EHV Composites..............................9.3-10

Table 9.3-10: Injection Molding Conditions for EHV Composites...........................9.3-11

Table 9.3-11: Injection Molding Conditions for EHV Composites..........................9.3-12

Table 9.4-1: Vectra A950RX LCP............................................................................. 9.4-1

Table 9.4-2: 2.5 wt\% Ketjenblack EC600 JD / Vectra A950RX LCP .........................9.4-1

Table 9.4-3: 4 wt\% Ketjenblack EC600 JD / Vectra A950RX LCP ............................. 9.4-1

Table 9.4-4: 5 wt\% Ketjenblack EC600 JD / Vectra A950RX LCP ............................ 9.4-2

Table 9.4-5: 6 wt\% Ketjenblack EC600 JD / Vectra A950RX LCP ............................ 9.4-2

Table 9.4-6: 7.5 wt\% Ketjenblack EC600 JD / Vectra A950RX LCP .........................9.4-2

Table 9.4-7: 10 wt\% Ketjenblack EC600 JD / Vectra A950RX LCP ..........................9.4-3

Table 9.4-8: 15 wt\% Ketjenblack EC600 JD / Vectra A950RX LCP .........................9.4-3

Table 9.4-9: 10 wt\% Thermocarb TC300 / Vectra A950RX LCP ............................... 9.4-4

Table 9.4-10: 15 wt\% Thermocarb TC300 / Vectra A950RX LCP .............................9.4-4

Table 9.4-11: 20 wt\% Thermocarb TC300 / Vectra A950RX LCP .............................9.4-4

Table 9.4-12: 25 wt\% Thermocarb TC300 / Vectra A950RX LCP ..............................9.4-5

Table 9.4-13: 30 wt\% Thermocarb TC300 / Vectra A950RX LCP ................................4.5

Table 9.4-14: 35 wt\% Thermocarb TC300 / Vectra A950RX LCP .............................9.4-5

Table 9.4-15: 40 wt\% Thermocarb TC300 / Vectra A950RX LCP .............................9.4-6

Table 9.4-16: 45 wt\% Thermocarb TC300 / Vectra A950RX LCP .............................9.4-6

Table 9.4-17: 50 wt\% Thermocarb TC300 / Vectra A950RX LCP .............................9.4-6

Table 9.4-18: 55 wt\% Thermocarb TC300 / Vectra A950RX LCP .............................9.4-7

Table 9.4-19: 60 wt\% Thermocarb TC300 / Vectra A950RX LCP .............................9.4-7

Table 9.4-20: 65 wt\% Thermocarb TC300 / Vectra A950RX LCP .............................9.4-7

Table 9.4-21: 70 wt\% Thermocarb TC300 / Vectra A950RX LCP .............................9.4-8

Table 9.4-22: 75 wt\% Thermocarb TC300 / Vectra A950RX LCP .............................9.4-8

Table 9.4-23: 40 wt\% Asbury Synthetic Graphite 4012 / Vectra A950RX LCP ........ 9.4-9

Table 9.4-24: 60 wt\% Asbury Synthetic Graphite 4012 / Vectra A950RX LCP ........ 9.4-9

Table 9.4-25: 70 wt\% Asbury Synthetic Graphite 4012 / Vectra A950RX LCP ........ 9.4-9

Table 9.4-26: 40 wt\% Asbury 3160 Natural Flake Graphite / Vectra A950RX LCP 9.4-10

Table 9.4-27: 60 wt\% Asbury 3160 Natural Flake Graphite / Vectra A950RX LCP9.4-10

Table 9.4-28: 70 wt\% Asbury 3160 Natural Flake Graphite / Vectra A950RX LCP9.4-10

Table 9.4-29: 40 wt\% Asbury F108A CNC / Vectra A950RX LCP ..........................9.4-11

Table 9.4-30: 60 wt\% Asbury F108A CNC / Vectra A950RX LCP ..........................9.4-11

Table 9.4-31: 70 wt\% Asbury F108A CNC / Vectra A950RX LCP ..........................9.4-11

Table 9.4-32: 5 wt\% Fortafil 243 / Vectra A950RX LCP ..........................................9.4-12

Table 9.4-33: 7.5 wt\% Fortafil 243 / Vectra A950RX LCP ......................................9.4-12

Table 9.4-34: 10 wt\% Fortafil 243 / Vectra A950RX LCP ...................................... 9.4-12

Table 9.4-35: 15 wt\% Fortafil 243 / Vectra A950RX LCP ........................................9.4-13 
Table 9.4-36: 20 wt\% Fortafil 243 / Vectra A950RX LCP ......................................9.4-13

Table 9.4-37: 25 wt\% Fortafil 243 / Vectra A950RX LCP ......................................9.4-13

Table 9.4-38: 30 wt\% Fortafil 243 / Vectra A950RX LCP .........................................9.4-14

Table 9.4-39: 35 wt\% Fortafil 243 / Vectra A950RX LCP .......................................9.4-14

Table 9.4-40: 40 wt\% Fortafil 243 / Vectra A950RX LCP .......................................9.4-14

Table 9.4-41: 45 wt\% Fortafil 243 / Vectra A950RX LCP ........................................ 9.4-15

Table 9.4-42: 50 wt\% Fortafil 243 / Vectra A950RX LCP ......................................9.4-15

Table 9.4-43: 55 wt\% Fortafil 243 / Vectra A950RX LCP ........................................9.4-15

Table 9.4-44: 60 wt\% Fortafil 243 / Vectra A950RX LCP ........................................9.4-16

Table 9.5-1: Vectra A950RX LCP......................................................................... 9.5-1

Table 9.5-2: 10 wt\% Thermocarb TC300 / Vectra A950RX LCP .............................. 9.5-1

Table 9.5-3: 15 wt\% Thermocarb TC300 / Vectra A950RX LCP ............................... 9.5-1

Table 9.5-4: 20 wt\% Thermocarb TC300 / Vectra A950RX LCP .............................. 9.5-2

Table 9.5-5: 30 wt\% Thermocarb TC300 / Vectra A950RX LCP ................................ 9.5-2

Table 9.5-6: 30 wt\% Thermocarb TC300 / Vectra A950RX LCP ............................... 9.5-2

Table 9.5-7: 50 wt\% Thermocarb TC300 / Vectra A950RX LCP ............................... 9.5-3

Table 9.5-8: 55 wt\% Thermocarb TC300 / Vectra A950RX LCP ............................... 9.5-3

Table 9.5-9: 60 wt\% Thermocarb TC300 / Vectra A950RX LCP ............................... 9.5-3

Table 9.5-10: 65 wt\% Thermocarb TC300 / Vectra A950RX LCP ............................ 9.5-4

Table 9.5-11: 70 wt\% Thermocarb TC300 / Vectra A950RX LCP ............................. 9.5-4

Table 9.5-12: 75 wt\% Thermocarb TC300 / Vectra A950RX LCP ............................9.5-4

Table 9.5-13: 40 wt\% Asbury Synthetic Graphite 4012 / Vectra A950RX LCP ........ 9.5-5

Table 9.5-14: 60 wt\% Asbury Synthetic Graphite 4012 / Vectra A950RX LCP ........ 9.5-5

Table 9.5-15: 70 wt\% Asbury Synthetic Graphite 4012 / Vectra A950RX LCP ........ 9.5-5

Table 9.5-16: 40 wt\% Asbury 3160 Natural Flake Graphite / Vectra A950RX LCP .9.5-6

Table 9.5-17: 60 wt\% Asbury 3160 Natural Flake Graphite / Vectra A950RX LCP .9.5-6

Table 9.5-18: 70 wt\% Asbury 3160 Natural Flake Graphite / Vectra A950RX LCP .9.5-6

Table 9.5-19: 40 wt\% Asbury F108A CNC / Vectra A950RX LCP ........................... 9.5-7

Table 9.5-20: 60 wt\% Asbury F108A CNC / Vectra A950RX LCP ............................ 9.5-7

Table 9.5-21: 70 wt\% Asbury F108A CNC / Vectra A950RX LCP ............................ 9.5-7

Table 9.5-22: 5 wt\% Fortafil 243 / Vectra A950RX LCP ........................................... 9.5-8

Table 9.5-23: 7.5 wt\% Fortafil 243 / Vectra A950RX LCP ........................................ 9.5-8

Table 9.5-24: 10 wt\% Fortafil 243 / Vectra A950RX LCP ......................................... 9.5-8

Table 9.5-25: 15 wt\% Fortafil 243 / Vectra A950RX LCP ......................................... 9.5-9

Table 9.5-26: 20 wt\% Fortafil 243 / Vectra A950RX LCP ......................................... 9.5-9

Table 9.5-27: 30 wt\% Fortafil 243 / Vectra A950RX LCP ........................................ 9.5-9

Table 9.5-28: 35 wt\% Fortafil 243 / Vectra A950RX LCP .......................................9.5-10

Table 9.5-29: Theoretical Values for Fortafil 243 / Vectra Composites .................... 9.5-10

Table 9.6-1: 10 wt\% Thermocarb TC300 / Vectra A950RX LCP ............................... 9.6-1

Table 9.6-2: 15 wt\% Thermocarb TC300 / Vectra A950RX LCP ...............................9.6-1

Table 9.6-3: 20 wt\% Thermocarb TC300 / Vectra A950RX LCP .............................. 9.6-1

Table 9.6-4: 25 wt\% Thermocarb TC300 / Vectra A950RX LCP ................................ 9.6-2

Table 9.6-5: 30 wt\% Thermocarb TC300 / Vectra A950RX LCP ............................... 9.6-2

Table 9.6-6: 35 wt\% Thermocarb TC300 / Vectra A950RX LCP ............................... 9.6-2

Table 9.6-7: 40 wt\% Fortafil 243 Carbon Fiber / Vectra A950RX LCP ..................... 9.6-3

Table 9.6-8: 45 wt\% Thermocarb TC300 / Vectra A950RX LCP ............................... 9.6-3 
Table 9.6-9: 50 wt\% Thermocarb TC300 / Vectra A950RX LCP ................................ 9.6-3

Table 9.6-10: 55 wt\% Thermocarb TC300 / Vectra A950RX LCP ..............................9.6-4

Table 9.6-11: 60 wt\% Thermocarb TC300 / Vectra A950RX LCP ..............................9.6-4

Table 9.6-12: 65 wt\% Thermocarb TC300 / Vectra A950RX LCP ..............................9.6-4

Table 9.6-13: $70 \mathrm{wt} \%$ Thermocarb TC300 / Vectra A950RX LCP .............................. 9.6-5

Table 9.6-14: 75 wt\% Thermocarb TC300 / Vectra A950RX LCP ............................. 9.6-5

Table 9.6-15: 40 wt\% Asbury Synthetic Graphite 4012 / Vectra A950RX LCP ........ 9.6-5

Table 9.6-16: 60 wt\% Asbury Synthetic Graphite 4012 / Vectra A950RX LCP ........ 9.6-6

Table 9.6-17: 70 wt\% Asbury Synthetic Graphite 4012 / Vectra A950RX LCP ........ 9.6-6

Table 9.6-18: 40 wt\% Asbury 3160 Natural Flake Graphite / Vectra A950RX LCP .9.6-6

Table 9.6-19: 60 wt\% Asbury 3160 Natural Flake Graphite / Vectra A950RX LCP .9.6-7

Table 9.6-20: 70 wt\% Asbury 3160 Natural Flake Graphite / Vectra A950RX LCP .9.6-7

Table 9.6-21: 5wt\% Fortafil 243 Carbon Fiber / Vectra A950RX LCP ........................ 9.6-7

Table 9.6-22: 7.5wt\% Fortafil 243 Carbon Fiber / Vectra A950RX LCP ..................... 9.6-8

Table 9.6-23: 10wt\% Fortafil 243 Carbon Fiber / Vectra A950RX LCP ...................... 9.6-8

Table 9.6-24: 15wt\% Fortafil 243 Carbon Fiber / Vectra A950RX LCP ...................... 9.6-8

Table 9.6-25: 20wt\% Fortafil 243 Carbon Fiber / Vectra A950RX LCP ...................... 9.6-9

Table 9.6-26: 25wt\% Fortafil 243 Carbon Fiber / Vectra A950RX LCP ...................... 9.6-9

Table 9.6-27: 30wt\% Fortafil 243 Carbon Fiber / Vectra A950RX LCP....................... 9.6-9

Table 9.6-28: 35wt\% Fortafil 243 Carbon Fiber / Vectra A950RX LCP .................... 9.6-10

Table 9.6-29: 40wt\% Fortafil 243 Carbon Fiber / Vectra A950RX LCP .................... 9.6-10

Table 9.6-30: 45wt\% Fortafil 243 Carbon Fiber / Vectra A950RX LCP .................... 9.6-10

Table 9.6-31: 50wt\% Fortafil 243 Carbon Fiber / Vectra A950RX LCP .................... 9.6-11

Table 9.6-32: 55wt\% Fortafil 243 Carbon Fiber / Vectra A950RX LCP .................... 9.6-11

Table 9.6-33: 60wt\% Fortafil 243 Carbon Fiber / Vectra A950RX LCP .................... 9.6-12

Table 9.7-1: Vectra A950RX LCP.......................................................................... 9.7-1

Table 9.7-2: 2.5 wt\% Ketjenblack EC600 JD / Vectra A950RX LCP ..........................9.7-1

Table 9.7-3: 4 wt\% Ketjenblack EC600 JD / Vectra A950RX LCP ............................. 9.7-1

Table 9.7-4: 5 wt\% Ketjenblack EC600 JD / Vectra A950RX LCP ............................. 9.7-2

Table 9.7-5: 6 wt\% Ketjenblack EC600 JD / Vectra A950RX LCP ............................. 9.7-2

Table 9.7-6: 7.5 wt\% Ketjenblack EC600 JD / Vectra A950RX LCP .......................... 9.7-2

Table 9.7-7: 10 wt\% Ketjenblack EC600 JD / Vectra A950RX LCP .......................... 9.7-3

Table 9.7-8: 15 wt\% Ketjenblack EC600 JD / Vectra A950RX LCP ........................... 9.7-3

Table 9.7-9: $10 \mathrm{wt} \%$ Thermocarb TC300 / Vectra A950RX LCP ................................ 9.7-3

Table 9.7-10: 15 wt\% Thermocarb TC300 / Vectra A950RX LCP ............................. 9.7-4

Table 9.7-11: 20 wt\% Thermocarb TC300 / Vectra A950RX LCP .............................. 9.7-4

Table 9.7-12: 25 wt\% Thermocarb TC300 / Vectra A950RX LCP .............................. 9.7-4

Table 9.7-13: 30 wt\% Thermocarb TC300 / Vectra A950RX LCP ............................... 9.7-5

Table 9.7-14: 35 wt\% Thermocarb TC300 / Vectra A950RX LCP ............................. 9.7-5

Table 9.7-15: 40 wt\% Thermocarb TC300 / Vectra A950RX LCP ............................. 9.7-5

Table 9.7-16: 45 wt\% Thermocarb TC300 / Vectra A950RX LCP ............................. 9.7-6

Table 9.7-17: 50 wt\% Thermocarb TC300 / Vectra A950RX LCP ............................. 9.7-6

Table 9.7-18: 55 wt\% Thermocarb TC300 / Vectra A950RX LCP .............................. 9.7-6

Table 9.7-19: 60 wt\% Thermocarb TC300 / Vectra A950RX LCP .............................. 9.7-7

Table 9.7-20: 65 wt\% Thermocarb TC300 / Vectra A950RX LCP .............................. 9.7-7

Table 9.7-21: 70 wt\% Thermocarb TC300 / Vectra A950RX LCP .............................. 9.7-7 
Table 9.7-22: 75 wt\% Thermocarb TC300 / Vectra A950RX LCP ............................9.7-8

Table 9.7-23: 40 wt\% Asbury Synthetic Graphite 4012 / Vectra A950RX LCP ........ 9.7-8

Table 9.7-24: 60 wt\% Asbury Synthetic Graphite 4012 / Vectra A950RX LCP ........ 9.7-8

Table 9.7-25: 70 wt\% Asbury Synthetic Graphite 4012 / Vectra A950RX LCP ........ 9.7-9

Table 9.7-26: 40 wt\% Asbury 3160 Natural Flake Graphite / Vectra A950RX LCP . 9.7-9

Table 9.7-27: 60 wt\% Asbury 3160 Natural Flake Graphite / Vectra A950RX LCP .9.7-9

Table 9.7-28: 70 wt\% Asbury 3160 Natural Flake Graphite / Vectra A950RX LCP 9.7-10

Table 9.7-29: 40 wt\% Asbury F108A CNC / Vectra A950RX LCP ......................... 9.7-10

Table 9.7-30: 60 wt\% Asbury F108A CNC / Vectra A950RX LCP .......................... 9.7-10

Table 9.7-31: 70 wt\% Asbury F108A CNC / Vectra A950RX LCP ..........................9.7-11

Table 9.7-32: 5 wt\% Fortafil 243 / Vectra A950RX LCP ........................................9.7-11

Table 9.7-33: 7.5 wt\% Fortafil 243 / Vectra A950RX LCP ..................................... 9.7-11

Table 9.7-34: 10 wt\% Fortafil 243 / Vectra A950RX LCP ....................................... 9.7-12

Table 9.7-35: 15 wt\% Fortafil 243 / Vectra A950RX LCP ....................................... 9.7-12

Table 9.7-36: 20 wt\% Fortafil 243 / Vectra A950RX LCP ........................................ 9.7-12

Table 9.7-37: 25 wt\% Fortafil 243 / Vectra A950RX LCP ...................................... 9.7-13

Table 9.7-38: 30 wt\% Fortafil 243 / Vectra A950RX LCP ...................................... 9.7-13

Table 9.7-39: 35 wt\% Fortafil 243 / Vectra A950RX LCP ........................................ 9.7-13

Table 9.7-40: 40 wt\% Fortafil 243 / Vectra A950RX LCP ...................................... 9.7-14

Table 9.7-41: 45 wt\% Fortafil 243 / Vectra A950RX LCP ........................................ 9.7-14

Table 9.7-42: 50 wt\% Fortafil 243 / Vectra A950RX LCP ...................................... 9.7-14

Table 9.7-43: 55 wt\% Fortafil 243 / Vectra A950RX LCP .......................................9.7-15

Table 9.7-44: 60 wt\% Fortafil 243 / Vectra A950RX LCP ....................................... 9.7-15

Table 9.8-1: Thermocarb TC300 / Vectra A950RX LCP (In-Plane)........................... 9.8-1

Table 9.8-2: Thermocarb TC300 / Vectra A950RX LCP (Through-Plane) ................. 9.8-1

Table 9.8-3: Asbury Synthetic Graphite 4012 / Vectra A950RX LCP (In-Plane) ...... 9.8-1

Table 9.8-4: Asbury Synthetic Graphite 4012 / Vectra A950RX LCP (Through-Plane)

Table 9.8-5: Asbury 3160 Natural Flake Graphite / Vectra A950RX LCP (In-Plane) 9.8-2 Table 9.8-6: Asbury 3160 Natural Flake Graphite / Vectra A950RX LCP (Through-

Plane) 9.8-2

Table 9.8-7: Asbury F108A CNC / Vectra A950RX LCP (In-Plane) ......................... 9.8-2

Table 9.8-8: Asbury F108A CNC / Vectra A950RX LCP (Through-Plane)............... 9.8-2

Table 9.8-9: Fortafil 243 Carbon Fiber / Vectra A950RX LCP (In-Plane) .................. 9.8-3

Table 9.8-10: Fortafil 243 Carbon Fiber / Vectra A950RX LCP (Through-Plane)..... 9.8-3

Table 9.11-1: Rule of Mixtures, Carbon Black Composite ......................................9.11-1

Table 9.11-2: Rule of Mixtures, Synthetic Graphite Composite ............................... 9.11-2

Table 9.11-3: Rule of Mixtures, Carbon Fiber Composite ...................................... 9.11-3

Table 9.11-4: Inverse Rule of Mixtures, Carbon Black Composite ........................... 9.11-4

Table 9.11-5: Inverse Rule of Mixtures, Synthetic Graphite Composite ................... 9.11-5

Table 9.11-6: Inverse Rule of Mixtures, Carbon Fiber Composite ...........................9.11-6

Table 9.11-7: Geometric Rule of Mixtures, Carbon Black Composite ....................... 9.11-7

Table 9.11-8: Geometric Rule of Mixtures, Synthetic Graphite Composite ............. 9.11-8

Table 9.11-9: Geometric Rule of Mixtures, Carbon Fiber Composite ....................... 9.11-9

Table 9.11-10: Nielsen’s Model, Carbon Black Composite ...................................9.11-10

Table 9.11-11: Nielsen’s Model, Synthetic Graphite Composite .............................9.11-11 
Table 9.11-12: Nielsen’s Model, Carbon Fiber Composite.

$9.11-12$

Table 9.11-13: Modified Nielsen's Model, Carbon Black Composite ..................... 9.11-13

Table 9.11-14: Modified Nielsen's Model, Synthetic Graphite Composite .............9.11-14

Table 9.11-15: Modified Nielsen's Model, Carbon Fiber Composite......................9.11-15

Table 9.11-16: Optimized Nielsen's Model, Carbon Black Composite ...................9.11-16

Table 9.11-17: Optimized Nielsen’s Model, Synthetic Graphite Composite .......... 9.11-17

Table 9.11-18: Optimized Nielsen’s Model, Carbon Fiber Composite .................... 9.11-18

Table 9.11-19: Optimized Modified Nielsen’s Model, Carbon Black Composite .. 9.11-19

Table 9.11-20: Optimized Modified Nielsen’s Model, Synthetic Graphite Composite

9.11-20

Table 9.11-21: Optimized Modified Nielsen’s Model, Carbon Fiber Composite ...9.11-21 


\section{Section 0.7: Table of Nomenclature}

A

A

B

B

$\mathrm{C}_{\mathrm{p}}$

C

$\mathrm{E}_{\mathrm{C}}$

$E_{P}$

$\mathrm{G}_{\mathrm{C}}$

$\mathrm{G}_{\mathrm{P}}$

K

$\mathrm{k}$

$\mathrm{k}_{\mathrm{b}}$

$\mathrm{k}_{\mathrm{C}}$

$\mathrm{k}_{\mathrm{E}}$

$\mathrm{k}_{\mathrm{i}}$

$\mathrm{k}_{\mathrm{ij}}$

$k_{\text {in }}$

$\mathrm{k}_{\mathrm{P}}$

$\mathrm{k}_{\text {thru }}$

$\mathrm{N}_{\mathrm{O}}$

$\mathrm{P}$

$\mathrm{Q}$

$\mathrm{Q}_{\mathrm{R}}$

$\mathrm{q}_{\mathrm{i}}$

$\mathrm{R}_{\mathrm{n}}$

$\mathrm{R}_{\mathrm{no}}$

$r^{\prime}$

$\mathrm{T}$

$\mathrm{t}$

u

$\mathrm{V}_{\mathrm{EXP}}$

$\mathrm{V}_{\mathrm{OCV}}$

$\mathrm{W}$

$\mathrm{x}_{\mathrm{i}}$

$\mathrm{y}_{\mathrm{i}}$

$\mathrm{y}_{\mathrm{i}}$

Nielsen Model equation parameter

Trendline equation parameter

Nielsen Model equation parameter

Trendline equation parameter

Heat capacity of component $(\mathrm{J} / \mathrm{kgK})$

Volumetric heat capacity $\left(\mathrm{J} / \mathrm{m}^{3} \mathrm{~K}\right)$

Elastic modulus of composite (bar)

Elastic modulus of polymer (bar)

Shear modulus of composite (bar)

Shear modulus of polymer (bar)

Thermal conductivity of composite $(\mathrm{W} / \mathrm{mK})$

Thermal conductivity (W/mK)

Boltzmann constant

Thermal conductivity of composite (W/mK)

Einstein coefficient

Thermal conductivity of component (W/mK)

Direction-dependent thermal conductivity (W/mK)

In-plane thermal conductivity (W/mK)

Thermal conductivity of polymer $(\mathrm{W} / \mathrm{mK})$

Through-plane thermal conductivity (W/mK)

Avogadro's number

Power (W)

Power (W)

Power per unit length $(\mathrm{W} / \mathrm{m})$

Heat flux $\left(\mathrm{W} / \mathrm{m}^{2}\right)$

Resistance at time n $(\Omega)$

Resistance at time $0(\Omega)$

Radius of sensor 'ring' (m)

Temperature (K)

Time (s)

Speed of sound in a material $(\mathrm{m} / \mathrm{s})$

Experimental cell voltage (V)

Theoretical cell voltage (V)

Mass of component (kg)

Particle count parameter (non-dimensional)

Shape factor (non-dimensional)

Particle count parameter (non-dimensional)

$\begin{array}{ll}\alpha & \text { Thermal diffusivity }\left(\mathrm{m}^{2} / \mathrm{s}\right) \\ \beta & \text { Temperature coefficient of resistance }(1 / \mathrm{K}) \\ \chi & \text { Halpin-Tsai equation parameter } \\ \Delta \mathrm{T} & \text { Change in temperature }(\mathrm{K})\end{array}$




$\begin{array}{ll}\delta & \text { Dirac delta function } \\ \delta \mathrm{T} / \delta \mathrm{x}_{\mathrm{i}} & \text { Temperature gradient }(\mathrm{K} / \mathrm{m}) \\ \phi_{\mathrm{i}} & \text { volume fraction of component (non-dimensional) } \\ \phi_{\mathrm{m}} & \text { maximum packing fraction of component (non-dimensional) } \\ \eta_{\mathrm{C}} & \text { Efficiency (non-dimensional) } \\ \eta_{\mathrm{C}} & \text { Viscosity of composite }(\mathrm{kg} / \mathrm{m}-\mathrm{s}) \\ \eta_{\mathrm{P}} & \text { Viscosity of polymer }(\mathrm{kg} / \mathrm{m}-\mathrm{s}) \\ \varphi & \text { McCullough equation parameter } \\ \lambda & \text { Mean free path }(\mathrm{m}) \Theta \\ \theta_{\mathrm{D}} & \text { Debye temperature }(\mathrm{K}) \\ \rho & \text { Density of component }\left(\mathrm{kg} / \mathrm{m}^{3}\right) \\ \rho_{\mathrm{theo}} & \text { Theoretical density of composite }\left(\mathrm{kg} / \mathrm{m}^{3}\right) \\ \rho_{\text {water }} & \text { Density of water }\left(\mathrm{kg} / \mathrm{m}^{3}\right) \\ \tau & \text { Hot Disk equation parameter } \\ \omega & \text { Frequency of vibration }(1 / \mathrm{sec}) \\ \omega_{\mathrm{D}} & \text { Debye frequency of vibration }(1 / \mathrm{sec}) \\ \psi & \text { Particle sphericity (non-dimensional) } \\ \psi & \text { Nielsen Model equation parameter } \\ \zeta & \text { Halpin-Tsai equation parameter } \\ \hbar & \\ & \text { Planck's constant }\end{array}$




\section{Chapter 1: Introduction \\ Section 1.1: Background}

Polymers are generally very poor materials to use in thermally conductive applications. By and large, for these types of applications metals are used. However, by adding conductive fillers to polymers it is possible to increase the thermal conductivity of the polymer to values greater than $1 \mathrm{~W} / \mathrm{mK}$, at which point they become useful in thermal conductivity applications. These thermally conductive polymers have many advantages over a pure metal: a lower density, improved corrosion / oxidation / chemical resistance and more direct control over the properties of the material.

A prime application for thermally conductive resins is thermal energy regulation. Computers, laptops, fuel cells and transformer housings all need to disperse the thermal energy during use. Heat exchangers and radiators could also benefit from advances in this field. In all of these cases, the polymer composite would need a thermal conductivity greater than $1 \mathrm{~W} / \mathrm{mK}$. However, developing the materials with the precise properties necessary for the application at hand is very costly if done by trial and error. Being able to predict the thermal conductivity of a composite material will vastly streamline this process, allowing for savings in time, labor and materials cost.

In recent years, there has been a large increase in the demand for smaller and lighter electronic devices and similar machinery. Industry has also been specializing in materials with properties tailored to the specific needs of the application. More and more often, composite materials are used to fill these specific needs. Composite materials are a mixture of two or more different kinds of materials (such as ceramics, metals, and polymers) which, when combined, produce a material with physical properties that are a 
mixture of the constituent materials. Examples of widely used composite materials include fiberglass and concrete. In this study, carbon-filled thermoplastic polymer composites will be investigated. This dissertation will focus on the thermal conductivity of these composites.

Since most polymers are very poor thermal conductors, the most common way to improve them for this application is to add thermally conductive fillers to the polymer matrix. Previous studies have investigated different single-filler additions to a polymer matrix to improve the thermal conductivity of the polymer composite [1-6]. Different types of carbon fillers are used to adjust the thermal and electrical conductivities of these polymer composites dependent on their end use. Carbon filler will increase the conductivity of the composite relative to the neat polymer, but not to the level of the pure carbon filler. Previous work [7-8] has shown that a multiple-filler system has given synergistic effects in the increasing of thermal conductivity; the total increase in thermal conductivity when the fillers are mixed together is greater than the sum of the increase in thermal conductivity in the single-filler systems. 


\section{Section 1.2: Thermal Conductivity}

Thermal conductivity has had a profound impact on human existence [9].

Materials with low thermal conductivity have helped people in non-tropical climates retain the heat necessary to survive while allowing people in tropical climates to build structures that were effective at keeping the heat out. In more modern times, space vehicles designed for atmospheric passage and re-entry are dependent on materials with a very low thermal conductivity to keep the massive amounts of thermal energy away from the rest of the vessel. Thermal conductivity has been important throughout the ages and promises to be integral to our continued advancement. Table 1.2-1 lists the thermal conductivity of some common materials [10].

Table 1.2-1: Thermal Conductivity of Common Materials [10]

\begin{tabular}{|l|l|}
\hline Materials & $\begin{array}{l}\text { Thermal Conductivity } \\
\text { (W/mK) }\end{array}$ \\
\hline Polymers & 0.19 to 0.30 \\
\hline PAN-based Carbon Fiber & 8 to 70 \\
\hline Pitch-based Carbon Fiber & 20 to 1000 \\
\hline Stainless Steel & 11 to 24 \\
\hline Aluminum & 218 to 243 \\
\hline Copper & 385 \\
\hline Silver & 418 \\
\hline Diamond & 990 \\
\hline
\end{tabular}




\section{Section 1.3: Motivation}

The demand for conductive composites continues to grow in the United States. In 1995, the demand for conductive polymer composites was 221 million lbs. It was projected to grow 6.1 percent annually to 565 million pounds (including both resins and additives) by 2004. Its projected value was to reach $\$ 1.5$ billion by 2004 , consisting of the cost of resins and additives, as well as labor and other overhead costs incurred during the production of the conductive compound [11]. It is clear that this increasing demand requires more research and development of conductive polymer composites, both to produce new materials and to streamline the cost and time of production. Most conductive resins in widespread use today are used in electromagnetic frequency interference (EMI) and/or radio frequency interference (RFI) shielding or in electrostatic dissipation (ESD) applications. Research into these composites could allow for multifunctional composite materials. Another application of conductive polymer composites will now be described. 


\section{Section 1.4: Fuel Cells}

Fundamental and applied research is needed for the development of cost effective fuel cells for stationary and transportation applications. The proton exchange membrane fuel cell (PEMFC) is one of the most promising alternative fuel technologies to power cars and buses. Hydrogen is the fuel which reacts with oxygen (from the air) to produce DC electricity to power motors and auxiliary equipment for the vehicle. The byproducts of the reaction are heat and water [12].

Hydrogen gas flows into the fuel cell on the anode side of the membrane, where it encounters a platinum catalyst, which facilitates the separation of the hydrogen gas into electrons and protons (hydrogen ions). The hydrogen ions pass through the membrane, and, again encounter a platinum catalyst, which helps combine the hydrogen ions, oxygen gas, and electrons on the cathode side to produce water as the product. The electrons, which cannot pass through the membrane, flow from the anode to the cathode side of the fuel cell through an external circuit containing a motor or other electric load, which consumes the power generated by the fuel cell. The voltage generated from one single cell is typically 0.7 volts. The cells are typically arranged in a stack to provide a proportionally larger voltage. Since commercial electric motors often operate at 300 volts, often 430 bipolar plates are needed for a fuel cell assembly [12]. In a PEMFC, the efficiency is expressed by Equation 1.1:

$$
\eta=\frac{V_{E X P}}{V_{O C V}}
$$

In this equation, $\eta$ is non-dimensional, $V_{E X P}$ is the measured voltage of a single cell (V) and $V_{O C V}$ is the open circuit voltage $(\mathrm{V})$, which is the theoretical maximum voltage output of a single cell. $V_{O C V}$ is dependent on the fuel used in the fuel cell and, in the case of a 
PEMFC, the state of the water that comes out (steam or liquid). Using hydrogen as the fuel and assuming the product comes out as steam results in Equation 1.2:

$$
\eta=\frac{V_{E X P}}{1.25 V}
$$

Assuming the typical 0.7 volt output as discussed above, $\eta=0.56$. This means $56 \%$ of the energy content of the fuel is converted into electrical energy, with the other $44 \%$ converted into heat energy. Increasing the electrical conductivity of the material used in the bipolar plate may increase the measured voltage of the single cell and increase the efficiency; increasing the thermal conductivity will increase the rate at which heat energy is pulled out of the bipolar plate and will help with thermal management of the fuel cell.

Bipolar plates serve many different functions in a fuel cell. They separate the proton exchange membranes from each other, conduct heat generated by the chemical reactions and electron flow out of the system, distribute the feed gases uniformly across the proton exchange membrane, and conduct the electrons generated in the anode halfreaction into the load circuit to generate work. Current bipolar plate technology uses conductive resins as the foundation for the bipolar plate, with different fillers being used to modify the physical properties. A more detailed description follows in the next section. 


\section{Section 1.5: Bipolar Plates}

Bipolar plate technology plays a key role in fuel cell technology. The bipolar plate separates one cell from the next, with this plate carrying hydrogen gas on one side and air (oxygen) on the other side. The bipolar plate must be made of gas impermeable material. Otherwise, the fuel sources and the electrons they generate are wasted since they cannot be sent to an external circuit to do useful electrical work. In addition, the bipolar plate must be electrically conductive to minimize ohmic losses and be thermally conductive to conduct the generated heat (reaction byproduct) away. Ideally, the bipolar plates should be as thin as possible to minimize electrical resistance and to make the fuel cells stack small $[11,13,14]$. An illustration of a fuel cell unit is shown in Figure 1.5-1; the bipolar plates are the structures to the left and right of the gas diffusion backings [13].

\section{CROSS SECTION OF POLYMER ELECTROLYTE FUEL CELL}

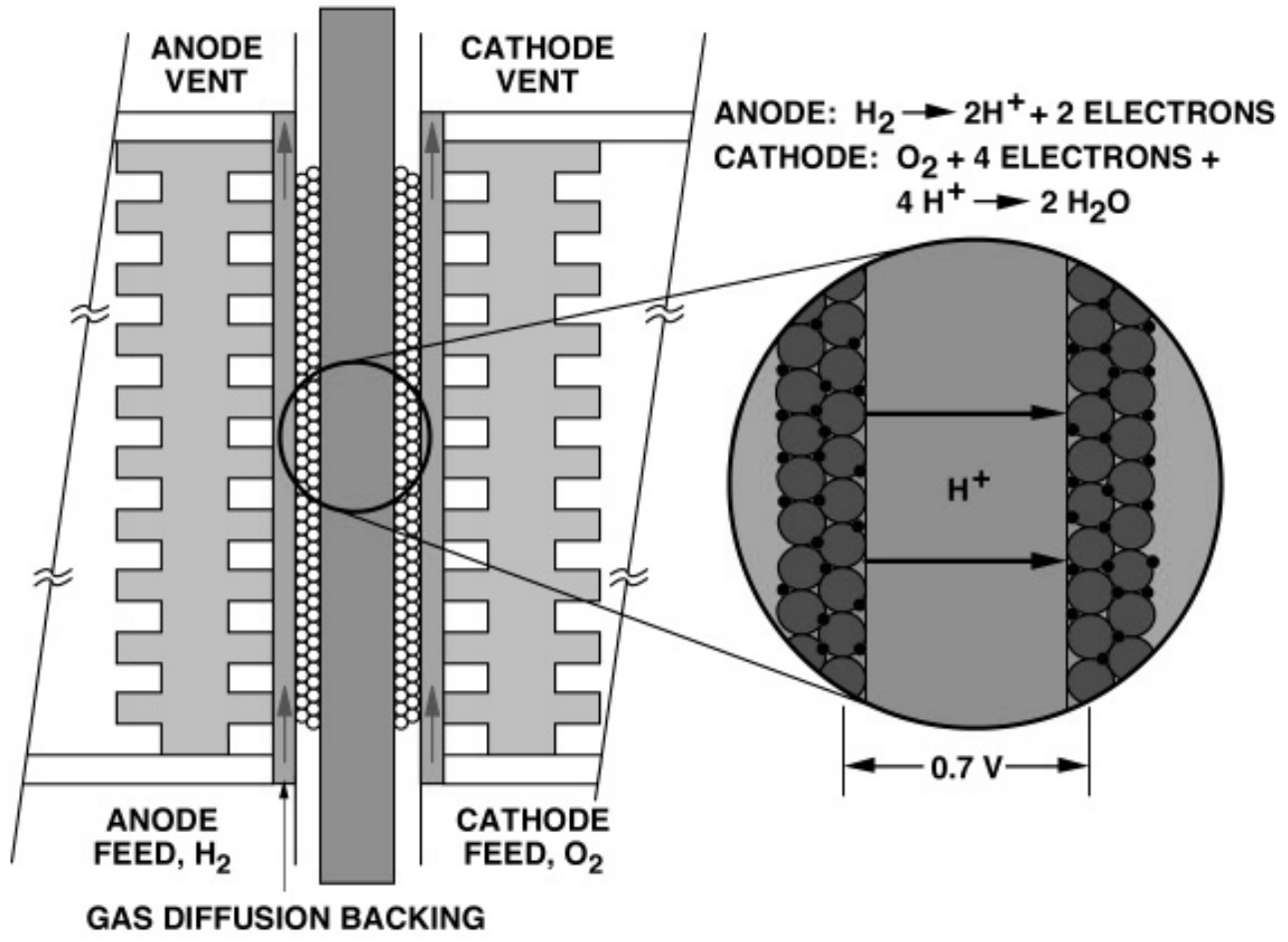

Figure 1.5-1: Cross Section of Polymer Electrolyte Fuel Cell [13] 
The desired properties for bipolar plates for fuel cells are as follows [15-18]:

- Electrical conductivity greater than $50 \mathrm{~S} / \mathrm{cm}$

- Thermal conductivity greater than $20 \mathrm{~W} / \mathrm{mK}$

- Flexural strength greater than $35 \mathrm{MPa}$

- Flexural modulus greater than $6 \mathrm{GPa}$

- Tensile strength greater than $25 \mathrm{MPa}$

- Tensile modulus greater than $6 \mathrm{GPa}$

- Unnotched Izod impact strength greater than $0.1 \mathrm{~N}-\mathrm{m} / \mathrm{cm}$

- Hydrogen permeation rate less than $2 \times 10^{-6} \mathrm{~cm}^{3} /\left(\mathrm{sec}-\mathrm{cm}^{2}\right)$

In addition, the bipolar plates need to have excellent thermal and dimensional stability up to $150^{\circ} \mathrm{C}$ for the next generation of fuel cells which will operate at this temperature instead of the current $80^{\circ} \mathrm{C}$ [16-18]. 


\section{Section 1.6: Research Objectives}

The objectives of this project were to:

1. Create thermally conductive composites

2. Characterize and analyze carbon filled polymer composites

3. Develop a model to predict thermal conductivity of carbon-filled polymer composites

These objectives have been reached in an experimental study where data was collected and analyzed. The study centered on the production, testing, and analysis of single-filler conductive resins. This study examined polymer composites filled with carbon black, natural flake graphite, synthetic graphite, calcined needle coke, or carbon fiber in a liquid crystal polymer matrix. Their thermal conductivity was determined for both the longitudinal and transverse directions. The knowledge gained from this study forms the foundation for the modeling work.

The transverse thermal conductivity results gathered from this study were then used to improve a current transverse thermal-conductivity model. The resulting model more accurately predicts the composite transverse thermal conductivity. The model that was used is a function of the volume fraction of filler, maximum packing fraction, and filler thermal conductivities, as well as the polymer volume fraction and thermal conductivity. The longitudinal thermal conductivity results were used to help derive a model relating the longitudinal thermal conductivity, the transverse thermal conductivity and the volume fraction of the carbon fillers in the composite material. 


\section{Section 1.7: References}

1. D. M. Bigg, “Thermally Conductive Polymer Compositions”. Polymer Composites, Vol. 7, No. 3, 1986, pp. 125.

2. D. Hansen, and G. A. Bernier, “Thermal Conductivity of Polyethylene: The Effects of Crystal Size, Density, and Orientation on the Thermal Conductivity”. Polymer Engineering and Science, Vol. 12, No. 3, 1972, pp. 204.

3. Y. Agari, and T. Uno, “Thermal Conductivity of Polymer Filled with Carbon Materials: Effect of Conductive Particle Chains on Thermal Conductivity”. Journal of Applied Polymer Science, Vol. 30, 1985, pp. 2225-2236.

4. Y. Agari, A. Ueda, and S. Nagai, “Thermal Conductivities of Composites in Several Types of Dispersion Systems”. Journal of Applied Polymer Science, Vol. 42, 1991, pp. 1655-1669.

5. R. C. Progelhof, J. L. Throne, and R. R. Ruetsch, "Methods of Predicting Thermal Conductivity of Composite Systems: A Review”. Reg. Tech. Cond. - Soc. Plast. Eng, 1975, pp. 221-257.

6. L. E. Nielsen, “The Thermal and Electrical Conductivity of Two-Phase Systems”. I\&EC Fundamentals, Vol. 13, No. 1, 1974, pp. 17-20.

7. E. H. Weber, M. L. Clingerman, and J. A. King, "Thermally Conductive Nylon 6,6 and Polycarbonate Based Resin. Part 1: Synergistic Effects of Carbon Fillers”, Journal of Applied Polymer Science, Vol. 88, pp. 112-122, 2003.

8. E. H. Weber, M. L. Clingerman, and J. A. King, “Thermally Conductive Nylon 6,6 and Polycarbonate Based Resin. Part 2: Modelling”, Journal of Applied Polymer Science, Vol. 88, pp. 123-130, 2003. 
9. J. E. Parrott, and A. D. Stuckes, Thermal Conductivity of Solids. Pion Limited, London, 1975.

10. http://www.matweb.com/search/SearchProperty.asp?e=1, accessed April 14, 2006.

11. The Freedonia Group, Inc., “Conductive Polymers”. Cleveland, OH 44143-2326, 2000.

12. S. Gottesfeld, C. F. Keller, S. Moller-Holst A. Redondo and J. Milliken, "Fuel Cells: Green Power”, Los Alamos National Laboratory, LA-UR-99-3231, 1999.

13. "Fuel Cells”, Los Alamos National Laboratory, http://www.lanl.gov/orgs/ee/fuelcells/index.shtml and http://education.lanl.gov/RESOURCES/H2/gottesfeld/education.html, accessed May 22, 2006.

14. "Material Opportunities in Fuel Cell technology: 2002 \& Beyond”, Principia Partners, www.principiaconsulting.com/PDF/brochure_fuelcells.pdf, accessed December 23, 2003, Exton, PA, 19341.

15. J. Larminie and A. Dicks, Fuel Cell Systems Explained, $2^{\text {nd }}$ edition, John Wiley\& Sons, West Sussex, England, 2003.

16. L. E. Nunnery, Jr., "Fuel Cell Technology”, Society of Automotive Engineers (SAE) Conference, 1998.

17. R. Leaversuch, “Fuel Cells Jolt Plastics Innovation”, Plastics Technology Online, November 2001, www.plasticstechnology.com/articles/200111fa2.html., accessed May 22, 2006. 
18. N. Garland, “Materials for Bipolar Plates”, http://www1.eere.energy.gov/hydrogenandfuelcells/pdfs/nn0123s.pdf, Department of Energy sponsored research presented May 9-10, 2002 in Golden, CO, accessed May 22, 2006. 


\section{Chapter 2: Fundamentals of Polymers, Heat Transfer and Fuel Cell Bipolar Plates}

\section{Section 2.1: Polymeric and Composite Materials}

A polymer molecule is a long molecule composed of many repeating units [1-3].

Most polymers have very few intermolecular interactions except for van der Waals forces; however, these forces are not strong enough to hold the molecules together in a solid form. The length of the polymeric molecules allows them to entwine each other and form entanglements that restrict the flow of the molecules. The stability of these entanglements is dependent on the molecular weight, flexibility and steric hindrance of the composite molecules. These entanglements influence the viscoelastic, melt viscosity, and mechanical properties of the polymer [1].

Another quality of the polymer that affects its physical properties is its degree of crystallinity. Most polymers have a very low degree of crystallinity if they possess any at all. Polymers without crystallinity are called amorphous [1]. Figure 2.1-1 shows how the polymer chains are arranged in an amorphous polymer matrix. Amorphous polymers tend to have good mechanical properties, good dimensional stability, consistent shrinking rates during cooling, and tend to be transparent / translucent materials [2].

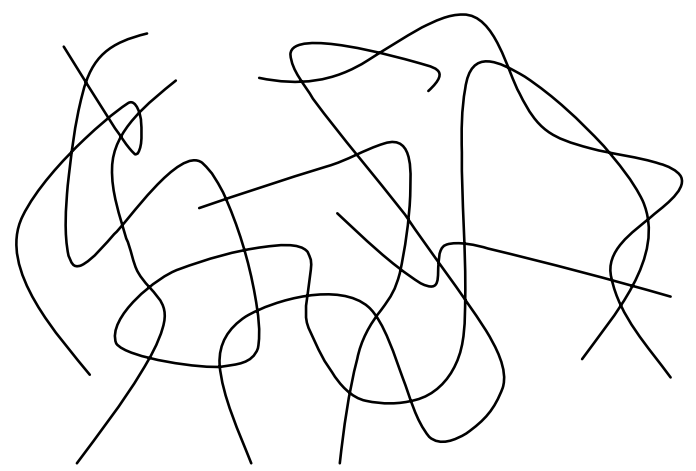

Figure 2.1-1: Representation of Polymer Chains in an Amorphous Polymer [1-2] 
In contrast, semi-crystalline polymers generally arrange themselves in a lamellar structure [2]; examples of these structures in nature are the spores of a mushroom or the gills of a fish. For polymer crystallization to occur, the cooling conditions have to allow for time for the polymer chains to orient themselves properly. The crystalline sheets that form may be as thin as $100-200 \AA$, with amorphous regions between them [1]. In polyethylene, it was found that as the thickness of the lamellar structures increased, the thermal conductivity increased as well [4]. Figure 2.1-2 illustrates variations on twodimensional lamellar structures which can be expanded to account for three dimensions. Semi-crystalline polymers have anisotropic shrinking properties, good electrical properties and are generally chemically resistant [2].

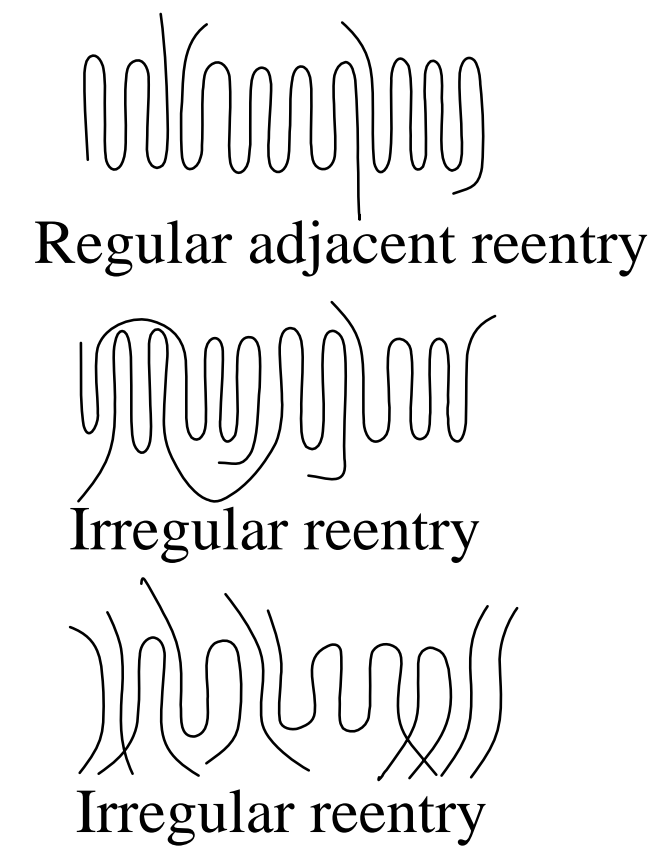

Figure 2.1-2: 2D Representation of Polymer Chains in a Semi-Crystalline Polymer $[1,3]$

Thermal conductivity has been experimentally shown to increase with increasing crystallinity or orientation of polymer chains [4-6], which implies that amorphous 
polymers will be less conductive than semi-crystalline polymers. It has also been shown that filled amorphous polymer systems are less thermally conductive than filled semicrystalline polymers [7]. 


\section{Section 2.2: Thermal Conductivity Background}

There are three mechanisms of heat transfer: radiation, convection and conduction. In solid systems, the primary mechanism of heat transfer is by conduction, quantified using Fourier’s law (Equation 2.1) [8-10].

$$
q_{i}=-k_{i j} \frac{\partial T}{\partial x_{i}}
$$

This equation shows that heat flux $\left(q_{i}\right)$ is dependent on both the thermal conductivity of the material $\left(k_{i j}\right)$ and the temperature gradient in the direction of conduction. In the above equation, the thermal conductivity term is assumed to be a constant value; in reality the thermal conductivity of a material varies with temperature, with the degree of variation being dependent on the material. The material thermal conductivity, referred to in the above equation, is the summation of different heat transfer methods. There are two primary methods of conductive heat transport in solids. These methods are electron transport and phonon transport. In pure metals, electron transport is the dominant method; in dielectric materials such as polymers, phonon transport is the dominant method. Mixtures of these classes of materials can have both forms of transport be significant in the overall heat transport [8-9].

A phonon is the quantum frequency of an atomic vibration. Phonons are carriers of heat energy and transfer this energy by interacting with other phonons and with other subatomic particles [11]. To understand these interactions, imagine a series of atoms with the bonds between them represented by small springs. An atom is excited and vibrates slightly, pushing or pulling on the springs connected to it, which disturbs the atoms connected to those springs, which moves the springs connected to those atoms, and 
so on. The energy from the original atomic excitation would be propagated through the array. Figure 2.2-1 shows a two-dimensional example of this mechanism [12].

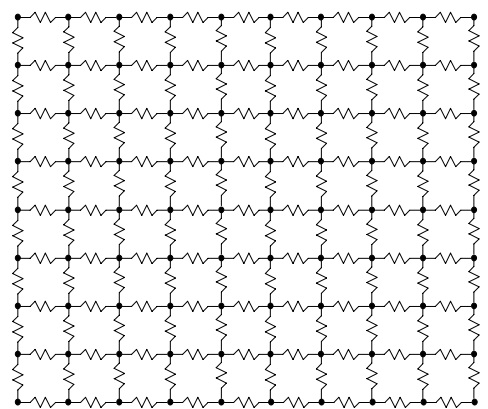

\section{Figure 2.2-1: Two-Dimensional Array of Atoms Connected by Springs}

Phonon heat transfer is highly dependent on the scattering of the phonons as they propagate through the material [11]. Different atoms, clustered atoms or missing atoms all have varying effects on the path of the phonon and the energy transferred between atoms. The dominant feature of phonon heat transfer is the distance between scattering incidents. Scattering incidents occur when a phonon encounters an atom and is either absorbed into it or deflects off it in a different direction. The longer the distance between scattering effects, the greater the thermal conductivity of a dielectric material is. This concept is illustrated by the Debye model for heat conduction in dielectric solids [4].

$$
k=1 / 3 \cdot c \cdot u \cdot \lambda
$$

In this model, $k$ is the thermal conductivity, $c$ is the volumetric heat capacity, $u$ is the velocity of sound in the material, and $\lambda$ is the mean free path (the average distance between scattering incidents) of the phonons in the material. A high mean free path will lead to a higher thermal conductivity than a low mean free path. For a typical material, the speed of sound is approximately $5 \times 10^{5} \mathrm{~cm} / \mathrm{s}$ and is relatively independent of temperature [13]. The mean free path decreases with an increase in temperature. 
The heat capacity of a material can be calculated using the Debye model as found in Equation 2.3 [14]. In this equation, $c$ is the volumetric heat capacity, $k_{B}$ is the Boltzmann's constant, $N_{o}$ is Avogadro's number, $T$ is the absolute temperature in Kelvin, $\theta_{D}$ is the Debye temperature in Kelvin, $\hbar$ is Planck's Constant, $\omega$ is the frequency of vibration, and $\omega_{D}$ is the Debye frequency of vibration.

$$
\begin{gathered}
c=9 \cdot k_{B} \cdot N_{0}\left(\frac{T}{\theta_{D}}\right)^{3} \int_{0}^{\theta_{D} / T} \frac{x^{4} \cdot e^{x}}{\left(e^{x}-1\right)^{2}} d x \\
\text { Where: } x=\frac{\hbar \cdot \omega}{k_{B} \cdot T} \text { and } \theta_{D}=\frac{\hbar \cdot \omega_{D}}{k_{B}}
\end{gathered}
$$

Heat conduction by phonons is the main conduction method in polymers, carbons, and their composites. Polymers are dielectric materials so they generally follow the Debye model. Many carbon fillers (including all the carbon fillers used in this project) are electrically conductive, but their thermal conductivity is essentially due to phonon transport.

Thermal conductivity in carbon/polymer composites is a bulk property. This is different from electrical conductivity, which is a path-dependent property. Previous experimental research has shown thermal conductivity increases continuously over the whole concentration range, whereas electrical conductivity increases by as many as 10 orders of magnitude over a small range of filler concentration known as the "percolation threshold" [15-16]. At the percolation threshold, the fillers get close enough to conduct current with little resistance. Thermal conductivity does not show a large and sudden increase with increasing filler concentration. This indicates that proximity of filler particles and the contact between them is not a significant factor in thermal conductivity and further indicates that thermal conductivity is a bulk property of a material. 
Another way to examine thermal conductivity is to look at the scattering of phonons that occurs with touching filler particles. Assume that there is an array of filler particles touching each other edge to edge. In one case (see Figure 2.2-2a), the fillers are surrounded by vacuum; in another (see Figure 2.2-2b), the fillers are surrounded by a dielectric matrix material. Also, assume that no heat transfer occurs by radiation - all the heat transfer must be accomplished by conduction. In the case of Figure 2.2-2a, phonons are scattered and transmitted only at filler-filler contact points since any phonons scattered into the vacuum are lost by the 'no radiation' assumption. In the case of Figure 2.2-2b, phonons are still scattered and transmitted at filler-filler interface points, but the phonons that scatter at filler edge points connected to the dielectric matrix material are not lost because the matrix material can absorb and transmit the phonons. This matrix allows a far greater heat transfer than the first case. For a path-dependent property, the first and second cases should yield an identical heat transfer, which has been shown experimentally to not be true. This is another indicator that thermal conductivity is a bulk property.

a)

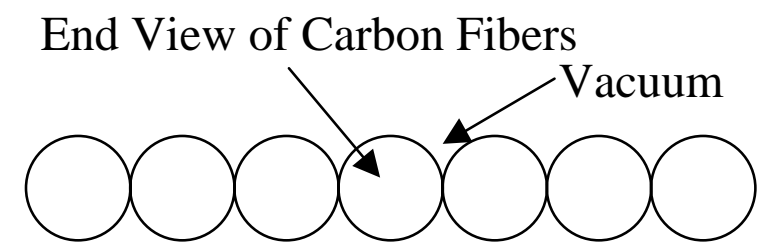

Direction of Conduction

b)

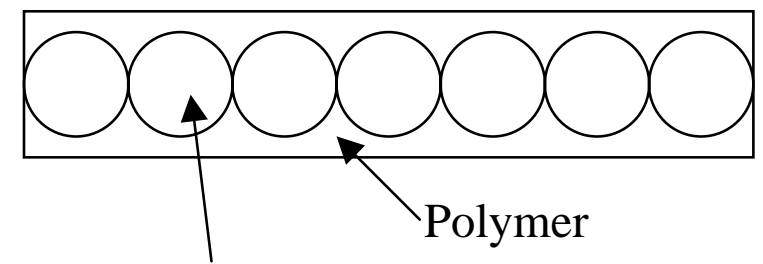

End View of Carbon Fibers

Figure 2.2-2: Fiber Configurations [(a) carbon fiber in a vacuum, (b) carbon fiber in polymer matrix] 


\section{Section 2.3: Thermal Conductivity Models}

In conductive resins, there are two methods of heat transfer: lattice vibrations and electron transport. Lattice vibrations are the primary method of transfer. There are several different factors that affect the thermal conductivity of a composite material. These factors include the thermal conductivity of the component materials and the crystallinity of the matrix material. The size and shape of the filler particles, the concentration and dispersion (degree of mixing) of the filler particles in the matrix material, and the orientation and bonding between the filler and the matrix material are also important factors. Orientation is significant because most carbon-based fillers are anisotropic, with greatly different thermal conductivities depending on the direction of measurement.

Thermal conductivity has a numerical relationship between a composite material and its pure polymer counterpart; this relationship is similar to phenomena noted in viscosity, tensile modulus, and shear modulus. Equation 2.4 demonstrates these numerical relationships between the composite and the pure polymer [11]. This equation uses $k$ for thermal conductivity, $\eta$ for the viscosity, $E$ for the elastic modulus, and $G$ for the shear modulus, with the subscripts $c$ and $p$ representing the composite material and the pure polymer respectively.

$$
\frac{k_{c}}{k_{p}}=\frac{\eta_{c}}{\eta_{p}}=\frac{E_{c}}{E_{p}}=\frac{G_{c}}{G_{p}}
$$




\section{Section 2.3.1: Basic Thermal Conductivity Models}

The most basic thermal-conductivity models start with the standard mixture rule (Equation 2.5), inverse mixture rule (Equation 2.6), and the geometric mixture rule (Equation 2.7) [17]. These equations use $K$ for the thermal conductivity of the composite, $n$ for the number of constituents in the composite (fillers and matrix materials), $i$ for the index variable for the composite constituents, $\phi$ for the volume fraction of constituents, and $k_{i}$ for the thermal conductivity of the $\mathrm{i}^{\text {th }}$ constituent.

$$
\begin{aligned}
& K=\sum_{i=1}^{n} \phi_{i} \cdot k_{i} \\
& K=\sum_{i=1}^{n} \frac{\phi_{i}}{k_{i}} \\
& K=\sum_{i=1}^{n} k_{i}^{\phi_{i}}
\end{aligned}
$$

To estimate the composite thermal conductivity parallel to the primary filler orientation, the rule of mixtures model is often used. This model is the weighted average of the filler and matrix material conductivities weighted by the volume fractions of the constituents. The premise is that the more volume a constituent occupies in the mixture, the more its thermal conductivity will dominate the composite thermal conductivity. This model is typically used to predict the thermal conductivity of a composite with continuous fiber fillers oriented in a single direction. To estimate the composite thermal conductivity perpendicular to the primary filler orientation, the rule of inverse mixtures model is often used. The geometric mixing rule model is less commonly used.

For this research, four different types of carbon fillers were studied: carbon fibers ( $\approx 3.2 \mathrm{~mm}$ long), carbon black powder (30-100nm), graphite particles $(50-300 \mu \mathrm{m})$, and 
calcined needle coke $(150-600 \mu \mathrm{m})$ were used as the conductive filler. These models will be a good starting point for study, but the discontinuous nature of the fillers will require an alteration to the models.

\section{Section 2.3.2: Advanced Thermal Conductivity Models}

There are many models currently proposed for composite systems. The basis of many of them is the Maxwell Theoretical Model. This model uses potential theory to obtain an exact solution for the conductivity of a system with spherical non-interacting particles in a continuous matrix [18]. Since most systems do not have non-interacting spherical particles, this model is not widely applicable to many composite materials without modification. The original model is detailed in Equation 2.8. This equation uses $K$ for the thermal conductivity of the composite, $\phi$ for the volume fraction of constituents, and $k$ for the thermal conductivity of the constituents. The subscript 1 indicates the properties of the pure polymer, and 2 indicates the filler properties.

$$
K=k_{1}\left(\frac{k_{2}+2 k_{1}+2 \phi_{2}\left(k_{2}-k_{1}\right)}{k_{2}+2 k_{1}-\phi_{2}\left(k_{2}-k_{1}\right)}\right)
$$

Bruggeman developed another theoretical model to exactly solve for thermal conductivity using potential theory. This model is based on Maxwell's work and also addresses systems of spherical, non-interacting particles in a continuous matrix; the primary difference in the models derives from assumptions made about the permeability and field strength of the system. Equation 2.9 shows Bruggeman’s model [18]. This equation uses the subscript 1 to indicate the properties of the pure polymer, and 2 to indicate the fillers properties. $K$ is used for the thermal conductivity of the composite, $\phi$ 
is used for the volume fraction of constituents, and $k$ is used for the thermal conductivity of the constituents.

$$
1-\phi_{2}=\frac{k_{2}-K}{k_{2}-k_{1}} \cdot\left(\frac{k_{1}}{K}\right)^{1 / 3}
$$

The Hamilton and Crosser Semi-Theoretical Model has multiple applications. This model is applicable to two-phase systems, multiple-phase systems, and can take the shape of the particle into account. This model is derived from work done by Maxwell and Fricke and is shown in Equations 2.10a-b [18]. These two equations use the subscript 1 to indicate the properties of the pure polymer, 2 to indicate the particle properties, $K$ to indicate the thermal conductivity of the composite, $\phi$ to indicate the volume fraction of constituents, $k$ to indicate the thermal conductivity of the constituents, and $\psi$ to indicate the sphericity of the particles. The sphericity of the particle is the surface area of a sphere with the same volume as the particle divided by the surface area of the actual particles. The value of $\psi$ is between 0.58 and 1.0 for the investigated data sets [18].

$$
\begin{aligned}
& K=k_{1}\left(\frac{k_{2}+(n-1) k_{1}+(n-1) \phi_{2}\left(k_{2}-k_{1}\right)}{k_{2}+(n-1) k_{1}-\phi_{2}\left(k_{2}-k_{1}\right)}\right) \\
& n=\frac{3}{\psi}
\end{aligned}
$$

In Maxwell's model, $n=3$. This follows from the definition of sphericity above. Hamilton and Crosser correlated large sets of data to derive and confirm Equation 2.10b [19].

McCullough proposed a general method for combining mixture rules for predicting transport properties, such as thermal conductivity, for composite systems [17]. This method uses a generalized equation in combination with traditional mixing rules and 
a reference state. This generalized method is for a class of composites that show orthotropic symmetry. There are multiple different sets of equations for this model to deal with various types of composite systems; only the diffuse transport case will be discussed here. The generalized equations are found in Equation 2.11a-d. This general model is based on the standard rule of mixtures. The $K_{*}$ term is the reference state that changes dependent on the composite system. $K_{j}$ is the thermal conductivity in the $j$ direction, where $j=1$ for measurements in the longitudinal direction (the direction of greatest thermal conductivity in an anisotropic material) and where $j=2$ or 3 for measurements in a direction transverse to $j=1 . y_{i}$ is the shape factor; this quantity is calculated from the orientation and general shape of the particles. $K_{i}$ is the thermal conductivity of the $i^{\text {th }}$ constituent, where 1 stands for the matrix and 2 stands for the filler. $\phi_{i}$ is the volume fraction of the $\mathrm{i}^{\text {th }}$ constituent.

$$
\begin{aligned}
& K_{j}=K_{*}+\frac{\left(\langle K\rangle-K_{*}\right) \cdot K_{*}+y_{j} \cdot \Delta K_{1} \cdot \Delta K_{2}}{\left(1-y_{j}\right) \cdot K_{*}+y_{j} \cdot\langle\varphi\rangle} \\
& \Delta K_{i}=K_{i}-K_{*} \quad(\mathrm{i}=1,2) \\
& \langle K\rangle=\phi_{2} \cdot K_{2}+\phi_{1} \cdot K_{1} \\
& \langle\varphi\rangle=\phi_{1} \cdot K_{2}+\phi_{2} \cdot K_{1}
\end{aligned}
$$

Using this form of McCullough’s model with some rearrangement leads to the Halpin-Tsai equations [17]. In this set of equations, $K_{*}=K_{1}$. The Halpin-Tsai equations are the starting point for the derivation of the Nielsen Model. The Halpin-Tsai equations can be found in Equation 2.12a-c.

$$
\frac{K}{k_{1}}=\frac{1+\xi \cdot \chi \cdot \phi_{2}}{1-\chi \cdot \phi_{2}}
$$




$$
\begin{aligned}
& \chi=\frac{K_{2}-K_{1}}{K_{1}-\xi \cdot K_{1}} \\
& \xi=\frac{1-y_{i}}{y_{i}}
\end{aligned}
$$

The Nielsen model [20-21] originates from Albert Einstein’s model for the viscosity of a fluid with dispersed spheres. This model was first studied with regards to viscosity, but can also be used to predict the elastic modulus of a two-phase composite. Lewis and Nielsen developed an improved model for the elastic modulus using the Halpin-Tsai equations as a starting point [21]. Nielsen made a couple of nomenclature changes while developing the model; $\chi$ became $B$ and $\xi$ became $A$. In addition, Nielsen added a value to the denominator of the primary equation and termed it $\psi$. This term was added to take into account the orientation and the packing of the filler in the matrix. Nielsen also changed how the $A$ term was determined. In the Halpin-Tsai equations, the $\xi$ term only took into account the shape of the filler; Nielsen incorporated both the orientation and shape of the filler particles into the $A$ term.

Equations 2.13a-c comprise the Nielsen model for thermal conductivity of a twophase system (polymer plus one filler).

$$
\begin{aligned}
& \frac{K}{k_{1}}=\frac{1+A \cdot B \cdot \phi_{2}}{1-B \cdot \psi \cdot \phi_{2}} \\
& B=\frac{k_{2} / k_{1}-1}{k_{2} / k_{1}+A} \\
& \psi \cong 1+\frac{1-\phi_{m}}{\phi_{m}^{2}} \cdot \phi_{2}
\end{aligned}
$$


In Equation 2.13a-c, $K$ is the thermal conductivity of the composite and $k_{i}$ is the thermal conductivity of an individual component. The subscript 1 represents the polymer matrix, and the subscript 2 represents the filler. The $A$ parameter takes into account the geometry of the filler, with the primary factor in the geometry being the aspect ratio (length divided by diameter of the filler particle). The $A$ parameter can be theoretically calculated by $A=1-k_{e}$, where $k_{e}$ is the Einstein coefficient. The $A$ parameter has been determined for some filler types and orientation, which are shown in Table 2.3-1 [11]. The $\phi_{m}$ term is the maximum volumetric packing fraction of the filler. Sample values for $\phi_{m}$ are located in Table 2.3-2 [11].

Table 2.3-1: Shape Factor 'A' for Common Filler Types [11]

\begin{tabular}{|l|c|c|}
\hline \multicolumn{1}{|c|}{ Filler Type } & Aspect Ratio & A \\
\hline Cubes & 1 & 2 \\
\hline Spheres & 1 & 1.5 \\
\hline Random Fibers & 2 & 1.58 \\
\hline Random Fibers & 4 & 2.08 \\
\hline Random Fibers & 6 & 2.80 \\
\hline Random Fibers & 10 & 4.93 \\
\hline Random Fibers & 15 & 8.38 \\
\hline Uniaxially Oriented Fibers & -- & $2 \mathrm{~L}^{(\mathrm{a})}$ \\
\hline Uniaxially Oriented Fibers & -- & $0.5^{(\mathrm{b})}$ \\
\hline
\end{tabular}

${ }^{\mathrm{a}}$ Heat flow in direction of fibers

${ }^{\mathrm{b}}$ Heat flow in transverse to fiber direction 
Table 2.3-2: Maximum Packing Fraction of Selected Fillers [11]

\begin{tabular}{|l|l|c|}
\hline Particle Shape & \multicolumn{1}{|c|}{ Packing order } & $\phi_{\mathbf{m}}$ \\
\hline Spheres & Hexagonal Close & 0.7405 \\
\hline Spheres & Face Centered Cubic & 0.7405 \\
\hline Spheres & Body Centered Cubic & 0.60 \\
\hline Spheres & Simple Cubic & 0.524 \\
\hline Spheres & Random Loose & 0.601 \\
\hline Spheres & Random Close & 0.637 \\
\hline Irregular & Random Close & $\sim 0.637$ \\
\hline Fibers & Three Dimensional Random & 0.52 \\
\hline Fibers & Uniaxial Hexagonal Close & 0.907 \\
\hline Fibers & Uniaxial Simple Cubic & 0.785 \\
\hline Fibers & Uniaxial Random & 0.82 \\
\hline
\end{tabular}

Progelhof et al. [22] reviewed many composite thermal-conductivity models.

This review determined that the Nielsen model fit the data the best over the given data range (0 to 30 volume percent) for a two-phase system. This review studied 62-88 micron diameter glass spheres and 62-125 micron diameter magnesium oxide powder in polyethylene.

McGee and McCullough proposed an improvement to the $\psi$ term [21], using natural silica in epoxy resin and glass spheres in epoxy and polyester resin as test systems [23]. Their improved $\psi$ equation, shown in Equation 2.14, is significantly more complicated than the original equation, seen in Equation 2.13c. The equation again uses the subscript 1 for the pure polymer and 2 for the filler, $\phi$ for the volume fraction, and $\phi_{m}$ for the maximum volumetric packing fraction.

$$
\psi \cong 1+\frac{\phi_{1}}{\phi_{m}}\left[\phi_{m} \cdot \phi_{2}+\left(1-\phi_{m}\right) \cdot \phi_{1}\right]
$$

The problem with using the Nielsen model in its present form for this research is that it was originally designed for two-phase systems. To extend the model in this form 
to multiple-phase systems, one would take the polymer and one of the fillers and compute the thermal conductivity of the composite of these two materials. This composite material and another of the fillers are then used to calculate the thermal conductivity of the polymer and two filler composite, and so on until all fillers have been included in the calculations. The problem manifests when one considers the order in which the fillers are considered; depending on when fillers are added into the calculations, the end thermal conductivity of the composite varies.

Work done by Weber [24] has expanded the Nielsen model into a form more applicable for multiple-filler systems. The primary change in the system of equations occurs in Equation 2.15a, where the contributions from fillers are accounted for in a summation term. Hereafter in this text, unless specifically noted, references to the Nielsen Model will be referring to Equations 2.15a-c. McGee and McCullough’s modification to the $\psi$ term results in a modified Nielsen model. This modification, after updating the subscripts for a multiple-filler system, appears in Equation 2.15d; hereafter in this text, unless specifically noted, references to the Modified Nielsen Model will be referring to Equations 2.15a,b,d.

$$
\begin{aligned}
& \frac{K}{k_{1}}=\frac{1+\sum_{i=2}^{n} A_{i} \cdot B_{i} \cdot \phi_{i}}{1-\sum_{i=2}^{n} B_{i} \cdot \psi_{i} \cdot \phi_{i}} \\
& B_{i}=\frac{k_{i} / k_{1}-1}{k_{i} / k_{1}+A_{i}} \\
& \psi_{i} \cong 1+\frac{1-\phi_{m i}}{\phi_{m i}^{2}} \cdot \phi_{i}
\end{aligned}
$$




$$
\psi_{i} \cong 1+\frac{\phi_{1}}{\phi_{m i}}\left[\phi_{m i} \cdot \phi_{i}+\left(1-\phi_{m i}\right) \cdot \phi_{1}\right]
$$

$K$ is the thermal conductivity of the composite, and $k_{i}$ is the thermal conductivity of each constituent. The subscript $i$ represents the constituent where a subscript of 1 stands for the neat polymer matrix and greater subscripts $(2,3, \ldots)$ represent the different fillers. $\phi_{i}$ is the volume fraction of the indicated filler. As in the case of the original model, Nielsen's method of choosing the $A_{i}$ parameter can be found in Table 2.3-1 and the $\phi_{m i}$ parameter for various filler geometries can be found in Table 2.3-2. 


\section{Section 2.4: Current Bipolar Plate Technology}

Numerous materials have been used in the past for bipolar plates for fuel cells. Metallic plates have been utilized but these have several disadvantages, relative to conductive resins, including higher cost and weight, and corrosion. Hence, conductive resins have been developed. Currently, thermosetting matrix materials (epoxies, phenolics, vinyl esters, etc) are used. One design uses $80 \mathrm{wt} \%$ synthetic graphite particles (44 to 150 microns in size) in a vinyl ester resin [13]. To produce the thermosetting conductive resins, a high weight percentage of a single type of graphite powder is mixed with a viscous ester liquid polymer and curing agents are added in a batch process. This mixture is transferred to a mold, where the resin is cured (chemical reaction occurs and a solid is formed) at elevated temperatures [10]. On the other hand, when a thermoplastic is heated, it melts (no chemical reaction occurs) and can be used again.

Thermosets have several disadvantages as compared to thermoplastics. First, relatively long molding cycle times (one minute) are needed to cure the thermosets (to allow for the chemical reaction to take place) as compared to 5 to 10 seconds for thermoplastics. Second, thermosets cannot be remelted. Thermoplastic based resins can be recycled; therefore, used plates and any scrap generated in the manufacturing process can be remelted and used to produce new bipolar plates. Third, bipolar plates made using thermosetting resins are relatively thick and heavy, adding to the volume and weight of commercial fuel cells. Thermoplastics can be formed into thinner bipolar plates. The cost of this current thermoset based technology is approximately $\$ 8$ to $\$ 10$ / bipolar plate. The Department of Energy has set a target of $\$ 2 /$ bipolar plate (or $\$ 10 / \mathrm{kW}$ ) to facilitate affordable integration of fuel cell technology into public transportation [9]. Clearly, 
improvements are need.

Lately, some researchers have begun to investigate using various thermoplastic (polypropylene, polyethylene, polyphenylene sulfide, polyphenylene oxide, nylon, etc.) polymers for bipolar plates $[9,14,17]$. Conductive thermoplastics are mixed in an extruder, which can then directly go to a continuous thermoforming stamping process, which reduces manufacturing costs.

Conductive fillers that have been investigated include various carbon and graphite powders, particles, and fibers [14, 17, 19, 25]. Current technology adds as much of a single type of graphite powder as possible to achieve the needed electrical and thermal conductivity, while still allowing the material to flow into the mold [10]. These values vary depending on the specific needs of the fuel cell. 


\section{Section 2.5: References}

1. J. R. Fried, Polymer Science and Technology. Prentice Hall, New Jersey, 1995.

2. GE Engineering Thermoplastic Product Guide: Material Selection. GE Plastics.

3. M. P. Stevens, Polymer Chemistry: An Introduction. Oxford University Press, New York, 1999.

4. D. Hansen, and G. A. Bernier, "Thermal Conductivity of Polyethylene: The Effects of Crystal Size, Density, and Orientation on the Thermal Conductivity”. Polymer Engineering and Science, Vol. 12, No. 3, 1972, pp. 204.

5. J-P. Issi, B. Nysten, A. Jonas, A. Demain, L. Piraux, and B. Poulaert, “Tailoring the Thermal Conductivity of Organic Materials”. Thermal Conductivity 21, Plenum Press, 1990, pp 629-646.

6. L. Piraux, E. Ducarme, and J-P. Issi, “Thermal Conductivity of Oriented Polyacetylene Films”. Synthetic Metals, 41-43, 1991, pp 129-132.

7. D. W. Sundstrom and Y. Lee, "Thermal Conductivity of Polymer Filled with Particulate Solids”. Journal of Applied Polymer Science, Vol. 16, 1972 pp 31593167.

8. J. E. Parrott, and A. D. Stuckes, Thermal Conductivity of Solids. Pion Limited, London, 1975.

9. R. Berman, Thermal Conduction in Solids. Claredon, Oxford, 1976.

10. R. B. Bird, W. E. Stewart, and E. N. Lightfoot, Transport Phenomena. Wiley, New York, 1960.

11. D. M. Bigg, “Thermally Conductive Polymer Compositions”. Polymer Composites, Vol. 7, No. 3, 1986, pp. 125. 
12. J-P. Issi, “Improved Materials for Thermal Management”. Presentation 7-27-92, Wilmington, DE.

13. L-G. Tang, and J. L. Kardos, "A review of methods for improving the interfacial adhesion between carbon fiber and polymer matrix”. Polymer Composites, Vol. 18, No. 1, 1997.

14. R. E. Hummel, Electronic Properties of Materials, 2nd ed. Springer-Verlag, Berlin, 1993.

15. Y. Agari, and T. Uno, "Thermal Conductivity of Polymer Filled with Carbon Materials: Effect of Conductive Particle Chains on Thermal Conductivity”. Journal of Applied Polymer Science, Vol. 30, 1985, pp. 2225-2236.

16. Y. Agari, A. Ueda, and S. Nagai, "Thermal Conductivities of Composites in Several Types of Dispersion Systems”. Journal of Applied Polymer Science, Vol. 42, 1991, pp. 1655-1669.

17. R. McCullough, “Generalized Combining Rules for Predicting Transport Properties of Composite Materials”. Composites Science and Technology, Vol. 22, 1985.

18. R. C. Progelhof, J. L. Throne, and R. R. Ruetsch, "Methods of Predicting Thermal Conductivity of Composite Systems: A Review”. Tech. Pap., Reg. Tech. Conf. Soc. Plast. Eng., 1975.

19. R. L. Hamilton and O. K. Crosser, "Thermal Conductivity of Heterogeneous Two-Component Systems”. I\&EC Fundamentals, Vol. 1, No. 3, 1962, pp 187191.

20. L. E. Nielsen, "The Thermal and Electrical Conductivity of Two-Phase Systems”. 
I\&EC Fundamentals, Vol. 13, No. 1, 1974, pp. 17-20.

21. L. E. Nielsen, and R. F. Landel, Mechanical Properties of Polymers and Composites. 2nd ed., Marcel Dekker, New York, 1994.

22. R. C. Progelhof, J. L. Throne, and R. R. Ruetsch, "Methods of Predicting Thermal Conductivity of Composite Systems: A Review”. Reg. Tech. Cond. - Soc. Plast. Eng, 1975, pp. 221-257.

23. S. McGee and R. L. McCullough, "Combining Rules for Predicting the Thermoplastic Properties of Particulate Filled Polymers, Polyblends, and Foams”. Polymer Composites, Vol. 2, No. 4, 1981, pp. 149-161.

24. E. H. Weber, "Development and Modeling of Thermally Conductive Polymer/Carbon Composites”, Ph.D. Dissertation, Michigan Technological University, Houghton, MI, 2001.

25. H.-J. Ott, “Thermal Conductivity of Composite Materials”. Plastic and Rubber Processing and Applications, Vol. 1, 1981, pp. 9-24. 


\section{Chapter 3: Materials and Experimental Procedures}

\section{Section 3.1: Materials}

\section{Section 3.1.1: Matrix Materials}

\section{Section 3.1.1.1: Vectra A950RX LCP}

The matrix used for this project was Ticona's Vectra A950RX Liquid Crystal Polymer (LCP), which is a highly ordered thermoplastic copolymer consisting of 73 mole \% hydroxybenzoic acid (HBA) and 27 mole \% hydroxynaphtholic acid (HNA). This LCP has the properties needed for bipolar plates, namely high dimensional stability up to a temperature of $250^{\circ} \mathrm{C}$, extremely short molding times (often 5-10 seconds), exceptional dimensional reproducibility, chemically resistant in acidic environments present in a fuel cell, and a low hydrogen gas permeation rate [1-2]. The properties of this polymer are shown in Table 3.1-1 [1].

Table 3.1-1: Properties of Ticona's Vectra A950RX LCP [1]

\begin{tabular}{|c|c|}
\hline Melting Point & $280{ }^{\circ} \mathrm{C}$ \\
\hline Tensile Modulus (1mm/min) & $10.6 \mathrm{GPa}$ \\
\hline Tensile Stress at break (5mm/min) & $182 \mathrm{MPa}$ \\
\hline Tensile Strain at break (5mm/min) & $3.4 \%$ \\
\hline Flexural Modulus at $23^{\circ} \mathrm{C}$ & $9.1 \mathrm{GPa}$ \\
\hline Notched Izod Impact Strength at $23^{\circ} \mathrm{C}$ & $95 \mathrm{KJ} / \mathrm{m}^{2}$ \\
\hline Density at $23^{\circ} \mathrm{C}$ & $1.40 \mathrm{~g} / \mathrm{cC}$ \\
\hline Volumetric Electrical Resistivity at $23^{\circ} \mathrm{C}$ & $10^{15} \mathrm{ohm}-\mathrm{cm}$ \\
\hline Surface Electrical Resistivity & $10^{14} \mathrm{ohm}$ \\
\hline Thermal Conductivity at $23^{\circ} \mathrm{C}$ & $0.2 \mathrm{~W} / \mathrm{mK}(\mathrm{approx})$. \\
\hline Humidity Absorption (23 $\left.{ }^{\circ} \mathrm{C} / 50 \% \mathrm{RH}\right)$ & $0.03 \mathrm{wt} \%$ \\
\hline Mold Shrinkage-parallel & $0.0 \%$ \\
\hline Mold Shrinkage-normal & $0.7 \%$ \\
\hline Coefficient. of linear thermal expansion- parallel & $0.04 \times 10^{-4} /{ }^{\circ} \mathrm{C}$ \\
\hline Coefficient. of linear thermal expansion- normal & $0.38 \times 10^{-4} /{ }^{\circ} \mathrm{C}$ \\
\hline
\end{tabular}




\section{Section 3.1.2: Filler Materials}

\section{Section 3.1.2.1: Ketjenblack}

Carbon black has been used in many different industrial applications for thousands of years. Its two primary uses today are as a reinforcement material for rubber and as a pigmenting material. Approximately $90 \%$ of all carbon black produced is used for rubber reinforcement; most of the remainder is used for pigmenting (which includes fillers for polymer systems)[3].

There are two major methods through which carbon black is produced. The first method, which is also the more common of the two, is collecting the residue from the incomplete combustion of hydrocarbons. In a complete combustion of a hydrocarbon, all the carbon molecules leave the system as carbon dioxide. Incomplete combustion does not remove all the carbon molecules from the system, and the carbon residue that remains is the source of the carbon black. The second method of production is the thermal decomposition of hydrocarbons, which leaves a carbon residue as in the previous method. Table 3.1-2 shows the major categories of carbon black, the process of their production, and typical applications. The major process that is used to produce carbon black today is the furnace black process [3]. However, the quality of carbon black varies by process; two processes that produce high-quality carbon black are the acetylene and thermal decomposition processes. 
Table 3.1-2: Classification of Manufacturing Processes, Feedstocks, and Uses of Carbon Black [3]

\begin{tabular}{|c|c|c|c|}
\hline Chemical Process & Production Process & Feedstock & Uses \\
\hline \multicolumn{4}{|c|}{ Thermal-oxidative decomposition } \\
\hline \multirow[t]{2}{*}{\begin{tabular}{|l|l} 
Closed System \\
(Turbulent flow)
\end{tabular}} & Furnace black process & $\begin{array}{l}\text { Aromatic oils based } \\
\text { on coal tar or crude } \\
\text { oil, natural gas }\end{array}$ & $\begin{array}{l}\text { Tires, non-tire } \\
\text { rubber applications, } \\
\text { and pigments }\end{array}$ \\
\hline & Lampblack process & $\begin{array}{l}\text { Aromatic oils based } \\
\text { on coal tar or crude } \\
\text { oil }\end{array}$ & $\begin{array}{l}\text { Mechanical rubber } \\
\text { goods, electrodes, } \\
\text { and carbon brushes }\end{array}$ \\
\hline \begin{tabular}{|l} 
Open System \\
(Diffusion flames)
\end{tabular} & $\begin{array}{l}\text { Dequssa gas black } \\
\text { process } \\
\text { (Channel black }^{\text {process) }}{ }^{\mathrm{a}}\end{array}$ & Coal tar distillates & $\begin{array}{l}\text { Mechanical rubber } \\
\text { goods, electrodes, } \\
\text { and carbon brushes } \\
\text { Pigments }\end{array}$ \\
\hline \multicolumn{4}{|c|}{ Thermal decomposition } \\
\hline Discontinuous & Thermal black process & Natural Gas (Oils) & $\begin{array}{l}\text { Specialty } \\
\text { applications }\end{array}$ \\
\hline Continuous & $\begin{array}{l}\text { Acetylene black } \\
\text { process }\end{array}$ & Acetylene & $\begin{array}{l}\text { Electric cells and } \\
\text { conductive and } \\
\text { antistatic rubber and } \\
\text { plastic applications }\end{array}$ \\
\hline
\end{tabular}

${ }^{\mathrm{a}}$ historical process

These two processes have many similarities. They both work by thermal decomposition of a feed material in a reactor. The reactor is heated to a preset temperature while the feed stream is combusting with an air stream. When the reactor comes to temperature, the air stream is shut off while the feed stream continues to flow. At this point, the feed stops combusting to carbon dioxide and water and instead thermally decomposes to carbon black and hydrogen gas. This process continues as long as the feed stream continues to flow. The carbon black particles collect on the side of the reactor, where they begin to aggregate and form highly branched networks of molecules. The acetylene process has several advantages relative to the thermal black process. Its first advantage is that its single feed material, acetylene, allows for much higher purity 
and uniformity of product. Its second advantage is that is an exothermic net reaction, meaning that once it is initiated it will continue of its own volition, with a little cooling needed to prevent a runaway reaction. In comparison, the thermal black process will function on a mix of various light hydrocarbons, but this versatility comes at the cost of a more variable product composition. Also, the thermal black process is an endothermic reaction requiring a constant heat input to maintain the reaction [3].

The carbon black used in this work is Ketjenblack EC-600 JD, produced by Akzo Nobel. Table 3.1-3 shows the properties of this material. This carbon black is a specialty product, designed for the purpose of enhancing electrical conductivity in polymer composites. It significantly reduces the electrical resistivity of a composite at a low filler loading. In work by Narkis [4], this carbon black was found to have the largest impact per volume on the resistivity. In addition, its highly branched structure, as depicted in Figure 3.1-1, allows it to contact large volumes of polymer with minimal filler loading [5]. 
Table 3.1-3: Properties of Akzo Nobel Ketjenblack EC-600 JD Carbon Black [5]

\begin{tabular}{|l|l|}
\hline Electrical Resistivity & $0.01-0.1 \mathrm{ohm}-\mathrm{cm}$ \\
\hline Aggregate Size & $20-100 \mathrm{~nm}$ \\
\hline Specific Gravity & $1.8 \mathrm{~g} / \mathrm{cm}^{3}$ \\
\hline Apparent bulk density & $100-120 \mathrm{~kg} / \mathrm{m}^{3}$ \\
\hline Ash content, max \% & 0.1 \\
\hline Moisture, max \% & 0.5 \\
\hline BET Surface Area & $1250 \mathrm{~m}^{2} / \mathrm{g}$ \\
\hline Pore Volume & $480-510 \mathrm{~cm}^{3} / 100 \mathrm{~g}$ \\
\hline pH & $8-10$ \\
\hline
\end{tabular}

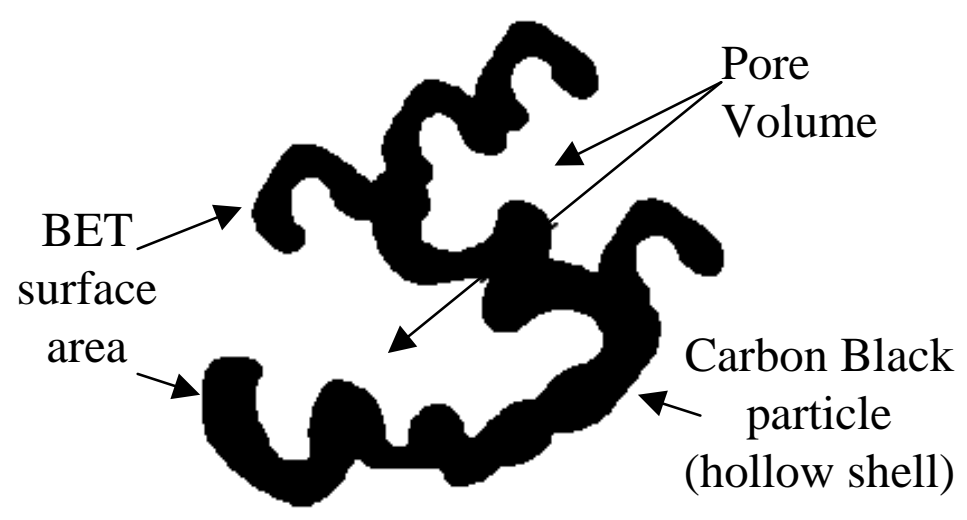

Figure 3.1-1: Carbon Black Illustration [5] 


\section{Section 3.1.2.2: Asbury Thermocarb Synthetic Graphite}

Synthetic graphite can be created from any material that leaves a carbon residue upon heating; however, the most common base material is petroleum coke [6,7]. There are many different grades of synthetic graphite, which is graded by properties including crystallite orientation, void fraction, size of voids, degree of graphitization, particle sizes, and particle size distribution. This graphite is normally graphitized at a temperature between 2500 and $3000^{\circ} \mathrm{C}$ in an inert atmosphere [7]. This product is intimately dependent on the choice of feed materials, and its final form depends on the intended end use. For polymer processing applications, the graphite is typically used in particle form. Compared to natural graphite, formed under heat and pressure within the earth and then mined for use, a typical synthetic graphite has the advantages of higher mechanical strength, lower ash content and more uniform properties [7].

The synthetic graphite that was used in this project is Asbury’s Thermocarb ${ }^{\mathrm{TM}}$ TC-300 Specialty Graphite [8-10]. Table 3.1-4 shows the properties of this material. This material was used in this project due to its high thermal conductivity and its good results in previous projects $[8,9,11]$. Figure $3.1-2$ is a representative SEM micrograph of this filler. 
Table 3.1-4: Properties of Conoco's Thermocarb TC-300 [10]

\begin{tabular}{|c|c|}
\hline Filler & Thermocarb Synthetic Graphite \\
\hline Carbon Content, wt\% & 99.91 \\
\hline Ash, wt\% & $<0.1$ \\
\hline Sulfur, wt\% & 0.004 \\
\hline Density, g/cc & 2.24 \\
\hline Thermal Conductivity at $23^{\circ} \mathrm{C}, \mathrm{W} / \mathrm{mK}$ & 600. \\
\hline Electrical Resistivity at $23^{\circ} \mathrm{C}$, ohm-cm & $10^{-5}$ \\
\hline Particle Shape & acicular \\
\hline Particle Aspect Ratio & 1.7 \\
\hline \multicolumn{2}{|l|}{ Sieve Analysis, Microns, wt $\%$} \\
\hline+600 microns & 0.19 \\
\hline+500 microns & 0.36 \\
\hline+425 microns & -- \\
\hline +300 microns & 5.24 \\
\hline+212 microns & 12.04 \\
\hline+180 microns & 8.25 \\
\hline+150 microns & 12.44 \\
\hline-150 microns & -- \\
\hline+75 microns & 34.89 \\
\hline+44 microns & 16.17 \\
\hline-44 microns & 10.42 \\
\hline
\end{tabular}

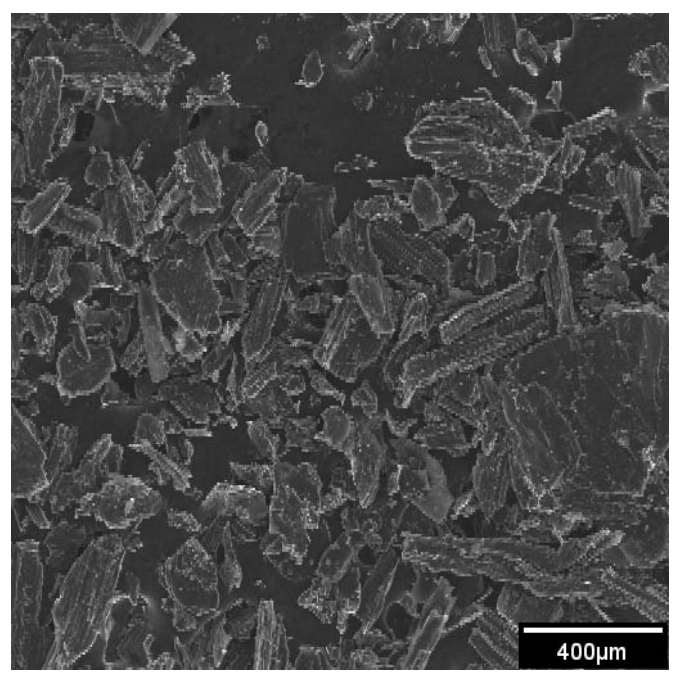

Figure 3.1-2: Thermocarb TC-300 SEM image 


\section{Section 3.1.2.3: Asbury Synthetic Graphite 4012}

Synthetic graphite is manufactured by high temperature heat treatment of amorphous carbonaceous materials. The primary feed stocks used in the United States for making synthetic graphite are calcined petroleum coke and coal tar pitch, both of which contain highly graphitizable forms of carbon. The manufacturing process consists of various mixing, molding, and baking operations, followed by heat-treating to temperatures between $2500^{\circ} \mathrm{C}$ and $3000^{\circ} \mathrm{C}$. This high temperature is needed to drive the carbon from an amorphous phase to a graphitic phase. The high temperate also helps in burning off impurities that may have been present in the carbon, including metal oxides, sulfur, nitrogen, hydrogen, and all organic components that were part of the original petroleum or coal tar pitch [12]. Table 3.1-5 [10] lists the important properties of this material. Figure 3.1-3 is a representative SEM micrograph of this filler. 
Table 3.1-5: Properties of Asbury Synthetic Graphite 4012 [10]

\begin{tabular}{|c|c|}
\hline Filler & 4012 Synthetic Graphite \\
\hline Carbon Content, wt\% & 99.67 \\
\hline Ash, wt\% & $<0.5$ \\
\hline Sulfur, wt $\%$ & $<0.1$ \\
\hline Density, g/cc & 2.24 \\
\hline Thermal Conductivity at $23^{\circ} \mathrm{C}, \mathrm{W} / \mathrm{mK}$ & 600. (approx.) \\
\hline Electrical Resistivity at $23^{\circ} \mathrm{C}, \mathrm{ohm}-\mathrm{cm}$ & $10^{-5}$ \\
\hline Particle Shape & acicular \\
\hline Particle Aspect Ratio & 1.7 \\
\hline & \\
\hline Sieve Analysis, Microns, wt $\%$ & \\
\hline+180 microns & 0.22 \\
\hline+150 microns & 0.86 \\
\hline-150 microns & -- \\
\hline+75 microns & 71.65 \\
\hline+44 microns & 24.43 \\
\hline-44 microns & 2.82 \\
\hline & \\
\hline & \\
\hline
\end{tabular}

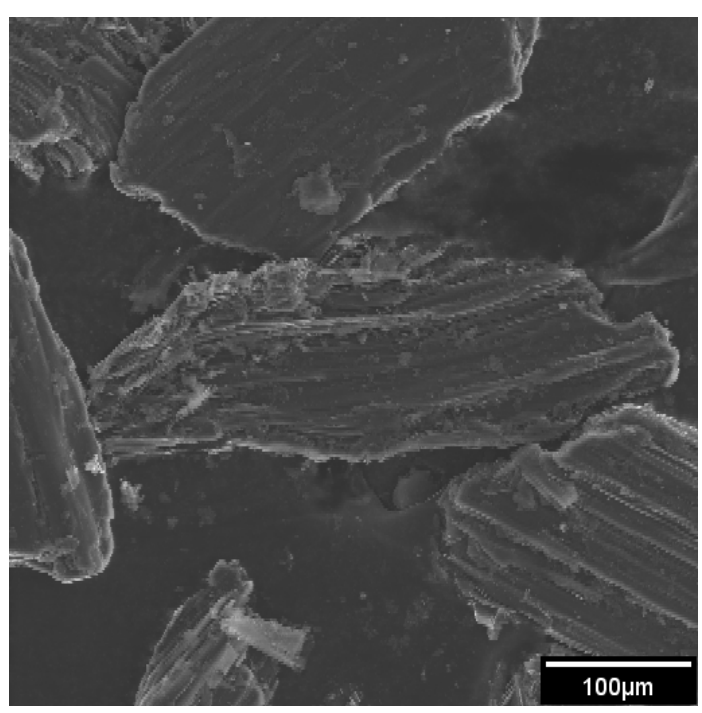

Figure 3.1-3: Asbury Synthetic Graphite 4012 SEM image 


\section{Section 3.1.2.4: Asbury Natural Flake Graphite 3160}

Flake graphite is a naturally occurring form of graphite. It naturally occurs as discrete flakes with diameters of $50-800$ microns and thicknesses of $1-50$ microns thick. Natural flake graphite displays a very high degree of crystallinity; this translates to physical properties of low void fraction, excellent thermal and electrical conductivities, and enhanced molding properties [12]. Table 3.1-6 [10] lists the important properties of this material. Figure 3.1-4 is a representative SEM micrograph of this filler. 
Table 3.1-6: Properties of Asbury Natural Flake Graphite 3160 [10]

\begin{tabular}{|c|c|}
\hline Filler & 3160 Natural Flake Graphite \\
\hline Carbon Content, wt\% & 99.30 \\
\hline Ash, wt\% & 0.7 \\
\hline Sulfur, wt\% & $<0.1$ \\
\hline Density, g/cc & 2.24 \\
\hline Thermal Conductivity at $23^{\circ} \mathrm{C}, \mathrm{W} / \mathrm{mK}$ & 600 (approx.) \\
\hline Electrical Resistivity at $23^{\circ} \mathrm{C}, \mathrm{ohm}-\mathrm{cm}$ & $10^{-5}$ \\
\hline Particle Shape & flake \\
\hline Particle Aspect Ratio & 4.8 \\
\hline & \\
\hline Sieve Analysis, Microns, wt\% & 1.9 \\
\hline+180 microns & 9.7 \\
\hline+150 microns & -- \\
\hline-150 microns & 50.4 \\
\hline+75 microns & 21.6 \\
\hline+44 microns & 16.4 \\
\hline-44 microns & \\
\hline
\end{tabular}

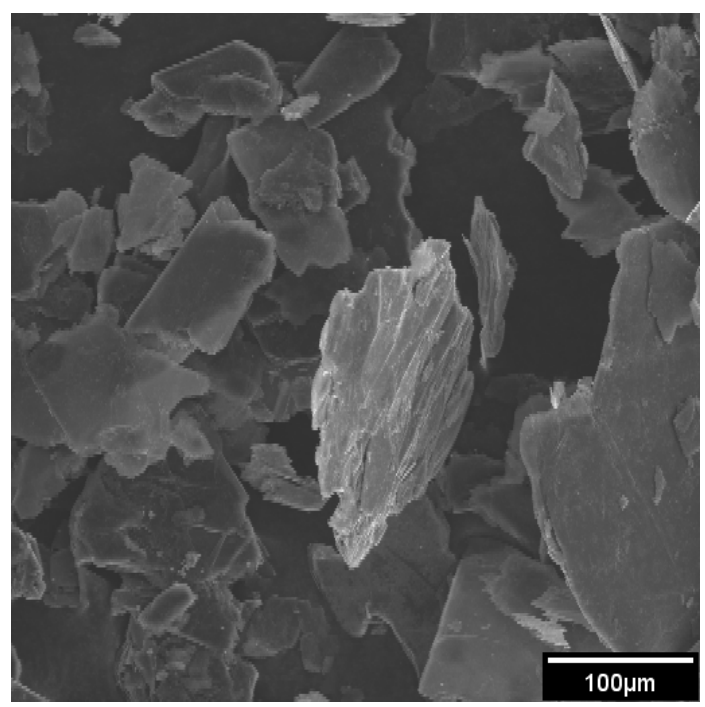

Figure 3.1-4: Asbury Natural Flake Graphite 3160 SEM Image 


\section{Section 3.1.2.5: Asbury Calcined Needle Coke F108A}

Calcined needle coke is a variety of petroleum coke. It is called needle coke in reference to its structure; it is commonly found as needle-like structures that are clearly visible without magnification and rises from the liquid-crystalline alignment that occurs during the coking procedure. The high degree of orientation is consistent with feedstocks of high aromaticity. Calcined needle coke is typically higher in carbon and lower in ash constituents, such as sulfur and metals, than standard calcined petroleum coke [12]. Table 3.1-7 [10] lists the important properties of this material. Figure 3.1-5 is a representative SEM micrograph of this filler. 
Table 3.1-7: Properties of Asbury Calcined Needle Coke F108A [10]

\begin{tabular}{|c|c|}
\hline Filler & Calcined Needle Coke F108A \\
\hline Carbon Content, wt\% & 99.10 \\
\hline Ash, wt\% & 0.3 \\
\hline Sulfur, wt\% & 0.5 \\
\hline Density, g/cc & 2.1 \\
\hline Thermal Conductivity at $23^{\circ} \mathrm{C}, \mathrm{W} / \mathrm{mK}$ & 10 to 20 (approx.) \\
\hline Electrical Resistivity at $23^{\circ} \mathrm{C}, \mathrm{ohm}-\mathrm{cm}$ & $10^{-3}$ (approx.) \\
\hline Particle Shape & Acicular \\
\hline Particle Aspect Ratio & 2.3 \\
\hline & \\
\hline Sieve Analysis, Microns, wt\% & 0.13 \\
\hline+600 microns & -- \\
\hline+500 microns & 4.16 \\
\hline+425 microns & 19.05 \\
\hline+300 microns & 42.84 \\
\hline+212 microns & 17.56 \\
\hline+180 microns & 10.64 \\
\hline+150 microns & 5.62 \\
\hline-150 microns & \\
\hline
\end{tabular}

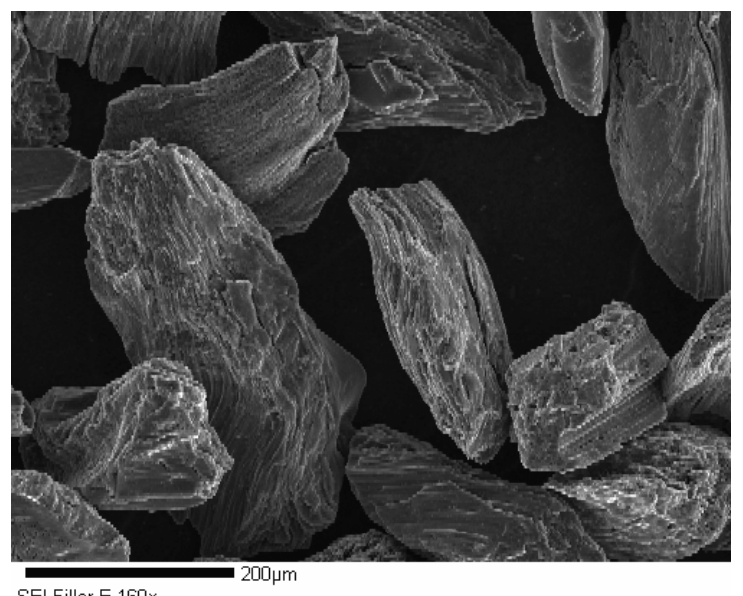

SEI Filler E 160x

Figure 3.1-5: Asbury Calcined Needle Coke F108A SEM Image 


\section{Section 3.1.2.6: Fortafil 243 Carbon Fiber}

Akzo Nobel's Fortafil 243 polyacrylonitrile (PAN) based 3.2 mm chopped, surface treated and pelletized carbon fiber was also used to improve the electrical and thermal conductivity of the resin. A proprietary polymer was used as a binder for the pellets that also promoted adhesion with nylon. Table 3.1-8 [13] lists the properties for these fibers. Figure 3.1-6 is a representative SEM micrograph of this filler.

Table 3.1-8: Properties of Akzo Nobel Fortafil 243 PAN based 3.2mm Chopped and Pelletized Carbon Fiber [13]

\begin{tabular}{|c|c|}
\hline Tensile Strength & $3800 \mathrm{MPa}$ \\
\hline Tensile Modulus & $227 \mathrm{GPa}$ \\
\hline Electrical & $16.7 \mu \mathrm{ohm}-\mathrm{m}$ \\
\hline Thermal & $20 \mathrm{~W} / \mathrm{m} \mathrm{K}$ (axial direction) \\
\hline Bulk Density & 356 g/liter \\
\hline Fiber Diameter & 7.3 microns \\
\hline Filament Shape & Round \\
\hline Fiber Mean & $3.2 \mathrm{~mm}$ (entire range is $2.3 \mathrm{~mm}$ to $4.1 \mathrm{~mm})$ \\
\hline Carbon Assay & $95 \%$ \\
\hline Binder Content & $2.6 \mathrm{wt} \%$ proprietary polymer that adheres pellet together and \\
promotes adhesion with nylon matrix
\end{tabular}

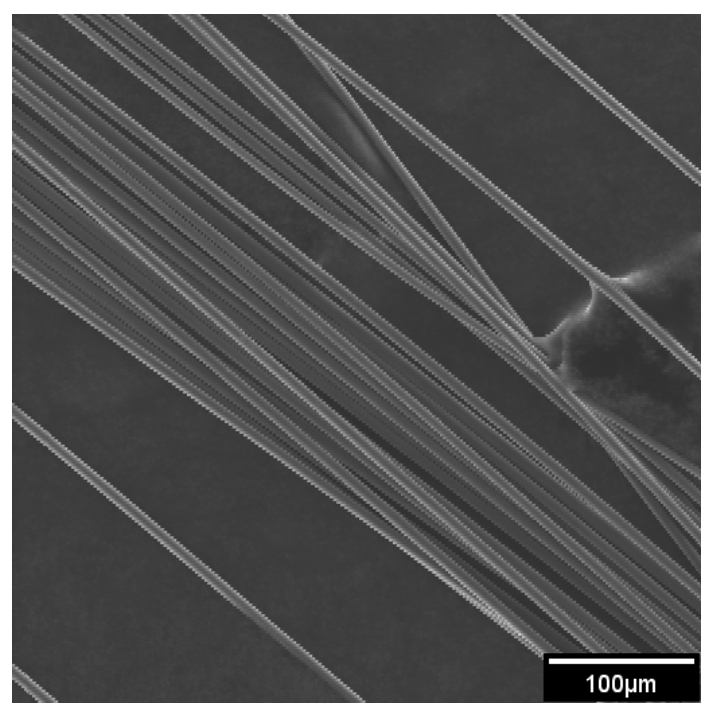

Figure 3.1-6: Fortafil 243 Carbon Fiber SEM Image 


\section{Section 3.2: Experimental Design}

The experiment was designed in two stages. Stage one was the filler screening stage, where various graphite carbon particles and calcined needle coke could be compared to each other to determine the best one to use for further experimentation. In the screening stage for the graphite and calcined coke particles, loading levels were set at 40, 60 and 70 weight percent (wt\%). The carbon black loading levels were set at 2.5, 4, 5, 6, 7.5, 10 and $15 \mathrm{wt} \%$.

The naming convention used for this work is shown below:

EuVwX-y-z

Where:

$\mathrm{E}=$ the project description $(\mathrm{E}=\mathrm{DOE})$

$\mathrm{u}=$ Filler type $(\mathrm{A}=$ carbon black, $\mathrm{B}=$ synthetic graphite particles, $\mathrm{H}=$ milled pitch-based carbon fiber)

$\mathrm{V}=$ Matrix polymer ( $\mathrm{V}$ for Vectra)

$\mathrm{w}=$ Replicate or original (none for original, $\mathrm{R}$ for replicate, $\mathrm{RR}$ for second replicate, etc.)

$\mathrm{x}=$ Weight percent of filler added $(5,10,15, \ldots)$

$\mathrm{y}=$ Specimen type (F for flex, $\mathrm{T}$ for tensile, TC for thermal conductivity disks)

$\mathrm{z}=$ Specimen number 


\section{Section 3.3: Methods}

\section{Section 3.3.1: Fabrication Methods}

\section{Section 3.3.1.1: Drying}

For this entire project, the fillers were used as received (not dried). The Vectra A950RX LCP was dried in a Bry Air System indirect heated dehumidifying dryer (dew point of recirculating air $=-40^{\circ}$ ) at ambient temperature. Approximately 300 pounds of Vectra was dried in 20 pound batches at $302^{\circ} \mathrm{F}$ for 24 hrs. Figure $3.3-1$ illustrates the Bry Air dryer used. After drying, the polymer was stored in moisture barrier bags.

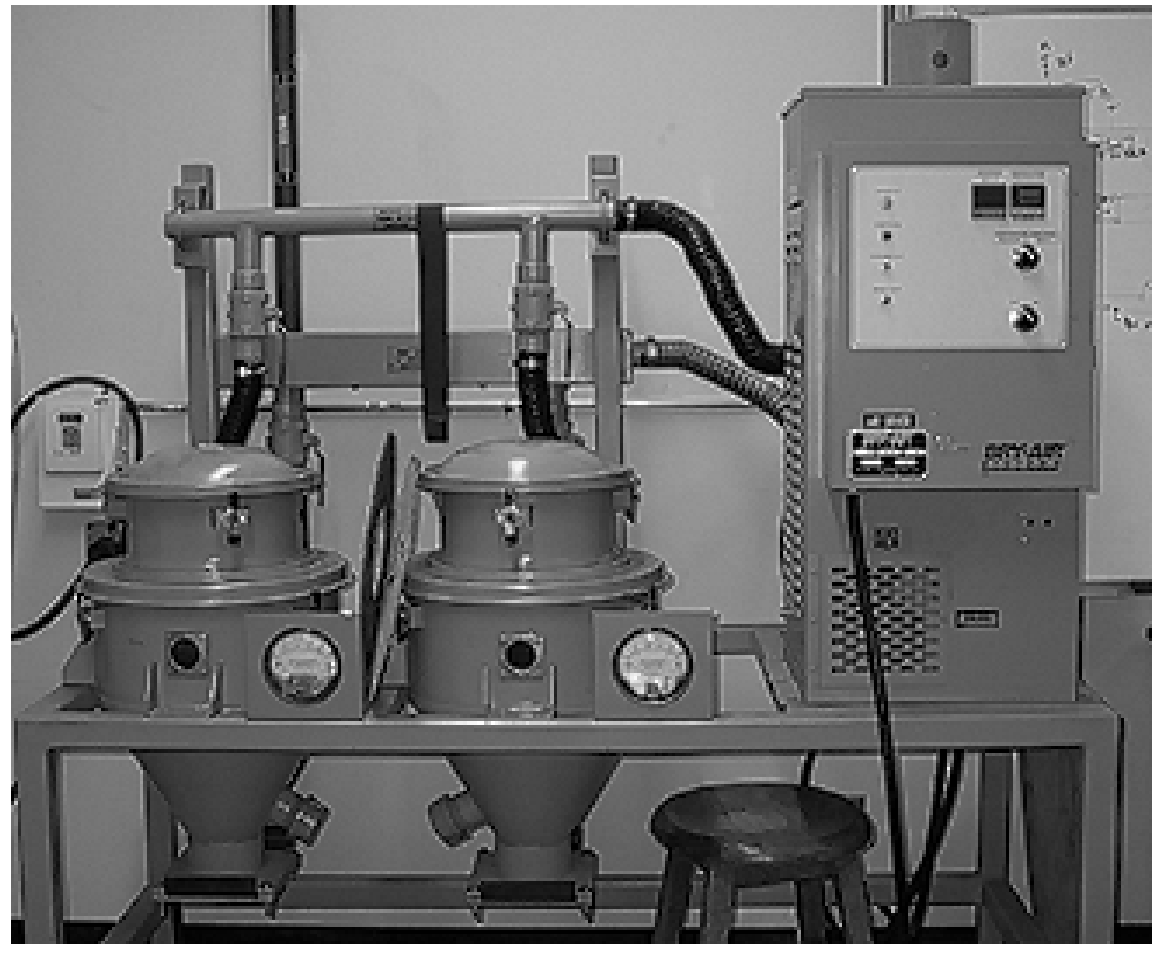

Figure 3.3-1: Bry Air Dryer

\section{Section 3.3.1.2: Extrusion}

An American Leistritz Extruder Corp. Model ZSE27 27mm co-rotating intermeshing twin-screw extruder was used to create the composite materials for this work. This extruder has a length to diameter ratio of 40:1 with ten independent heating 
zones and a water-cooled feed port. An image of the extruder is shown in Figure 3.3-2. The screw design used for the extrusion runs was chosen with the primary goals of producing a uniformly mixed composite while minimizing the degradation of the filler. A diagram of this design can be found in Section 9.1.

Referring to the ten temperature control zones of the extruder, Zone 1 contains the main feed port where the polymer is always added. This zone is water cooled so the polymer does not melt and plug the feed port. The polymer is fed by an AccuRate low range Flexwall gravimetric feeder; an image of this feeder is shown in Figure 3.3-3. Zones 2 and 3 are closed. Zone 4 is back-vented to the atmosphere allowing for gases that may have been evolved from melting the polymer, or vapors or gases from the filler feed in zone 5, to escape. The first side stuffer is located in Zone 5. All fillers used in this work were added in this zone. Zone 6 is closed, and Zone 7 contains the second side stuffer (not used in this work). Zone 8 is another closed zone. Zone 9 was vented to the atmosphere for this work, but it can be set up to pull a vacuum. Zone 10 is another closed zone. The nozzle used for this project had three $3 \mathrm{~mm}$ holes through which the composite material was forced. The nozzle also had a pressure and temperature sensor to measure properties of the exiting stream.

The side stuffer located in Zones 5 was fed by AccuRate Conisteel loss in weight feeders. An image of the Accurate Conisteel feeder can be seen in Figure 3.3-4. 


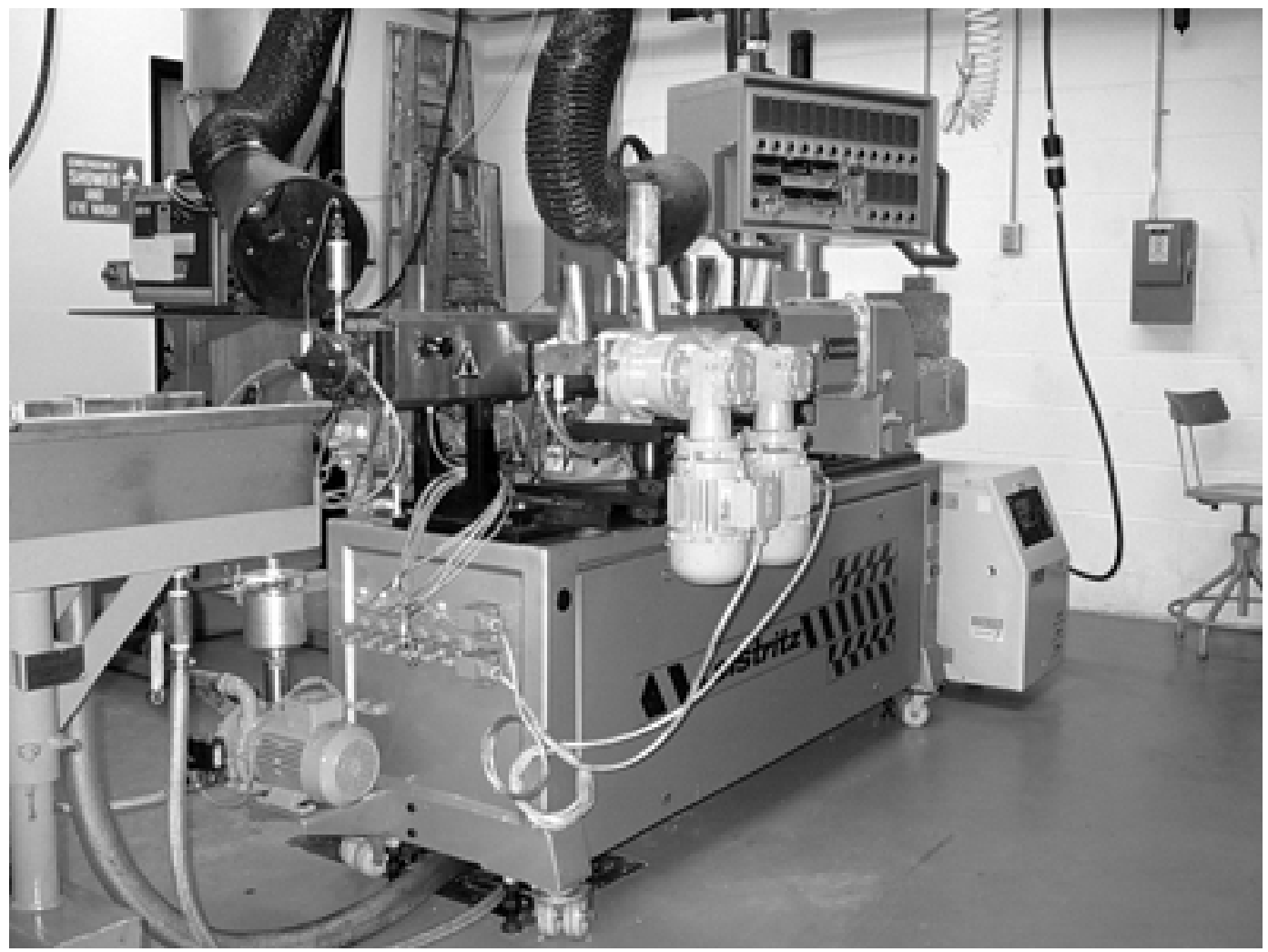

Figure 3.3-2: 27mm Twin Screw American Leistritz Extruder
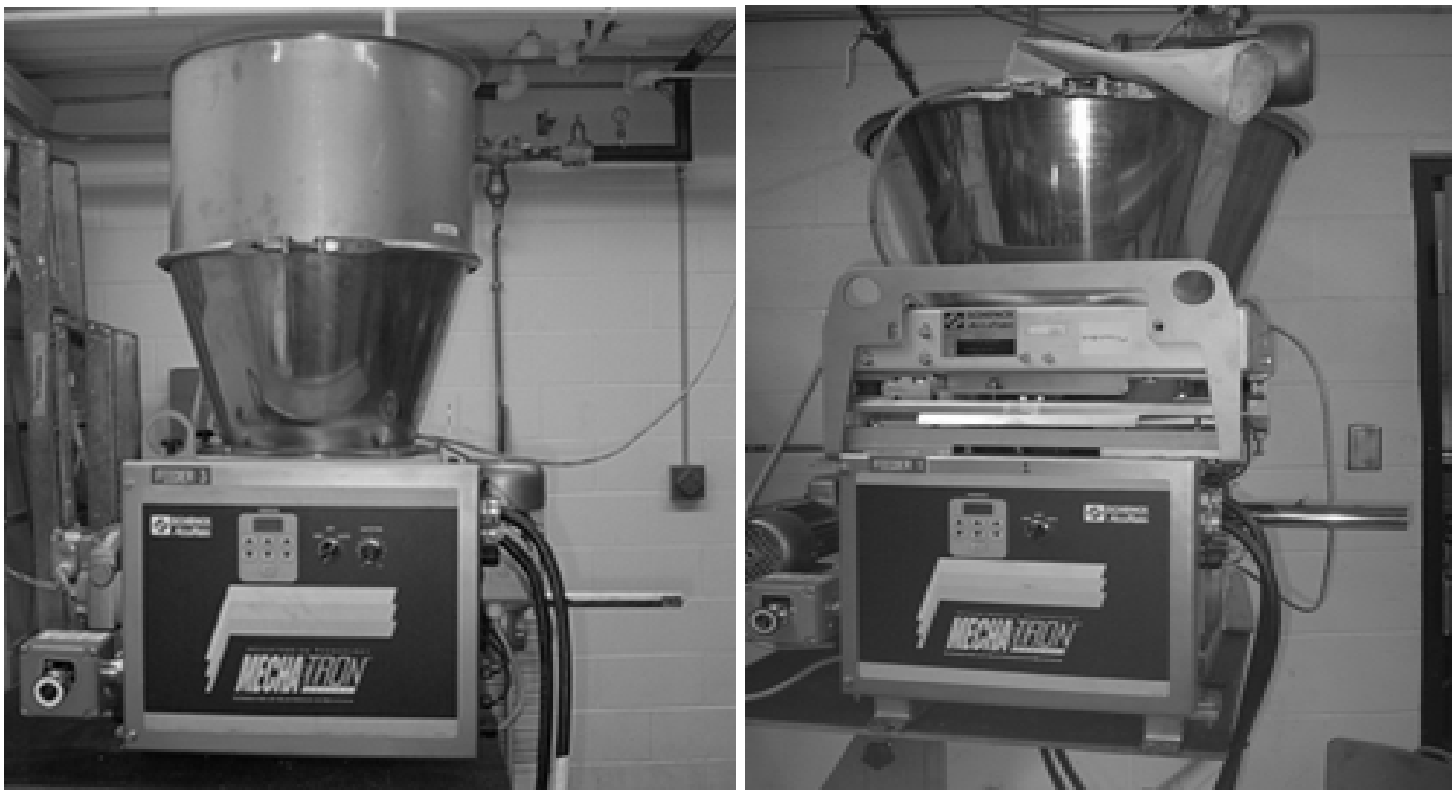

Figure 3.3-3: AccuRate Flexwall Feeder

Figure 3.3-4: AccuRate Conisteel Feeder 
An important element in the extrusion process is the screw design used. This design can have a significant effect on the mixing and degradation of the fillers, which in turn can have a significant effect on the mechanical, thermal and electrical properties of the composites. The screw designs used for this work include screw elements for conveyance and pressure control of the melt and kneading elements for mixing the polymer and filler in a uniform fashion. Over the course of this work, two different screw designs were used, both of the same basic design. Diagrams of the screw designs can be found in Section 9.1. The first three elements in the design were screw elements to convey the polymer pellets into the heating zones and pressurize the melting polymer. The next six elements in this design were kneading elements; four blocks with an increasingly steep thread angle to mix the polymer more and more vigorously as it passes down the extruder and two disks to continue the mixing as the molten polymer approached the first filler entry zone. The next three screw elements were conveyance elements, the first two to elongate the polymer flow and allow an air gap for filler addition and offgas flow and the third to increase the polymer pressure into the next elements.

The next two elements were kneading blocks to integrate the newly added filler into the molten polymer matrix. The two subsequent elements were screw elements; as before, they elongated the flow to allow for introduction of filler at the second sidestuffer and then recompressed the polymer flow for the last set of kneading elements. The next three elements were kneading blocks to integrate the newly added filler into the existing polymer system. The last three elements were screw elements; the first one 
elongated the melt one last time to allow vapors to escape before the final two compressive elements forced the melt out of the nozzle.

The three molten strands were forced into the water bath upon leaving the extruder. The composite strands were removed from the water bath while still hot, allowing most of the water to evaporate off. For most composite formulations, no more than two or three feet of the water bath were used. Most of the remaining water was then removed with an air knife. The air stream from the air knife blew directly on the extruder; therefore, a plastic shield was used. The shield minimized the movement of the fillers and the cooling of the extruder. The water bath was $10 \mathrm{ft}$ long, with the air knife located at the end opposite the extruder. After the composite strand passed through the air knife, the strands were pelletized by a ConAir Model 20402HP-14A strand pelletizer. An image of the pelletizer and water bath can be seen in Figure 3.3-5.

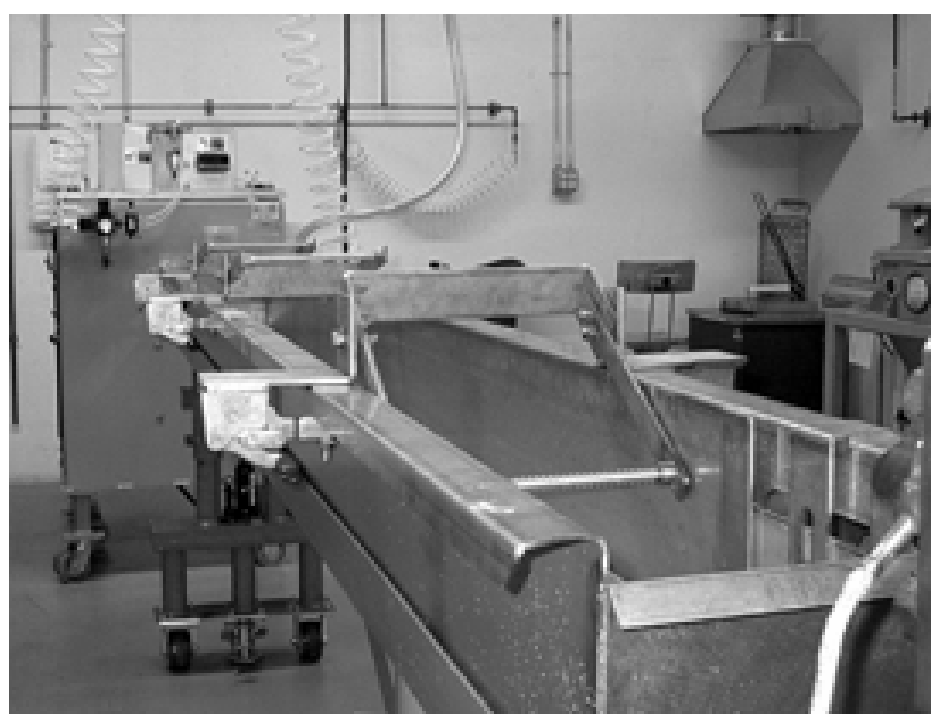

\section{Figure 3.3-5: Water Bath and Pelletizer}

For each composite formulation, typically ten pounds of pelletized material was produced. The conditions for each extrusion run performed can be found in Section 9.2. 
These wet pellets were dried prior to injection molding in vacuum ovens at $302^{\circ} \mathrm{F}$ for 20 to 24 hours in the Bry Air drier and subsequently stored in moisture barrier bags [14].

\section{Section 3.3.1.3: Injection Molding}

For this project, a 4.55 ounce polystyrene shot size Niigata injection-molding machine, model NE85UA4, was used [15]. An image of the injection molder can be seen in Figure 3.3-6. This machine has a $40 \mathrm{~mm}$ diameter single screw with a length over diameter ratio of 18:1. The lengths of the feed, compression, and metering sections of the single screw are 396 mm, $180 \mathrm{~mm}$, and $144 \mathrm{~mm}$, respectively. This machine has a maximum injection pressure of 22,610 psig, a maximum screw speed of $320 \mathrm{rpm}$, and a maximum clamp force of 82.5 US tons. The injection-molding process was completed in full automatic mode. Deltatherm was used to control the temperature of the mold at $190^{\circ} \mathrm{F}$ [16]. A four-cavity mold was used to injection mold 2.5 ” diameter by $1 / 8$ ” thick disk, and 6.5” long by 1/8” thick ASTM tensile bars (end gated only) and 5” long by 1/8” thick by 0.5 ” wide flex bars [17]. An image of the four-cavity mold can be seen in Figure 3.3-7. A feed hopper dryer was not used although every effort was made to ensure that the dried polymer pellets were exposed to atmospheric conditions for less than one hour. Section 9.3 lists the injection molding conditions for each composite formulation. Zone 4 is the heated zone nearest the feed hopper and zone 1 is the die nozzle heater. 


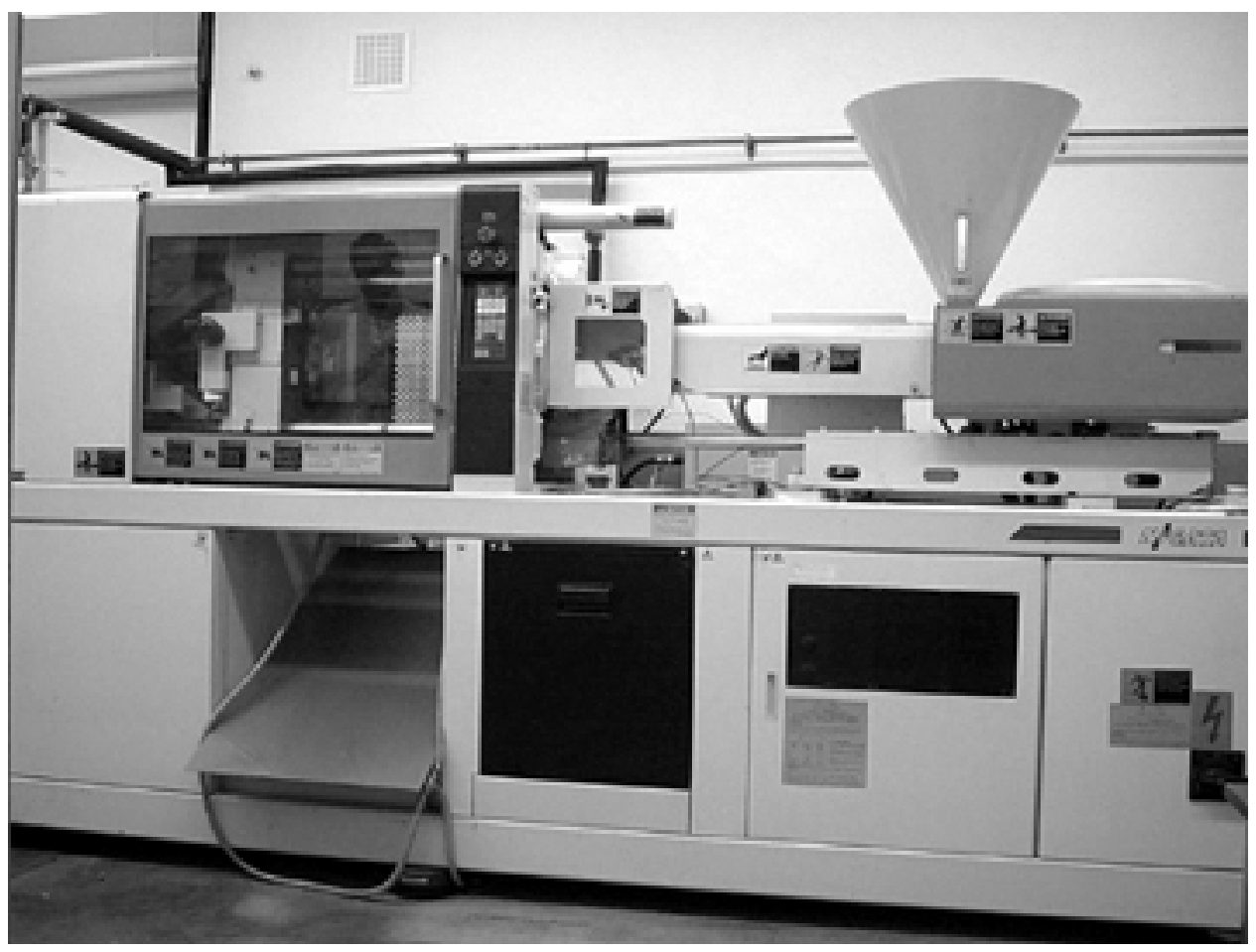

Figure 3.3-6: Niigata Injection Molding Machine

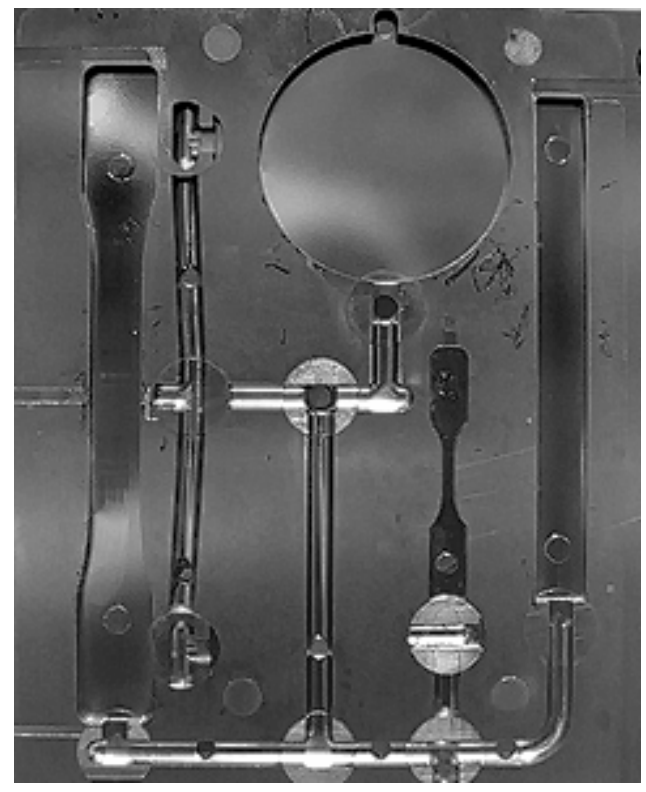

Figure 3.3-7: Four-Cavity Mold 
The following procedure was used for the injection molding of the composites [18].

1. The machine was brought up to correct operation temperature for the material to be run. Then Vectra A950RX LCP was run to purge out all of the material that might have been in the injection-molding machine previously.

2. Approximately $4 \mathrm{lbs}$. of each dried formulation were injection molded into 30 tensile bars, flex bars and 2.5” disks. Conditions were kept as constant as possible, and would only be changed if operational problems were encountered. The only parameter that was changed for every composite formulation was the shot size. This was changed in small increments until a very small amount of flash was present showing that the mold was completely full. The generated samples were stored in low-density polyethylene (LDPE) bags.

3. Once all samples for one formulation were injection molded, the injection-molding machine was operated until it could not fill another shot. The next formulation was then added to the hopper and the next five shots were thrown out as being transition material. During this time, the shot size was optimized for the new material. Once this process was completed, the new composite formulation samples were collected as described in step 2.

4. At the end of each day, the pure polymer was run through the machine until the melted polymer had no more carbon in it. Then polypropylene was used to purge out the high temperature polymer. Polypropylene was also run until the carbon was removed from the injection-molding machine. 


\section{Section 3.3.2: Test Methods}

Unless specifically mentioned otherwise, all samples tested by the following test methods were conditioned at 50\% relative humidity and room temperature for 88 hours prior to testing in accordance with ISO 291 [19].

\section{Section 3.3.2.1: TCA Analysis (Transverse Thermal Conductivity) (ASTM F433-98)}

Transverse thermal conductivity of an 1/8” thick by 2” diameter disc-shaped test specimen was measured at $55^{\circ} \mathrm{C}$ using a Holometrix Model TCA-300 Thermal Conductivity Analyzer, which uses the guarded heat flow meter method (ASTM F43398) [20-21]. Figure 3.3-8 illustrates this test method, and an image of the equipment can be seen in Figure 3.3-9. The estimated accuracy of this test method is $\pm 3 \%$ [21].

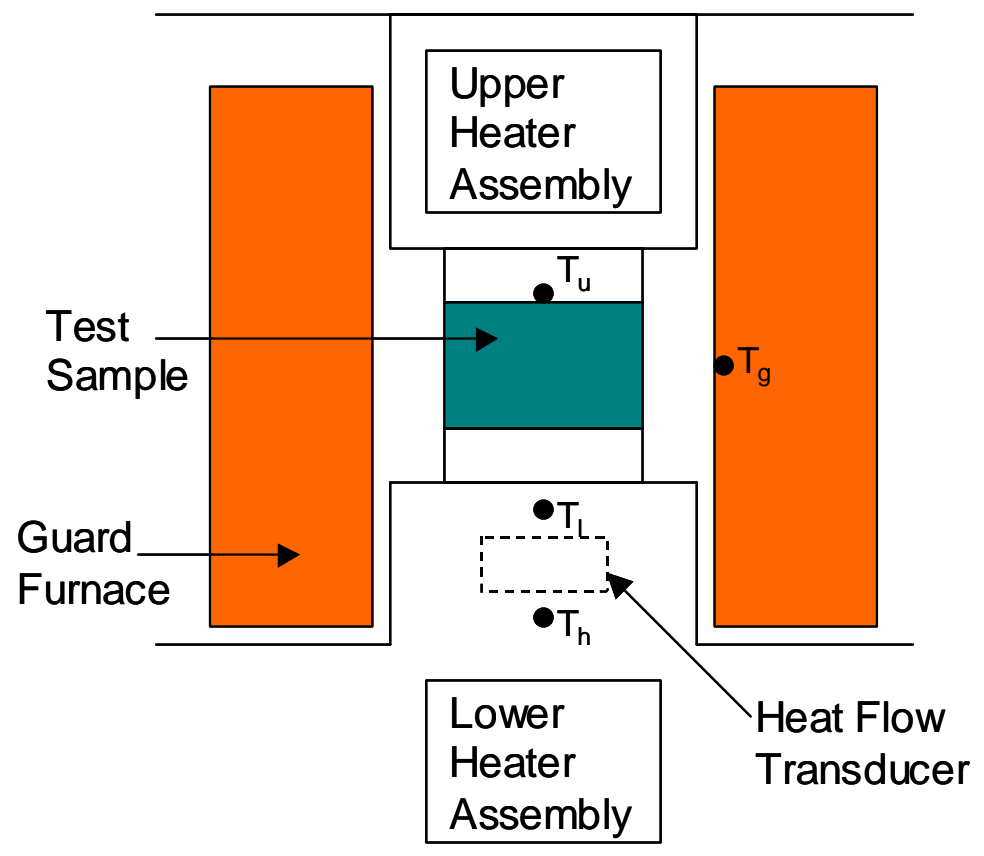

Where:

$\mathrm{T}_{\mathrm{g}}=$ Guard Temperature

$\mathrm{T}_{\mathrm{u}}=$ Upper Heater Assembly Temperature

$\mathrm{T}_{1}=$ Lower Heater Assembly Temperature

Figure 3.3-8: Diagram of Thermal Conductivity Test Method [21] 


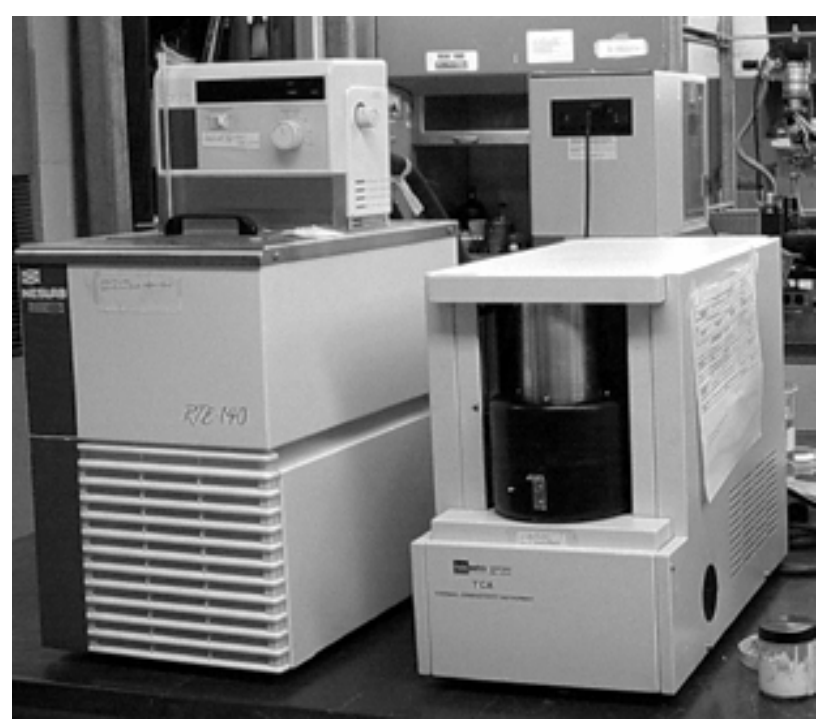

Figure 3.3-9: Image of TCA 300

To prepare these samples, the $63.5 \mathrm{~mm}$ diameter injection molded disks were cut to $50.8 \mathrm{~mm}$ diameter disks using a water jet cutter. The complete results for each test specimen can be found in Section 9.4.

\section{Section 3.3.2.2: HotDisk Analysis (Specific Heat, Transverse / Longitudinal Thermal}

\section{Conductivity)}

The Mathis Instruments Hot Disk Heat Capacity Cell is a device for measuring the specific heat of a composite material. Three disks, $25 \mathrm{~mm}$ in diameter and $3.2 \mathrm{~mm}$ thick, are stacked in an insulated copper cup. A known amount of power is run through the cup for a given time. The change in resistivity of the nickel in the sensor attached to the cup allows for measurement of the temperature rise which, when compared to the data for an empty sample sup, allows for calculation of the specific heat of a compound. Results for specific heat testing can be found in Section 9.5.

The Mathis Instruments Hot Disk Thermal Constants Analyser is an emerging technology that can measure the in-plane and through-plane thermal conductivity of an 
anisotropic material in the same test, using the transient plane source technique [22-26]. The sensor used in this test method consisted of a $10 \mu \mathrm{m}$ thick nickel foil embedded between two $25.4 \mu \mathrm{m}$ thick layers of Kapton polyimide film. The nickel foil was wound in a double spiral pattern with a radius $R$ of $3.189 \mathrm{~mm}$. The thermal conductivities were measured at $23^{\circ} \mathrm{C}$.

Figure 3.3.10 shows how the sensor is positioned between two samples of composite material. In this experiment, the samples tested were composite disks of diameter $D=63.5 \mathrm{~mm}$ and thickness $T=3.18 \mathrm{~mm}$. To help ensure that the assumption of an infinite sample domain was met and that heat was not penetrating completely through the sample in the axial direction, two of these composite disks were stacked together above the sensor and two were stacked below it, giving us a sample of double thickness. This stacking of disks allowed the generation of more reproducible data.

The sensor then had a constant electrical current (variable by sample from $0.03 \mathrm{~W}$ $-1.25 \mathrm{~W}$ ) over a short period of time (variable by sample from $2.5 \mathrm{~s}-40 \mathrm{~s}$ ) passed through. The generated heat dissipated within the double spiral was conducted through the Kapton insulating layer and into the surrounding sample, causing a rise in the temperature of the sensor and the sample. 


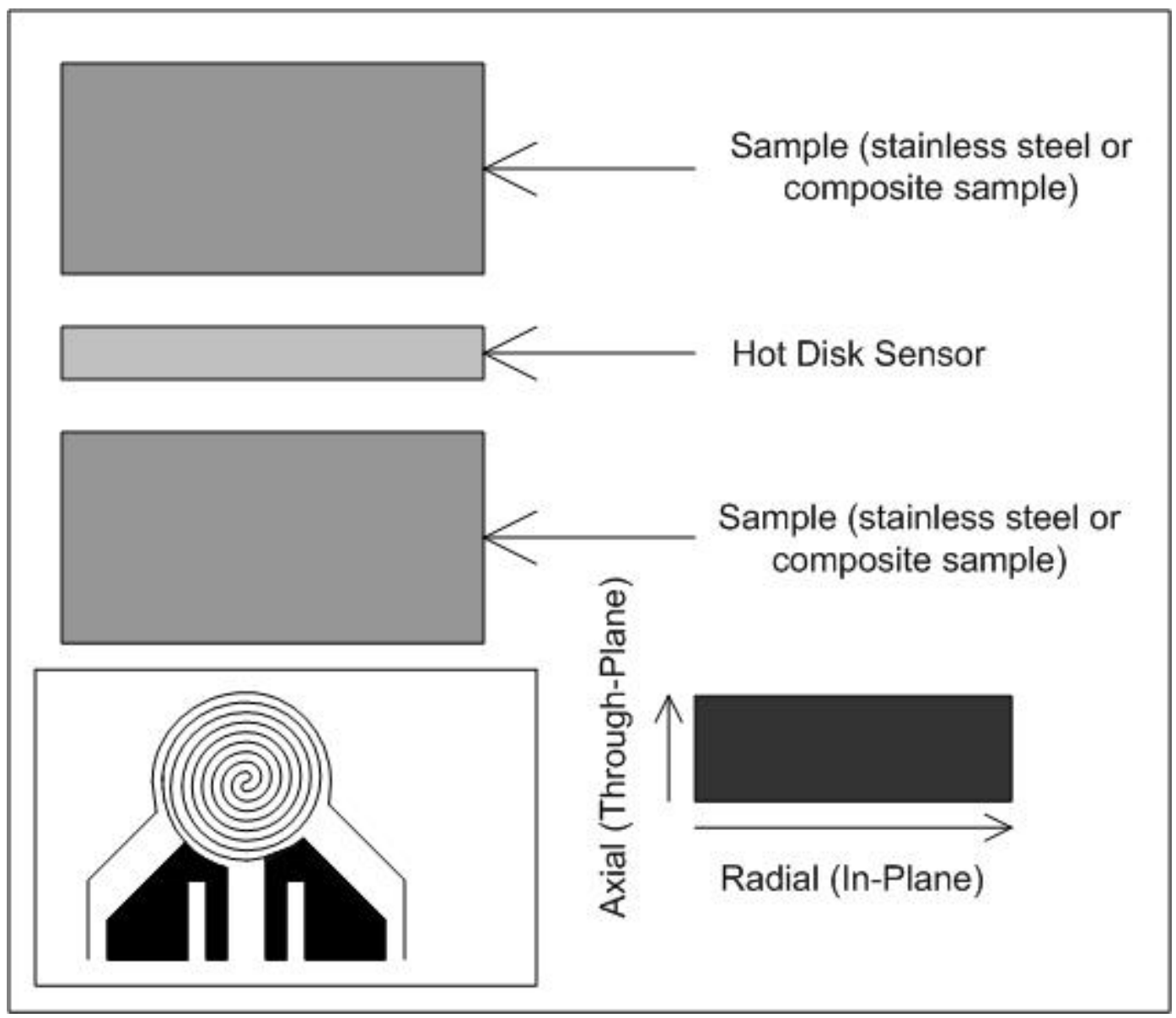

Figure 3.3-10: Schematic of Samples and Sensor. The inset at the lower left shows the double spiral heating element.

From a theoretical standpoint, the double spiral pattern can be approximated as a series of concentric, equally spaced ring sources. The characteristic heat conduction equation, assuming radial symmetry in the sample, is then given as:

$$
\left(\rho C_{p}\right) \frac{\partial T}{\partial t}=k_{\text {in }} \frac{1}{r}\left(\frac{\partial}{\partial r}\left(r \frac{\partial T}{\partial r}\right)\right)+k_{\text {thru }} \frac{\partial^{2} T}{\partial z^{2}}+\sum_{\text {rings }} Q_{r} \delta\left(r-r^{\prime}\right) \delta(z)
$$

where $\rho$ is the density of the sample $\left(\mathrm{kg} / \mathrm{m}^{3}\right), C_{p}$ is the heat capacity of the sample $(\mathrm{J} /(\mathrm{kg} \bullet \mathrm{K})), T$ is the temperature of the sample $(\mathrm{K}), t$ is the time of the measurement (s), $k_{\text {in }}$ and $k_{\text {thru }}$ are the in-plane and through-plane thermal conductivities of the sample $(\mathrm{W} / \mathrm{m} \bullet \mathrm{K}), \delta$ is the Dirac delta function, $r^{\prime}$ is the radius of one of the ring sources, and $Q_{r}$ 
is the power supplied to that ring per unit length of the ring $(\mathrm{W} / \mathrm{m})$. The total power for each ring is proportional to the circumference of the ring $2 \pi r^{\prime}$, such that the total power supplied for all of the rings is $Q(\mathrm{~W})$. This total power $Q$ is an input parameter to the Hot Disk Thermal Constants Analyser. The first term in Equation 3.1 represents accumulation of thermal energy, the second term radial (referred to as in-plane in our experiments) heat conduction, the third term axial (referred to as through-plane in our experiments) heat conduction, and the final term is a heat source.

The sample can be approximated as an infinite domain if the experimental time is much less than the characteristic thermal diffusion time. For an anisotropic material in a cylindrical geometry, the experimental time must meet the following two criteria: $t<<(D / 2)^{2} /\left(\alpha_{\text {in }}\right)$ and $t<<T^{2} /\left(\alpha_{\text {thru }}\right)$. In these formulas $\alpha=k /\left(\rho C_{p}\right)$, which is the thermal diffusivity of the composite material.

The average transient temperature increase of the sensor is simultaneously measured by recording the change in electrical resistance of the nickel sensor [22-26] according to:

$$
\Delta T=\frac{1}{\beta}\left(\frac{R_{n}}{R_{\text {по }}}-1\right)
$$

where: $\Delta T$ is the change in temperature at time $\mathrm{t}(\mathrm{K}), \beta$ is the temperature coefficient of resistance (TCR) of the material $(1 / \mathrm{K}), R_{n}$ is the electrical resistance of the nickel at time t $(\Omega)$, and $R_{n o}$ is the electrical resistance of the nickel at time $0(\Omega)$. The temperature rise in Equation 3.2 is correlated with the in-plane and through-plane thermal conductivities through the solution of Equation 3.1 as: 


$$
\Delta T=\frac{P}{\pi^{3 / 2} R \sqrt{k_{\text {in }} k_{\text {thru }}}} F(\tau)
$$

where $F(\tau)$ is a dimensionless time dependent function of $\tau=\sqrt{\alpha_{\text {thru }} t / R^{2}}$ given by an integral of a double series over the number of rings $m$ :

$$
F(\tau)=[m(m+1)]^{-2} \int_{0}^{\tau} \sigma^{-2}\left[\sum_{l=1}^{m} l \sum_{k=1}^{m} k \exp \left(-\frac{l^{2}+k^{2}}{4 m^{2} \sigma^{2}}\right) I_{0}\left(\frac{l k}{2 m^{2} \sigma^{2}}\right)\right] d \sigma
$$

A more detailed derivation of Equations 3.3 and 3.4 is given by He [27]. The complete results for the through-plane and in-plane thermal conductivity of each test specimen can be found in Section 9.6.

The results of this testing, described more fully in chapters 5 and 6 , revealed the following relationship between thermal conductivity and volume fraction of filler:

$$
\sqrt{k_{\text {in }} k_{\text {thru }}}=A e^{B \phi}
$$

' $k_{\text {in }}$ ' stands for the in-plane thermal conductivity, ' $k_{t h r u}$ ' stands for the through-plane thermal conductivity, ' $\phi$ ' stands for the volume fraction of filler in the sample, and A and $\mathrm{B}$ are system-dependent parameters.

\section{Section 3.3.2.3: Density (ASTM D792-98)}

The density of specimens from all formulations was determined using ASTM D792-98, density of plastics by water displacement [28]. The injection-molded parts were first weighed while dry. The samples were then weighed while submerged in water. The temperature of the water was noted as well. From these three pieces of data, the density of the sample was calculated using Equation 3.5. The density was measured on the thermal conductivity disks after they were tested. The theoretical density was also calculated for each composite formulation using Equation 3.6. The results for each 
sample can be found in Section 9.7. In these equations, ' $\rho_{\mathrm{i}}$ ' is the density of the constituents, $\phi_{\mathrm{i}}$ is the volume fraction of the constituents, and ' $\rho_{\text {Theoo }}$ ' is the calculated theoretical density.

$$
\begin{aligned}
& \rho=\frac{\text { DryWeight }}{\text { DryWeight }- \text { WetWeight }} \cdot \rho_{\text {Water }}(T) \\
& \rho_{\text {Theo }}=\frac{1}{\sum_{i} \frac{\phi_{i}}{\rho_{i}}}
\end{aligned}
$$

\section{Section 3.3.2.4: Solvent Digestion (ASTM D5526-98)}

Solvent digestion was used to liberate the fillers from injection-molded parts. The ASTM D5226-98 [29] method was followed to digest the polymers. The liberated fillers were used to determine the length and aspect ratio of the fillers after being processed. A 0.2g sample was obtained from the scraps of each transverse thermal-conductivity sample after they were tested and subsequently cut for use in determination of orientation discussed in Chapter 3.3.3. This resulted in three solvent digestion samples being run for each composite formulation.

The solvent digestion procedure is described in the following paragraphs. The $0.2 \mathrm{~g}$ composite sample was placed in a 2 ounce glass vial with a polytetrafluoroethylene lid. The sample identification was recorded on the side of the vial. The vials were filled approximately halfway with diethylenetriamine (DETA). The exact amount of solvent is not critical since the solvent was pulled through the filler and disposed of in a manner consistent with regulations. The only constraint on the amount of solvent used is that it be enough to completely dissolve the $0.2 \mathrm{~g}$ samples. The samples were allowed to soak in 
the solvent until the entire polymer matrix was completely dissolved. These samples took between four to six hours to dissolve at a minimum temperature of $170^{\circ} \mathrm{C}$.

While the samples were dissolving, the filter papers and Petri dishes were weighed separately using a four-place Denver Instruments A-250 scale and the weights subsequently recorded. The Petri dishes were labeled to ensure the correct filters were used for each sample. The filters used were $0.45 \mu \mathrm{m}$ pore size modified polyvinylidene fluoride filters produced by Millipore and named Durapore® membrane filters. All samples used only one filter.

For all steps in this process where a solvent was being used, the proper personal protection equipment was used (safety glasses, polyurethane gloves, lab coat, long pants, and closed toed shoes). In addition, all steps that used a solvent were carried out in a fume hood to minimize exposure to vapors from the solvents.

Once the matrix was completely dissolved, the polymer/filler/solvent solution was filtered. This was carried out using the apparatus seen in Figure 3.3-11. The apparatus contained a Fisher Brand 47mm microanalysis filter assembly, vacuum flask, and vacuum pump. The pre-weighed filter paper was placed in the filtration assembly, and the shaken solution was poured on the filter. The vacuum pulled the solvent and dissolved matrix through the filter leaving the filler on the filter paper. The vial and funnel were rinsed with solvent, to make sure that all of the filler was on the filter paper. The vacuum was kept on until all standing liquid was removed from the samples. The filter paper and filler were placed in the pre-weighted and labeled Petri dishes. The Petri dishes were left open and placed in a hood overnight to allow the remaining solvent to evaporate. It was quickly found in this process that carbon black would immediately 
plug the filter; therefore, only composites filled with carbon fiber and synthetic graphite particles could be run. Once the samples were completely dried, the Petri dish containing the filter paper and filler were weighed.

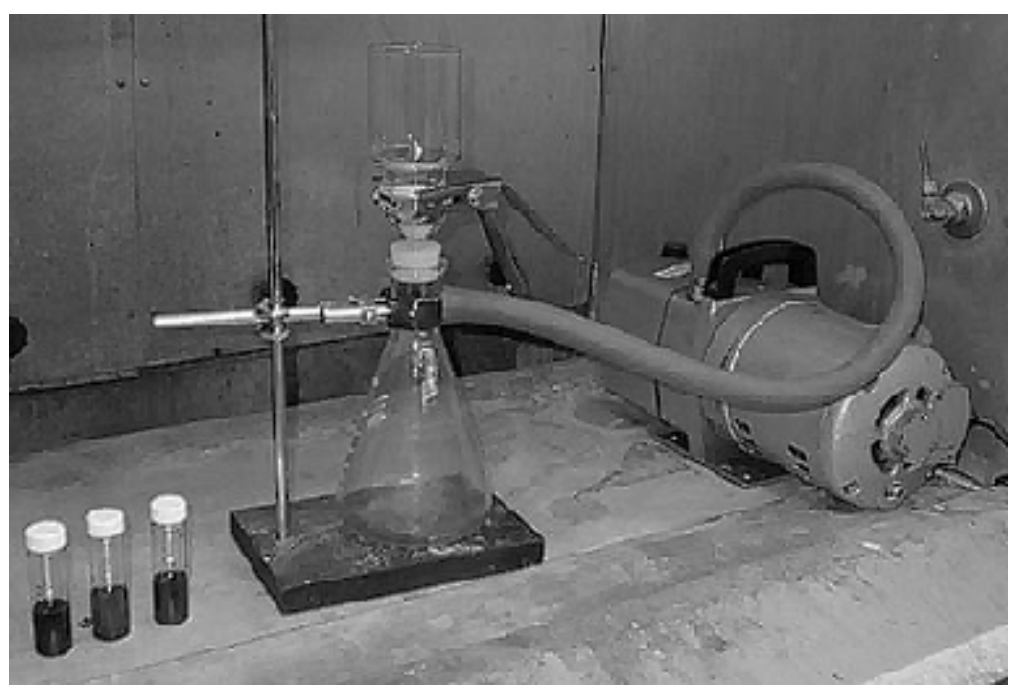

\section{Figure 3.3-11: Solvent Digestion Filtration Apparatus}

The weight percent filler was calculated using Equation 3.7.

$$
w t \%=\frac{W t_{\text {Final }}-W_{\text {Filter(s) }}-W_{\text {PetriDish }}}{W_{\text {Composite }}}
$$

\section{Section 3.3.2.5: Filler Length and Aspect Ratio}

The filler liberated from the composites was used to determine the filler length and aspect ratio that was in the injection molded samples. Solvent digestion produced three samples of liberated fibers per formulation. The as-received fillers were also measured to see how the material changed due to extrusion and injection molding.

A diagram of the apparatus used to disperse the fillers can be found in Figure 3.312. The filler from each sample was removed from the filter paper using a micro-spatula. Using the micro-spatula, a small amount (typically about $0.01 \mathrm{~g}$ ) of the filler was placed in the crucible while the one-hole stopper was removed. The amount was small enough 
so that a large number of particles were not overlapping in the images. The apparatus was prepared to disperse the filler by replacing the one-hole stopper and placing the flask over the glass slide on the cleaned surface. The fiber was dispersed onto the glass slide using a short burst from a duster can that contained 1,1,1,2-tetrafluoroethane. The nozzle of the duster was placed through the stopper but not into the crucible. Care was taken to clean the apparatus and surface on which the slide was placed between each run.

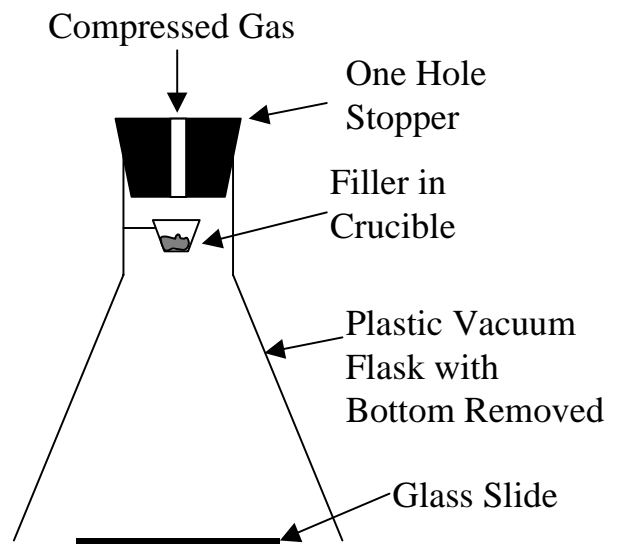

\section{Figure 3.3-12: Fiber Dispersion Apparatus}

The glass slide with the dispersed filler was placed on a Prior automatic stage for the microscope setup. An image of this setup can be seen in Figure 3.3-13. The microscope used for the imaging was an Olympus SZH10 optical microscope with an Optronics Engineering LX-750 video camera for digital imaging. The images were collected using an automated series of steps (macro) in Scion Image version 1.62. The macro that was used was originally written by Dr. Larry Sutter and it was modified for this project. All images were collected at 60x magnification. 


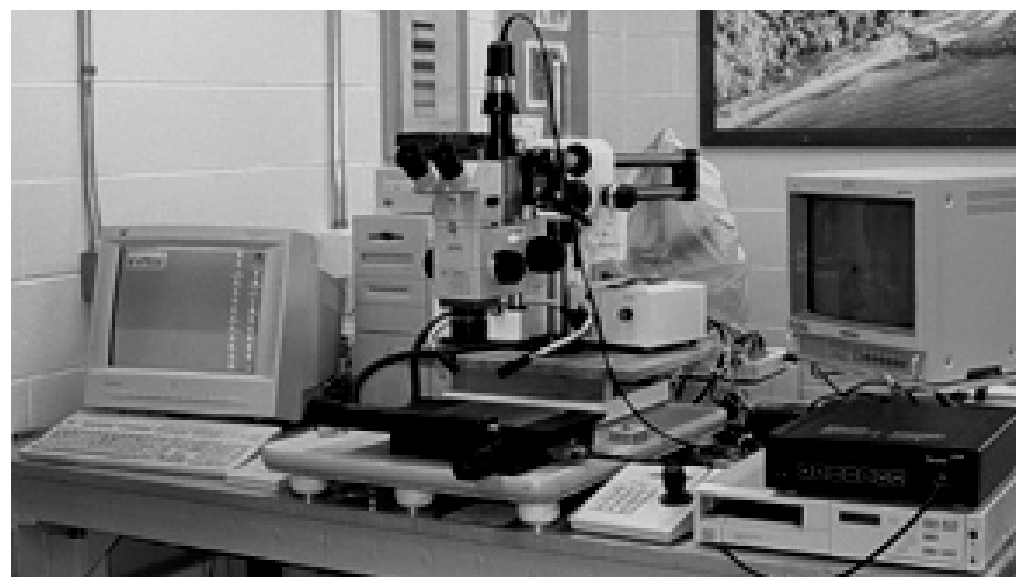

\section{Figure 3.3-13: Image of Microscope Setup used for Filler Length and Aspect Ratio}

The resulting images were processed and measured using the academic version of Adobe Photoshop 5.0 and a package of filters called The Image Processing Tool Kit (version 3.0). An action was created so the batch operation could be used for the processing of the images, since between 20 and 85 images were collected for each sample examined. The action contained the following steps:

1. Convert image from RGB to grayscale

2. Fit and remove the background to remove the uneven lighting of the image

3. Automatic leveling of the image, which standardizes the contrast of the image

4. Threshold, this converts the image to a binary image in which all the fillers are in black

5. Feature cutoff and threshold, this removed all the features that came in contact with the edge of image

6. Calibrate, this loaded a predetermined calibration based on the magnification and resolution of the image

7. Measure all, this measured 26 different items of each feature in the image and stored them in a text file that was appended to for each new image 
This process was used for all single filler samples. Between 1000 and 6000 particles were measured for each sample.

The length and aspect ratio were measured using an algorithm that measured the maximum and minimum caliper distance of each feature. The caliper length and height of the feature was measured every $11.25^{\circ}$, from this the maximum (length) and minimum (breath) caliper distance were calculated. The aspect ratio is calculated by dividing the length by the breath. This method worked well for all particles except for ones that are long and thin; then it measured only the length accurately. The inaccuracy in the breath measurement comes from the fact that the measurement is made only every $11.25^{\circ}$ and the chances of getting the exact smallest dimension of the particle is highly improbable. This issue is compounded by the particle being long so a small deviation will make the particle breath appear even larger. This difficulty led to dividing the length of the fibers by literature diameter to produce the aspect ratio.

\section{Section 3.3.3: Determination of Particle Orientation in the Composite}

\section{Section 3.3.3.1: Sample Preparation}

Four 0.5 ” by 0.5 ” squares were cut out of the center of each of the thermal conductivity samples to generate the through-plane samples studied. Three portions of matchsticks used in ER testing were used to generate the in-plane samples studied. The epoxy mixture was carefully poured over the samples, and they were carefully pushed down. The epoxy used, Epoxide Cold Mounting Resin and Hardener, was a two-part epoxy purchased from Mager Scientific. The epoxy was mixed by weight in a five parts 
resin to one part hardener ratio. The epoxy plugs were allowed to cure overnight at room temperature and were subsequently removed from the sample holders.

\section{Section 3.3.3.2: Polishing}

After curing, the epoxy plugs were polished using a multi-step process. The polishing was done using a Buehler Ecomet 4 Grinder/Polisher with an Automet 2 Power Head. A ten-sample holder was used to hold the samples. An image of this apparatus can be seen in Figure 3.3-14. The samples were washed in an ultrasonic bath after each polishing step to remove the polishing media. The procedures that were used for polishing are shown in Tables 3.3-1 and 3.3-2. These processes were developed by Buehler’s technical service department [30-31]. The process as described in Table 3.3-1 was used on all formulations except for the EHV family.

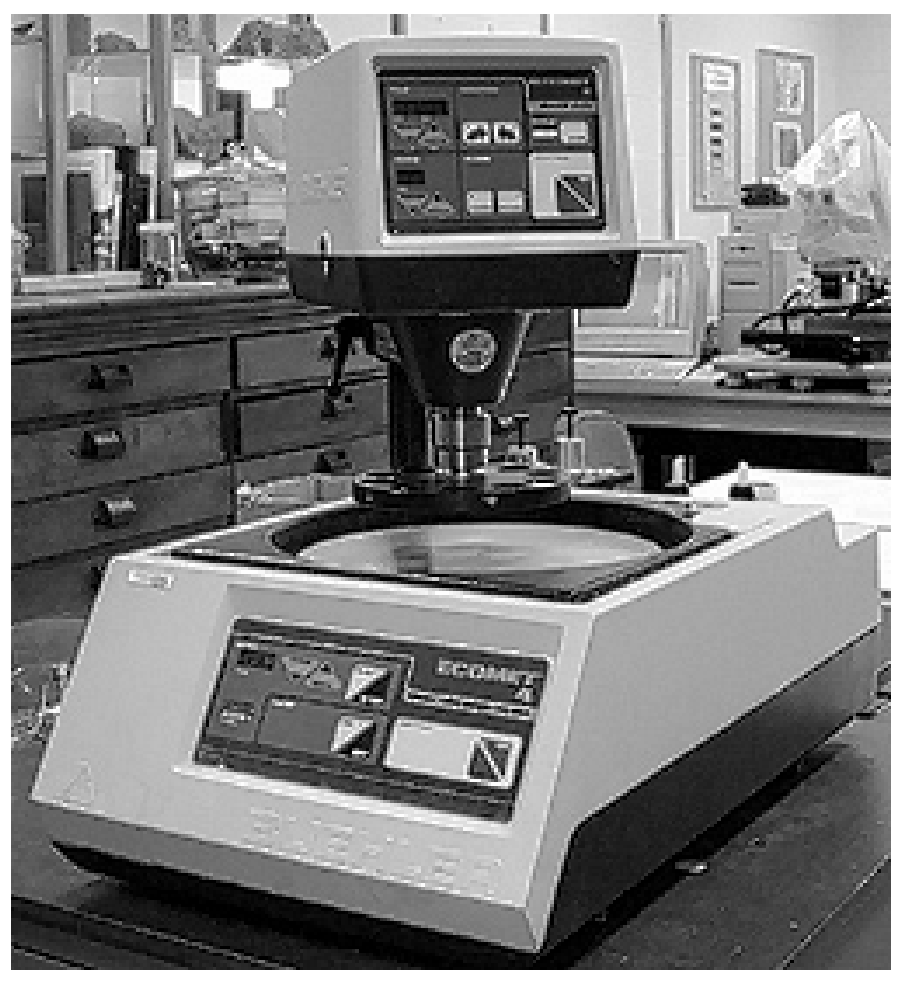

Figure 3.3-14: Polishing Apparatus 
Table 3.3-1: Polishing Procedure [30]

\begin{tabular}{|c|c|c|c|c|c|c|c|}
\hline & Polishing Media & Time & RPM & $\begin{array}{c}\text { Polishing } \\
\text { Cloth }\end{array}$ & Direction & $\begin{array}{c}\text { Force Per } \\
\text { Sample } \\
\end{array}$ & Lubricant \\
\hline 1 & 320 Grit SiC & $30 \mathrm{sec}$ & 250 & None & Contra & 4 lbs. & Water \\
\hline 2 & $\begin{array}{l}9 \mu \mathrm{m} \text { Mono } \\
\text { Crystalline Diamond }\end{array}$ & $4 \mathrm{~min}$ & 150 & Ultra-Pol ${ }^{\mathrm{TM}^{*}}$ & Contra & 5 lbs. & None \\
\hline 3 & $\begin{array}{l}3 \mu \mathrm{m} \text { Mono } \\
\text { Crystalline Diamond }\end{array}$ & $4 \mathrm{~min}$ & 120 & Texmet $\AA 1000^{*}$ & $\begin{array}{c}\text { Co- } \\
\text { Current }\end{array}$ & 6 lbs. & None \\
\hline 4 & $\begin{array}{l}0.05 \mu \mathrm{m} \\
\text { Deagglomerated } \\
\text { Alumna Suspension }\end{array}$ & $3 \mathrm{~min}$ & 120 & Mastertex ${ }^{*}$ & Contra & 3 lbs. & None \\
\hline
\end{tabular}

Table 3.3-2: Polishing Procedure [31]

\begin{tabular}{|c|c|c|c|c|c|c|c|}
\hline & Polishing Media & Time & RPM & $\begin{array}{l}\text { Polishing } \\
\text { Cloth }\end{array}$ & Direction & $\begin{array}{c}\text { Force Per } \\
\text { Sample }\end{array}$ & Lubricant \\
\hline 1 & 240 Grit SiC & $15 \mathrm{~min}$ & 250 & None & Contra & 5 lbs. & Water \\
\hline 2 & 320 Grit SiC & $55 \mathrm{~min}$ & 250 & None & Contra & 5 lbs. & Water \\
\hline 3 & 400 Grit SiC & $70 \mathrm{~min}$ & 250 & None & Contra & 5 lbs. & Water \\
\hline 4 & 600 Grit SiC & $45 \mathrm{~min}$ & 250 & None & Contra & 5 lbs. & Water \\
\hline 5 & 800 Grit SiC & $45 \mathrm{~min}$ & 250 & None & Contra & 5 lbs. & Water \\
\hline 6 & $\begin{array}{l}3 \mu \mathrm{m} \text { Mono } \\
\text { Crystalline Diamond }\end{array}$ & $30 \mathrm{~min}$ & 120 & Texmet ${ }^{\circledR} 1000^{*}$ & Comp & 5 lbs. & $\begin{array}{c}\text { Green } \\
\text { Solution }\end{array}$ \\
\hline 7 & $\begin{array}{l}0.05 \mu \mathrm{m} \\
\text { Deagglomerated } \\
\text { Alumna Suspension }\end{array}$ & $20 \mathrm{~min}$ & 120 & Mastertex ${ }^{*}$ & Comp & 4 lbs. & $\begin{array}{l}\text { White } \\
\text { Solution }\end{array}$ \\
\hline
\end{tabular}

\section{Section 3.3.3.3: Optical Imaging Methods}

The polished samples were imaged using an Olympus BX60 microscope at 100x and 200x magnification. An image of the microscope can be seen in Figure 3.3-15. The images were collected using Scion Image Version 1.62. The images were taken across 
the thickness of the sample, which was the direction of conduction that was measured in the transverse thermal-conductivity test. These images were pieced together to get a large composite image for analysis.

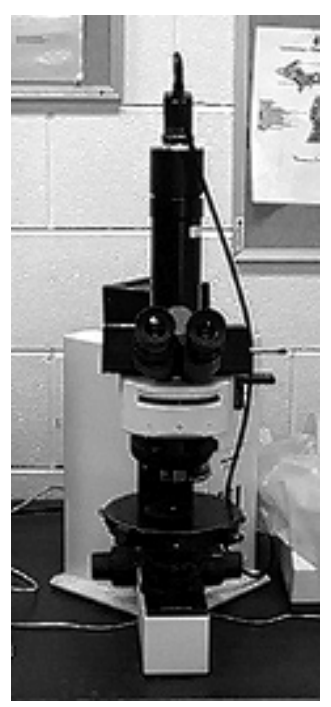

Figure 3.3-15: Olympus BX60 Microscope
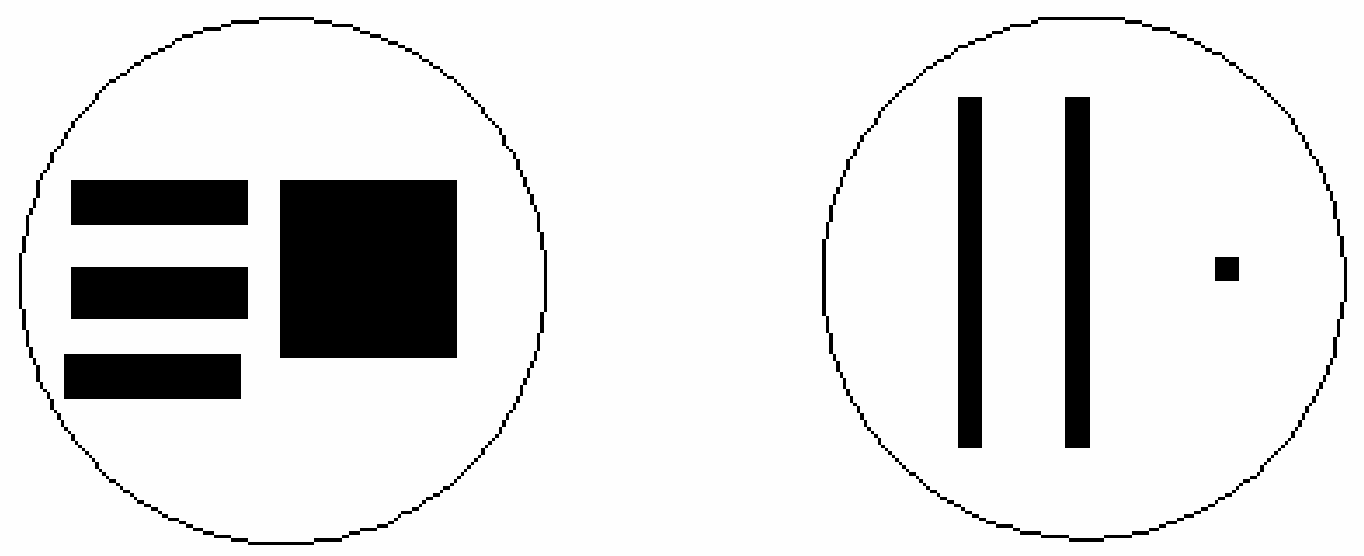

Figure 3.3-16: Top View of Sample Pucks used in Image Analysis (Through-Plane and In-Plane) 


\section{Section 3.3.3.4: Image Processing}

The image processing was carried out using the Image Processing Tool Kit and Adobe Photoshop ${ }^{\circledR}$. The first step in the image processing was to take each of the sixteen images and remove the color and then fit and remove the background variation. This step turned each image into an 8 bit gray scale image and leveled the uneven lighting. The next step was to paste each of the sixteen images into one composite image making sure all the image edges matched. The image was then thresholded to produce a binary image with the fillers being black. Next, a Euclidean distance map (EDM) open operation was done to remove small artifacts in the image and better separate the fillers from the matrix. The EDM open operation shrunk each feature by a set number of pixels then dilated them by the same number of pixels. The EDM version of “open” command kept the shape of the particle better then the standard morphological open. A "cutoff” operation was then completed to remove all features touching the edge and remove features smaller than 50 pixels.

\section{Section 3.3.3.5: Image Analysis and Measurements}

The moment angle was measured for each filler particle as a measure of the orientation. This measurement gives some insight into the orientation of the fillers in the composites. The angle was measured from the direction of heat conduction. The angle of the particle was measured using a method similar to fitting a line to a set of data [32]. It was calculated using the Equations 3.8a-i [32]. The summations of the location of each pixel in each particle are calculated in Equations 3.8a-e. The moment around the $\mathrm{x}$ and $\mathrm{y}$ axes are calculated in Equations 3.8f-h. The angle of minimum momentum or moment angle is calculated in Equation 3.8i. This method uses each pixel in a particle as a 
separate data point. This method is a robust method because it does not fit an ellipse to the outside of the particle and uses the main axes calculate the angle. In the ellipse method, a single pixel can cause the angle to be substantially different from the actual angle. The moment angle method is a much more robust method because if a single pixel or two stick out on the edge of the feature the angle does not change significantly. The moment angles from each feature were measured using PhotoShop ${ }^{\circledR}$ and the Image Processing Tool Kit®. The results from this analysis can be found in Section 9.8. Micrographs of through-plane and in-plane samples can be found in Appendices I and J respectively.

$$
\begin{aligned}
& S_{x}=\sum x_{i} \\
& S_{y}=\sum y_{i} \\
& S_{x x}=\sum x_{i}^{2} \\
& S_{y y}=\sum y_{i}^{2} \\
& S_{x y}=\sum x_{i} \cdot y_{i} \\
& M_{x x}=S_{x x}-\frac{S_{x}^{2}}{\operatorname{Area}} \\
& M_{y y}=S_{y y}-\frac{S_{y}^{2}}{\text { Area }} \\
& M_{x y}=S_{x y}-\frac{S_{x} \cdot S_{y}}{\operatorname{Area}} \\
& \theta=\tan ^{-1}\left\{\frac{M_{x x}-M_{y y}+\sqrt{\left(M_{x x}-M_{y y}\right)^{2}+4 \cdot M_{x y}^{2}}}{2 \cdot M_{x y}}\right\}
\end{aligned}
$$




\section{Section 3.4: References}

1. Ticona Vectra Liquid Crystal Polymer (LCP) Product Information, Ticona, Summit, NJ, 07901, 2000.

2. Chiou, J. S.; Paul, D. R. Journal of Polymer Science Part B: Polymer Physics, 1987, 25, 1699.

3. J.-B. Donnet, R. C. Bansal, M.-J. Wang, Carbon Black, $2^{\text {nd }}$. Marcel Dekker, New York, 1993.

4. The Freedonia Group, Inc., “Conductive Polymers”. Cleveland, OH 44143-2326, 2000.

5. Akzo Nobel Electrically Conductive Ketjenblack Product Literature, Akzo Nobel.

6. The Industrial Graphite Engineering Handbook. Union Carbide Corp, NY, 1970.

7. L. C. F. Blackman, Modern Aspects of Graphite Technology. Academic Press, NY, 1970.

8. J.A. King, K. W. Tucker, B. D. Vogt, E. H. Weber, and C. Quan, “Conductive High Temperature Nylon”. Journal of Composite Materials, Vol. 34, No. 24, 2000, pp. 2038-2060.

9. J. A. King, K. W. Tucker, J. D. Meyers, E. H. Weber, M. L. Clingerman, and K. R. Ambrosius, "Factorial Design Approach Applied to Electrically and Thermally Conductive Nylon 6,6”. Polymer Composites, Vol. 22, No. 1, 2001, pp. 142-154.

10. Asbury Carbons Product Information, Asbury, NJ, 08802 (2004). 
11. J. A. King, K. W. Tucker, B. D. Vogt, E. H. Weber, and C. Quan, “Electrically and Thermally Conductive Nylon 6,6”. Polymer Composites, Vol. 20, No. 5, 1999.

12. www.asbury.com, Materials Chapter, accessed 4/20/2006.

13 Akzo Nobel, “Fortafil Carbon Fibers”, Fortafil Fibers, Inc., 8870 Cedar Springs Lane, Suite 8, Knoxville, TN 37923.

14. E. H. Weber, M. L. Clingerman, and J. A. King, "Thermally Conductive Nylon 6,6 and Polycarbonate Based Resin. Part 1: Synergistic Effects of Carbon Fillers”, Journal of Applied Polymer Science, Vol. 88, pp. 112-122, 2003.

15. Niigata Engineering Co. Ltd., Nagaoka Works, Model NE85UA4, Machine No. 50031F. Nagaoka Works, Niigata, Japan.

16. Deltatherm Model A410, Serial No. 12003, 4500 Watts/Heater, Delta T Systems Inc., Richfield, WI 53076, phone 800-733-4204.

17. Four Cavity Mold, Master Precision Molds, Inc., Greenville, MI, Phone No. 800632-8912.

18. $\quad$ Zytel $®$ nylon resin: Product and Property Guide. DuPont.

19. International Organization for Standardization (ISO). Plastics - Standard Atmospheres for Conditioning and Testing; ISO 291; 1997, 1998.

20. “Evaluating Thermal Conductivity of Gasket Materials”, ASTM Standard F433 77 Reapproved 1993, American Society for Testing and Materials, Philadelphia, Pennsylvania, 1996. 
21. Holometrix Model TCA - 300 Thermal Conductivity Analyzer using Guarded Heat Flow Meter Method, 25 Wiggins Avenue, Bedford, Massachusetts.

22. Gustavsson, M.; Karawacki, E.; Gustafsson, S. E. Rev. Sci. Instrum., 1994, 65 (12), 3856-3859.

23. Log, T.; Gustafsson, S. E. Fire and Materials, 1995, 19, 43-49.

24. Bohac, V.; Gustavsson, M. K.; Kubicar, L.; Gustafsson, S. E. Rev. Sci. Instrum., 2000, 71(6), 2452-2455.

25. Hot Disk Thermal Constants Analyser Instruction Manual, Mathis Instruments, Ltd., Fredericton, New Brunswick, Canada, 2001.

26. Transient Plane Source - Gustafsson Hot Disk Technique, Standards for Contact Transient-Measurements of Thermal Properties, National Physical Laboratory, United Kingdom, accessed February 2006 at http://www.npl.co.uk/thermal/ctm/

27. He, Y. Thermochim. Acta, 2005, 436, 122-129.

28. “Specific Gravity and Density of Plastics by Displacement”, ASTM Standard D792 - 66 (Re-approved 1975), American Society for Testing and Materials, Philadelphia, Pennsylvania, 1986.

29. “Standard Practice for Dissolving Polymer Materials”, ASTM Standard D5226 98, American Society for Testing and Materials, Philadelphia, Pennsylvania, 1998.

30. George Blann from Buehler, Letter to J. King, January 25, 2001.

31. Buehler Corporation, Correspondence with J. King, Summer 2006. 
32. J. C. Russ, The Image Processing Handbook, $3^{\text {rd }}$ ed. CRC and IEEE Press, Boca Raton, 1999. 


\section{Chapter 4: Carbon Black and Carbon Particle Studies}

The first thing to be done in this work was to characterize the thermal conductivity of composites using the preselected carbon black and to determine which carbon particle (hereinafter, in this chapter, 'carbon particle’ applies to synthetic graphite, natural flake graphite, and calcined needle coke particles) would be used for further study.

\section{Section 4.1: Materials}

The matrix material for all composites discussed in this chapter was Vectra A950RX LCP; the filler materials being tested were Ketjenblack EC-600 JD, Thermocarb TC-300, Asbury SG 4012, Asbury NFG 3160, and Asbury Calcined Needle Coke F108A. More information on these materials is provided in Chapters 3.1.1.1 and 3.1.2.1 - 3.1.2.5 of this dissertation. 


\section{Section 4.2: Experimental Method}

The studies of the carbon black composites and the carbon particle composites were designed to give two different types of information. The carbon black study was meant to give a wide range of data points for the generation of thermal conductivity vs. filler loading curves; as such, seven composites ranging from $2.5 \mathrm{wt} \%$ - $15 \%$ carbon black were generated. The carbon particle study was meant to help choose between the carbon particles for continued study. As the carbon particle was intended to be a large part of the final composite product, three composites for each particle were generated using fairly high filler loadings between 40 - 70wt\%. Table 4.2-1 shows the weight and volume percent loading levels for the fillers in this study.

Table 4.2-1: Single Filler Loading Levels in Vectra A950RX

\begin{tabular}{|c|l|}
\hline Filler & \multicolumn{1}{|c|}{ Filler Concentrations } \\
\hline Ketjenblack EC-600 JD & Wt\%: 2.5, 4.0, 5.0, 6.0, 7.5, 10.0, 15.0 \\
& Vol\%:1.9, 3.1, 3.9, 4.7, 6.0, 8.0, 12.1 \\
\hline Thermocarb TC-300 & Wt\%: 40.0, 60.0, 70.0 \\
Synthetic Graphite & Vol\%: 29.3, 48.4, 59.3 \\
\hline 4012 Synthetic Graphite & Wt\%: 40.0, 60.0, 70.0 \\
& Vol\%: 29.3, 48.4, 59.3 \\
\hline 3160 Natural Flake & Wt\%: 40.0, 60.0, 70.0 \\
Graphite & Vol\%: 29.3, 48.4, 59.3 \\
\hline Calcined Needle Coke & Wt\%: 40.0, 60.0, 70.0 \\
F108A & Vol\%: 30.8, 50.2, 61.4 \\
\hline
\end{tabular}




\section{Section 4.3: Sample Fabrication}

The fillers were used as-received for this study; the matrix material was dried as described in Chapter 3.3.1.1. The composite materials were blended, extruded and pelletized as described in Chapter 3.3.1.2 using the first screw design as shown in Section 9.1. The pellets were then injection molded as described in Chapter 3.3.1.3.

\section{Section 4.4: Sample Testing}

All samples were conditioned as described in Chapter 3.3.2 prior to the thermal conductivity testing. Four samples from each formulation were then tested as described in Chapter 3.3.2.1. In addition, filler orientation testing was performed on samples containing the carbon particles as described in Chapter 3.3.3. The carbon black particles were too small to be seen by optical microscopy. 


\section{Section 4.5: Results}

Figure 4.5-1 summarizes all of the thermal conductivity data collected in this study.

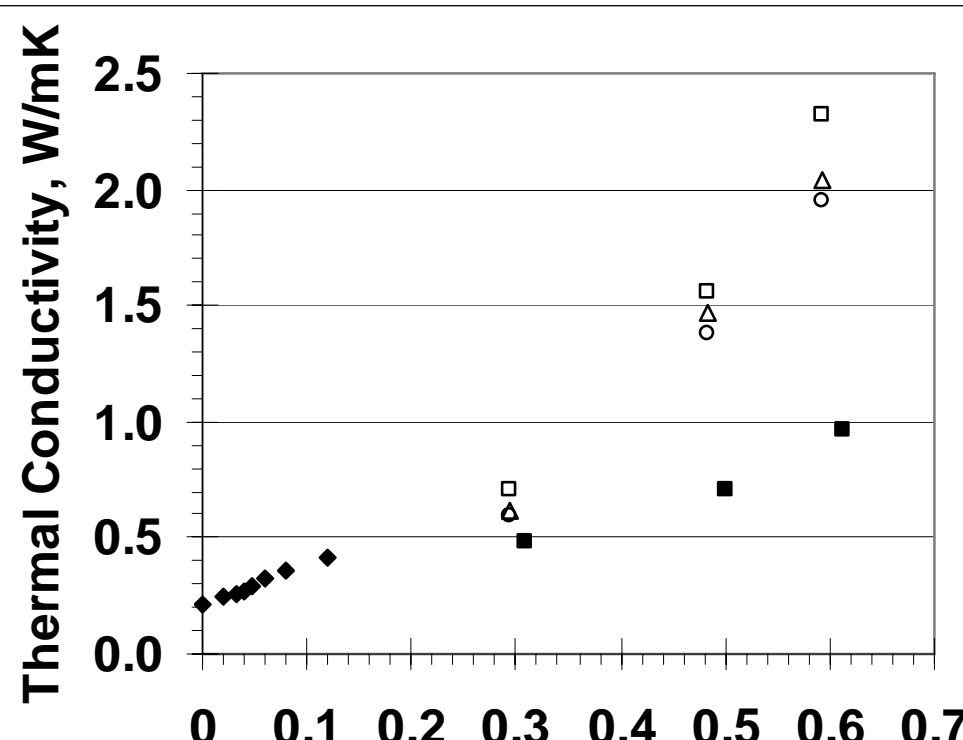

Filler Volume Fraction

- Carbon Black

- Thermocarb Synthetic Graphite

$\triangle 4012$ Synthetic Graphite

- Flake Graphite

- Calcined Coke

Figure 4.5-1: Through-Plane Thermal Conductivity Results

\section{Section 4.5.1: Thermal Conductivity Results}

Figure 4.5-1 shows the mean through-plane thermal conductivity of the composites plotted as a function of the volume fraction of filler in the composite. These formulations are the same as those listed in Table 4.2.-1. The mean thermal conductivity of the matrix material, neat Vectra A950RX LCP, was $0.22 \mathrm{~W} / \mathrm{mK}$. In these 
measurements, the standard deviation was typically less than $5 \%$ of the mean value. The full data can be seen in Section 9.4.

\section{Section 4.5.1.1: Carbon Black Thermal Conductivity Results}

As shown above in Figure 4.1, the carbon black composite thermal conductivity ranged from $0.22 \mathrm{~W} / \mathrm{mK}$ at 0 vol\% filler to $0.42 \mathrm{~W} / \mathrm{mK}$ at $12.1 \mathrm{vol} \%$ filler. The thermal conductivity appears to be following a linear trend for the data gathered. Extrusion of this composite at 12.1 vol\% filler was very difficult with the equipment used due to the entangling nature of the carbon black particles; as such, it was decided to stop the study there. If other varieties of carbon are to be added to a multi-filler system, the loading level of the carbon black will have to be greatly reduced for processing concerns.

\section{Section 4.5.1.2: Carbon Particle Thermal Conductivity Results}

The results of the thermal conductivity screening study provided useful information. The first item to note is with regards to the calcined needle coke, which showed a much lower thermal conductivity $(0.5-1.0 \mathrm{~W} / \mathrm{mK})$ than the synthetic graphites and the natural flake graphite that were tested. This was attributed to the difference in chemical structure between these materials. Calcined needle coke and graphite both show excellent planar orientation; however, the orbital overlap between planes in calcined needle coke is much less symmetrical than that in graphite, which lowers the thermal conductivity in that direction dramatically. The second item of note is how the Thermocarb TC-300 synthetic graphite has a consistently higher thermal conductivity than the other two graphites $(0.75-2.35 \mathrm{~W} / \mathrm{mK}$, compared to $0.6-2.0 \mathrm{~W} / \mathrm{mK})$ and, further, that the difference increases with loading level. Thermocarb TC-300 has a very

high degree of crystallinity and a lower percentage of impurities, as discussed in Chapter 
3.1.1.2. These factors are probably the reason for the increased thermal conductivity relative to the other carbon particles.

\section{Section 4.5.2: Filler Orientation Results}

The data of interest in the filler orientation study was the angle between the filler and the direction of conductivity measurement. In this study, an angle of $0^{\circ}$ signifies that the filler particles are aligned parallel to the direction of measurement; an angle of $90^{\circ}$ signifies that the filler particles are aligned perpendicular to the direction of measurement. Figure 4.5-2 is a representative sample. It is clearly shown that the filler particles are more oriented transverse to the direction of measurement of conductivity. The mean filler angle was $52^{\circ}$; this result agrees with previous studies [1]. The full data for this study can be seen in Section 9.8.

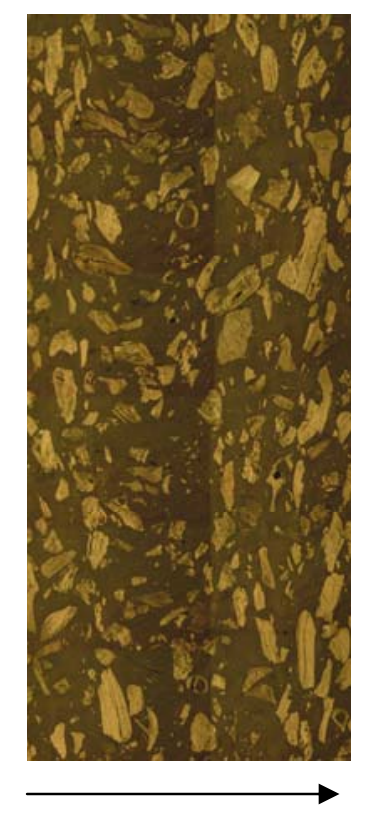

Figure 4.5-2: Through -Plane Thermal Conductivity Sample Containing $40 \mathrm{wt} \%$ Calcined Needle Coke F108A in Vectra A950RX at 100X Magnification 


\section{Section 4.6: Summary}

The data gathered in this study helped in determining which carbon particle would be used in continuing work for this project. The clear difference in thermal conductivity between the Thermocarb and the other carbon particles that were tested is of utmost importance in an application where the goal is a dramatic increase of thermal conductivity in a carbon-polymer composite. The data from the carbon black study is useful for characterizing the material as well as for understanding the processing concerns of this particular composite. 


\section{Section 4.7: References}

1. J. A. Heiser and J. A. King, Polym. Compos, 25, 186 (2004). 


\section{Chapter 5: Thermocarb TC-300 Study}

Having determined that Asbury Carbon's Thermocarb TC-300 had the most

desirable thermal conductivity properties of the synthetic graphites, natural flake graphite and calcined needle coke examined in the screening study, a second study was performed on this material over a wider range of filler loadings to better understand how the thermal conductivity varied with filler loading.

\section{Section 5.1: Materials}

The matrix material for all composites discussed in this chapter was Vectra A950RX LCP; the filler material being tested was Thermocarb TC-300. More information on these materials is provided in Chapter 3.1.1.1 and Chapter 3.1.2.2 of this dissertation. 


\section{Section 5.2: Experimental Method}

The primary purpose of this study was to provide a wide range of data points for the generation of thermal conductivity vs. filler loading curves. With this in mind, fourteen composites ranging from 10wt\% - 75wt\% (6.5 vol\% - $65.2 \mathrm{vol} \%$ ) synthetic graphite were generated. Table 5.2-1 shows the weight and volume percent loading levels for the filler in this study.

Table 5.2-1: Single Filler Loading Levels of Thermocarb TC-300 in Vectra A950RX LCP

\begin{tabular}{|l|l|}
\hline Filler wt \% & Filler vol\% \\
\hline 0.0 & 0.0 \\
\hline 10.0 & 6.5 \\
\hline 15.0 & 9.9 \\
\hline 20.0 & 13.5 \\
\hline 25.0 & 17.2 \\
\hline 30.0 & 21.1 \\
\hline 35.0 & 25.2 \\
\hline 40.0 & 29.3 \\
\hline 45.0 & 33.8 \\
\hline 50.0 & 38.5 \\
\hline 55.0 & 43.3 \\
\hline 60.0 & 48.4 \\
\hline 65.0 & 53.7 \\
\hline 70.0 & 59.3 \\
\hline 75.0 & 65.2 \\
\hline
\end{tabular}

A secondary purpose of this study was to elaborate upon a previously developed model [1] for thermal conductivity that predicted the in-plane thermal conductivity of a composite material using the volume percent of filler and the through-plane thermal conductivity of the composite material. 


\section{Section 5.3: Sample Fabrication}

The fillers were used as-received for this study; the matrix material was dried as described in Chapter 3.3.1.1. The composite materials were extruded and pelletized as described in Chapter 3.3.1.2. The pellets were then injection molded as described in Chapter 3.3.1.3. Extrusion and injection molding information can be found in Appendices B and C respectively.

\section{Section 5.4: Sample Testing}

All samples were conditioned as described in Chapter 3.3.2 prior to the thermal conductivity testing. Six samples from each formulation were tested as described in Chapter 3.3.2.1. Three different samples from each formulation were tested as described in Chapter 3.3.2.2. In addition, filler orientation testing was performed as described in Chapter 3.3.3. 


\section{Section 5.5: Results}

There were three important results generated from this study. The first result was the data set showing the relationship between thermal conductivities and filler loading for this composite. The second result was the generation of a predictive model for in-plane thermal conductivity that may be applicable to other filled systems. The third result was confirmation that these samples all had similar filler orientations and as such had similar heat transfer mechanisms.

\section{Section 5.5.1: Thermal Conductivity Results}

The through-plane thermal conductivity of the composites was measured using the two test methods mentioned above. Figure 5.5-1 shows the through-plane thermal conductivity as measured by the methods described in Chapter 3.3.2.1, while Figures 5.52 and 5.5-3 show the through-plane thermal conductivity and in-plane thermal conductivity as measured by the methods described in Chapter 3.3.2.2. As can be seen from the figures, the through-plane thermal conductivity rises in a mostly linear fashion, but the in-plane thermal conductivity begins exhibiting exponential behavior at approximately 35 vol\% filler. 


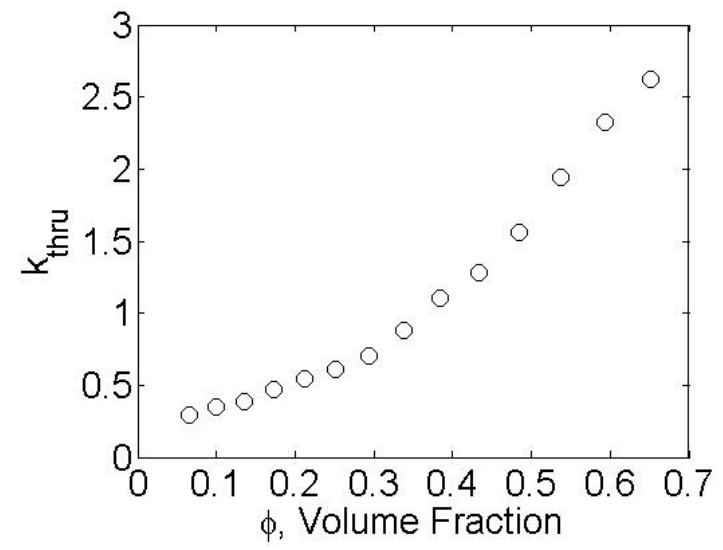

Figure 5.5-1: Through-Plane Thermal Conductivity $(\mathrm{W} / \mathrm{mK})$ vs. Volume Fraction Filler for Synthetic Graphite / Vectra Composite, TCA

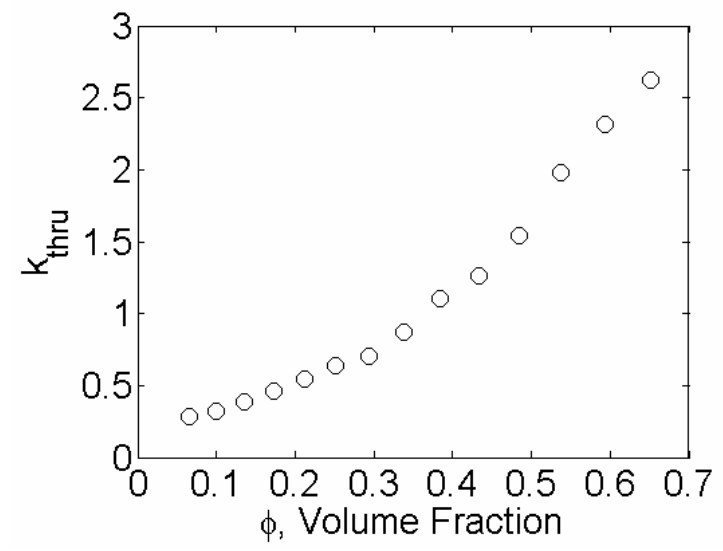

Figure 5.5-2: Through-Plane Thermal Conductivity $(\mathrm{W} / \mathrm{mK})$ vs. Volume Fraction Filler for Synthetic Graphite / Vectra Composite, HotDisk

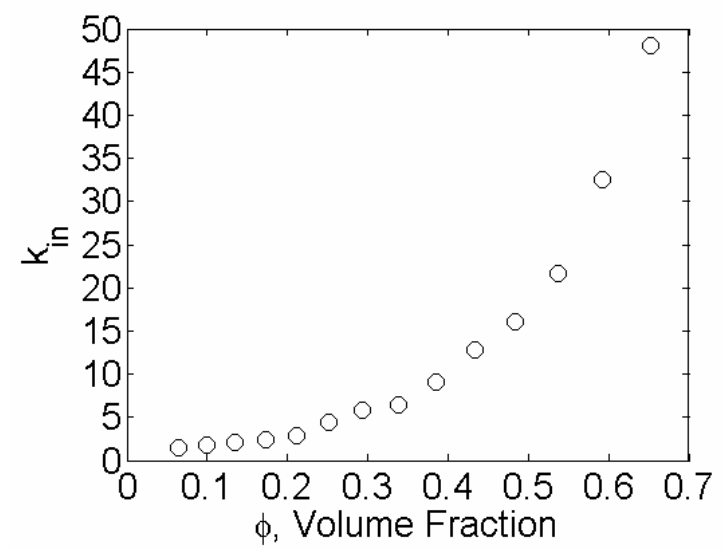

Figure 5.5-3: In-Plane Thermal Conductivity $(\mathrm{W} / \mathrm{mK})$ vs. Volume Fraction Filler for Synthetic Graphite / Vectra Composite, HotDisk 
Table 5.5-1 displays the mean, standard deviation, and number of samples tested for the through-plane thermal conductivity as measured by the TCA-300 as well as the through-plane and in-plane thermal conductivities as measured by the Hot Disk transient plane source method. There is good agreement between the test methods for the throughplane thermal conductivity results. As expected, the in-plane thermal conductivity was higher than the through-plane thermal conductivity in all cases. The ratio of the in-plane thermal conductivity to the through-plane thermal conductivity varied from 5 to 18 and generally increased as the volume fraction of filler $(\phi)$ increased. Full results from the TCA-300 and Hot Disk conductivity testing can be found in Appendices D and F.

\section{Table 5.5-1: Thermal Conductivity Results}

\begin{tabular}{|c|c|c|c|}
\hline & $\begin{array}{l}\text { Through-Plane } \\
\text { Thermal } \\
\text { Conductivity } \\
\text { (TCA-300) }\end{array}$ & $\begin{array}{l}\text { Through-Plane } \\
\text { Thermal } \\
\text { Conductivity } \\
\text { (Hot Disk) }\end{array}$ & $\begin{array}{l}\text { In-Plane Thermal } \\
\text { Conductivity } \\
\text { (Hot Disk) }\end{array}$ \\
\hline Formulation & $\mathrm{W} / \mathrm{mK}$ & $\mathrm{W} / \mathrm{mK}$ & $\mathrm{W} / \mathrm{mK}$ \\
\hline Neat Vectra A950RX LCP & $0.2169 \pm 0.0068 n=4$ & $\sim 0.22$ (TCA) & $\sim 0.22$ (TCA) \\
\hline \multicolumn{4}{|l|}{ Synthetic Graphite Filler } \\
\hline $10 \mathrm{wt} \%$ & $0.2935 \pm 0.010 n=4$ & $0.284 \pm 0.001 \mathrm{n}=3$ & $1.426 \pm 0.045 \mathrm{n}=3$ \\
\hline $15 \mathrm{wt} \%$ & $0.3494 \pm 0.013 n=4$ & $0.323 \pm 0.001 \mathrm{n}=3$ & $1.853 \pm 0.050 \mathrm{n}=3$ \\
\hline $20 \mathrm{wt} \%$ & $0.3869 \pm 0.012 n=5$ & $0.385 \pm 0.010 \mathrm{n}=3$ & $2.029 \pm 0.055 n=3$ \\
\hline $25 \mathrm{wt} \%$ & $0.4699 \pm 0.012 n=5$ & $0.459 \pm 0.022 n=3$ & $2.433 \pm 0.142 \mathrm{n}=3$ \\
\hline $30 \mathrm{wt} \%$ & $0.5464 \pm 0.019 \mathrm{n}=4$ & $0.545 \pm 0.015 n=3$ & $2.938 \pm 0.063 n=3$ \\
\hline $35 \mathrm{wt} \%$ & $0.6106 \pm 0.021 n=5$ & $0.635 \pm 0.021 \mathrm{n}=3$ & $4.403 \pm 0.594 \mathrm{n}=3$ \\
\hline 40 wt\% & $0.7064 \pm 0.010 n=4$ & $0.702 \pm 0.078 \mathrm{n}=5$ & $5.881 \pm 0.651 \mathrm{n}=5$ \\
\hline $45 \mathrm{wt} \%$ & $0.8804 \pm 0.043 n=5$ & $0.874 \pm 0.005 n=3$ & $6.441 \pm 0.284 \mathrm{n}=3$ \\
\hline $50 \mathrm{wt} \%$ & $1.1081 \pm 0.031 \mathrm{n}=4$ & $1.101 \pm 0.010 \mathrm{n}=3$ & $9.020 \pm 0.025 n=3$ \\
\hline $55 \mathrm{wt} \%$ & $1.2851 \pm 0.027 n=4$ & $1.265 \pm 0.010 \mathrm{n}=3$ & $12.80 \pm 0.622 \mathrm{n}=3$ \\
\hline $60 \mathrm{wt} \%$ & $1.5586 \pm 0.074 n=8$ & $1.545 \pm 0.044 \mathrm{n}=3$ & $16.03 \pm 0.301 \mathrm{n}=3$ \\
\hline 65 wt $\%$ & $1.9426 \pm 0.113 n=7$ & $1.982 \pm 0.052 \mathrm{n}=3$ & $21.60 \pm 0.606 \mathrm{n}=3$ \\
\hline $70 \mathrm{wt} \%$ & $2.3225 \pm 0.085 \mathrm{n}=7$ & $2.318 \pm 0.049 n=3$ & $32.55 \pm 1.221 \mathrm{n}=3$ \\
\hline 75 wt\% & $2.6251 \pm 0.097 n=5$ & $2.624 \pm 0.076 \mathrm{n}=3$ & $48.07 \pm 1.850 \mathrm{n}=3$ \\
\hline
\end{tabular}




\section{Section 5.5.2: Thermal Conductivity Model Results}

After analysis of the thermal conductivity data generated in this study, an exponential correlation between the square root of the product of the in-plane and through-plane thermal conductivities and the volume percent of filler was observed. This correlation is given by:

$$
\sqrt{k_{i n} k_{t h r u}}=0.4638 e^{4.9256 \phi}
$$

where $k_{\text {in }}$ and $k_{\text {thru }}$ have units of $(\mathrm{W} / \mathrm{mK})$. Rearranging for $k_{\text {in }}$ yields the following predictive equation:

$$
k_{\text {in }}=\frac{\left(0.4638 e^{4.9256 \phi}\right)^{2}}{k_{\text {thru }}}=\frac{0.2151 e^{9.8512 \phi}}{k_{\text {thru }}}
$$

This is an important result. The three variable parameters in this equation are $\phi, k_{t h r u}$ and $k_{\text {in. }} \phi$ is a known quantity and varies by composite. $k_{\text {thru }}$ can be calculated using a modified Nielsen model [2]. However, literature data for $k_{i n}$ in carbon-polymer systems is not readily available. A predictive equation for $k_{\text {in }}$ allows for much more efficient experimentation, as sample generation for specific thermal conductivities will involve much less trial and error. Figure 5.5-4 shows the experimental data plotted along with the predicted results of the model. The experimental data fits the model results quite well. 


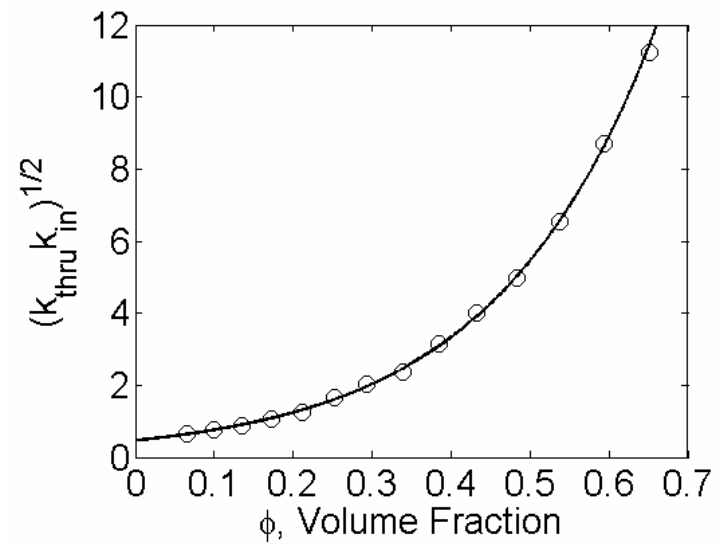

Figure 5.5-4: Combined Thermal Conductivity (W/mK) vs. Volume Fraction Filler for Synthetic Graphite / Vectra Composite (Exponential Fit)

\section{Section 5.5.3: Filler Orientation Results}

The data of interest in the filler orientation study was the angle between the filler and the direction of conductivity measurement. In this study, an angle of $0^{\circ}$ signifies that the filler particles are aligned parallel to the direction of measurement; an angle of $90^{\circ}$ signifies that the filler particles are aligned perpendicular to the direction of measurement. The images gathered show that the filler particles are more oriented transverse to the direction of measurement of conductivity. The mean filler angle was $52^{\circ}$; this result agrees with previous studies [3]. The full data for this study can be seen in Section 9.8. 


\section{Section 5.6: Summary}

A greater understanding of the thermal conductivity properties of Asbury

Carbon's Thermocarb TC-300 and, more importantly, how the filler loading affected the thermal properties of the composite, was obtained. An important result is that at 35 vol\% filler, the thermal conductivities begin to follow an exponential trend. This trend is more pronounced in the in-plane thermal conductivity trend. This data was used to develop a predictive model for the in-plane thermal conductivity which, in concert with the known volume percent of filler and the known or calculated through-plane thermal conductivity of the composite, aids experimental design in targeting desired thermal conductivity values. Additionally, filler orientation studies of the samples showed that the entire family of composites had similar filler orientation properties and therefore had similar thermal conduction properties. 


\section{Section 5.7: References}

1. $\quad$ Keith, J. M.; Hingst, C. D.; Miller, M. G.; King, J. A.; Hauser, R. A. Polym.

Compos., 2006, 27, 1-7.

2. Weber, E. H.; Clingerman, M. L.; King, J. A. J. Appl Polym. Sci., 2003, 88, 123130.

3. J. A. Heiser and J. A. King, Polym. Compos, 25, 186 (2004). 


\section{Chapter 6: Fortafil 243 Carbon Fiber Study}

The emphasis of this study was to characterize the thermal conductivity of composites using the preselected carbon fiber, Fortafil 243 carbon fiber.

\section{Section 6.1: Materials}

The matrix material for all composites discussed in this chapter was Vectra A950RX LCP; the filler material being tested was Fortafil 243 carbon fiber. More information on these materials is provided in Chapter 3.1.1.1 and Chapter 3.1.2.6 of this dissertation. 


\section{Section 6.2: Experimental Method}

The primary purpose of this study was to provide a wide range of data points for the generation of thermal conductivity vs. filler loading curves. With this in mind, thirteen composites ranging from 5wt\% - 60wt\% (4.1 vol\% - 54.7 vol\%) carbon fiber were generated. Table 6.2-1 shows the weight and volume percent loading levels for the filler in this study.

Table 6.2-1: Single Filler Loading Levels of Fortafil 243 Carbon Fiber in Vectra A950RX LCP

\begin{tabular}{|l|l|}
\hline \multicolumn{1}{|c|}{ Filler wt \% } & \multicolumn{1}{c|}{ Filler vol\% } \\
\hline \multicolumn{1}{|c|}{0.0} & 0.0 \\
\hline 5.0 & 4.1 \\
\hline 7.5 & 6.1 \\
\hline 10.0 & 8.2 \\
\hline 15.0 & 12.4 \\
\hline 20.0 & 16.8 \\
\hline 25.0 & 21.2 \\
\hline 30.0 & 25.5 \\
\hline 35.0 & 30.2 \\
\hline 40.0 & 34.9 \\
\hline 45.0 & 39.7 \\
\hline 50.0 & 44.6 \\
\hline 55.0 & 49.6 \\
\hline 60.0 & 54.7 \\
\hline
\end{tabular}

A secondary purpose of this study was to elaborate upon a previously developed model [1] for thermal conductivity that predicted the in-plane thermal conductivity of a composite material using the volume percent of filler and the through-plane thermal conductivity of the composite material. 


\section{Section 6.3: Sample Fabrication}

The fillers were used as-received for this study; the matrix material was dried as described in Chapter 3.3.1.1. The composite materials were extruded and pelletized as described in Chapter 3.3.1.2. The pellets were then injection molded as described in Chapter 3.3.1.3. Extrusion and injection molding conditions can be found in Appendices B and C.

\section{Section 6.4: Sample Testing}

All samples were conditioned as described in Chapter 3.3.2 prior to the thermal conductivity testing. Six samples from each formulation were tested as described in Chapter 3.3.2.1. Three different samples from each formulation were tested as described in Chapter 3.3.2.2. 


\section{Section 6.5: Results}

There were two important results generated from this study. The first result was the data set showing the relationship between thermal conductivities and filler loading for this composite. The second result was the generation of a predictive model for in-plane thermal conductivity that may be applicable to other filled systems.

\section{Section 6.5.1: Heat Capacity Results}

To obtain the heat capacity of the composite material, the following formula was used as a benchmark to compare experimental data to:

$$
\sum_{i=1}^{2} M_{i} \times C p_{i}
$$

In this equation, $M$ is the volume fraction of the material, $C p$ is the specific heat of the material, $i=1$ denotes the Vectra and $i=2$ denotes the Fortafil 243 carbon fiber. The formula results showed good agreement with experimental data. Experimental data and full formula results can be found in Section 9.5.

\section{Section 6.5.2: Thermal Conductivity Results}

The through-plane thermal conductivity of the composites was measured using the two test methods mentioned above. Figure 6.5-1 shows the through-plane thermal conductivity as measured by the methods described in Chapter 3.3.2.1, while Figures 6.52 and 6.5-3 show the through-plane thermal conductivity and in-plane thermal conductivity as measured by the methods described in Chapter 3.3.2.2. As can be seen from the figures, the through-plane thermal conductivity rises in a mostly linear fashion, but the in-plane thermal conductivity begins exhibiting exponential behavior at approximately 30vol\% filler. 


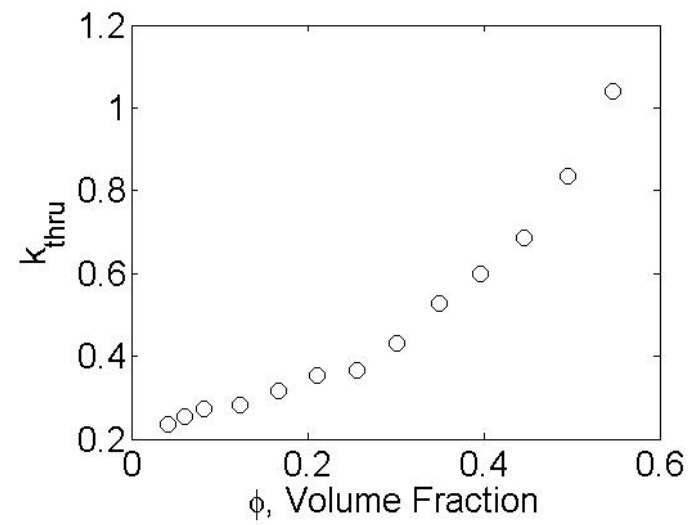

Figure 6.5-1: Through-Plane Thermal Conductivity $(\mathrm{W} / \mathrm{mK})$ vs. Volume Fraction Fortafil 243 Carbon Fiber, TCA

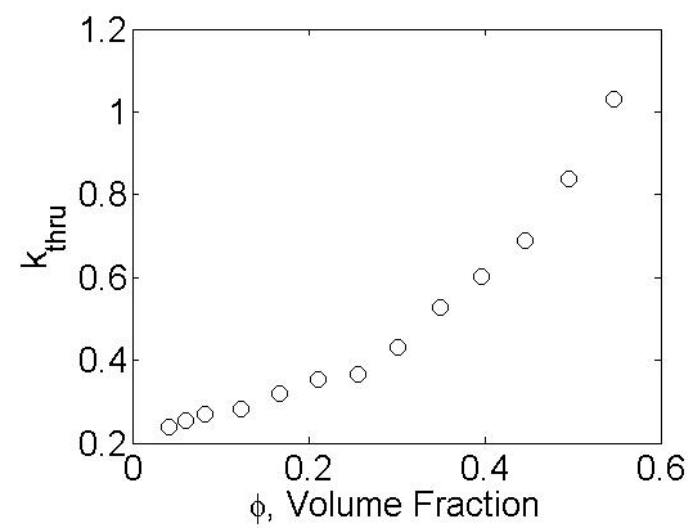

Figure 6.5-2: Through-Plane Thermal Conductivity $(\mathrm{W} / \mathrm{mK})$ vs. Volume Fraction Fortafil 243 Carbon Fiber, HotDisk

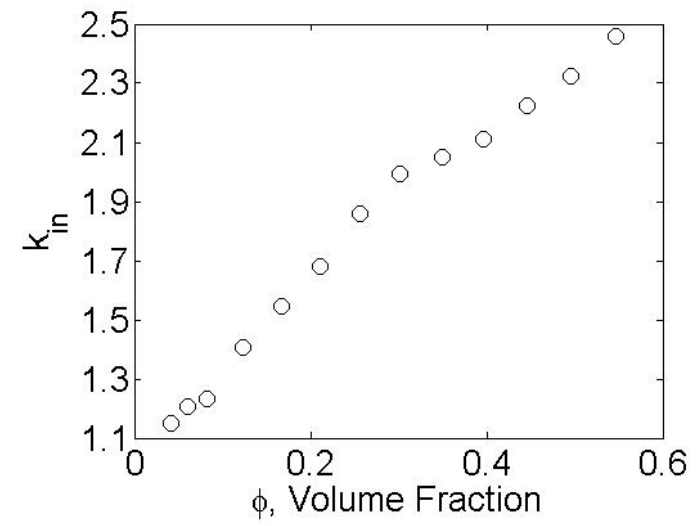

Figure 6.5-3: In-Plane Thermal Conductivity $(\mathrm{W} / \mathrm{mK})$ vs. Volume Fraction Fortafil 243 Carbon Fiber, HotDisk 
Table 6.5-1 displays the mean, standard deviation, and number of samples tested for the through-plane thermal conductivity as measured by the TCA-300 as well as the through-plane and in-plane thermal conductivities as measured by the Hot Disk transient plane source method. There is good agreement between the test methods for the throughplane thermal conductivity results. As expected, the in-plane thermal conductivity was higher than the through-plane thermal conductivity in all cases. The ratio of the in-plane thermal conductivity to the through-plane thermal conductivity varied from 2.3 to 5.1 and generally decreased as the volume fraction of filler $(\phi)$ increased. This ratio is lower than observed in the Thermocarb as discussed in Chapter 5; the Thermocarb is a more pure form of carbon than the Fortafil carbon fiber, which partially explains this behavior. Full conductivity data and results can be found in Appendices D and F. 
Table 6.5-1: Thermal Conductivity Results

\begin{tabular}{|l|l|l|l|l|}
\hline & $\begin{array}{l}\text { Through-Plane } \\
\text { Thermal } \\
\text { Conductivity } \\
\text { (TCA-300) }\end{array}$ & $\begin{array}{l}\text { Through-Plane } \\
\text { Thermal } \\
\text { Conductivity } \\
\text { (Hot Disk) }\end{array}$ & $\begin{array}{l}\text { In-Plane Thermal } \\
\text { Conductivity } \\
\text { (Hot Disk) }\end{array}$ & $\begin{array}{l}\text { In-Plane to } \\
\text { Through- } \\
\text { Plane Ratio } \\
\text { (Hot Disk) }\end{array}$ \\
\hline Formulation & W/mK & W/mK & W/mK & unitless \\
\hline $\begin{array}{l}\text { Neat Vectra } \\
\text { A950RX LCP }\end{array}$ & $0.217 \pm 0.007 n=4$ & $\sim 0.22$ (TCA) & $\sim 0.22$ (TCA) & 1.0 \\
\hline $\begin{array}{l}\text { Fortafil 243 } \\
\text { Carbon Fiber }\end{array}$ & & & & \\
\hline $5 w t \%$ & $0.237 \pm 0.006 \mathrm{n}=6$ & $0.238 \pm 0.002 n=5$ & $1.148 \pm 0.030 n=5$ & 4.8 \\
\hline $7.5 \mathrm{wt} \%$ & $0.256 \pm 0.004 \mathrm{n}=6$ & $0.255 \pm 0.002 \mathrm{n}=5$ & $1.208 \pm 0.034 \mathrm{n}=5$ & 4.7 \\
\hline $10 \mathrm{wt} \%$ & $0.272 \pm 0.006 \mathrm{n}=6$ & $0.271 \pm 0.005 \mathrm{n}=5$ & $1.234 \pm 0.052 \mathrm{n}=5$ & 4.6 \\
\hline $15 \mathrm{wt} \%$ & $0.282 \pm 0.008 \mathrm{n}=6$ & $0.282 \pm 0.004 \mathrm{n}=5$ & $1.407 \pm 0.012 \mathrm{n}=5$ & 5.0 \\
\hline $20 \mathrm{wt} \%$ & $0.316 \pm 0.010 \mathrm{n}=6$ & $0.320 \pm 0.004 \mathrm{n}=5$ & $1.548 \pm 0.026 \mathrm{n}=5$ & 4.8 \\
\hline $25 \mathrm{wt} \%$ & $0.352 \pm 0.006 \mathrm{n}=6$ & $0.353 \pm 0.000 \mathrm{n}=5$ & $1.680 \pm 0.026 \mathrm{n}=5$ & 4.8 \\
\hline $30 \mathrm{wt} \%$ & $0.366 \pm 0.009 \mathrm{n}=6$ & $0.365 \pm 0.003 \mathrm{n}=5$ & $1.857 \pm 0.028 \mathrm{n}=5$ & 5.1 \\
\hline $35 \mathrm{wt} \%$ & $0.430 \pm 0.025 \mathrm{n}=6$ & $0.432 \pm 0.004 \mathrm{n}=5$ & $1.996 \pm 0.005 \mathrm{n}=5$ & 4.6 \\
\hline $40 \mathrm{wt} \%$ & $0.527 \pm 0.014 \mathrm{n}=6$ & $0.527 \pm 0.003 \mathrm{n}=5$ & $2.050 \pm 0.036 \mathrm{n}=5$ & 3.9 \\
\hline $45 \mathrm{wt} \%$ & $0.599 \pm 0.033 \mathrm{n}=6$ & $0.602 \pm 0.006 \mathrm{n}=5$ & $2.109 \pm 0.015 \mathrm{n}=5$ & 3.5 \\
\hline $50 \mathrm{wt} \%$ & $0.687 \pm 0.034 \mathrm{n}=4$ & $0.688 \pm 0.004 \mathrm{n}=5$ & $2.239 \pm 0.037 \mathrm{n}=5$ & 3.3 \\
\hline $55 \mathrm{wt} \%$ & $0.836 \pm 0.044 \mathrm{n}=3$ & $0.838 \pm 0.009 \mathrm{n}=20$ & $2.324 \pm 0.069 \mathrm{n}=20$ & 2.8 \\
\hline $60 \mathrm{wt} \%$ & $1.039 \pm 0.018 \mathrm{n}=5$ & $1.030 \pm 0.023 \mathrm{n}=10$ & $2.459 \pm 0.057 \mathrm{n}=10$ & 2.4 \\
\hline
\end{tabular}

\section{Section 6.5.3: Thermal Conductivity Model Results}

After analysis of the thermal conductivity data generated in this study, an exponential correlation between the square root of the product of the in-plane and through-plane thermal conductivities and the volume percent of filler was observed. This correlation is given by:

$$
\sqrt{k_{\text {in }} k_{\text {thru }}}=0.4835 e^{2.1619 \phi}
$$

where $k_{\text {in }}$ and $k_{\text {thru }}$ have units of (W/mK). Rearranging for $k_{\text {in }}$ yields the following predictive equation: 


$$
k_{\text {in }}=\frac{\left(0.4835 e^{2.1619 \phi}\right)^{2}}{k_{\text {thru }}}=\frac{0.2338 e^{4.3238 \phi}}{k_{\text {thru }}}
$$

As discussed in Chapter 5.4.2, this result is important as it allows for further development of a predictive model for the thermal conductivity of composites [2]. Figure 6.5-4 shows the experimental data plotted along with the predicted results of the model. The experimental data fits the model results quite well.

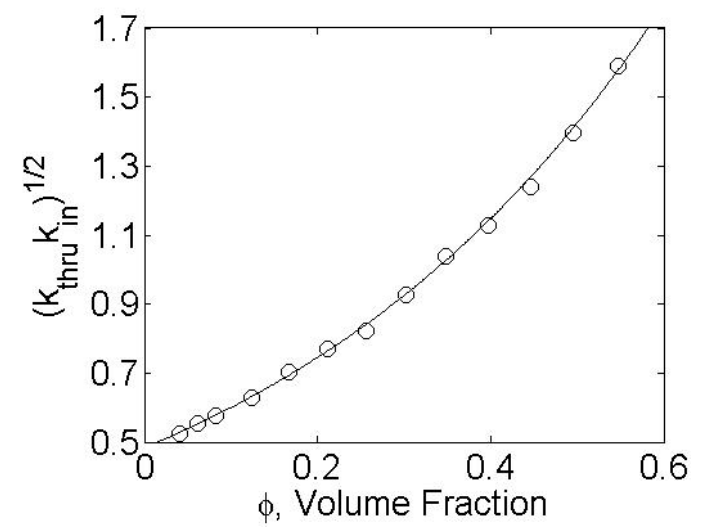

Figure 6.5-4: Combined Thermal Conductivity (W/mK) vs. Volume Fraction Fortafil 243 Carbon Fiber (Exponential Fit) 


\section{Section 6.6: Summary}

A greater understanding of the thermal conductivity properties of Fortafil 243 carbon fiber and, more importantly, how the filler loading affected the thermal properties of the composite, was obtained. An important result is that at 30 vol\% filler, the thermal conductivities begin to follow an exponential trend. This trend is more pronounced in the in-plane thermal conductivity trend. This data was used to develop a predictive model for the in-plane thermal conductivity which, in concert with the known volume percent of filler and the known or calculated through-plane thermal conductivity of the composite, aids experimental design in targeting desired thermal conductivity values. 


\section{Section 6.7: References}

1. Keith, J. M.; Hingst, C. D.; Miller, M. G.; King, J. A.; Hauser, R. A. Polym.

Compos., 2006, 27, 1-7.

2. Weber, E. H.; Clingerman, M. L.; King, J. A. J. Appl Polym. Sci., 2003, 88, 123130 


\section{Chapter 7: Modeling}

After the thermal conductivity data for the selected fillers was collected, it was subjected to assorted modeling procedures to see if a mathematical model could be extracted from the results. These mathematical models, if found, would allow for predictive analysis of composite mixtures, allowing for optimization of product to some degree before many materials and hours are expended to come to the same conclusion. In chapters 5 and 6, exponential trendlines were fit to the data for combined thermal conductivity (the positive square root of the product of through-plane and in-plane thermal conductivities of a composite material) versus volume fraction of filler. One of the parameters in these trendline equations is the through-plane thermal conductivity, of which there are several predictive models available. This chapter is a discussion of the most prevalent of these models. 


\section{Section 7.1: Basic Modeling}

All of the following models require the thermal conductivity of the constituents.

Table 7.1-1 is a compilation of these values from tables in Chapter 3 [1-4].

Table 7.1-1: Thermal Conductivity of Constituents [1-4]

\begin{tabular}{|c|c|}
\hline Material & Thermal Conductivity (W/mK) \\
\hline Vectra A950RX Liquid Crystal Polymer & 0.22 \\
\hline Ketjenblack EC-600 JD Carbon Black & 2.1 \\
\hline Thermocarb TC-300 Synthetic Graphite & 600 \\
\hline Fortafil 243 Carbon Fiber & 20 \\
\hline
\end{tabular}

In the following models, all subscripts of ' 1 ' are referring to the properties of the matrix material; all subscripts of ' 2 ' are referring to the properties of the filler material. In addition, all references to ' $K$ ' refer to the thermal conductivity of the composite; all references to ' $k$ ' refer to the thermal conductivity of a single component; ' $\phi_{1}$ ' and ' $\phi_{2}$ ' refer to the volume fractions of the components (which sum to 1). The Nielsen model discussed in Section 7.2 has some additional nomenclature which will be discussed in that section.

Basic thermal conductivity models take into account physical properties of the materials and, using only those properties, give a resulting value for the thermal conductivity of the composite material. There are no adjustable parameters in these models - the data is what it is. Three basic thermal conductivity models were examined in this work and will be discussed. 


\section{Section 7.1.1: Rule of Mixtures}

The Rule of Mixtures model, sometimes called the series model, can be expressed as follows in the case of a two-component (matrix and one filler) system:

$$
K=\phi_{1} k_{1}+\phi_{2} k_{2}
$$

This model works reasonably well to predict thermal conductivity in continuous fiber, well-aligned composites; previous work has shown that this model tends to overpredict thermal conductivity in short-fiber and/or particulate filler composites [5-6].

\section{Section 7.1.2: Inverse Rule of Mixtures}

The Inverse Rule of Mixtures model, sometimes called the parallel model, can be expressed as follows in the case of a two-component (matrix and one filler) system:

$$
\frac{1}{K}=\frac{\phi_{1}}{k_{1}}+\frac{\phi_{2}}{k_{2}}
$$

This model also works reasonably well to predict thermal conductivity in continuous fiber, well-aligned composites; previous work has shown that this model tends to underpredict thermal conductivity in short-fiber and/or particulate filler composites [5-6].

\section{Section 7.1.3: Geometric Rule of Mixtures}

The Geometric Rule of Mixtures model, sometimes called the geometric mean

model, can be expressed as follows in the case of a two-component (matrix and one filler) system:

$$
K=k_{1}^{\phi_{1}} k_{2}^{\phi_{2}}
$$


This model is better at predicting thermal conductivity in short-fiber and/or particulate filler composites than the two aforementioned models [5-6].

\section{Section 7.1.4: Basic Modeling Results}

Graphical results will be presented and discussed here - full data for these test cases can be found in Section 9.11. Two error analysis terms were calculated for these and the Nielsen models:

$$
\begin{gathered}
\varepsilon=\frac{\sum_{i}\left(y_{i}-y_{\mathrm{mod}, i}\right)^{2}}{\sum_{i} y_{i}^{2}} \\
S S=\sum_{i}\left(y_{i}-y_{\mathrm{mod}, i}\right)^{2}
\end{gathered}
$$

' $\varepsilon$ ' is a standardized lack of fit term; ' $\mathrm{y}_{\mathrm{i}}$ ' is an experimental through-plane thermal conductivity result; ' $y$ mod,i ' is the corresponding model-predicted through-plane thermal conductivity result; ' $\mathrm{i}$ ' is the summation variable which ranges from 1 to the total number of formulations; 'SS' is shorthand for Sum of Squares, which is the sum of the squares of the difference between the experimental value and predicted value of the thermal conductivity of a composite. A result of 0 for either of these equations indicates a perfect fit of the model to the data.

\section{Section 7.1.4.1: Carbon Black Basic Model Results}

As shown in Table 7.1-2, the Rule of Mixtures model was the best match to the experimental data, outperforming the other basic models tested by an order of magnitude in terms of minimizing the sum of squares and standardized lack of fit terms. As expected, the Rule of Mixtures tended to overpredict the thermal conductivity of the composite while the Inverse Rule of Mixtures tended to underpredict the thermal 
conductivity of the composite. In this case, the Geometric Rule of Mixtures

underpredicted the thermal conductivity of the composite. The Rule of Mixtures gave the closest predictive fit when compared with experimental data.

Table 7.1-2: Error Analysis - Basic Mixing Rules, Carbon Black Composite

\begin{tabular}{|c|c|c|c|}
\cline { 2 - 4 } \multicolumn{1}{c|}{} & Rule Of Mixtures & Inverse Rule Of Mixtures & Geometric Rule Of Mixtures \\
\hline EAV SS & 0.002643 & 0.059687 & 0.034871 \\
EAV $\varepsilon$ & 0.003577 & 0.080772 & 0.047189 \\
\hline
\end{tabular}

Figure 7.1-1 is a graphical comparison of the model results to the experimental data.

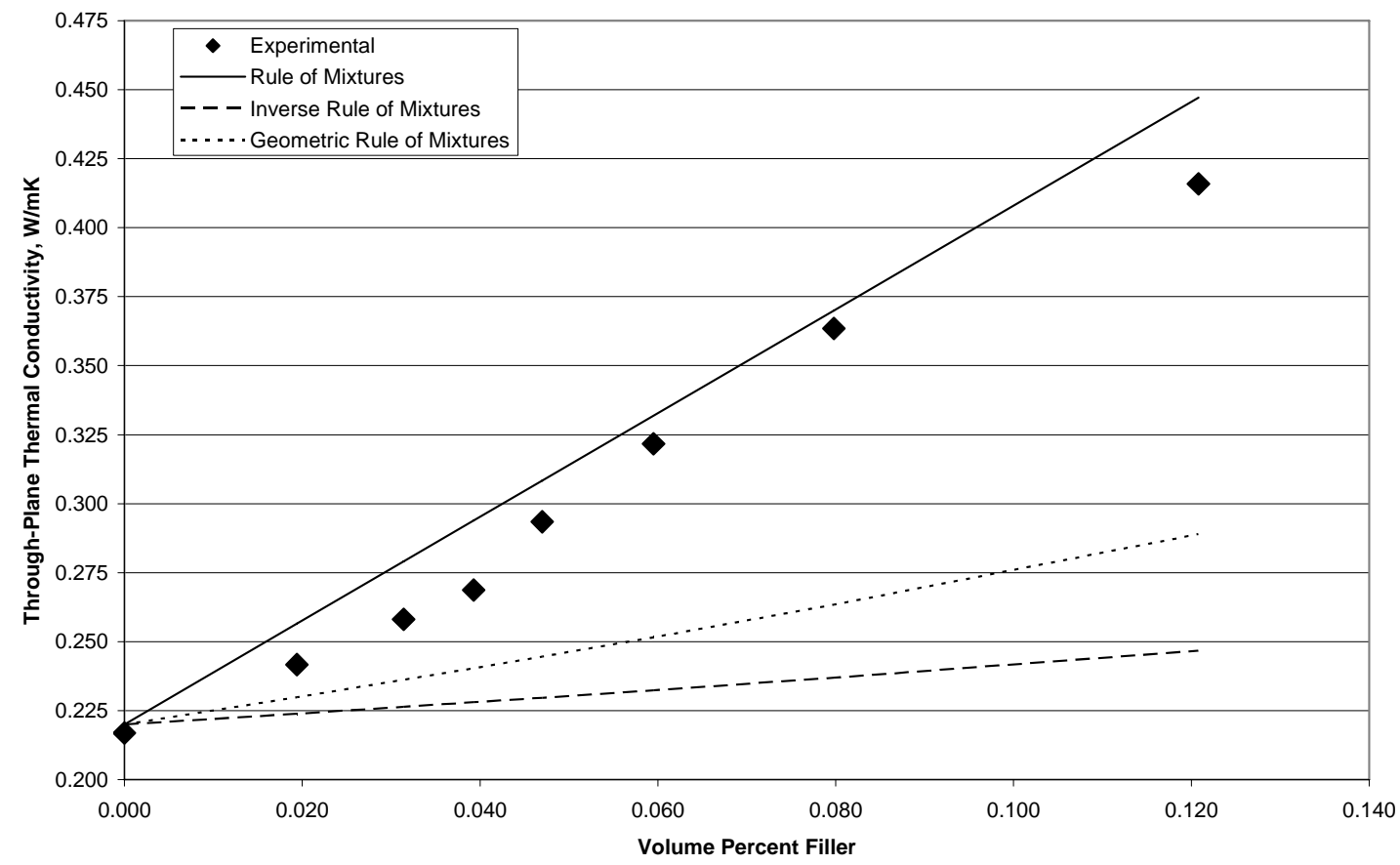

Figure 7.1-1: Basic Mixing Rule Model Results - Carbon Black Composites 


\section{Section 7.1.4.2: Synthetic Graphite Basic Model Results}

As shown in Table 7.1-3, the Inverse Rule of Mixtures model was the best match to the experimental data, outperforming the other basic models tested by several orders of magnitude in terms of minimizing the sum of squares and standardized lack of fit terms. As expected, the Rule of Mixtures tended to overpredict the thermal conductivity of the composite while the Inverse Rule of Mixtures tended to underpredict the thermal conductivity of the composite. In this case, the Geometric Rule of Mixtures overpredicted the thermal conductivity of the composite.

Table 7.1-3: Error Analysis - Basic Mixing Rules, Synthetic Graphite Composite

\begin{tabular}{|c|c|c|c|}
\cline { 2 - 4 } \multicolumn{1}{c|}{} & Rule Of Mixtures & Inverse Rule Of Mixtures & Geometric Rule Of Mixtures \\
\hline EBV SS & 714497 & 12.6547 & 2048.31 \\
EBV $\varepsilon$ & 29846.9 & 0.528627 & 85.5646 \\
\hline
\end{tabular}

Figures 7.1-2 and 7.1-3 are graphical comparisons of the model results to the experimental data. They share the same data; however, the Rule of Mixtures model is omitted from Figure 7.3 to allow a better look at how the other two models approximate the experimental data. 


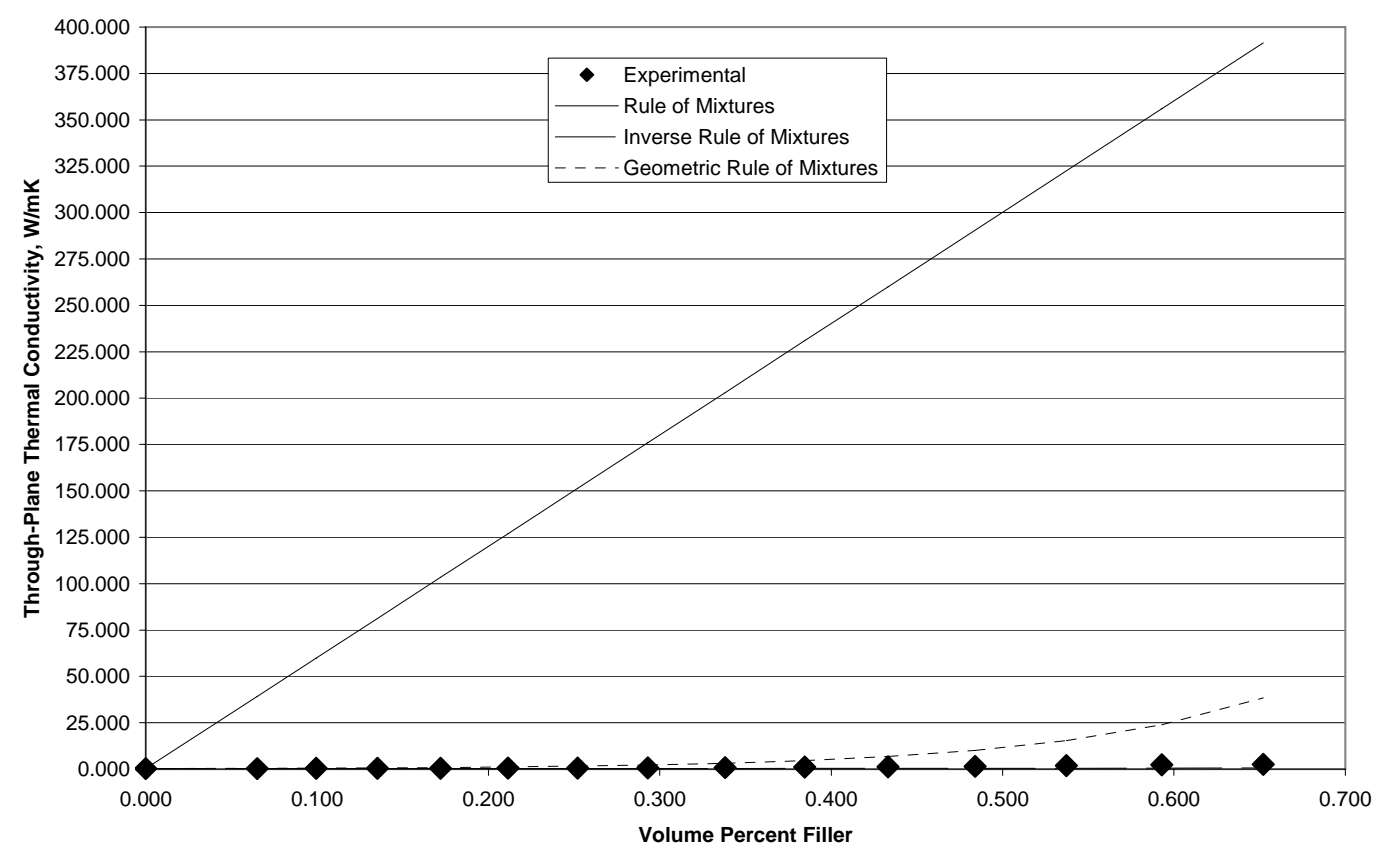

Figure 7.1-2: Basic Mixing Rule Model Results - Synthetic Graphite Composites

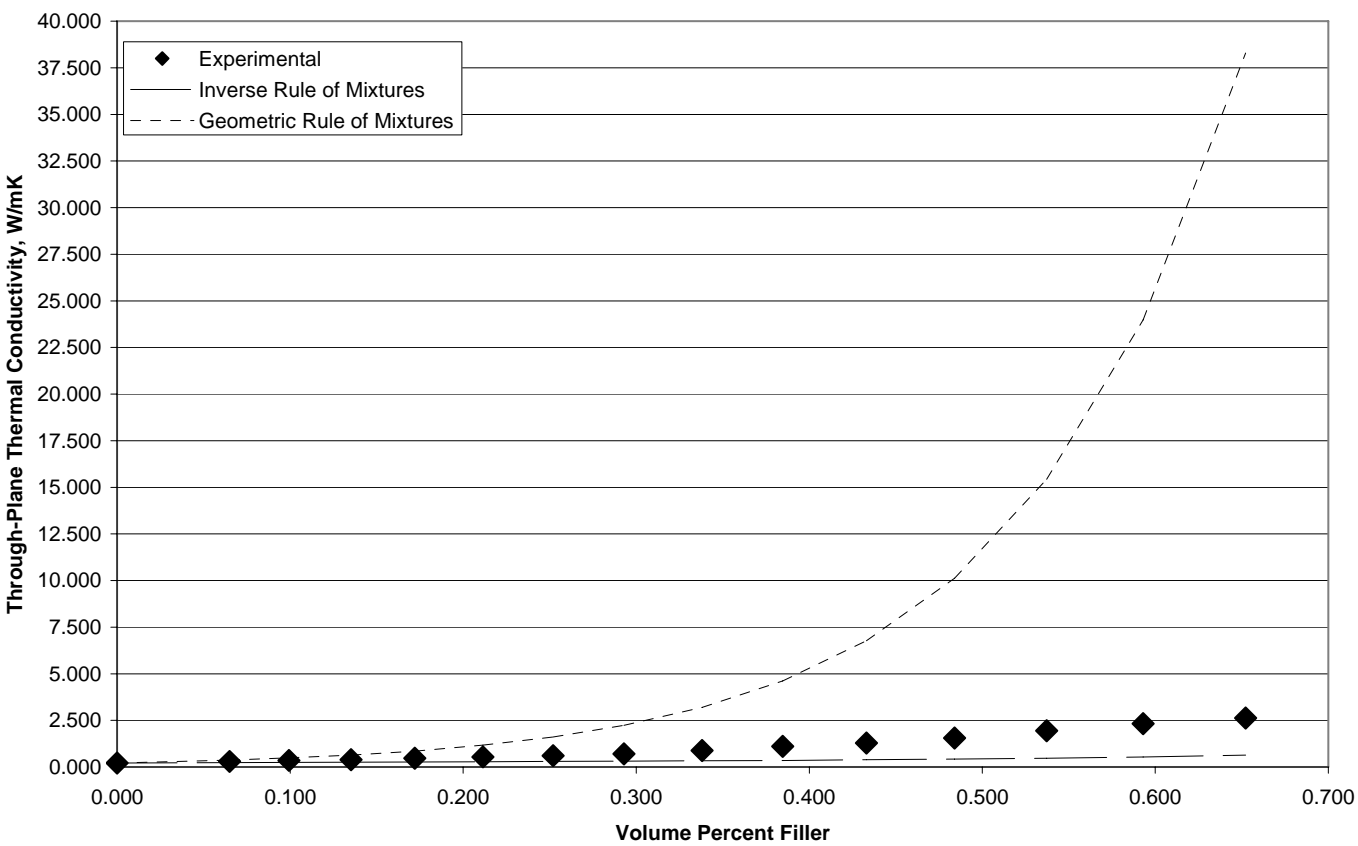

Figure 7.1-3: Selected Basic Mixing Rule Model Results - Synthetic Graphite Composites 


\section{Section 7.1.4.3: Carbon Fiber}

As shown in Table 7.1-4, the Inverse Rule of Mixtures model was the best match to the experimental data, outperforming the other basic models tested by varying orders of magnitude in terms of minimizing the sum of squares and standardized lack of fit terms. As expected, the Rule of Mixtures tended to overpredict the thermal conductivity of the composite while the Inverse Rule of Mixtures tended to underpredict the thermal conductivity of the composite. In this case, the Geometric Rule of Mixtures overpredicted the thermal conductivity of the composite.

Table 7.1-4: Error Analysis - Basic Mixing Rules, Carbon Fiber Composite

\begin{tabular}{|c|c|c|c|}
\cline { 2 - 4 } \multicolumn{1}{c|}{} & Rule Of Mixtures & Inverse Rule Of Mixtures & Geometric Rule Of Mixtures \\
\hline EHV SS & 448.065 & 0.679135 & 6.02546 \\
EHV $\varepsilon$ & 119.638 & 0.181337 & 1.60887 \\
\hline
\end{tabular}

Figures 7.1-4 and 7.1-5 are graphical comparisons of the model results to the experimental data. They share the same data; however, the Rule of Mixtures model is omitted from Figure 7.1-5 to allow a better look at how the other two models approximate the experimental data. 


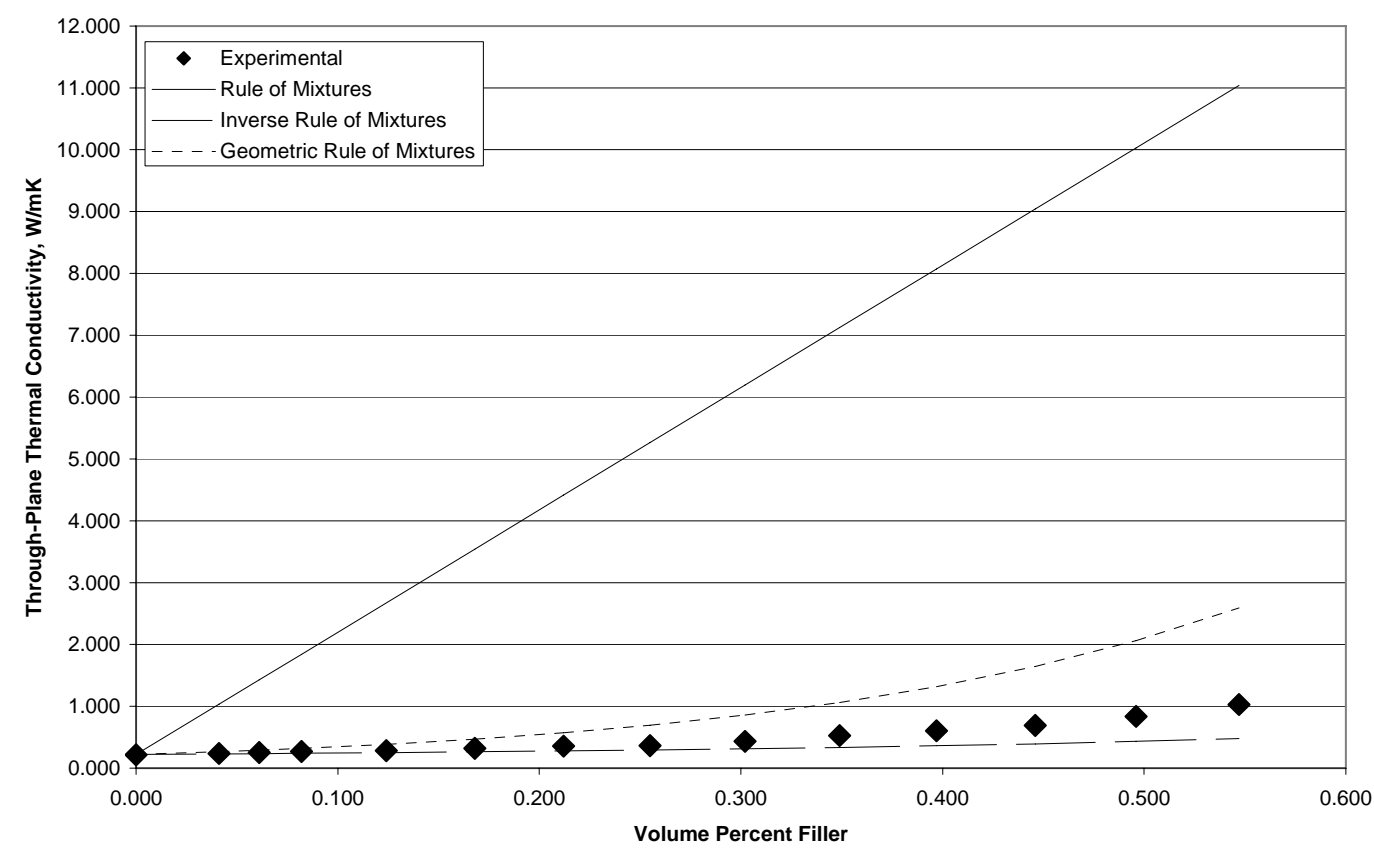

Figure 7.1-4: Basic Mixing Rule Model Results - Carbon Fiber Composites

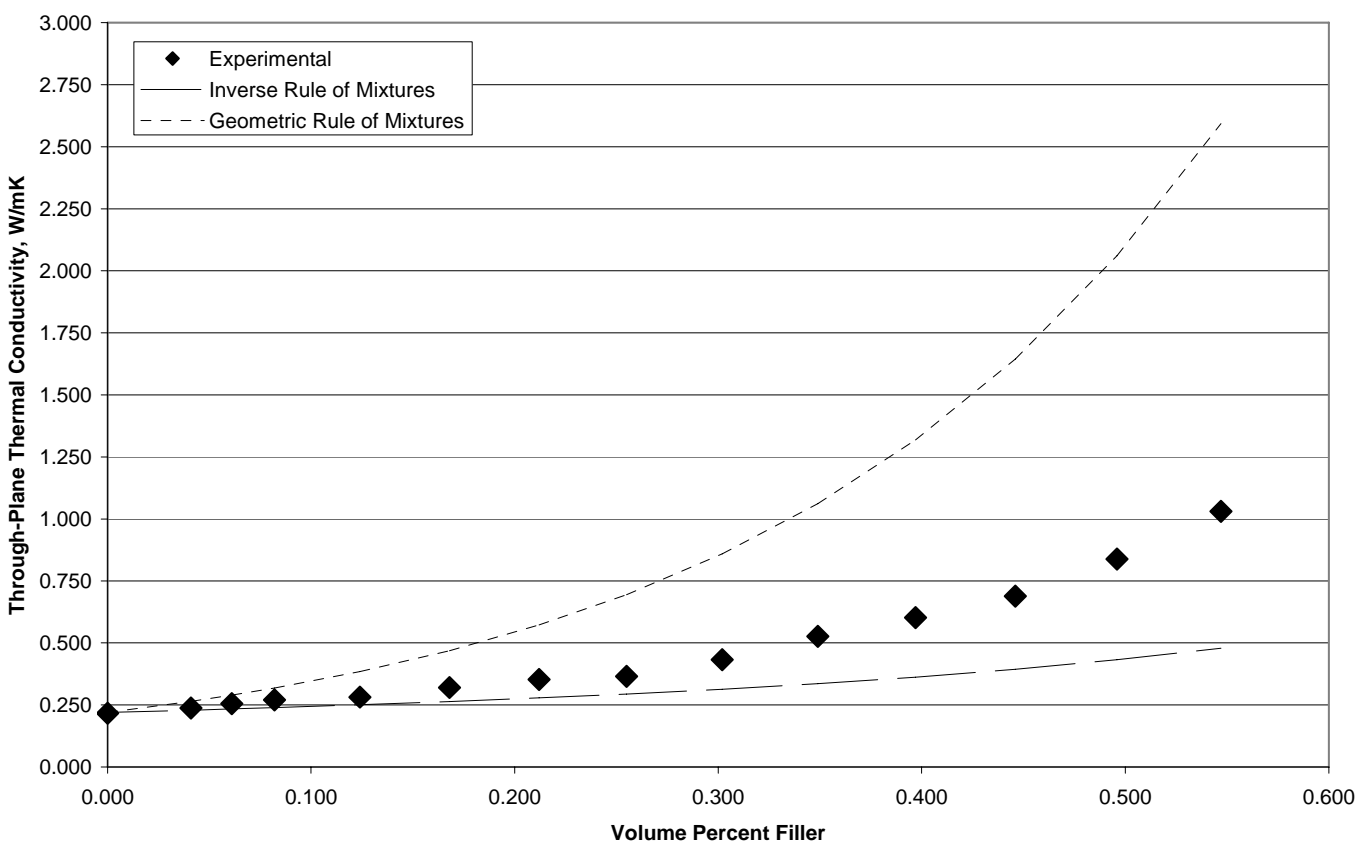

Figure 7.1-5: Selected Basic Mixing Rule Model Results - Carbon Fiber Composites 


\section{Section 7.2: Nielsen's Model and Variants}

The advanced model used in this work is Nielsen's Model. A review of thermal conductivity models by Progelhof et al [7] was the impetus for the selection of the Nielsen Model in work by Weber et al [5-6]. It was decided to continue with this model for this work to see how well the model adapted to higher volume fractions of filler than was studied by Weber et al [5-6].

The base equations for the Nielsen Model are as follows:

$$
\begin{aligned}
& \frac{K}{k_{1}}=\frac{1+A B \phi_{2}}{1-B \psi \phi_{2}} \\
& A=k_{E}-1 \\
& B=\frac{k_{2} / k_{1}-1}{k_{2} / k_{1}+A} \\
& \psi \cong 1+\frac{1-\phi_{m}}{\phi_{m}^{2}} \phi_{2}
\end{aligned}
$$

' $\mathrm{A}$ ' is a function of the aspect ratio and orientation of the filler and is related to the generalized Einstein coefficient, ' $\mathrm{k}_{\mathrm{E}}$ '. ' $\mathrm{B}$ ' is a factor that accounts for the relative thermal conductivity of the two components. ' $\psi$ ' is a factor that accounts for the maximum packing fraction of the filler, ' $\phi_{\mathrm{m}}$ '. The term ' $\psi \phi_{2}$ ' approaches 1.0 when $\phi_{2}=\phi_{\mathrm{m}}$.

McGee and McCullough [8] proposed a variant equation to determine $\psi$ :

$$
\psi \cong 1+\frac{\phi_{1}}{\phi_{m}}\left[\phi_{m} \phi_{2}+\left(1-\phi_{m}\right) \phi_{1}\right]
$$

Equations 7.6a-c and 7.6e comprise the Modified Nielsen Model.

Work by Weber et al [5-6] hinted at the potential for further optimizing the accuracy of the Nielsen Model and Modified Nielsen Model by varying the 'A' and ' $\phi_{\mathrm{m}}$ ' 
parameters to enhance the fit of the model to the data. This previous work determined that the best course of action was to optimize the 'A' parameter and to leave the ' $\phi_{\mathrm{m}}$ ' term as tabulated; as such, two cases of the Nielsen Model and Modified Nielsen Model were run - one with the tabulated values for ' $A$ ' and one with 'A' solved for to minimize the sum of squares error term. These are given the following names: Nielsen Model for the literature 'A' value and the original ' $\psi$ ' term, Modified Nielsen Model for the literature 'A' value and the modified ' $\psi$ ' term, Optimized Nielsen Model for the literature ' $A$ ' value and the original ' $\psi$ ' term, and the Optimized Modified Nielsen Model for the optimized 'A' value and the modified ' $\psi$ ' term.

Table 7.2-1 is a listing of ' $A$ ' and ' $\phi_{\mathrm{m}}$ ' parameters used and/or determined in this work. In the optimized cases, this 'A' parameter is a calculated value, in the nonoptimized cases, it is a literature value [9-10].

Table 7.2-1: Nielsen Model Parameters [9-10]

\begin{tabular}{|c|c|c|c|c|}
\hline Carbon Filler & Literature ' $\phi_{\mathrm{m}}$ ' & Literature ' $\mathrm{A}$ ' & $\begin{array}{l}\text { Optimized } \\
\text { Nielsen Model } \\
\text { 'A' }\end{array}$ & $\begin{array}{l}\text { Optimized } \\
\text { Modified } \\
\text { Nielsen Model } \\
\text { 'A' }\end{array}$ \\
\hline $\begin{array}{l}\text { Ketjenblack } \\
\text { EC-600 JD } \\
\text { Carbon Black } \\
\end{array}$ & 0.637 & 1.5 & 47.3142 & 41.5020 \\
\hline $\begin{array}{l}\text { Thermocarb } \\
\text { TC-300 } \\
\text { Synthetic } \\
\text { Graphite }\end{array}$ & 0.637 & 1.58 & 0.0000 & 1.8538 \\
\hline $\begin{array}{l}\text { Fortafil } 243 \\
\text { Carbon Fiber }\end{array}$ & 0.520 & 4.29 & 0.0000 & 0.0754 \\
\hline
\end{tabular}




\section{Section 7.3: Nielsen's Model and Variants Results}

\section{Section 7.3.1: Carbon Black Advanced Model Results}

Table 7.3-1 is a summary of the results of the four modeling cases performed on the carbon black composite. The Modified Nielsen Model performed better than the Nielsen Model with or without optimization, though not appreciably so. The optimization enhanced the degree of fit of the model to the data by approximately a factor of 5 in both cases. However, in optimization the value of ' $A$ ' ballooned from the literature value of 1.5 to experimental values of 47.3 and 41.5 (unmodified and modified cases, respectively).

\section{Table 7.3-1: Error Analysis - Nielsen's Model, Carbon Black Composites}

\begin{tabular}{|c|c|c|}
\hline & Nielsen’s Model & Optimized Nielsen's Model \\
\hline EAV SS & 0.039807 & 0.000701 \\
EAV $\varepsilon$ & 0.053869 & 0.000948 \\
\hline & Modified Nielsen's Model & Optimized Modified Nielsen's Model \\
\hline EAV SS & 0.032807 & 0.000691 \\
EAV $\varepsilon$ & 0.044397 & 0.000935 \\
\hline
\end{tabular}

Figure 7.3-1 is a graphical comparison of the model results to the experimental

data. The unoptimized models tend to underpredict the thermal conductivity of the composite; the optimized models follow it more closely. 


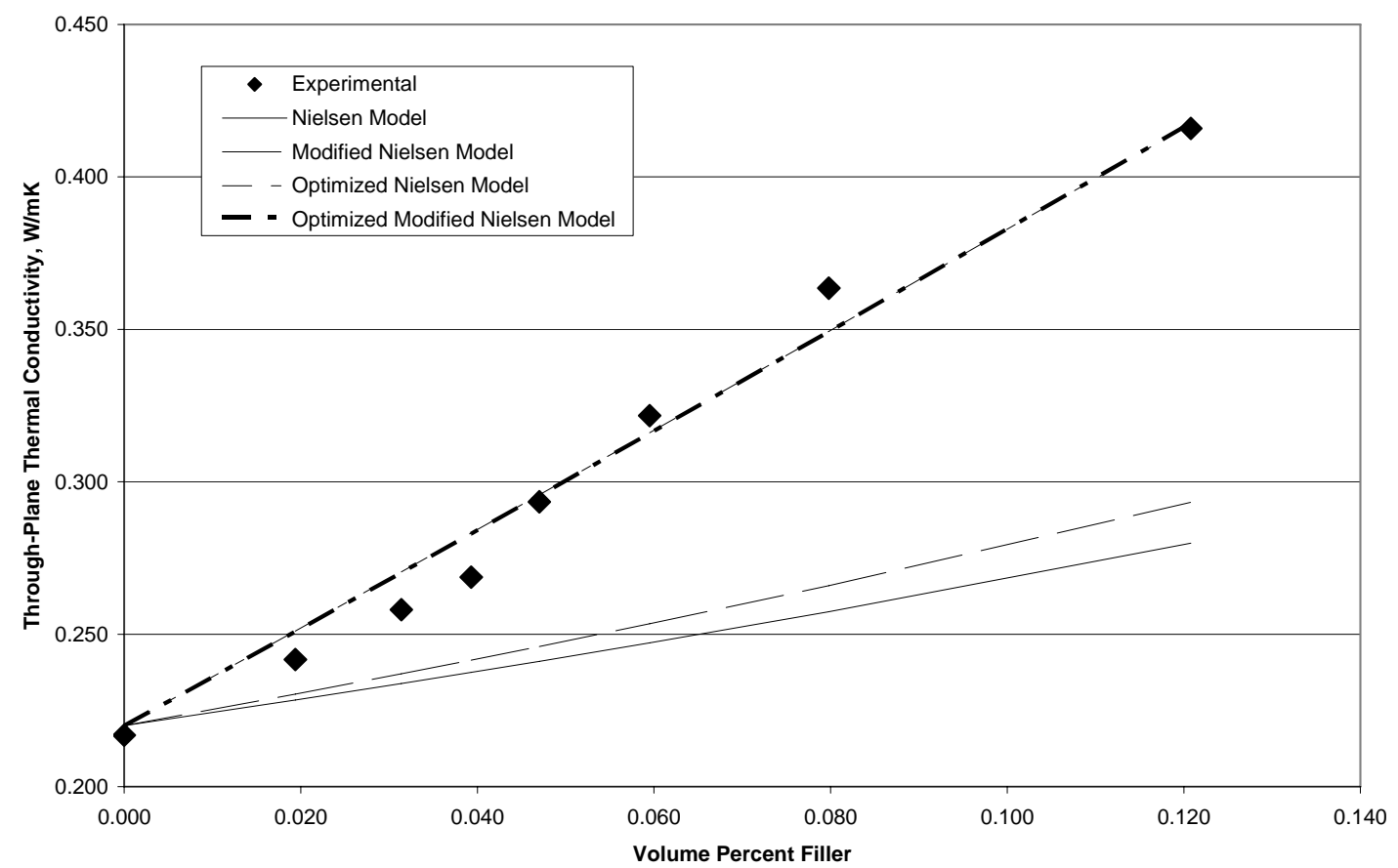

Figure 7.3-1: Advanced Model Results - Carbon Black Composites Section 7.3.2: Synthetic Graphite Advanced Model Results

Table 7.3-2 is a summary of the results of the four modeling cases performed on the synthetic graphite composite. The Modified Nielsen Model performed appreciably better than the Nielsen Model with or without optimization. A large part of this can be traced to a failing of the Nielsen Model - the method of calculation of ' $\psi$ ' leads to a prediction of a negative thermal conductivity at the $75 \mathrm{wt} \%$ composite, which introduces a large (by comparison to the other points) difference between experimental and theoretical values, which is then squared. More than $95 \%$ of the value of the sum of squares value in the Nielsen Model cases can be attributed to this last data point. The optimization enhanced the degree of fit of the model to the data by approximately a factor of 3 in the case of Nielsen's Model and 1.2 in the case of the Modified Nielsen's Model 
in both cases. In optimization the value of 'A' from the literature value of 1.5 to experimental values of 0 and 1.8538 (unmodified and modified cases, respectively). The result of 0 in the unmodified case can be attributed to the negative result it produces at 75 wt\% filler.

Table 7.3-2: Error Analysis - Nielsen’s Model, Synthetic Graphite Composites

\begin{tabular}{|c|c|c|}
\hline & Nielsen's Model & Optimized Nielsen's Model \\
\hline EBV SS & 284.010 & 91.8511 \\
EBV $\varepsilon$ & 11.8640 & 3.83693 \\
\hline & Modified Nielsen's Model & Optimized Modified Nielsen’s Model \\
\hline EBV SS & 0.723381 & 0.597762 \\
EBV $\varepsilon$ & 0.030218 & 0.024971 \\
\hline
\end{tabular}

Figure 7.3-2 is a graphical comparison of the model results to the experimental data. All of the models tend to underpredict the thermal conductivity of the composite until high filler loadings; the optimized models follow it more closely.

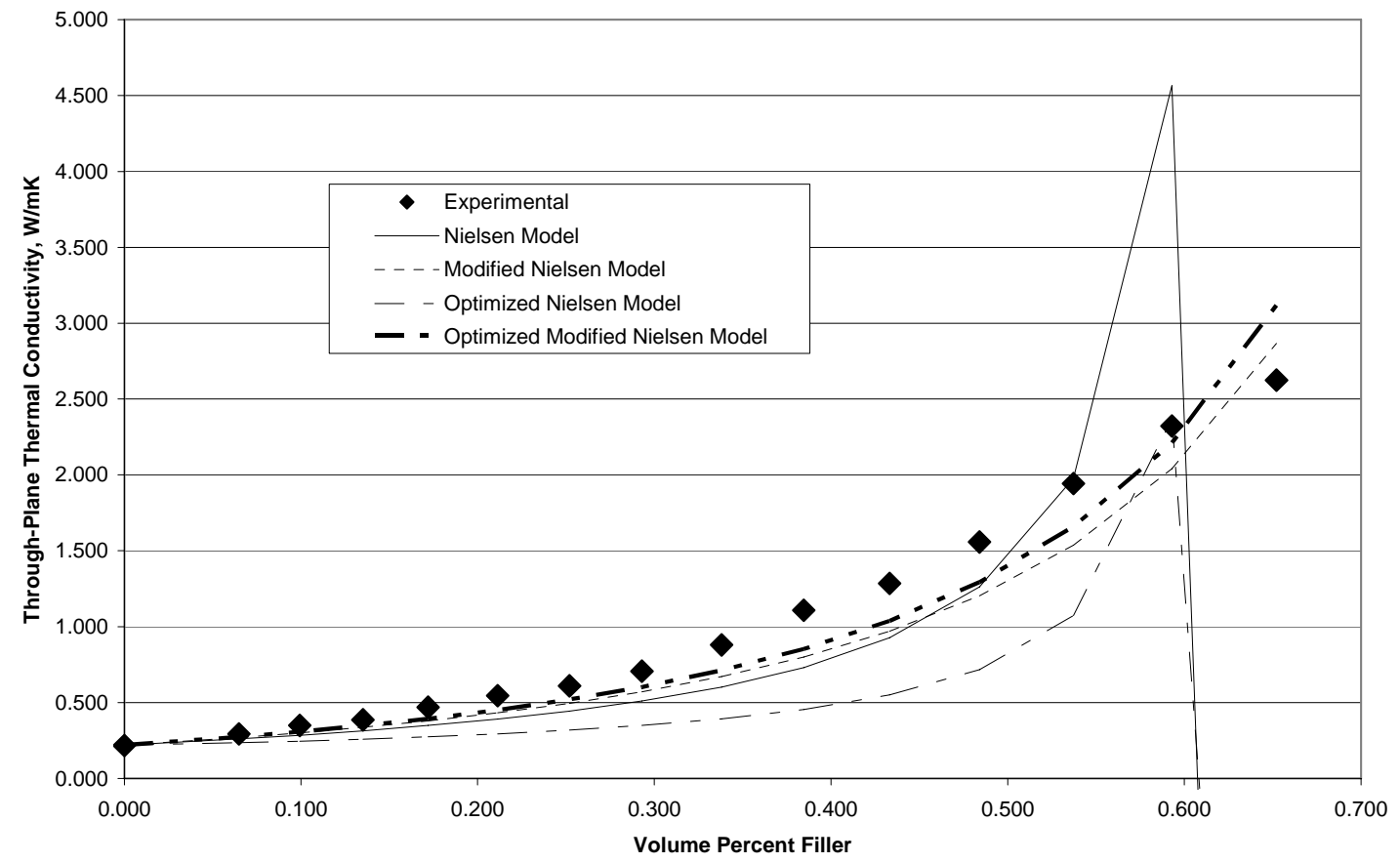

Figure 7.3-2: Advanced Model Results - Synthetic Graphite Composites 


\section{Section 7.3.3: Carbon Fiber Advanced Model Results}

Table 7.3-3 is a summary of the results of the four modeling cases performed on the synthetic graphite composite. The Modified Nielsen Model performed appreciably better than the Nielsen Model with or without optimization. A large part of this can be traced to a failing of the Nielsen Model - the method of calculation of ' $\psi$ ' leads to a prediction of a negative thermal conductivity at the $60 \mathrm{wt} \%$ composite, which introduces a large (by comparison to the other points) difference between experimental and theoretical values, which is then squared. More than $95 \%$ of the value of the sum of squares value in the Nielsen Model cases can be attributed to this last data point. The optimization enhanced the degree of fit of the model to the data by approximately a factor of 35 in the case of Nielsen's Model and 3600 in the case of the Modified Nielsen's Model in both cases. In optimization the value of 'A' from the literature value of 4.29 to experimental values of 0 and 0.0754 (unmodified and modified cases, respectively). The result of 0 in the unmodified case can be attributed to the negative result it produces at 60 wt\% filler.

Table 7.3-3: Error Analysis - Nielsen's Model, Carbon Fiber Composites

\begin{tabular}{|c|c|c|}
\hline & Nielsen’s Model & Optimized Nielsen’s Model \\
\hline EHV SS & 799.730 & 23.0534 \\
EHV $\varepsilon$ & 213.537 & 6.15553 \\
\hline & Modified Nielsen’s Model & Optimized Modified Nielsen's Model \\
\hline EHV SS & 5.80270 & 0.001609 \\
EHV $\varepsilon$ & 1.54939 & 0.000430 \\
\hline
\end{tabular}

Figure 7.3-3 is a graphical comparison of the model results to the experimental

data. The unoptimized models tend to overpredict the thermal conductivity of the composite; the optimized models follow it more closely. Note that the Optimized Nielsen's Model begins to lose fit and overpredict at $~ 45$ vol\% (50 wt\%). 


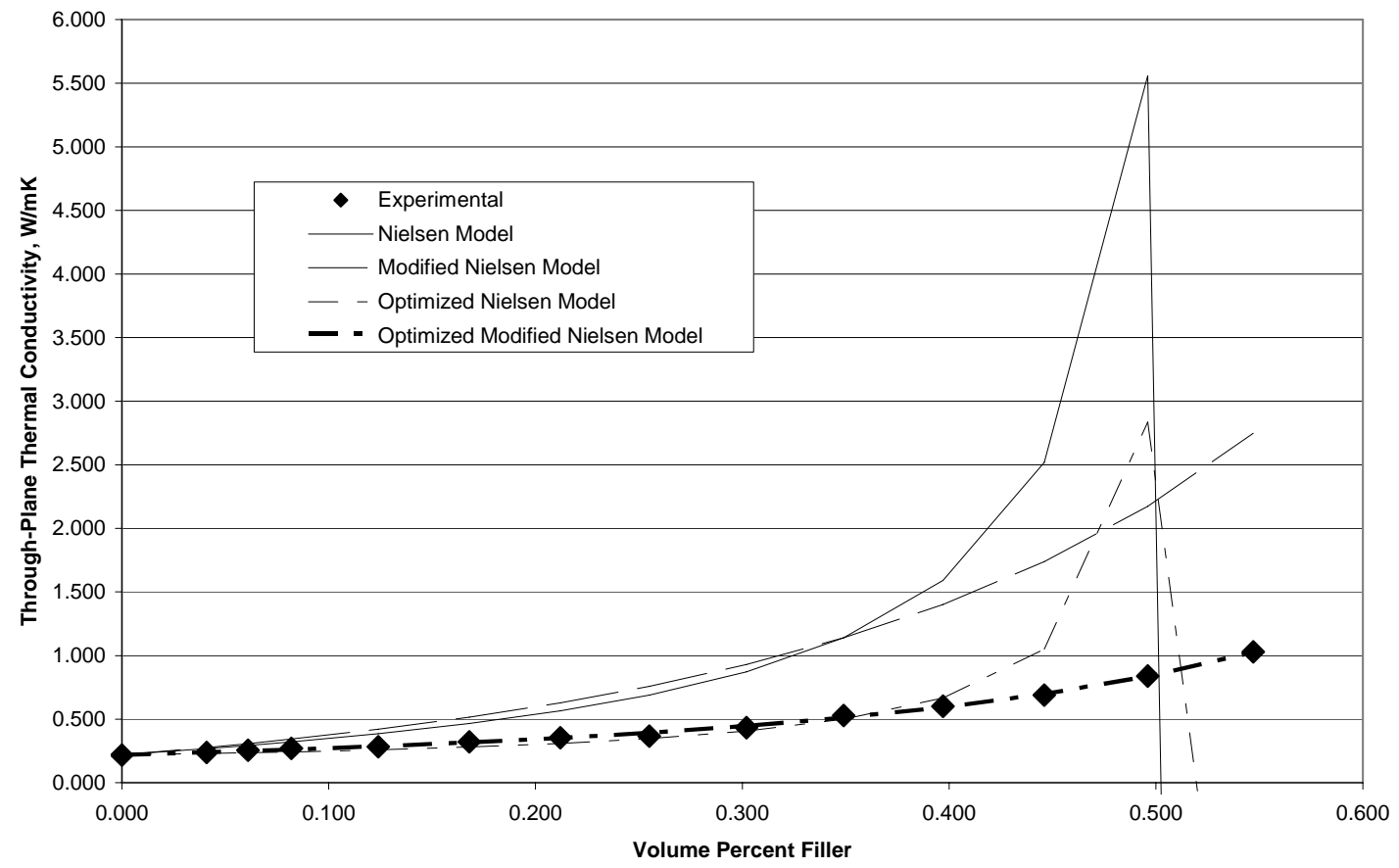

Figure 7.3-3: Advanced Model Results - Carbon Fiber Composites 


\section{Section 7.4: Modeling Summary}

Looking at the basic models, the Rule of Mixtures provided the best model fit to the experimental data obtained from the carbon black composites, while the Inverse Rule of Mixtures provided the best model fit to the experimental data obtained from the synthetic graphite and carbon black composites. However, none of these fits were comparable to that provided by the Optimized Modified Nielsen Model, which was the best model fit to the experimental data in all cases. The unmodified Nielsen Model cases broke down when the volume fraction of filler surpassed the theoretical maximum packing fraction for that filler; this may be a good area for exploration in future work to determine whether or not the theoretical maximum packing fractions are valid for the materials being used. 


\section{Section 7.5: References}

1. Ticona Vectra Liquid Crystal Polymer (LCP) Product Information, Ticona, Summit, NJ, 07901, 2000.

2. Akzo Nobel Electrically Conductive Ketjenblack Product Literature, Akzo Nobel.

3. Asbury Carbons Product Information, Asbury, NJ, 08802 (2004).

4. Akzo Nobel, “Fortafil Carbon Fibers”, Fortafil Fibers, Inc., 8870 Cedar Springs Lane, Suite 8, Knoxville, TN 37923.

5. E. H. Weber, M. L. Clingerman, and J. A. King, "Thermally Conductive Nylon 6,6 and Polycarbonate Based Resin. Part 1: Synergistic Effects of Carbon Fillers”, Journal of Applied Polymer Science, Vol. 88, pp. 112-122, 2003.

6. E. H. Weber, M. L. Clingerman, and J. A. King, “Thermally Conductive Nylon 6,6 and Polycarbonate Based Resin. Part 2: Modelling”, Journal of Applied Polymer Science, Vol. 88, pp. 123-130, 2003.

7. R. C. Progelhof, J. L. Throne, and R. R. Ruetsch, "Methods of Predicting Thermal Conductivity of Composite Systems: A Review”. Reg. Tech. Cond. - Soc. Plast. Eng, 1975, pp. 221-257.

8. R. McCullough, “Generalized Combining Rules for Predicting Transport Properties of Composite Materials”. Composites Science and Technology, Vol. 22, 1985.

9. L. E. Nielsen, “The Thermal and Electrical Conductivity of Two-Phase Systems”. I\&EC Fundamentals, Vol. 13, No. 1, 1974, pp. 17-20.

10. Bigg, D. M. Polym Compos 1986, 7, 125. 


\section{Chapter 8: Summary and Future Work Section 8.1: Impact of Carbon Black on Thermal Conductivity}

As discussed in Chapter 4, 0 - 15wt\% Ketjenblack EC-600 JD was added to Vectra A950RX LCP; the thermal conductivity of the resulting composites was measured in the through-plane direction. The through-plane thermal conductivity varied from 0.22 $\mathrm{W} / \mathrm{mK}$ at the minimum loading to $0.42 \mathrm{~W} / \mathrm{mK}$ at the maximum loading. This increase in through-plane thermal conductivity was the greatest of the three single-filler composites studied over the 0 - 15wt\% range; however, as noted earlier, testing of higher wt\% loadings of this filler was not possible. This is due to the very large increase in viscosity that this filler imparts to the composite material, even at very low filler loadings.

\section{Section 8.2: Impact of Carbon Particle on Thermal Conductivity}

Four carbon particles (two synthetic graphites, one natural flake graphite and one calcined needle coke) were screened at 40, 60 and $70 \mathrm{wt} \%$ loadings in Vectra A950RX LCP; the thermal conductivity of the resulting composites was measured in the throughplane direction. The results of this screening study are discussed in Chapter 4; it was noted that at every loading level, Thermocarb TC-300 Synthetic Graphite had the greatest effect on increasing the through-plane thermal conductivity of the composite. On the basis of these results, a second study was conducted using $0-75 \mathrm{wt} \%$ Thermocarb in Vectra; the thermal conductivity of the resulting composites was measured in both the through-plane and in-plane directions. The full results of this study are discussed in Chapter 5; in summary, the through-plane thermal conductivity ranged from $0.22 \mathrm{~W} / \mathrm{mK}$ at $0 \mathrm{wt} \%$ filler loading to $2.624 \mathrm{~W} / \mathrm{mK}$ at $75 \mathrm{wt} \%$ filler loading, while the in-plane 
thermal conductivity ranged from $0.22 \mathrm{~W} / \mathrm{mK}$ at $0 \mathrm{wt} \%$ filler loading to $48.07 \mathrm{~W} / \mathrm{mK}$ at $75 \mathrm{wt} \%$ filler loading. These effects are the largest positive improvement shown to thermal conductivity for any of the fillers studied.

\section{Section 8.3: Impact of Carbon Fiber on Thermal Conductivity}

Fortafil 243 Carbon Fiber was studied at filler loading of $0-60$ wt\% filler in Vectra A950RX LCP; the thermal conductivity of the resulting composites was measured in both the through-plane and in-plane directions. Full results of this study are discussed in Chapter 6; in summary, the through-plane and in-plane thermal conductivities were $0.22 \mathrm{~W} / \mathrm{mK}$ at $0 \mathrm{wt} \%$ filler loading and ranged to $1.030 \mathrm{~W} / \mathrm{mK}$ in the through-plane direction and $2.459 \mathrm{~W} / \mathrm{mK}$ in the in-plane direction at $60 \mathrm{wt} \%$ filler loading. These effects are not as significant as the ones shown by the synthetic graphite as discussed in Chapter 5; however, the geometry of the carbon fiber may be of aid in improving the mechanical properties of a multiple-composite filler.

\section{Section 8.4: Summary of Model Results}

Of the three basic thermal conductivity models analyzed, the Rule of Mixtures model was the best fit for the carbon black composites while the Inverse Rule of Mixtures model was the best fit for the synthetic graphite and carbon fiber composites.

Several things were noted in the analysis of the Nielsen's Model cases. The one of most immediate importance was the fact that the Nielsen's Model, before and after optimization of the 'A' parameter, yielded a negative thermal conductivity result on the last data point of both the synthetic graphite and carbon fiber composites. The Modified Nielsen's Model did not have this problem. The next thing of note is that the Modified 
Nielsen's Model outperformed the Nielsen's Model, even when the negative thermal conductivity result data was dropped from the analysis. As expected, the Optimized Modified Nielsen’s Model outperformed the Modified Nielsen’s Model; however, the optimized 'A' parameters are radically different from the literature values of these parameters in the cases of the carbon black and carbon fiber composites.

\section{Section 8.5: Contributions}

The first contribution to the field was made when analyzing the thermal conductivity of the synthetic graphite composite. The three highest loading samples had in-plane thermal conductivities greater than $20 \mathrm{~W} / \mathrm{mK}$. This is significant in the context of the announced DOE target values for thermal conductivity in bipolar plates. These highly-filled synthetic graphite composites are logical starting places for adjusting the through-plane thermal conductivity of future composites.

The second contribution to the field was made while analyzing the data sets of the synthetic graphite and carbon fiber composites. A relationship was found between the inplane thermal conductivity, the through-plane thermal conductivity, and the volume fraction of filler in a composite sample. Further rearrangement yielded a model that isolated the in-plane thermal conductivity in terms of those other two variables. This is significant because most of the research and model-fitting in the field has been devoted to through-plane thermal conductivity. An in-plane thermal conductivity model, particularly one relating to the through-plane thermal conductivity, has not been as well explored. 


\section{Section 8.6: Recommendations for Future Work}

Based on the work done in the course of generating this dissertation, the following studies are recommended to follow up on questions raised in this work:

1. A $2^{3}$ factorial design (two levels, three variables) should be conducted using the selected fillers to check for the presence or absence of synergistic or antagonistic effects on thermal conductivity. The three variables would be the three fillers; the two levels would be present at a designated level or totally absent.

2. More work should be done with the Modified Nielsen's Model to see if optimization is an accurate reflection on the physical reality of the system; in addition, work should be done to expand this model to account for multiplefiller systems. The work of Weber et al [1-2] is a good starting place for this.

3. A study should be performed to determine the effect that the method of manufacture has on the properties of the composite, if any. All samples studied in this work were prepared by injection molding, which has the effect of inducing at least some degree of orientation of the filler in the sample. Compression molding of composite pellets would be of a more random orientation, which could change the properties of the sample significantly - or possibly not at all. 


\section{Section 8.7: References}

1. E. H. Weber, M. L. Clingerman, and J. A. King, "Thermally Conductive Nylon

6,6 and Polycarbonate Based Resin. Part 1: Synergistic Effects of Carbon Fillers”, Journal of Applied Polymer Science, Vol. 88, pp. 112-122, 2003.

2. E. H. Weber, M. L. Clingerman, and J. A. King, "Thermally Conductive Nylon 6,6 and Polycarbonate Based Resin. Part 2: Modelling”, Journal of Applied Polymer Science, Vol. 88, pp. 123-130, 2003. 
Chapter 9: Appendices 


\section{Section 9.1: Extrusion Screw Designs}

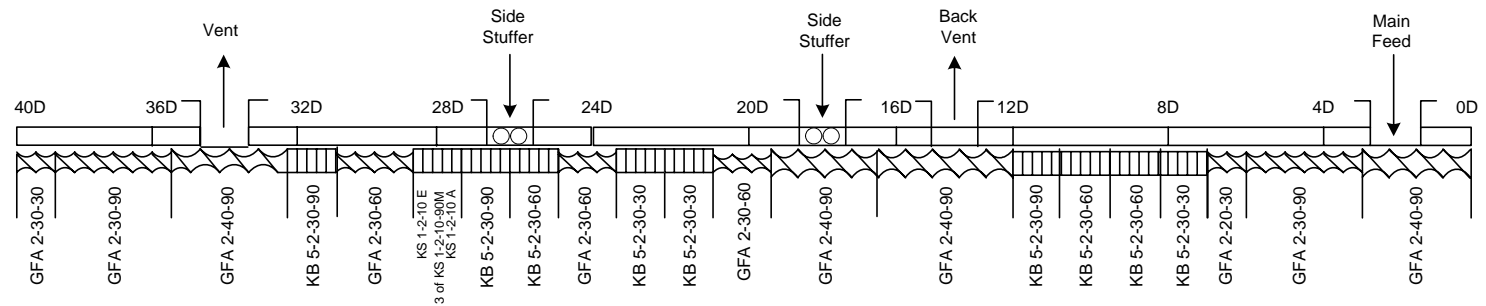

Figure 9.1-1: 5-12-2004 Screw Design (Used for extrusion in this work prior to May 2005)

\section{For Screw Type Elements}

GFA-d-ee-ff

$\mathrm{G}=$ co-rotating $\quad \mathrm{F}=$ conveying

$A=$ free-meshing $\quad d=$ number of threads

ee $=$ pitch (length in millimeters for one complete rotation)

$\mathrm{ff}=$ length of screw elements in millimeters

\section{Kneading disks}

KBj-d-kk-ll $\quad \mathrm{KB}=$ kneading block

$\mathrm{j}=$ number of kneading segments $\mathrm{d}=$ number of threads

$\mathrm{k}=$ length of kneading block in millimeters

$\mathrm{l}=$ twisting angle of the individual kneading segments

\section{Kneading disks}

KS1-d-hh-I $\quad$ KS1 = Kneading disc

$\mathrm{d}=$ number of threads $\quad \mathrm{h}=$ length of kneading disc in millimeters

$\mathrm{i}=\mathrm{A}$ for initial disc and $\mathrm{E}$ for end disc

\section{Zones}

$0 \mathrm{D}$ to $4 \mathrm{D}$ is Zone 1 (water cooled, not heated)

$4 \mathrm{D}$ to $8 \mathrm{D}$ is Zone 2 and Heating Zone 1

$8 \mathrm{D}$ to $12 \mathrm{D}$ is Zone 3 and Heating Zone 2

$12 \mathrm{D}$ to $16 \mathrm{D}$ is Zone 4 and Heating Zone 3

$16 \mathrm{D}$ to $20 \mathrm{D}$ is Zone 5 and Heating Zone 4

$20 \mathrm{D}$ to $24 \mathrm{D}$ is Zone 6 and Heating Zone 5

$24 \mathrm{D}$ to $28 \mathrm{D}$ is Zone 7 and Heating Zone 6

$28 \mathrm{D}$ to $32 \mathrm{D}$ is Zone 8 and Heating Zone 7

32D to 36D is Zone 9 and Heating Zone 8

$36 \mathrm{D}$ to $40 \mathrm{D}$ is Zone 10 and Heating Zone 9

Nozzle is Heating Zone 10 


\section{Section 9.2: Extrusion Conditions}

Notes:

Naming Convention - EXVN where:

$\mathrm{X}$ denotes the filler (A, B, C, D, E, H).

A denotes Ketjenblack EC 600-JD.

B denotes Thermocarb TC-300 Synthetic Graphite.

C denotes Asbury Synthetic Graphite 4012.

D denotes Asbury Natural Flake Graphite 3160.

E denotes Asbury Calcined Needle Coke F108A.

$\mathrm{H}$ denotes Fortafil 243 Carbon Fiber.

$\mathrm{V}$ denotes the matrix material Vectra A950RX LCP.

$\mathrm{N}$ denotes the weight percent of the filler in Vectra.

An $\mathrm{R}$ at the end of the name denotes the first replicate run of the material.

All extrusion dates before 5/14/2005 use the Extrusion Date as shown in Section 9.1, Figure 9.1-1.

All extrusion dates after 5/14/2005 use the Extrusion Date as shown in Section 9.1, Figure 9.1-2.

Feeder Material Codes

EC600 denotes Ketjenblack EC 600-JD.

TC300 denotes Thermocarb TC-300 Synthetic Graphite.

4012 denotes Asbury Synthetic Graphite 4012.

3160 denotes Asbury Natural Flake Graphite 3160.

F108A denotes Asbury Calcined Needle Coke F108A.

F243 denotes Fortafil 243 Carbon Fiber. 
Table 9.2-1: Extrusion Conditions, EAV Composites

\begin{tabular}{|c|c|c|c|c|}
\hline Material Number & EAV2.5 & EAV4R & EAV5R & EAV6 \\
\hline Extrusion Date & $7 / 6 / 2004$ & $7 / 7 / 2004$ & $7 / 7 / 2004$ & $7 / 7 / 2004$ \\
\hline Extruder RPM & 250 & 350 & 275 & 300 \\
\hline Motor Amperage, \% & 63 & 62 & & $63-66$ \\
\hline Melt Temperature, ${ }^{\circ} \mathrm{C}$ & 328 & 320 & 335 & 332 \\
\hline Melt Pressure, psig & $360-380$ & 450 & $390-400$ & $490-540$ \\
\hline \#3 Feeder Setting, lb/hr & 40 & 40 & 38 & 31.33 \\
\hline Material in Feeder \#3 & Vectra & Vectra & Vectra & Vectra \\
\hline \#4 Feeder Setting, lb/hr & 1.03 & 1.67 & 2 & 2 \\
\hline Material in Feeder \#4 & EC600 & EC600 & EC600 & EC600 \\
\hline Vacuum Port & $1 \mathrm{~atm}$ & $1 \mathrm{~atm}$ & $1 \mathrm{~atm}$ & $1 \mathrm{~atm}$ \\
\hline Zone 5 Side Stuffer Setting, rpm & 300 & 300 & 300 & 300 \\
\hline Feeder at Zone 5 & EC600 & EC600 & EC600 & EC600 \\
\hline \multicolumn{5}{|l|}{ Feed Section Temperature } \\
\hline Zone 1 Temperature, ${ }^{\circ} \mathrm{C}$ & 230 & 230 & 230 & 230 \\
\hline Zone 2 Temperature, ${ }^{\circ} \mathrm{C}$ & 250 & 250 & 250 & 250 \\
\hline Zone 3 Temperature, ${ }^{\circ} \mathrm{C}$ & 265 & 257 & 263 & 260 \\
\hline Zone 4 Temperature, ${ }^{\circ} \mathrm{C}$ & 267 & 257 & 263 & 260 \\
\hline Zone 5 Temperature, ${ }^{\circ} \mathrm{C}$ & 268 & 257 & 263 & 260 \\
\hline Zone 6 Temperature, ${ }^{\circ} \mathrm{C}$ & 270 & 258 & 269 & 260 \\
\hline Zone 7 Temperature, ${ }^{\circ} \mathrm{C}$ & 270 & 265 & 270 & 264 \\
\hline Zone 8 Temperature, ${ }^{\circ} \mathrm{C}$ & 270 & 273 & 270 & 270 \\
\hline Zone 9 Temperature, ${ }^{\circ} \mathrm{C}$ & 270 & 280 & 270 & 270 \\
\hline Zone 10 Temperature, ${ }^{\circ} \mathrm{C}$ & 270 & 270 & 270 & 270 \\
\hline Die Type and Gap & $3 \times 3 \mathrm{~mm}$ & $3 \times 3 \mathrm{~mm}$ & $3 \times 3 \mathrm{~mm}$ & $3 \times 3 \mathrm{~mm}$ \\
\hline $\mathrm{H}_{2} \mathrm{O}$ Bath/Conveyor & $\mathrm{H}_{2} \mathrm{O}$ cooled & $\mathrm{H}_{2} \mathrm{O}$ cooled & $\mathrm{H}_{2} \mathrm{O}$ cooled & $\mathrm{H}_{2} \mathrm{O}$ cooled \\
\hline Output Rate, Ibs/hr & 41.03 & 40 & 40 & 33.33 \\
\hline
\end{tabular}


Table 9.2-2: Extrusion Conditions, EAV Composites

\begin{tabular}{|c|c|c|c|}
\hline Material Number & EAV7.5 & EAV10 & EAV15 \\
\hline Extrusion Date & $7 / 7 / 2004$ & $7 / 7 / 2004$ & $7 / 7 / 2004$ \\
\hline Extruder RPM & 320 & 350 & 400 \\
\hline Motor Amperage, \% & $65-67$ & $72-74$ & 84 \\
\hline Melt Temperature, ${ }^{\circ} \mathrm{C}$ & 323 & $320-325$ & 325 \\
\hline Melt Pressure, psig & $600-650$ & $1150-1190$ & $1660-1760$ \\
\hline \#3 Feeder Setting, lb/hr & 24.67 & 18 & 11.33 \\
\hline Material in Feeder \#3 & Vectra & Vectra & Vectra \\
\hline \#4 Feeder Setting, lb/hr & 2 & 2 & 2 \\
\hline Material in Feeder \#4 & EC600 & EC600 & EC600 \\
\hline Vacuum Port & $1 \mathrm{~atm}$ & $1 \mathrm{~atm}$ & $1 \mathrm{~atm}$ \\
\hline Zone 5 Side Stuffer Setting, rpm & 300 & 300 & 300 \\
\hline Feeder at Zone 5 & EC600 & EC600 & EC600 \\
\hline \multicolumn{4}{|l|}{ Feed Section Temperature } \\
\hline Zone 1 Temperature, ${ }^{\circ} \mathrm{C}$ & 230 & 230 & 230 \\
\hline Zone 2 Temperature, ${ }^{\circ} \mathrm{C}$ & 250 & 250 & 250 \\
\hline Zone 3 Temperature, ${ }^{\circ} \mathrm{C}$ & 258 & 257 & 257 \\
\hline Zone 4 Temperature, ${ }^{\circ} \mathrm{C}$ & 258 & 257 & 257 \\
\hline Zone 5 Temperature, ${ }^{\circ} \mathrm{C}$ & 258 & 257 & 257 \\
\hline Zone 6 Temperature, ${ }^{\circ} \mathrm{C}$ & 259 & 258 & 258 \\
\hline Zone 7 Temperature, ${ }^{\circ} \mathrm{C}$ & 259 & 258 & 258 \\
\hline Zone 8 Temperature, ${ }^{\circ} \mathrm{C}$ & 265 & 263 & 263 \\
\hline Zone 9 Temperature, ${ }^{\circ} \mathrm{C}$ & 270 & 270 & 270 \\
\hline Zone 10 Temperature, ${ }^{\circ} \mathrm{C}$ & 270 & 270 & 270 \\
\hline Die Type and Gap & $3 \times 3 \mathrm{~mm}$ & $3 \times 3 \mathrm{~mm}$ & $3 \times 3 \mathrm{~mm}$ \\
\hline $\mathrm{H}_{2} \mathrm{O}$ Bath/Conveyor & $\mathrm{H}_{2} \mathrm{O}$ cooled & $\mathrm{H}_{2} \mathrm{O}$ cooled & $\mathrm{H}_{2} \mathrm{O}$ cooled \\
\hline Output Rate, Ibs/hr & 26.67 & 20 & 13.33 \\
\hline
\end{tabular}


Table 9.2-3: Extrusion Conditions, EBV Composites

\begin{tabular}{|c|c|c|c|c|}
\hline Material Number & EBV10 & EBV15 & EBV20 & EBV25 \\
\hline Extrusion Date & $11 / 17 / 2004$ & $11 / 17 / 2004$ & $11 / 17 / 2004$ & $6 / 7 / 2005$ \\
\hline Extruder RPM & 250 & 250 & 250 & 300 \\
\hline Motor Amperage, $\%$ & 62 & 49 & 46 & 53 \\
\hline Melt Temperature, ${ }^{\circ} \mathrm{C}$ & 315 & 323 & 325 & 333 \\
\hline Melt Pressure, psig & 360 & 350 & 360 & 340 \\
\hline \#3 Feeder Setting, lb/hr & 4.3 & 4.3 & 5 & 10 \\
\hline Material in Feeder \#3 & TC300 & TC300 & TC300 & TC300 \\
\hline \#4 Feeder Setting, lb/hr & 38.7 & 24.4 & 20 & 30 \\
\hline Material in Feeder \#4 & Vectra & Vectra & Vectra & Vectra \\
\hline Vacuum Port & $1 \mathrm{~atm}$ & $1 \mathrm{~atm}$ & $1 \mathrm{~atm}$ & $1 \mathrm{~atm}$ \\
\hline Zone 5 Side Stuffer Setting, rpm & 300 & 300 & 300 & 300 \\
\hline Feeder at Zone 5 & TC300 & TC300 & TC300 & TC300 \\
\hline \multicolumn{5}{|l|}{ Feed Section Temperature } \\
\hline Zone 1 Temperature, ${ }^{\circ} \mathrm{C}$ & 230 & 230 & 230 & 230 \\
\hline Zone 2 Temperature, ${ }^{\circ} \mathrm{C}$ & 250 & 250 & 250 & 250 \\
\hline Zone 3 Temperature, ${ }^{\circ} \mathrm{C}$ & 258 & 258 & 258 & 258 \\
\hline Zone 4 Temperature, ${ }^{\circ} \mathrm{C}$ & 258 & 258 & 258 & 258 \\
\hline Zone 5 Temperature, ${ }^{\circ} \mathrm{C}$ & 258 & 258 & 258 & 258 \\
\hline Zone 6 Temperature, ${ }^{\circ} \mathrm{C}$ & 259 & 259 & 259 & 259 \\
\hline Zone 7 Temperature, ${ }^{\circ} \mathrm{C}$ & 259 & 259 & 259 & 259 \\
\hline Zone 8 Temperature, ${ }^{\circ} \mathrm{C}$ & 265 & 265 & 265 & 265 \\
\hline Zone 9 Temperature, ${ }^{\circ} \mathrm{C}$ & 270 & 270 & 270 & 270 \\
\hline Zone 10 Temperature, ${ }^{\circ} \mathrm{C}$ & 270 & 270 & 270 & 270 \\
\hline Die Type and Gap & $3 \times 3 \mathrm{~mm}$ & $3 \times 3 \mathrm{~mm}$ & $3 \times 3 \mathrm{~mm}$ & $3 \times 3 \mathrm{~mm}$ \\
\hline $\mathrm{H}_{2} \mathrm{O}$ Bath/Conveyor & $\mathrm{H}_{2} \mathrm{O}$ cooled & $\mathrm{H}_{2} \mathrm{O}$ cooled & $\mathrm{H}_{2} \mathrm{O}$ cooled & $\mathrm{H}_{2} \mathrm{O}$ cooled \\
\hline Output Rate, Ibs/hr & 43 & 28.7 & 25 & 40 \\
\hline
\end{tabular}


Table 9.2-4: Extrusion Conditions, EBV Composites

\begin{tabular}{|c|c|c|c|c|}
\hline Material Number & EBV30 & EBV35 & EBV40 & EBV45 \\
\hline Extrusion Date & $11 / 17 / 2004$ & $6 / 7 / 2005$ & $5 / 12 / 2004$ & $6 / 7 / 2005$ \\
\hline Extruder RPM & 300 & 300 & 300 & 300 \\
\hline Motor Amperage, \% & 49 & 48 & 37 & 50 \\
\hline Melt Temperature, ${ }^{\circ} \mathrm{C}$ & 324 & 330 & 336 & 323 \\
\hline Melt Pressure, psig & 390 & 330 & 390 & 400 \\
\hline \#3 Feeder Setting, lb/hr & 10 & 12 & 12 & 15 \\
\hline Material in Feeder \#3 & TC300 & TC300 & TC300 & TC300 \\
\hline \#4 Feeder Setting, lb/hr & 23.3 & 22.3 & 18 & 18.3 \\
\hline Material in Feeder \#4 & Vectra & Vectra & Vectra & Vectra \\
\hline Vacuum Port & $1 \mathrm{~atm}$ & $1 \mathrm{~atm}$ & $1 \mathrm{~atm}$ & $1 \mathrm{~atm}$ \\
\hline Zone 5 Side Stuffer Setting, rpm & 300 & 300 & 300 & 300 \\
\hline Feeder at Zone 5 & TC300 & TC300 & TC300 & TC300 \\
\hline \multicolumn{5}{|l|}{ Feed Section Temperature } \\
\hline Zone 1 Temperature, ${ }^{\circ} \mathrm{C}$ & 230 & 230 & 230 & 230 \\
\hline Zone 2 Temperature, ${ }^{\circ} \mathrm{C}$ & 250 & 250 & 250 & 250 \\
\hline Zone 3 Temperature, ${ }^{\circ} \mathrm{C}$ & 258 & 258 & 280 & 258 \\
\hline Zone 4 Temperature, ${ }^{\circ} \mathrm{C}$ & 258 & 258 & 285 & 258 \\
\hline Zone 5 Temperature, ${ }^{\circ} \mathrm{C}$ & 258 & 258 & 285 & 258 \\
\hline Zone 6 Temperature, ${ }^{\circ} \mathrm{C}$ & 259 & 259 & 285 & 259 \\
\hline Zone 7 Temperature, ${ }^{\circ} \mathrm{C}$ & 259 & 259 & 285 & 259 \\
\hline Zone 8 Temperature, ${ }^{\circ} \mathrm{C}$ & 265 & 265 & 285 & 265 \\
\hline Zone 9 Temperature, ${ }^{\circ} \mathrm{C}$ & 270 & 270 & 285 & 270 \\
\hline Zone 10 Temperature, ${ }^{\circ} \mathrm{C}$ & 270 & 270 & 285 & 270 \\
\hline Die Type and Gap & $3 \times 3 \mathrm{~mm}$ & $3 \times 3 \mathrm{~mm}$ & $3 \times 3 \mathrm{~mm}$ & $3 \times 3 \mathrm{~mm}$ \\
\hline $\mathrm{H}_{2} \mathrm{O}$ Bath/Conveyor & $\mathrm{H}_{2} \mathrm{O}$ cooled & $\mathrm{H}_{2} \mathrm{O}$ Cooled & $\mathrm{H}_{2} \mathrm{O}$ Cooled & $\mathrm{H}_{2} \mathrm{O}$ Cooled \\
\hline Output Rate, Ibs/hr & 33.3 & 34.3 & 30 & 33.3 \\
\hline
\end{tabular}


Table 9.2-5: Extrusion Conditions, EBV Composites

\begin{tabular}{|c|c|c|c|c|}
\hline Material Number & EBV50 & EBV50R & EBV55 & EBV60 \\
\hline Extrusion Date & $12 / 1 / 2004$ & $6 / 7 / 2005$ & $12 / 1 / 2004$ & $5 / 12 / 2004$ \\
\hline Extruder RPM & 320 & 300 & 350 & 346 \\
\hline Motor Amperage, $\%$ & 51 & 48 & 51 & 40 \\
\hline Melt Temperature, ${ }^{\circ} \mathrm{C}$ & 324 & 337 & 324 & 337 \\
\hline Melt Pressure, psig & 520 & 490 & 590 & 650 \\
\hline \#3 Feeder Setting, lb/hr & 15 & 16 & 16 & 18 \\
\hline Material in Feeder \#3 & TC300 & TC300 & TC300 & TC300 \\
\hline \#4 Feeder Setting, lb/hr & 15 & 13.1 & 13.1 & 12 \\
\hline Material in Feeder \#4 & Vectra & Vectra & Vectra & Vectra \\
\hline Vacuum Port & $1 \mathrm{~atm}$ & $1 \mathrm{~atm}$ & $1 \mathrm{~atm}$ & $1 \mathrm{~atm}$ \\
\hline Zone 5 Side Stuffer Setting, rpm & 300 & 300 & 300 & 300 \\
\hline Feeder at Zone 5 & TC300 & TC300 & TC300 & TC300 \\
\hline \multicolumn{5}{|l|}{ Feed Section Temperature } \\
\hline Zone 1 Temperature, ${ }^{\circ} \mathrm{C}$ & 230 & 230 & 230 & 230 \\
\hline Zone 2 Temperature, ${ }^{\circ} \mathrm{C}$ & 250 & 250 & 250 & 250 \\
\hline Zone 3 Temperature, ${ }^{\circ} \mathrm{C}$ & 258 & 258 & 258 & 280 \\
\hline Zone 4 Temperature, ${ }^{\circ} \mathrm{C}$ & 258 & 258 & 258 & 285 \\
\hline Zone 5 Temperature, ${ }^{\circ} \mathrm{C}$ & 258 & 258 & 258 & 285 \\
\hline Zone 6 Temperature, ${ }^{\circ} \mathrm{C}$ & 259 & 259 & 259 & 285 \\
\hline Zone 7 Temperature, ${ }^{\circ} \mathrm{C}$ & 259 & 259 & 259 & 285 \\
\hline Zone 8 Temperature, ${ }^{\circ} \mathrm{C}$ & 265 & 265 & 265 & 285 \\
\hline Zone 9 Temperature, ${ }^{\circ} \mathrm{C}$ & 270 & 270 & 270 & 285 \\
\hline Zone 10 Temperature, ${ }^{\circ} \mathrm{C}$ & 270 & 270 & 270 & 290 \\
\hline Die Type and Gap & $3 \times 3 \mathrm{~mm}$ & $3 \times 3 \mathrm{~mm}$ & $3 \times 3 \mathrm{~mm}$ & $3 \times 3 \mathrm{~mm}$ \\
\hline $\mathrm{H}_{2} \mathrm{O}$ Bath/Conveyor & $\mathrm{H}_{2} \mathrm{O}$ Cooled & $\mathrm{H}_{2} \mathrm{O}$ Cooled & $\mathrm{H}_{2} \mathrm{O}$ Cooled & $\mathrm{H}_{2} \mathrm{O}$ Cooled \\
\hline Output Rate, Ibs/hr & 30 & 29.1 & 29.1 & 30 \\
\hline
\end{tabular}




\section{Table 9.2-6: Extrusion Conditions, EBV Composites}

\begin{tabular}{|c|c|c|c|c|}
\hline Material Number & EBV60R & EBV65 & EBV70 & EBV70R \\
\hline Extrusion Date & $6 / 7 / 2005$ & $12 / 1 / 2004$ & $12 / 1 / 2004$ & $6 / 7 / 2005$ \\
\hline Extruder RPM & 350 & 400 & 400 & 400 \\
\hline Motor Amperage, \% & $50-54$ & 49 & 46 & 43 \\
\hline Melt Temperature, ${ }^{\circ} \mathrm{C}$ & 337 & 311 & 324 & 358 \\
\hline Melt Pressure, psig & 580 & 730 & $700-1000$ & 730 \\
\hline \#3 Feeder Setting, Ib/hr & 18 & 16 & 12 & 11 \\
\hline Material in Feeder \#3 & TC300 & TC300 & TC300 & TC300 \\
\hline \#4 Feeder Setting, Ib/hr & 12 & 8.6 & 5.1 & 4.7 \\
\hline Material in Feeder \#4 & Vectra & Vectra & Vectra & Vectra \\
\hline Vacuum Port & $1 \mathrm{~atm}$ & $1 \mathrm{~atm}$ & $1 \mathrm{~atm}$ & $1 \mathrm{~atm}$ \\
\hline Zone 5 Side Stuffer Setting, rpm & 300 & 300 & 300 & 300 \\
\hline Feeder at Zone 5 & TC300 & TC300 & TC300 & TC300 \\
\hline \multicolumn{5}{|l|}{ Feed Section Temperature } \\
\hline Zone 1 Temperature, ${ }^{\circ} \mathrm{C}$ & 230 & 230 & 230 & 230 \\
\hline Zone 2 Temperature, ${ }^{\circ} \mathrm{C}$ & 250 & 250 & 250 & 250 \\
\hline Zone 3 Temperature, ${ }^{\circ} \mathrm{C}$ & 258 & 258 & 258 & 258 \\
\hline Zone 4 Temperature, ${ }^{\circ} \mathrm{C}$ & 258 & 258 & 258 & 258 \\
\hline Zone 5 Temperature, ${ }^{\circ} \mathrm{C}$ & 258 & 258 & 258 & 258 \\
\hline Zone 6 Temperature, ${ }^{\circ} \mathrm{C}$ & 259 & 259 & 259 & 259 \\
\hline Zone 7 Temperature, ${ }^{\circ} \mathrm{C}$ & 259 & 259 & 259 & 259 \\
\hline Zone 8 Temperature, ${ }^{\circ} \mathrm{C}$ & 265 & 265 & 265 & 265 \\
\hline Zone 9 Temperature, ${ }^{\circ} \mathrm{C}$ & 270 & 270 & 270 & 265 \\
\hline Zone 10 Temperature, ${ }^{\circ} \mathrm{C}$ & 260 & 270 & 270 & 265 \\
\hline Die Type and Gap & $3 \times 3 \mathrm{~mm}$ & $3 \times 3 \mathrm{~mm}$ & $3 \times 3 \mathrm{~mm}$ & $3 \times 3 \mathrm{~mm}$ \\
\hline $\mathrm{H}_{2} \mathrm{O}$ Bath/Conveyor & $\mathrm{H}_{2} \mathrm{O}$ Cooled & $\mathrm{H}_{2} \mathrm{O}$ Cooled & $\mathrm{H}_{2} \mathrm{O}$ Cooled & $\mathrm{H}_{2} \mathrm{O}$ Cooled \\
\hline Output Rate, Ibs/hr & 30 & 24.6 & 17.1 & 15.7 \\
\hline
\end{tabular}


Table 9.2-7: Extrusion Conditions, EBV Composites

\begin{tabular}{|c|c|c|c|c|}
\hline Material Number & EBV75 & EBV75R & EBV80 & EBV80R \\
\hline Extrusion Date & $12 / 1 / 2004$ & $6 / 7 / 2005$ & $5 / 12 / 2004$ & $6 / 7 / 2005$ \\
\hline Extruder RPM & $400-450$ & 420 & 450 & 450 \\
\hline Motor Amperage, $\%$ & $45-48$ & 46 & 34 & 44 \\
\hline Melt Temperature, ${ }^{\circ} \mathrm{C}$ & 330 & 352 & 360 & 351 \\
\hline Melt Pressure, psig & $1000-1300$ & 1100 & 1140 & 1230 \\
\hline \#3 Feeder Setting, lb/hr & 14 & 14 & 16 & 16 \\
\hline Material in Feeder \#3 & TC300 & TC300 & TC300 & TC300 \\
\hline \#4 Feeder Setting, Ib/hr & 4.7 & 4.7 & 4 & 4 \\
\hline Material in Feeder \#4 & Vectra & Vectra & Vectra & Vectra \\
\hline Vacuum Port & $1 \mathrm{~atm}$ & $1 \mathrm{~atm}$ & $1 \mathrm{~atm}$ & $1 \mathrm{~atm}$ \\
\hline Zone 5 Side Stuffer Setting, rpm & 300 & 300 & 300 & 300 \\
\hline Feeder at Zone 5 & TC300 & TC300 & TC300 & TC300 \\
\hline \multicolumn{5}{|l|}{ Feed Section Temperature } \\
\hline Zone 1 Temperature, ${ }^{\circ} \mathrm{C}$ & 230 & 230 & 230 & 230 \\
\hline Zone 2 Temperature, ${ }^{\circ} \mathrm{C}$ & 250 & 250 & 250 & 250 \\
\hline Zone 3 Temperature, ${ }^{\circ} \mathrm{C}$ & 258 & 258 & 280 & 258 \\
\hline Zone 4 Temperature, ${ }^{\circ} \mathrm{C}$ & 258 & 258 & 285 & 258 \\
\hline Zone 5 Temperature, ${ }^{\circ} \mathrm{C}$ & 258 & 258 & 285 & 258 \\
\hline Zone 6 Temperature, ${ }^{\circ} \mathrm{C}$ & 259 & 259 & 285 & 259 \\
\hline Zone 7 Temperature, ${ }^{\circ} \mathrm{C}$ & 259 & 259 & 285 & 255 \\
\hline Zone 8 Temperature, ${ }^{\circ} \mathrm{C}$ & 265 & 260 & 285 & 257 \\
\hline Zone 9 Temperature, ${ }^{\circ} \mathrm{C}$ & 270 & 260 & 285 & 257 \\
\hline Zone 10 Temperature, ${ }^{\circ} \mathrm{C}$ & 270 & 250 & 320 & 250 \\
\hline Die Type and Gap & $3 \times 3 \mathrm{~mm}$ & $3 \times 3 \mathrm{~mm}$ & $3 \times 3 \mathrm{~mm}$ & $3 \times 3 \mathrm{~mm}$ \\
\hline $\mathrm{H}_{2} \mathrm{O}$ Bath/Conveyor & $\mathrm{H}_{2} \mathrm{O}$ Cooled & $\mathrm{H}_{2} \mathrm{O}$ Cooled & $\mathrm{H}_{2} \mathrm{O}$ Cooled & $\mathrm{H}_{2} \mathrm{O}$ Cooled \\
\hline Output Rate, Ibs/hr & 18.7 & 18.7 & 20 & 20 \\
\hline
\end{tabular}


Table 9.2-8: Extrusion Conditions, ECV Composites

\begin{tabular}{|c|c|c|c|c|}
\hline Material Number & ECV40 & ECV60 & ECV70 & ECV80 \\
\hline Extrusion Date & $5 / 12 / 2004$ & $5 / 12 / 2004$ & $5 / 12 / 2004$ & $5 / 12 / 2004$ \\
\hline Extruder RPM & 300 & 350 & 375 & 450 \\
\hline Motor Amperage, $\%$ & 33 & 30 & 33 & 31 \\
\hline Melt Temperature, ${ }^{\circ} \mathrm{C}$ & 305 & 300 & 312 & 360 \\
\hline Melt Pressure, psig & 300 & 460 & 870 & $900-1100$ \\
\hline \#3 Feeder Setting, lb/hr & 11 & 11 & 11 & 11 \\
\hline Material in Feeder \#3 & 4012 & 4012 & 4012 & 4012 \\
\hline \#4 Feeder Setting, Ib/hr & 16.5 & 7.3 & 4.7 & 2.75 \\
\hline Material in Feeder \#4 & Vectra & Vectra & Vectra & Vectra \\
\hline Vacuum Port & $1 \mathrm{~atm}$ & $1 \mathrm{~atm}$ & 1 atm & $1 \mathrm{~atm}$ \\
\hline Zone 5 Side Stuffer Setting, rpm & 300 & 300 & 300 & 300 \\
\hline Feeder at Zone 5 & 4012 & 4012 & 4012 & 4012 \\
\hline \multicolumn{5}{|l|}{ Feed Section Temperature } \\
\hline Zone 1 Temperature, ${ }^{\circ} \mathrm{C}$ & 230 & 230 & 230 & 230 \\
\hline Zone 2 Temperature, ${ }^{\circ} \mathrm{C}$ & 250 & 250 & 250 & 250 \\
\hline Zone 3 Temperature, ${ }^{\circ} \mathrm{C}$ & 280 & 280 & 280 & 280 \\
\hline Zone 4 Temperature, ${ }^{\circ} \mathrm{C}$ & 280 & 280 & 280 & 280 \\
\hline Zone 5 Temperature, ${ }^{\circ} \mathrm{C}$ & 285 & 285 & 285 & 285 \\
\hline Zone 6 Temperature, ${ }^{\circ} \mathrm{C}$ & 285 & 285 & 285 & 285 \\
\hline Zone 7 Temperature, ${ }^{\circ} \mathrm{C}$ & 285 & 285 & 285 & 285 \\
\hline Zone 8 Temperature, ${ }^{\circ} \mathrm{C}$ & 285 & 285 & 285 & 285 \\
\hline Zone 9 Temperature, ${ }^{\circ} \mathrm{C}$ & 285 & 285 & 285 & 285 \\
\hline Zone 10 Temperature, ${ }^{\circ} \mathrm{C}$ & 260 & 260 & 270 & 310 \\
\hline Die Type and Gap & $3 \times 3 \mathrm{~mm}$ & $3 \times 3 \mathrm{~mm}$ & $3 \times 3 \mathrm{~mm}$ & $3 \times 3 \mathrm{~mm}$ \\
\hline $\mathrm{H}_{2} \mathrm{O}$ Bath/Conveyor & $\mathrm{H}_{2} \mathrm{O}$ Cooled & $\mathrm{H}_{2} \mathrm{O}$ Cooled & $\mathrm{H}_{2} \mathrm{O}$ Cooled & $\mathrm{H}_{2} \mathrm{O}$ Cooled \\
\hline Output Rate, Ibs/hr & 27.5 & 18.3 & 15.7 & 13.75 \\
\hline
\end{tabular}


Table 9.2-9: Extrusion Conditions, EDV Composites

\begin{tabular}{|c|c|c|c|}
\hline Material Number & EDV40 & EDV60 & EDV70 \\
\hline Extrusion Date & $7 / 6 / 2004$ & $7 / 6 / 2004$ & $7 / 6 / 2004$ \\
\hline Extruder RPM & 300 & 350 & 375 \\
\hline Motor Amperage, $\%$ & 40 & 40 & 35 \\
\hline Melt Temperature, ${ }^{\circ} \mathrm{C}$ & 318 & 316 & 316 \\
\hline Melt Pressure, psig & $360-380$ & $540-570$ & $700-760$ \\
\hline \#3 Feeder Setting, lb/hr & 12 & 12 & 12 \\
\hline Material in Feeder \#3 & 3160 & 3160 & 3160 \\
\hline \#4 Feeder Setting, lb/hr & 18 & 12 & 11 \\
\hline Material in Feeder \#4 & Vectra & Vectra & Vectra \\
\hline Vacuum Port & $1 \mathrm{~atm}$ & $1 \mathrm{~atm}$ & $1 \mathrm{~atm}$ \\
\hline Zone 5 Side Stuffer Setting, rpm & 300 & 300 & 300 \\
\hline Feeder at Zone 5 & 3160 & 3160 & 3160 \\
\hline \multicolumn{4}{|l|}{ Feed Section Temperature } \\
\hline Zone 1 Temperature, ${ }^{\circ} \mathrm{C}$ & 230 & 230 & 230 \\
\hline Zone 2 Temperature, ${ }^{\circ} \mathrm{C}$ & 250 & 250 & 250 \\
\hline Zone 3 Temperature, ${ }^{\circ} \mathrm{C}$ & 270 & 270 & 270 \\
\hline Zone 4 Temperature, ${ }^{\circ} \mathrm{C}$ & 280 & 280 & 280 \\
\hline Zone 5 Temperature, ${ }^{\circ} \mathrm{C}$ & 280 & 280 & 280 \\
\hline Zone 6 Temperature, ${ }^{\circ} \mathrm{C}$ & 282 & 280 & 277 \\
\hline Zone 7 Temperature, ${ }^{\circ} \mathrm{C}$ & 282 & 280 & 271 \\
\hline Zone 8 Temperature, ${ }^{\circ} \mathrm{C}$ & 280 & 275 & 271 \\
\hline Zone 9 Temperature, ${ }^{\circ} \mathrm{C}$ & 277 & 273 & 270 \\
\hline Zone 10 Temperature, ${ }^{\circ} \mathrm{C}$ & 270 & 270 & 270 \\
\hline Die Type and Gap & $3 \times 3 \mathrm{~mm}$ & $3 \times 3 \mathrm{~mm}$ & $3 \times 3 \mathrm{~mm}$ \\
\hline $\mathrm{H}_{2} \mathrm{O}$ Bath/Conveyor & $\mathrm{H}_{2} \mathrm{O}$ Cooled & $\mathrm{H}_{2} \mathrm{O}$ Cooled & $\mathrm{H}_{2} \mathrm{O}$ Cooled \\
\hline Output Rate, Ibs/hr & 30 & 30 & 15.7 \\
\hline
\end{tabular}




\section{Table 9.2-10: Extrusion Conditions, EEV Composites}

\begin{tabular}{|c|c|c|c|}
\hline Material Number & EEV40 & EEV60 & EEV70 \\
\hline Extrusion Date & $7 / 6 / 2004$ & $7 / 6 / 2004$ & $7 / 6 / 2004$ \\
\hline Extruder RPM & 300 & 350 & 375 \\
\hline Motor Amperage, \% & 39 & 40 & 34 \\
\hline Melt Temperature, ${ }^{\circ} \mathrm{C}$ & 315 & 314 & 316 \\
\hline Melt Pressure, psig & 340 & 440 & $510-530$ \\
\hline \#3 Feeder Setting, lb/hr & 12 & 18 & 11 \\
\hline Material in Feeder \#3 & F108A & F108A & F108A \\
\hline \#4 Feeder Setting, lb/hr & 18 & 12 & 4.7 \\
\hline Material in Feeder \#4 & Vectra & Vectra & Vectra \\
\hline Vacuum Port & $1 \mathrm{~atm}$ & $1 \mathrm{~atm}$ & $1 \mathrm{~atm}$ \\
\hline Zone 5 Side Stuffer Setting, rpm & 300 & 300 & 300 \\
\hline Feeder at Zone 5 & F108A & F108A & F108A \\
\hline \multicolumn{4}{|l|}{ Feed Section Temperature } \\
\hline Zone 1 Temperature, ${ }^{\circ} \mathrm{C}$ & 230 & 230 & 230 \\
\hline Zone 2 Temperature, ${ }^{\circ} \mathrm{C}$ & 250 & 250 & 250 \\
\hline Zone 3 Temperature, ${ }^{\circ} \mathrm{C}$ & 270 & 270 & 270 \\
\hline Zone 4 Temperature, ${ }^{\circ} \mathrm{C}$ & 280 & 280 & 280 \\
\hline Zone 5 Temperature, ${ }^{\circ} \mathrm{C}$ & 280 & 280 & 280 \\
\hline Zone 6 Temperature, ${ }^{\circ} \mathrm{C}$ & 277 & 275 & 280 \\
\hline Zone 7 Temperature, ${ }^{\circ} \mathrm{C}$ & 271 & 271 & 270 \\
\hline Zone 8 Temperature, ${ }^{\circ} \mathrm{C}$ & 271 & 271 & 270 \\
\hline Zone 9 Temperature, ${ }^{\circ} \mathrm{C}$ & 270 & 270 & 270 \\
\hline Zone 10 Temperature, ${ }^{\circ} \mathrm{C}$ & 270 & 270 & 270 \\
\hline Die Type and Gap & $3 \times 3 \mathrm{~mm}$ & $3 \times 3 \mathrm{~mm}$ & $3 \times 3 \mathrm{~mm}$ \\
\hline $\mathrm{H}_{2} \mathrm{O}$ Bath/Conveyor & $\mathrm{H}_{2} \mathrm{O}$ Cooled & $\mathrm{H}_{2} \mathrm{O}$ Cooled & $\mathrm{H}_{2} \mathrm{O}$ Cooled \\
\hline Output Rate, Ibs/hr & 30 & 30 & 15.7 \\
\hline
\end{tabular}




\section{Table 9.2-11: Extrusion Conditions, EHV Composites}

\begin{tabular}{|c|c|c|c|c|}
\hline Material Number & EHV5 & EHV7.5 & EHV10 & EHV15 \\
\hline Extrusion Date & $12 / 5 / 2005$ & $12 / 5 / 2005$ & $12 / 5 / 2005$ & $12 / 5 / 2005$ \\
\hline Extruder RPM & 250 & 250 & 250 & 300 \\
\hline Motor Amperage, \% & 58 & 52 & $52-57$ & 50 \\
\hline Melt Temperature, ${ }^{\circ} \mathrm{C}$ & 325 & 315 & $321-323$ & $325-328$ \\
\hline Melt Pressure, psig & 280 & 250 & $240-260$ & $250-310$ \\
\hline \#3 Feeder Setting, Ib/hr & 2 & 2.5 & 3 & 5 \\
\hline Material in Feeder \#3 & F243 & F243 & F243 & F243 \\
\hline \#4 Feeder Setting, Ib/hr & 38 & 30.83 & 27 & 28.33 \\
\hline Material in Feeder \#4 & Vectra & Vectra & Vectra & Vectra \\
\hline Vacuum Port & $1 \mathrm{~atm}$ & $1 \mathrm{~atm}$ & $1 \mathrm{~atm}$ & $1 \mathrm{~atm}$ \\
\hline Zone 5 Side Stuffer Setting, rpm & 300 & 300 & 300 & 300 \\
\hline Feeder at Zone 5 & F243 & F243 & F243 & $\mathrm{F} 243$ \\
\hline \multicolumn{5}{|l|}{ Feed Section Temperature } \\
\hline Zone 1 Temperature, ${ }^{\circ} \mathrm{C}$ & 230 & 230 & 230 & 230 \\
\hline Zone 2 Temperature, ${ }^{\circ} \mathrm{C}$ & 250 & 250 & 250 & 250 \\
\hline Zone 3 Temperature, ${ }^{\circ} \mathrm{C}$ & 255 & 255 & 255 & 255 \\
\hline Zone 4 Temperature, ${ }^{\circ} \mathrm{C}$ & 255 & 255 & 255 & 255 \\
\hline Zone 5 Temperature, ${ }^{\circ} \mathrm{C}$ & 255 & 255 & 255 & 255 \\
\hline Zone 6 Temperature, ${ }^{\circ} \mathrm{C}$ & 255 & 255 & 255 & 255 \\
\hline Zone 7 Temperature, ${ }^{\circ} \mathrm{C}$ & 255 & 255 & 255 & 255 \\
\hline Zone 8 Temperature, ${ }^{\circ} \mathrm{C}$ & 255 & 255 & 255 & 255 \\
\hline Zone 9 Temperature, ${ }^{\circ} \mathrm{C}$ & 255 & 255 & 255 & 255 \\
\hline Zone 10 Temperature, ${ }^{\circ} \mathrm{C}$ & 250 & 250 & 250 & 250 \\
\hline Die Type and Gap & $3 \times 3 \mathrm{~mm}$ & $3 \times 3 \mathrm{~mm}$ & $3 \times 3 \mathrm{~mm}$ & $3 \times 3 \mathrm{~mm}$ \\
\hline $\mathrm{H}_{2} \mathrm{O}$ Bath/Conveyor & $\mathrm{H}_{2} \mathrm{O}$ Cooled & $\mathrm{H}_{2} \mathrm{O}$ Cooled & $\mathrm{H}_{2} \mathrm{O}$ Cooled & $\mathrm{H}_{2} \mathrm{O}$ Cooled \\
\hline Output Rate, Ibs/hr & 40 & 32.83 & 30 & 33.33 \\
\hline
\end{tabular}


Table 9.2-12: Extrusion Conditions, EHV Composites

\begin{tabular}{|c|c|c|c|c|}
\hline Material Number & EHV20 & EHV25 & EHV30 & EHV35 \\
\hline Extrusion Date & $12 / 5 / 2005$ & $12 / 5 / 2005$ & $12 / 6 / 2005$ & $12 / 6 / 2005$ \\
\hline Extruder RPM & 300 & 300 & 325 & 325 \\
\hline Motor Amperage, \% & $44-52$ & $41-43$ & $48-50$ & $46-47$ \\
\hline Melt Temperature, ${ }^{\circ} \mathrm{C}$ & 326 & 322 & 334 & 334 \\
\hline Melt Pressure, psig & 240 & $270-300$ & $290-370$ & $360-380$ \\
\hline \#3 Feeder Setting, lb/hr & 6 & 6 & 9 & 10.5 \\
\hline Material in Feeder \#3 & F243 & F243 & F243 & $\mathrm{F} 243$ \\
\hline \#4 Feeder Setting, lb/hr & 24 & 18 & 21 & 19.5 \\
\hline Material in Feeder \#4 & Vectra & Vectra & Vectra & Vectra \\
\hline Vacuum Port & $1 \mathrm{~atm}$ & $1 \mathrm{~atm}$ & $1 \mathrm{~atm}$ & $1 \mathrm{~atm}$ \\
\hline Zone 5 Side Stuffer Setting, rpm & 300 & 300 & 300 & 300 \\
\hline Feeder at Zone 5 & F243 & F243 & F243 & F243 \\
\hline \multicolumn{5}{|l|}{ Feed Section Temperature } \\
\hline Zone 1 Temperature, ${ }^{\circ} \mathrm{C}$ & 230 & 230 & 230 & 230 \\
\hline Zone 2 Temperature, ${ }^{\circ} \mathrm{C}$ & 250 & 250 & 250 & 250 \\
\hline Zone 3 Temperature, ${ }^{\circ} \mathrm{C}$ & 255 & 255 & 255 & 255 \\
\hline Zone 4 Temperature, ${ }^{\circ} \mathrm{C}$ & 255 & 255 & 255 & 255 \\
\hline Zone 5 Temperature, ${ }^{\circ} \mathrm{C}$ & 255 & 255 & 255 & 255 \\
\hline Zone 6 Temperature, ${ }^{\circ} \mathrm{C}$ & 255 & 255 & 255 & 255 \\
\hline Zone 7 Temperature, ${ }^{\circ} \mathrm{C}$ & 255 & 255 & 255 & 255 \\
\hline Zone 8 Temperature, ${ }^{\circ} \mathrm{C}$ & 255 & 255 & 250 & 250 \\
\hline Zone 9 Temperature, ${ }^{\circ} \mathrm{C}$ & 255 & 255 & 250 & 250 \\
\hline Zone 10 Temperature, ${ }^{\circ} \mathrm{C}$ & 250 & 250 & 210 & 210 \\
\hline Die Type and Gap & $3 \times 3 \mathrm{~mm}$ & $3 \times 3 \mathrm{~mm}$ & $3 \times 3 \mathrm{~mm}$ & $3 \times 3 \mathrm{~mm}$ \\
\hline $\mathrm{H}_{2} \mathrm{O}$ Bath/Conveyor & $\mathrm{H}_{2} \mathrm{O}$ Cooled & $\mathrm{H}_{2} \mathrm{O}$ Cooled & $\mathrm{H}_{2} \mathrm{O}$ Cooled & $\mathrm{H}_{2} \mathrm{O}$ Cooled \\
\hline Output Rate, Ibs/hr & 30 & 24 & 30 & 30 \\
\hline
\end{tabular}


Table 9.2-13: Extrusion Conditions, EHV Composites

\begin{tabular}{|c|c|c|c|c|}
\hline Material Number & EHV40 & EHV50 & EHV50R & EHV55 \\
\hline Extrusion Date & $12 / 6 / 2005$ & $8 / 2 / 2005$ & $2 / 22 / 2006$ & $2 / 22 / 2006$ \\
\hline Extruder RPM & 350 & 250 & 350 & 350 \\
\hline Motor Amperage, $\%$ & $46-48$ & 50 & 49 & 49 \\
\hline Melt Temperature, ${ }^{\circ} \mathrm{C}$ & 335 & 340 & 328 & 337 \\
\hline Melt Pressure, psig & $380-400$ & 490 & $420-500$ & $500-600$ \\
\hline \#3 Feeder Setting, lb/hr & 12 & 12.5 & 15 & 16.5 \\
\hline Material in Feeder \#3 & F243 & F243 & F243 & F243 \\
\hline \#4 Feeder Setting, lb/hr & 18 & 12.5 & 15 & 13.5 \\
\hline Material in Feeder \#4 & Vectra & Vectra & Vectra & Vectra \\
\hline Vacuum Port & $1 \mathrm{~atm}$ & $1 \mathrm{~atm}$ & $1 \mathrm{~atm}$ & $1 \mathrm{~atm}$ \\
\hline Zone 5 Side Stuffer Setting, rpm & 300 & 300 & 300 & 300 \\
\hline Feeder at Zone 5 & F243 & F243 & F243 & F243 \\
\hline \multicolumn{5}{|l|}{ Feed Section Temperature } \\
\hline Zone 1 Temperature, ${ }^{\circ} \mathrm{C}$ & 230 & 230 & 230 & 230 \\
\hline Zone 2 Temperature, ${ }^{\circ} \mathrm{C}$ & 250 & 250 & 250 & 250 \\
\hline Zone 3 Temperature, ${ }^{\circ} \mathrm{C}$ & 255 & 255 & 255 & 255 \\
\hline Zone 4 Temperature, ${ }^{\circ} \mathrm{C}$ & 255 & 255 & 255 & 255 \\
\hline Zone 5 Temperature, ${ }^{\circ} \mathrm{C}$ & 255 & 255 & 255 & 255 \\
\hline Zone 6 Temperature, ${ }^{\circ} \mathrm{C}$ & 255 & 255 & 255 & 255 \\
\hline Zone 7 Temperature, ${ }^{\circ} \mathrm{C}$ & 255 & 255 & 255 & 255 \\
\hline Zone 8 Temperature, ${ }^{\circ} \mathrm{C}$ & 250 & 257 & 250 & 250 \\
\hline Zone 9 Temperature, ${ }^{\circ} \mathrm{C}$ & 250 & 257 & 250 & 250 \\
\hline Zone 10 Temperature, ${ }^{\circ} \mathrm{C}$ & 210 & 250 & 210 & 210 \\
\hline Die Type and Gap & $3 \times 3 \mathrm{~mm}$ & $3 \times 3 \mathrm{~mm}$ & $3 \times 3 \mathrm{~mm}$ & $3 \times 3 \mathrm{~mm}$ \\
\hline $\mathrm{H}_{2} \mathrm{O}$ Bath/Conveyor & $\mathrm{H}_{2} \mathrm{O}$ Cooled & $\mathrm{H}_{2} \mathrm{O}$ Cooled & Conveyor & Conveyor \\
\hline Output Rate, Ibs/hr & 30 & 25 & 30 & 30 \\
\hline
\end{tabular}


Table 9.2-14: Extrusion Conditions, EHV Composites

\begin{tabular}{|c|c|c|}
\hline Material Number & EHV60 & EHV60R \\
\hline Extrusion Date & $8 / 2 / 2005$ & $2 / 22 / 2006$ \\
\hline Extruder RPM & 250 & 350 \\
\hline Motor Amperage, \% & 57 & 53 \\
\hline Melt Temperature, ${ }^{\circ} \mathrm{C}$ & 340 & 347 \\
\hline Melt Pressure, psig & $940-1000$ & $700-1000$ \\
\hline \#3 Feeder Setting, lb/hr & 15 & 18 \\
\hline Material in Feeder \#3 & F243 & F243 \\
\hline \#4 Feeder Setting, lb/hr & 10 & 12 \\
\hline Material in Feeder \#4 & Vectra & Vectra \\
\hline Vacuum Port & $1 \mathrm{~atm}$ & $1 \mathrm{~atm}$ \\
\hline Zone 5 Side Stuffer Setting, rpm & 300 & 300 \\
\hline Feeder at Zone 5 & F243 & F243 \\
\hline \multicolumn{3}{|l|}{ Feed Section Temperature } \\
\hline Zone 1 Temperature, ${ }^{\circ} \mathrm{C}$ & 230 & 230 \\
\hline Zone 2 Temperature, ${ }^{\circ} \mathrm{C}$ & 250 & 250 \\
\hline Zone 3 Temperature, ${ }^{\circ} \mathrm{C}$ & 255 & 255 \\
\hline Zone 4 Temperature, ${ }^{\circ} \mathrm{C}$ & 255 & 255 \\
\hline Zone 5 Temperature, ${ }^{\circ} \mathrm{C}$ & 255 & 255 \\
\hline Zone 6 Temperature, ${ }^{\circ} \mathrm{C}$ & 255 & 255 \\
\hline Zone 7 Temperature, ${ }^{\circ} \mathrm{C}$ & 255 & 255 \\
\hline Zone 8 Temperature, ${ }^{\circ} \mathrm{C}$ & 257 & 257 \\
\hline Zone 9 Temperature, ${ }^{\circ} \mathrm{C}$ & 257 & 257 \\
\hline Zone 10 Temperature, ${ }^{\circ} \mathrm{C}$ & 250 & 250 \\
\hline Die Type and Gap & $3 \times 3 \mathrm{~mm}$ & $3 \times 3 \mathrm{~mm}$ \\
\hline $\mathrm{H}_{2} \mathrm{O}$ Bath/Conveyor & $\mathrm{H}_{2} \mathrm{O}$ Cooled & Conveyor \\
\hline Output Rate, Ibs/hr & 25 & 30 \\
\hline
\end{tabular}




\section{Section 9.3: Injection Molding Conditions}

Notes:

Naming Convention - EXVN where:

$\mathrm{X}$ denotes the filler (A, B, C, D, E, H).

A denotes Ketjenblack EC 600-JD.

B denotes Thermocarb TC-300 Synthetic Graphite.

C denotes Asbury Synthetic Graphite 4012.

D denotes Asbury Natural Flake Graphite 3160.

E denotes Asbury Calcined Needle Coke F108A.

$\mathrm{H}$ denotes Fortafil 243 Carbon Fiber.

$\mathrm{V}$ denotes the matrix material Vectra A950RX LCP.

$\mathrm{N}$ denotes the weight percent of the filler in Vectra A950RX LCP.

An $R$ at the end of the name denotes the first replicate run of the material.

An RR at the end of the name denotes the second replicate run of the material. 
Table 9.3-1: Injection Molding Conditions for EVRR and EAV Composites

\begin{tabular}{|c|c|c|c|c|c|c|}
\hline Notation & Injection Molding Conditions & EVRR & EAV2.5 & EAV4R & EAV5R & EAV6 \\
\hline $\mathrm{T}_{\text {mold }}$ & Mold Temperature (F) & 190 & 190 & 190 & 190 & 190 \\
\hline E1 & Zone 1 Temperature (F) (nozzle) & 580 & 600 & 600 & 600 & 600 \\
\hline E2 & Zone 2 Temperature (F) & 545 & 545 & 545 & 545 & 545 \\
\hline E3 & Zone 3 Temperature (F) & 545 & 545 & 545 & 545 & 545 \\
\hline E4 & Zone 4 Temperature (F) (feed zone) & 530 & 530 & 530 & 530 & 530 \\
\hline P1 & Injection pressure (psi) & 9044 & 9044 & 11305 & 11305 & 11305 \\
\hline P2 & Hold Pressure (psi) & 9044 & 9044 & 11305 & 11305 & 11305 \\
\hline P7 & Back Pressure (psi) & 45.22 & 45.22 & 45.22 & 45.22 & 45.22 \\
\hline S1 & Shot size (mm) & 37 & 47 & 44 & 44 & 45 \\
\hline S2 & Shot before (mm) & 0 & 1 & 1 & 1 & 1 \\
\hline S3 & Shot after (mm) & 0 & 1 & 1 & 1 & 1 \\
\hline S6 & Width of mold (mm) & 196 & 196 & 196 & 196 & 196 \\
\hline S8 & Screw Position to switch (mm) & 15 & 15 & 15 & 15 & 15 \\
\hline T1 & Injection Time (s) & 2 & 2 & 2 & 2 & 2 \\
\hline T2 & Cool Time (s) & 6 & 20 & 20 & 20 & 20 \\
\hline T3 & Interval Time (s) & 2 & 2 & 2 & 2 & 2 \\
\hline T6 & Retraction Time (s) & 0 & 1 & 1 & 1 & 1 \\
\hline T7 & Nozzle Retraction Delay Time (s) & 0 & 0 & 0 & 0 & 0 \\
\hline T8 & Injection Delay Time (s) & 0 & 0 & 0 & 0 & 0 \\
\hline T9 & Charge Delay Time (s) & 0 & 1 & 1 & 1 & 1 \\
\hline V1 & Injection Velocity (mm /s) & 100909 & 96832 & 96832 & 96832 & 96832 \\
\hline V6 & Screw Rotation (rpm) & 288 & 96 & 96 & 96 & 96 \\
\hline V9 & Retraction Velocity (rpm) & 288 & 160 & 160 & 160 & 160 \\
\hline V10 & Advance Velocity (rpm) & 288 & 160 & 160 & 160 & 160 \\
\hline V11 & Retraction Velocity (rpm) & 288 & 160 & 160 & 160 & 160 \\
\hline CF & Clamp Force (US tons) & 80 & 80 & 80 & 80 & 80 \\
\hline
\end{tabular}


Table 9.3-2: Injection Molding Conditions for EVRR and EAV Composites

\begin{tabular}{|c|c|c|c|c|}
\hline Notation & Injection Molding Conditions & EAV7.5 & EAV10 & EAV15 \\
\hline$T_{\text {mold }}$ & Mold Temperature (F) & 190 & 190 & 200 \\
\hline E1 & Zone 1 Temperature (F) (nozzle) & 600 & 640 & 675 \\
\hline E2 & Zone 2 Temperature (F) & 585 & 600 & 650 \\
\hline E3 & Zone 3 Temperature (F) & 585 & 585 & 590 \\
\hline E4 & Zone 4 Temperature (F) (feed zone) & 530 & 550 & 550 \\
\hline P1 & Injection pressure (psi) & 11305 & 16957.5 & 22383.9 \\
\hline P2 & Hold Pressure (psi) & 11305 & 16957.5 & 22383.9 \\
\hline P7 & Back Pressure (psi) & 45.22 & 45.22 & 45.22 \\
\hline S1 & Shot size (mm) & 48 & 56 & 35 \\
\hline S2 & Shot before (mm) & 1 & 1 & 0 \\
\hline S3 & Shot after (mm) & 1 & 1 & 0 \\
\hline S6 & Width of mold (mm) & 196 & 196 & 196 \\
\hline S8 & Screw Position to switch (mm) & 15 & 15 & 15 \\
\hline T1 & Injection Time (s) & 2 & 2 & 2 \\
\hline T2 & Cool Time (s) & 20 & 20 & 12 \\
\hline T3 & Interval Time (s) & 2 & 2 & 2 \\
\hline T6 & Retraction Time (s) & 1 & 1 & 0 \\
\hline T7 & Nozzle Retraction Delay Time (s) & 0 & 0 & 0 \\
\hline T8 & Injection Delay Time (s) & 0 & 0 & 0 \\
\hline T9 & Charge Delay Time (s) & 1 & 1 & 1 \\
\hline V1 & Injection Velocity (mm $\left.{ }^{3} / \mathrm{s}\right)$ & 96832 & 96832 & 100909 \\
\hline V6 & Screw Rotation (rpm) & 96 & 96 & 288 \\
\hline V9 & Retraction Velocity (rpm) & 160 & 160 & 288 \\
\hline V10 & Advance Velocity (rpm) & 160 & 160 & 288 \\
\hline V11 & Retraction Velocity (rpm) & 160 & 160 & 288 \\
\hline CF & Clamp Force (US tons) & 80 & 80 & 80 \\
\hline
\end{tabular}


Table 9.3-3: Injection Molding Conditions for EBV Composites

\begin{tabular}{|c|c|c|c|c|c|c|}
\hline Notation & Injection Molding Conditions & EBV10 & EBV15 & EBV20 & EBV25 & EBV30 \\
\hline $\mathrm{T}_{\text {mold }}$ & Mold Temperature (F) & 190 & 190 & 190 & 190 & 190 \\
\hline E1 & Zone 1 Temperature (F) (nozzle) & 580 & 580 & 580 & 580 & 580 \\
\hline E2 & Zone 2 Temperature (F) & 545 & 545 & 545 & 545 & 545 \\
\hline E3 & Zone 3 Temperature (F) & 545 & 545 & 545 & 545 & 545 \\
\hline E4 & Zone 4 Temperature (F) (feed zone) & 530 & 530 & 530 & 530 & 530 \\
\hline P1 & Injection pressure (psi) & 9044 & 9044 & 10174.5 & 10174.5 & 10174.5 \\
\hline P2 & Hold Pressure (psi) & 9044 & 9044 & 10174.5 & 10174.5 & 10174.5 \\
\hline P7 & Back Pressure (psi) & 45.22 & 45.22 & 45.22 & 45.22 & 45.22 \\
\hline S1 & Shot size (mm) & 38 & 38 & 38 & 38 & 38 \\
\hline S2 & Shot before (mm) & 0 & 0 & 0 & 0 & 0 \\
\hline S3 & Shot after (mm) & 0 & 0 & 0 & 0 & 0 \\
\hline S6 & Width of mold (mm) & 196 & 196 & 196 & 196 & 196 \\
\hline S8 & Screw Position to switch (mm) & 15 & 15 & 15 & 15 & 15 \\
\hline T1 & Injection Time (s) & 2 & 2 & 2 & 2 & 2 \\
\hline T2 & Cool Time (s) & 6 & 6 & 6 & 6 & 6 \\
\hline T3 & Interval Time (s) & 2 & 2 & 2 & 2 & 2 \\
\hline T6 & Retraction Time (s) & 0 & 0 & 0 & 0 & 0 \\
\hline T7 & Nozzle Retraction Delay Time (s) & 0 & 0 & 0 & 0 & 0 \\
\hline T8 & Injection Delay Time (s) & 0 & 0 & 0 & 0 & 0 \\
\hline T9 & Charge Delay Time (s) & 0 & 0 & 0 & 0 & 0 \\
\hline V1 & Injection Velocity (mm $/ \mathrm{s})$ & 100909 & 100909 & 100909 & 100909 & 100909 \\
\hline V6 & Screw Rotation (rpm) & 288 & 288 & 288 & 288 & 288 \\
\hline V9 & Retraction Velocity (rpm) & 288 & 288 & 288 & 288 & 288 \\
\hline V10 & Advance Velocity (rpm) & 288 & 288 & 288 & 288 & 288 \\
\hline V11 & Retraction Velocity (rpm) & 288 & 288 & 288 & 288 & 288 \\
\hline CF & Clamp Force (US tons) & 80 & 80 & 80 & 80 & 80 \\
\hline
\end{tabular}


Table 9.3-4: Injection Molding Conditions for EBV Composites

\begin{tabular}{|c|c|c|c|c|c|c|}
\hline Notation & Injection Molding Conditions & EBV35 & EBV40 & EBV45 & EBV55 & EBV60 \\
\hline $\mathrm{T}_{\text {mold }}$ & Mold Temperature (F) & 190 & 190 & 190 & 190 & 190 \\
\hline E1 & Zone 1 Temperature (F) (nozzle) & 580 & 560 & 625 & 650 & 610 \\
\hline E2 & Zone 2 Temperature (F) & 545 & 545 & 600 & 625 & 585 \\
\hline E3 & Zone 3 Temperature (F) & 545 & 545 & 550 & 600 & 585 \\
\hline E4 & Zone 4 Temperature (F) (feed zone) & 530 & 530 & 530 & 550 & 550 \\
\hline P1 & Injection pressure (psi) & 10174.5 & 9044 & 10174.5 & 9044 & 18088 \\
\hline P2 & Hold Pressure (psi) & 10174.5 & 9044 & 10174.5 & 9044 & 18088 \\
\hline P7 & Back Pressure (psi) & 45.22 & 45.22 & 45.22 & 45.22 & 45.22 \\
\hline S1 & Shot size (mm) & 38 & 65 & 38 & 39 & 70 \\
\hline S2 & Shot before (mm) & 0 & 1 & 0 & 0 & 1 \\
\hline S3 & Shot after (mm) & 0 & 2 & 0 & 0 & 2 \\
\hline S6 & Width of mold (mm) & 196 & N/A & 196 & 196 & 196 \\
\hline S8 & Screw Position to switch (mm) & 15 & 15 & 15 & 15 & 15 \\
\hline T1 & Injection Time (s) & 2 & 2 & 2 & 2 & 2 \\
\hline T2 & Cool Time (s) & 6 & 30 & 6 & 6 & 30 \\
\hline T3 & Interval Time (s) & 2 & 2 & 2 & 2 & 2 \\
\hline T6 & Retraction Time (s) & 0 & 1 & 0 & 0 & 1 \\
\hline T7 & Nozzle Retraction Delay Time (s) & 0 & 0 & 0 & 0 & 0 \\
\hline T8 & Injection Delay Time (s) & 0 & 0.5 & 0 & 0 & 0.5 \\
\hline T9 & Charge Delay Time (s) & 0 & 1 & 0 & 0 & 1 \\
\hline V1 & Injection Velocity (mm $\left.{ }^{3} / \mathrm{s}\right)$ & 100909 & 96832 & 100909 & 100909 & 96832 \\
\hline V6 & Screw Rotation (rpm) & 288 & 96 & 288 & 288 & 96 \\
\hline V9 & Retraction Velocity (rpm) & 288 & 160 & 288 & 288 & 160 \\
\hline V10 & Advance Velocity (rpm) & 288 & 160 & 288 & 288 & 160 \\
\hline V11 & Retraction Velocity (rpm) & 288 & 160 & 288 & 288 & 160 \\
\hline CF & Clamp Force (US tons) & 80 & 80 & 80 & 80 & 80 \\
\hline
\end{tabular}


Table 9.3-5: Injection Molding Conditions for EBV Composites

\begin{tabular}{|c|c|c|c|c|}
\hline Notation & Injection Molding Conditions & EBV65 & EBV70 & EBV75 \\
\hline $\mathrm{T}_{\text {mold }}$ & Mold Temperature (F) & 190 & 190 & 190 \\
\hline E1 & Zone 1 Temperature (F) (nozzle) & 675 & 700 & 691 \\
\hline E2 & Zone 2 Temperature (F) & 650 & 675 & 675 \\
\hline E3 & Zone 3 Temperature (F) & 625 & 640 & 640 \\
\hline E4 & Zone 4 Temperature (F) (feed zone) & 550 & 550 & $530-550$ \\
\hline P1 & Injection pressure (psi) & 14696.5 & 21479.5 & 22383.9 \\
\hline P2 & Hold Pressure (psi) & 14696.5 & 21479.5 & 22383.9 \\
\hline P7 & Back Pressure (psi) & 45.22 & 45.22 & 45.22 \\
\hline S1 & Shot size (mm) & 37.5 & 36 & 40 \\
\hline S2 & Shot before (mm) & 0 & 0 & 0 \\
\hline S3 & Shot after (mm) & 0 & 0 & 0 \\
\hline S6 & Width of mold (mm) & 196 & 196 & 196 \\
\hline S8 & Screw Position to switch (mm) & 15 & 15 & 15 \\
\hline T1 & Injection Time (s) & 2 & 2 & 2 \\
\hline T2 & Cool Time (s) & 6 & 6 & 6 \\
\hline T3 & Interval Time (s) & 2 & 2 & 2 \\
\hline T6 & Retraction Time (s) & 0 & 0 & 0 \\
\hline T7 & Nozzle Retraction Delay Time (s) & 0 & 0 & 0 \\
\hline T8 & Injection Delay Time (s) & 0 & 0 & 0 \\
\hline T9 & Charge Delay Time (s) & 0 & 0 & 0 \\
\hline V1 & Injection Velocity (mm $\left.{ }^{3} / \mathrm{s}\right)$ & 100909 & 100909 & 100909 \\
\hline V6 & Screw Rotation (rpm) & 288 & 288 & 288 \\
\hline V9 & Retraction Velocity (rpm) & 288 & 288 & 288 \\
\hline V10 & Advance Velocity (rpm) & 288 & 288 & 288 \\
\hline V11 & Retraction Velocity (rpm) & 288 & 288 & 288 \\
\hline CF & Clamp Force (US tons) & 80 & 80 & 80 \\
\hline
\end{tabular}


Table 9.3-6: Injection Molding Conditions for ECV Composites

\begin{tabular}{|c|c|c|c|c|}
\hline Notation & Injection Molding Conditions & ECV40 & ECV60 & ECV70 \\
\hline $\mathrm{T}_{\text {mold }}$ & Mold Temperature (F) & 190 & 190 & 190 \\
\hline E1 & Zone 1 Temperature (F) (nozzle) & 560 & 610 & 640 \\
\hline E2 & Zone 2 Temperature (F) & 545 & 585 & 630 \\
\hline E3 & Zone 3 Temperature (F) & 545 & 585 & 620 \\
\hline E4 & Zone 4 Temperature (F) (feed zone) & 530 & 550 & 560 \\
\hline P1 & Injection pressure (psi) & 9044 & 16957.5 & 22383.9 \\
\hline P2 & Hold Pressure (psi) & 9044 & 16957.5 & 22383.9 \\
\hline P7 & Back Pressure (psi) & 45.22 & 45.22 & 45.22 \\
\hline S1 & Shot size (mm) & 70 & 70 & 80 \\
\hline S2 & Shot before (mm) & 1 & 1 & 1 \\
\hline S3 & Shot after (mm) & 2 & 2 & 2 \\
\hline S6 & Width of mold (mm) & 196 & 196 & 196 \\
\hline S8 & Screw Position to switch (mm) & 15 & 15 & 15 \\
\hline T1 & Injection Time (s) & 2 & 2 & 2 \\
\hline T2 & Cool Time (s) & 30 & 30 & 30 \\
\hline T3 & Interval Time (s) & 2 & 2 & 2 \\
\hline T6 & Retraction Time (s) & 1 & 1 & 1 \\
\hline T7 & Nozzle Retraction Delay Time (s) & 0 & 0 & 0 \\
\hline T8 & Injection Delay Time (s) & 0.5 & 0.5 & 0.5 \\
\hline T9 & Charge Delay Time (s) & 1 & 1 & 1 \\
\hline V1 & Injection Velocity (mm $\left.{ }^{3} / \mathrm{s}\right)$ & 96832 & 96832 & 96832 \\
\hline V6 & Screw Rotation (rpm) & 96 & 96 & 96 \\
\hline V9 & Retraction Velocity (rpm) & 160 & 160 & 160 \\
\hline V10 & Advance Velocity (rpm) & 160 & 160 & 160 \\
\hline V11 & Retraction Velocity (rpm) & 160 & 160 & 160 \\
\hline CF & Clamp Force (US tons) & 80 & 80 & 80 \\
\hline
\end{tabular}


Table 9.3-7: Injection Molding Conditions for EDV Composites

\begin{tabular}{|c|c|c|c|c|}
\hline Notation & Injection Molding Conditions & EDV40 & EDV60 & EDV70 \\
\hline$T_{\text {mold }}$ & Mold Temperature (F) & 190 & 190 & 190 \\
\hline E1 & Zone 1 Temperature (F) (nozzle) & 600 & 650 & 675 \\
\hline E2 & Zone 2 Temperature (F) & 585 & 625 & 650 \\
\hline E3 & Zone 3 Temperature (F) & 585 & 600 & 625 \\
\hline E4 & Zone 4 Temperature (F) (feed zone) & 540 & 550 & 550 \\
\hline P1 & Injection pressure (psi) & 9044 & 11305 & 14696.5 \\
\hline P2 & Hold Pressure (psi) & 9044 & 11305 & 14696.5 \\
\hline P7 & Back Pressure (psi) & 45.22 & 45.22 & 45.22 \\
\hline S1 & Shot size (mm) & 37 & 41 & 41 \\
\hline S2 & Shot before (mm) & 0 & 0 & 0 \\
\hline S3 & Shot after (mm) & 0 & 0 & 0 \\
\hline S6 & Width of mold (mm) & 196 & 196 & 196 \\
\hline S8 & Screw Position to switch (mm) & 15 & 15 & 15 \\
\hline T1 & Injection Time (s) & 2 & 2 & 2 \\
\hline T2 & Cool Time (s) & 6 & 6 & 6 \\
\hline T3 & Interval Time (s) & 2 & 2 & 2 \\
\hline T6 & Retraction Time (s) & 0 & 0 & 0 \\
\hline T7 & Nozzle Retraction Delay Time (s) & 0 & 0 & 0 \\
\hline T8 & Injection Delay Time (s) & 0 & 0 & 0 \\
\hline T9 & Charge Delay Time (s) & 0 & 0 & 0 \\
\hline V1 & Injection Velocity (mm $\left.{ }^{3} / \mathrm{s}\right)$ & 100909 & 100909 & 100909 \\
\hline V6 & Screw Rotation (rpm) & 288 & 288 & 288 \\
\hline V9 & Retraction Velocity (rpm) & 288 & 288 & 288 \\
\hline V10 & Advance Velocity (rpm) & 288 & 288 & 288 \\
\hline V11 & Retraction Velocity (rpm) & 288 & 288 & 288 \\
\hline CF & Clamp Force (US tons) & 80 & 80 & 80 \\
\hline
\end{tabular}


Table 9.3-8: Injection Molding Conditions for EEV Composites

\begin{tabular}{|c|c|c|c|c|}
\hline Notation & Injection Molding Conditions & EEV40 & EEV60 & EEV70 \\
\hline $\mathrm{T}_{\text {mold }}$ & Mold Temperature (F) & 190 & 190 & 190 \\
\hline E1 & Zone 1 Temperature (F) (nozzle) & 600 & 650 & 675 \\
\hline E2 & Zone 2 Temperature (F) & 585 & 625 & 650 \\
\hline E3 & Zone 3 Temperature (F) & 600 & 600 & 625 \\
\hline E4 & Zone 4 Temperature (F) (feed zone) & 550 & 550 & 550 \\
\hline P1 & Injection pressure (psi) & 9044 & 11305 & 14696.5 \\
\hline P2 & Hold Pressure (psi) & 9044 & 11305 & 14696.5 \\
\hline P7 & Back Pressure (psi) & 45.22 & 45.22 & 45.22 \\
\hline S1 & Shot size (mm) & 37 & 42 & 38 \\
\hline S2 & Shot before (mm) & 0 & 0 & 0 \\
\hline S3 & Shot after (mm) & 0 & 0 & 0 \\
\hline S6 & Width of mold (mm) & 196 & 196 & 196 \\
\hline S8 & Screw Position to switch (mm) & 15 & 15 & 15 \\
\hline T1 & Injection Time (s) & 2 & 2 & 2 \\
\hline T2 & Cool Time (s) & 6 & 6 & 6 \\
\hline T3 & Interval Time (s) & 2 & 2 & 2 \\
\hline T6 & Retraction Time (s) & 0 & 0 & 0 \\
\hline T7 & Nozzle Retraction Delay Time (s) & 0 & 0 & 0 \\
\hline T8 & Injection Delay Time (s) & 0 & 0 & 0 \\
\hline T9 & Charge Delay Time (s) & 0 & 0 & 0 \\
\hline V1 & Injection Velocity (mm $\left.{ }^{3} / \mathrm{s}\right)$ & 100909 & 100909 & 100909 \\
\hline V6 & Screw Rotation (rpm) & 288 & 288 & 288 \\
\hline V9 & Retraction Velocity (rpm) & 288 & 288 & 288 \\
\hline V10 & Advance Velocity (rpm) & 288 & 288 & 288 \\
\hline V11 & Retraction Velocity (rpm) & 288 & 288 & 288 \\
\hline CF & Clamp Force (US tons) & 80 & 80 & 80 \\
\hline
\end{tabular}


Table 9.3-9: Injection Molding Conditions for EHV Composites

\begin{tabular}{|c|c|c|c|c|c|c|}
\hline Notation & Injection Molding Conditions & EHV5 & EHV7.5 & EHV10 & EHV15 & EHV20 \\
\hline$T_{\text {mold }}$ & Mold Temperature (F) & 190 & 190 & 190 & 190 & 190 \\
\hline E1 & Zone 1 Temperature (F) (nozzle) & 580 & 580 & 580 & 600 & 600 \\
\hline E2 & Zone 2 Temperature (F) & 545 & 545 & 545 & 550 & 550 \\
\hline E3 & Zone 3 Temperature (F) & 545 & 545 & 545 & 550 & 550 \\
\hline E4 & Zone 4 Temperature (F) (feed zone) & 530 & 530 & 530 & 530 & 530 \\
\hline P1 & Injection pressure (psi) & 9044 & 9044 & 9044 & 10174.5 & 10174.5 \\
\hline P2 & Hold Pressure (psi) & 9044 & 9044 & 9044 & 10174.5 & 10174.5 \\
\hline P7 & Back Pressure (psi) & 45.22 & 45.22 & 45.22 & 45.22 & 45.22 \\
\hline S1 & Shot size (mm) & 37 & 37 & 37 & 37 & 37 \\
\hline S2 & Shot before (mm) & 0 & 0 & 0 & 0 & 0 \\
\hline S3 & Shot after (mm) & 0 & 0 & 0 & 0 & 0 \\
\hline S6 & Width of mold (mm) & 196 & 196 & 196 & 196 & 196 \\
\hline S8 & Screw Position to switch (mm) & 15 & 15 & 15 & 15 & 15 \\
\hline T1 & Injection Time (s) & 2 & 2 & 2 & 2 & 2 \\
\hline T2 & Cool Time (s) & 6 & 6 & 6 & 6 & 6 \\
\hline T3 & Interval Time (s) & 2 & 2 & 2 & 2 & 2 \\
\hline T6 & Retraction Time (s) & 0 & 0 & 0 & 0 & 0 \\
\hline T7 & Nozzle Retraction Delay Time (s) & 0 & 0 & 0 & 0 & 0 \\
\hline T8 & Injection Delay Time (s) & 0 & 0 & 0 & 0 & 0 \\
\hline T9 & Charge Delay Time (s) & 0 & 0 & 0 & 0 & 0 \\
\hline V1 & Injection Velocity (mm $/ \mathrm{s})$ & 100909 & 100909 & 100909 & 100909 & 100909 \\
\hline V6 & Screw Rotation (rpm) & 288 & 288 & 288 & 288 & 288 \\
\hline V9 & Retraction Velocity (rpm) & 288 & 288 & 288 & 288 & 288 \\
\hline V10 & Advance Velocity (rpm) & 288 & 288 & 288 & 288 & 288 \\
\hline V11 & Retraction Velocity (rpm) & 288 & 288 & 288 & 288 & 288 \\
\hline CF & Clamp Force (US tons) & 80 & 80 & 80 & 80 & 80 \\
\hline
\end{tabular}


Table 9.3-10: Injection Molding Conditions for EHV Composites

\begin{tabular}{|c|c|c|c|c|c|c|}
\hline Notation & Injection Molding Conditions & EHV25 & EHV30 & EHV35 & EHV40 & EHV45 \\
\hline $\mathrm{T}_{\text {mold }}$ & Mold Temperature (F) & 190 & 190 & 190 & 190 & 190 \\
\hline E1 & Zone 1 Temperature (F) (nozzle) & 600 & 600 & 600 & 600 & 600 \\
\hline E2 & Zone 2 Temperature (F) & 550 & 550 & 550 & 550 & 550 \\
\hline E3 & Zone 3 Temperature (F) & 550 & 550 & 550 & 550 & 550 \\
\hline E4 & Zone 4 Temperature (F) (feed zone) & 530 & 530 & 530 & 530 & 530 \\
\hline P1 & Injection pressure (psi) & 10174.5 & 10174.5 & 10174.5 & 10174.5 & 11305 \\
\hline P2 & Hold Pressure (psi) & 10174.5 & 10174.5 & 10174.5 & 10174.5 & 11305 \\
\hline P7 & Back Pressure (psi) & 45.22 & 45.22 & 45.22 & 45.22 & 45.22 \\
\hline S1 & Shot size (mm) & 37 & 37 & 37 & 37 & 37 \\
\hline S2 & Shot before (mm) & 0 & 0 & 0 & 0 & 0 \\
\hline S3 & Shot after (mm) & 0 & 0 & 0 & 0 & 0 \\
\hline S6 & Width of mold (mm) & 196 & 196 & 196 & 196 & 196 \\
\hline S8 & Screw Position to switch (mm) & 15 & 15 & 15 & 15 & 15 \\
\hline T1 & Injection Time (s) & 2 & 2 & 2 & 2 & 2 \\
\hline T2 & Cool Time (s) & 6 & 6 & 6 & 6 & 6 \\
\hline T3 & Interval Time (s) & 2 & 2 & 2 & 2 & 2 \\
\hline T6 & Retraction Time (s) & 0 & 0 & 0 & 0 & 0 \\
\hline T7 & Nozzle Retraction Delay Time (s) & 0 & 0 & 0 & 0 & 0 \\
\hline T8 & Injection Delay Time (s) & 0 & 0 & 0 & 0 & 0 \\
\hline T9 & Charge Delay Time (s) & 0 & 0 & 0 & 0 & 0 \\
\hline V1 & Injection Velocity (mm $\left.{ }^{3} / \mathrm{s}\right)$ & 100909 & 100909 & 100909 & 100909 & 100909 \\
\hline V6 & Screw Rotation (rpm) & 288 & 288 & 288 & 288 & 288 \\
\hline V9 & Retraction Velocity (rpm) & 288 & 288 & 288 & 288 & 288 \\
\hline V10 & Advance Velocity (rpm) & 288 & 288 & 288 & 288 & 288 \\
\hline V11 & Retraction Velocity (rpm) & 288 & 288 & 288 & 288 & 288 \\
\hline CF & Clamp Force (US tons) & 80 & 80 & 80 & 80 & 80 \\
\hline
\end{tabular}


Table 9.3-11: Injection Molding Conditions for EHV Composites

\begin{tabular}{|c|c|c|c|c|c|c|}
\hline Notation & Injection Molding Conditions & EHV50 & EHV50R & EHV55 & EHV60 & EHV60R \\
\hline$T_{\text {mold }}$ & Mold Temperature (F) & 190 & 220 & 220 & 190 & 220 \\
\hline E1 & Zone 1 Temperature (F) (nozzle) & 600 & 630 & 630 & 630 & 630 \\
\hline E2 & Zone 2 Temperature (F) & 550 & 615 & 615 & 615 & 615 \\
\hline E3 & Zone 3 Temperature (F) & 550 & 580 & 580 & 580 & 580 \\
\hline E4 & Zone 4 Temperature (F) (feed zone) & 530 & 530 & 530 & 530 & 530 \\
\hline P1 & Injection pressure (psi) & 10174.5 & 11305 & 11305 & 14696.5 & 14696.5 \\
\hline P2 & Hold Pressure (psi) & 10174.5 & 11305 & 11305 & 14696.5 & 14696.5 \\
\hline P7 & Back Pressure (psi) & 45.22 & 45.22 & 45.22 & 45.22 & 45.22 \\
\hline S1 & Shot size (mm) & 38 & 38 & 38 & 38 & 38 \\
\hline S2 & Shot before (mm) & 0 & 0 & 0 & 0 & 0 \\
\hline S3 & Shot after (mm) & 0 & 0 & 0 & 0 & 0 \\
\hline S6 & Width of mold (mm) & 196 & 196 & 196 & 196 & 196 \\
\hline S8 & Screw Position to switch (mm) & 15 & 15 & 15 & 15 & 15 \\
\hline T1 & Injection Time (s) & 2 & 2 & 2 & 2 & 2 \\
\hline T2 & Cool Time (s) & 6 & 6 & 6 & 6 & 6 \\
\hline T3 & Interval Time (s) & 2 & 2 & 2 & 2 & 2 \\
\hline T6 & Retraction Time (s) & 0 & 0 & 0 & 0 & 0 \\
\hline T7 & Nozzle Retraction Delay Time (s) & 0 & 0 & 0 & 0 & 0 \\
\hline T8 & Injection Delay Time (s) & 0 & 0 & 0 & 0 & 0 \\
\hline T9 & Charge Delay Time (s) & 0 & 0 & 0 & 0 & 0 \\
\hline V1 & Injection Velocity (mm $/ \mathrm{s})$ & 100909 & 100909 & 100909 & 100909 & 100909 \\
\hline V6 & Screw Rotation (rpm) & 288 & 288 & 288 & 288 & 288 \\
\hline V9 & Retraction Velocity (rpm) & 288 & 288 & 288 & 288 & 288 \\
\hline V10 & Advance Velocity (rpm) & 288 & 288 & 288 & 288 & 288 \\
\hline V11 & Retraction Velocity (rpm) & 288 & 288 & 288 & 288 & 288 \\
\hline CF & Clamp Force (US tons) & 80 & 80 & 80 & 80 & 80 \\
\hline
\end{tabular}




\section{Section 9.4: TCA Through-Plane Thermal Conductivity}

Table 9.4-1: Vectra A950RX LCP

\begin{tabular}{|c|c|c|c|}
\hline Test Date & Sample Number & Through-Plane Thermal Conductivity (W/mK) & Temperature $\left({ }^{\circ} \mathrm{C}\right)$ \\
\hline $10 / 11 / 2004$ & EVR-TC-18 & 0.226 & 55 \\
\hline $10 / 11 / 2004$ & EVR-TC-20 & 0.214 & 55 \\
\hline $10 / 11 / 2004$ & EVR-TC-23 & 0.210 & 55 \\
\hline $10 / 18 / 2004$ & EVR-TC-15 & 0.218 & 55 \\
\hline \multicolumn{2}{|c|}{ Average } & 0.217 & \\
\cline { 1 - 2 } Standard Deviation & 0.007 & \\
\hline \multicolumn{2}{|c|}{ Number of Samples } & 4 & \\
\hline
\end{tabular}

Table 9.4-2: 2.5 wt\% Ketjenblack EC600 JD / Vectra A950RX LCP

\begin{tabular}{|c|c|c|c|}
\hline Test Date & Sample Number & Through-Plane Thermal Conductivity (W/mK) & Temperature $\left({ }^{\circ} \mathrm{C}\right)$ \\
\hline $10 / 11 / 2004$ & EAV2.5-TC-16 & 0.245 & 55 \\
\hline $10 / 11 / 2004$ & EAV2.5-TC-19 & 0.242 & 55 \\
\hline $10 / 11 / 2004$ & EAV2.5-TC-27 & 0.242 & 55 \\
\hline $10 / 18 / 2004$ & EAV2.5-TC-24 & 0.239 & 55 \\
\hline \multicolumn{2}{|c|}{ Average } & 0.242 & \\
\cline { 1 - 2 } Standard Deviation & 0.002 & \\
\hline \multicolumn{2}{|c|}{ Number of Samples } & 4 & \\
\hline
\end{tabular}

Table 9.4-3: 4 wt\% Ketjenblack EC600 JD / Vectra A950RX LCP

\begin{tabular}{|c|c|c|c|}
\hline Test Date & Sample Number & Through-Plane Thermal Conductivity (W/mK) & Temperature $\left({ }^{\circ} \mathrm{C}\right)$ \\
\hline 10/12/2004 & EAV4R-TC-16 & 0.260 & 55 \\
\cline { 2 - 4 } $10 / 12 / 2004$ & EAV4R-TC-14 & 0.265 & 55 \\
\cline { 2 - 4 } $10 / 12 / 2004$ & EAV4R-TC-27 & 0.255 & 55 \\
\hline $10 / 18 / 2004$ & EAV4R-TC-20 & 0.252 & 55 \\
\hline \multicolumn{2}{|c|}{ Average } & 0.258 & \\
\hline \multicolumn{2}{|c|}{ Standard Deviation } & 0.006 & \\
\hline \multicolumn{2}{|c|}{ Number of Samples } & 4 & \\
\hline
\end{tabular}


Table 9.4-4: 5 wt\% Ketjenblack EC600 JD / Vectra A950RX LCP

\begin{tabular}{|c|c|c|c|}
\hline Test Date & Sample Number & Through-Plane Thermal Conductivity (W/mK) & Temperature $\left({ }^{\circ} \mathrm{C}\right)$ \\
\hline 10/12/2004 & EAV5R-TC-17 & 0.277 & 55 \\
\cline { 2 - 4 } $10 / 12 / 2004$ & EAV5R-TC-22 & 0.272 & 55 \\
\cline { 2 - 4 } $10 / 12 / 2004$ & EAV5R-TC-27 & 0.270 & 55 \\
\hline $10 / 18 / 2004$ & EAV5R-TC-14 & 0.256 & 55 \\
\hline \multicolumn{2}{|c|}{ Average } & 0.269 & \\
\hline \multicolumn{2}{|c|}{ Standard Deviation } & 0.009 & \\
\hline \multicolumn{2}{|c|}{ Number of Samples } & 4 & \\
\hline
\end{tabular}

Table 9.4-5: 6 wt\% Ketjenblack EC600 JD / Vectra A950RX LCP

\begin{tabular}{|c|c|c|c|}
\hline Test Date & Sample Number & Through-Plane Thermal Conductivity (W/mK) & Temperature $\left({ }^{\circ} \mathrm{C}\right)$ \\
\hline 10/12/2004 & EAV6-TC-13 & 0.296 & 55 \\
\cline { 2 - 4 } $10 / 12 / 2004$ & EAV6-TC-19 & 0.301 & 55 \\
\cline { 2 - 4 } $10 / 12 / 2004$ & EAV6-TC-36 & 0.292 & 55 \\
\hline $10 / 18 / 2004$ & EAV6-TC-23 & 0.285 & 55 \\
\hline \multicolumn{2}{|r|}{ Average } & 0.293 & \\
\hline \multicolumn{2}{|r|}{ Standard Deviation } & 0.007 & \\
\hline \multicolumn{2}{|r|}{ Number of Samples } & 4 & \\
\hline
\end{tabular}

Table 9.4-6: 7.5 wt\% Ketjenblack EC600 JD / Vectra A950RX LCP

\begin{tabular}{|c|c|c|c|}
\hline Test Date & Sample Number & Through-Plane Thermal Conductivity (W/mK) & Temperature $\left({ }^{\circ} \mathrm{C}\right)$ \\
\hline $10 / 12 / 2004$ & EAV7.5-TC-16 & 0.321 & 55 \\
\hline $10 / 12 / 2004$ & EAV7.5-TC-20 & 0.330 & 55 \\
\hline $10 / 12 / 2004$ & EAV7.5-TC-23 & 0.321 & 55 \\
\hline $10 / 18 / 2004$ & EAV7.5-TC-26 & 0.315 & 55 \\
\cline { 1 - 2 } \multicolumn{2}{|c|}{ Average } & 0.322 & \multirow{2}{*}{} \\
\cline { 1 - 2 } Standard Deviation & 0.006 & \\
\hline \multicolumn{2}{|c|}{ Number of Samples } & 4 & \\
\hline
\end{tabular}


Table 9.4-7: 10 wt\% Ketjenblack EC600 JD / Vectra A950RX LCP

\begin{tabular}{|c|c|c|c|}
\hline Test Date & Sample Number & Through-Plane Thermal Conductivity (W/mK) & Temperature $\left({ }^{\circ} \mathrm{C}\right)$ \\
\hline $10 / 12 / 2004$ & EAV10-TC-23 & 0.365 & 55 \\
\hline $10 / 12 / 2004$ & EAV10-TC-24 & 0.369 & 55 \\
\hline $10 / 12 / 2004$ & EAV10-TC-32 & 0.375 & 55 \\
\hline $10 / 19 / 2004$ & EAV10-TC-20 & 0.346 & 55 \\
\cline { 1 - 2 } \multicolumn{2}{|r|}{ Average } & 0.364 & \\
\cline { 1 - 2 } Standard Deviation & 0.012 & \\
\hline \multicolumn{2}{|c|}{ Number of Samples } & 4 & \\
\hline
\end{tabular}

Table 9.4-8: 15 wt\% Ketjenblack EC600 JD / Vectra A950RX LCP

\begin{tabular}{|c|c|c|c|}
\hline Test Date & Sample Number & Through-Plane Thermal Conductivity (W/mK) & Temperature $\left({ }^{\circ} \mathrm{C}\right)$ \\
\hline $10 / 13 / 2004$ & EAV15-TC-24 & 0.402 & 55 \\
\hline $10 / 13 / 2004$ & EAV15-TC-26 & 0.407 & 55 \\
\hline $10 / 19 / 2004$ & EAV15-TC-13 & 0.428 & 55 \\
\hline $10 / 19 / 2004$ & EAV15-TC-18 & 0.427 & 55 \\
\hline \multicolumn{2}{|c|}{ Average } & 0.416 & \\
\hline \multicolumn{2}{|c|}{ Standard Deviation } & 0.013 & \\
\hline \multicolumn{2}{|c|}{ Number of Samples } & 4 & \\
\hline
\end{tabular}


Table 9.4-9: 10 wt\% Thermocarb TC300 / Vectra A950RX LCP

\begin{tabular}{|c|c|c|c|}
\hline Test Date & Sample Number & Through-Plane Thermal Conductivity (W/mK) & Temperature $\left({ }^{\circ} \mathrm{C}\right)$ \\
\hline $3 / 24 / 2005$ & EBV10-TC-19 & 0.279 & 55 \\
\hline $3 / 24 / 2005$ & EBV10-TC-16 & 0.303 & 55 \\
\hline $3 / 24 / 2005$ & EBV10-TC-18 & 0.296 & 55 \\
\hline $3 / 24 / 2005$ & EBV10-TC-28 & 0.296 & 55 \\
\hline \multicolumn{2}{|c|}{ Average } & 0.293 & \\
\cline { 1 - 2 } Standard Deviation & 0.010 & \\
\hline \multicolumn{2}{|c|}{ Number of Samples } & 4 & \\
\hline
\end{tabular}

Table 9.4-10: 15 wt\% Thermocarb TC300 / Vectra A950RX LCP

\begin{tabular}{|c|c|c|c|}
\hline Test Date & Sample Number & Through-Plane Thermal Conductivity (W/mK) & Temperature $\left({ }^{\circ} \mathrm{C}\right)$ \\
\hline $3 / 24 / 2005$ & EBV15-TC-23 & 0.354 & 55 \\
\hline $3 / 24 / 2005$ & EBV15-TC-19 & 0.355 & 55 \\
\hline $3 / 24 / 2005$ & EBV15-TC-21 & 0.358 & 55 \\
\hline $3 / 24 / 2005$ & EBV15-TC-28 & 0.330 & 55 \\
\hline \multicolumn{2}{|c|}{ Average } & 0.349 & \\
\hline \multicolumn{2}{|c|}{ Standard Deviation } & 0.013 & \\
\hline \multicolumn{2}{|c|}{ Number of Samples } & 4 & \\
\hline
\end{tabular}

Table 9.4-11: 20 wt\% Thermocarb TC300 / Vectra A950RX LCP

\begin{tabular}{|c|c|c|c|}
\hline Test Date & Sample Number & Through-Plane Thermal Conductivity (W/mK) & Temperature $\left({ }^{\circ} \mathrm{C}\right)$ \\
\hline $3 / 24 / 2005$ & EBV20-TC-19 & 0.372 & 55 \\
\cline { 2 - 4 } $3 / 24 / 2005$ & EBV20-TC-22 & 0.395 & 55 \\
\cline { 2 - 4 } $3 / 24 / 2005$ & EBV20-TC-24 & 0.376 & 55 \\
\cline { 2 - 4 } $3 / 24 / 2005$ & EBV20-TC-25 & 0.397 & 55 \\
\hline $3 / 24 / 2005$ & EBV20-TC-28 & 0.395 & 55 \\
\hline \multicolumn{2}{|c|}{ Average } & 0.387 & \\
\hline \multicolumn{2}{|c|}{ Standard Deviation } & 0.012 & \\
\hline \multicolumn{2}{|c|}{ Number of Samples } & 5 & \\
\hline
\end{tabular}


Table 9.4-12: 25 wt\% Thermocarb TC300 / Vectra A950RX LCP

\begin{tabular}{|c|c|c|c|}
\hline Test Date & Sample Number & Through-Plane Thermal Conductivity (W/mK) & Temperature $\left({ }^{\circ} \mathrm{C}\right)$ \\
\hline 9/28/2005 & EBV25-TC-18 & 0.483 & 55 \\
\hline 9/28/2005 & EBV25-TC-21 & 0.456 & 55 \\
\hline 9/28/2005 & EBV25-TC-15 & 0.477 & 55 \\
\hline 9/28/2005 & EBV25-TC-27 & 0.473 & 55 \\
\hline 9/28/2005 & EBV25-TC-24 & 0.460 & 55 \\
\hline \multicolumn{2}{|r|}{ Average } & 0.470 & \multirow{2}{*}{} \\
\cline { 1 - 2 } Standard Deviation & 0.012 & \\
\hline \multicolumn{2}{|r|}{ Number of Samples } & 5 & \\
\hline
\end{tabular}

Table 9.4-13: 30 wt\% Thermocarb TC300 / Vectra A950RX LCP

\begin{tabular}{|c|c|c|c|}
\hline Test Date & Sample Number & Through-Plane Thermal Conductivity (W/mK) & Temperature $\left({ }^{\circ} \mathrm{C}\right)$ \\
\hline $3 / 24 / 2005$ & EBV30-TC-17 & 0.557 & 55 \\
\hline $3 / 24 / 2005$ & EBV30-TC-19 & 0.518 & 55 \\
\hline $3 / 24 / 2005$ & EBV30-TC-25 & 0.556 & 55 \\
\hline $3 / 24 / 2005$ & EBV30-TC-29 & 0.554 & 55 \\
\hline \multicolumn{2}{|c|}{ Average } & 0.546 & \\
\hline \multicolumn{2}{|c|}{ Standard Deviation } & 0.019 & \\
\hline \multicolumn{2}{|c|}{ Number of Samples } & 4 & \\
\hline
\end{tabular}

Table 9.4-14: 35 wt\% Thermocarb TC300 / Vectra A950RX LCP

\begin{tabular}{|c|c|c|c|}
\hline Test Date & Sample Number & Through-Plane Thermal Conductivity (W/mK) & Temperature $\left({ }^{\circ} \mathrm{C}\right)$ \\
\hline 9/28/2005 & EBV35-TC-21 & 0.620 & 55 \\
\hline 9/28/2005 & EBV35-TC-15 & 0.593 & 55 \\
\hline $9 / 28 / 2005$ & EBV35-TC-27 & 0.585 & 55 \\
\hline $9 / 28 / 2005$ & EBV35-TC-18 & 0.623 & 55 \\
\hline 9/28/2005 & EBV35-TC-30 & 0.633 & 55 \\
\hline \multicolumn{2}{|r|}{ Average } & 0.611 & \\
\cline { 1 - 2 } Standard Deviation & 0.021 & \\
\hline \multicolumn{2}{|r|}{ Number of Samples } & 5 & \\
\hline
\end{tabular}


Table 9.4-15: 40 wt\% Thermocarb TC300 / Vectra A950RX LCP

\begin{tabular}{|c|c|c|c|}
\hline Test Date & Sample Number & Through-Plane Thermal Conductivity (W/mK) & Temperature $\left({ }^{\circ} \mathrm{C}\right)$ \\
\hline $3 / 11 / 2005$ & EBV40-TC-20 & 0.720 & 55 \\
\hline $3 / 11 / 2005$ & EBV40-TC-18 & 0.703 & 55 \\
\hline $3 / 11 / 2005$ & EBV40-TC-16 & 0.695 & 55 \\
\hline $3 / 11 / 2005$ & EBV40-TC-17 & 0.708 & 55 \\
\hline \multicolumn{2}{|c|}{ Average } & 0.706 & \\
\cline { 1 - 2 } Standard Deviation & 0.010 & \\
\hline \multicolumn{2}{|c|}{ Number of Samples } & 4 & \\
\hline
\end{tabular}

Table 9.4-16: 45 wt\% Thermocarb TC300 / Vectra A950RX LCP

\begin{tabular}{|c|c|c|c|}
\hline Test Date & Sample Number & Through-Plane Thermal Conductivity (W/mK) & Temperature $\left({ }^{\circ} \mathrm{C}\right)$ \\
\hline 9/29/2005 & EBV45-TC-15 & 0.859 & 55 \\
\hline 9/29/2005 & EBV45-TC-24 & 0.882 & 55 \\
\hline 9/29/2005 & EBV45-TC-18 & 0.929 & 55 \\
\hline 9/29/2005 & EBV45-TC-21 & 0.821 & 55 \\
\hline 9/29/2005 & EBV45-TC-30 & 0.911 & 55 \\
\hline \multicolumn{2}{|c|}{ Average } & 0.880 & \\
\hline \multicolumn{2}{|c|}{ Standard Deviation } & 0.043 & \\
\hline \multicolumn{2}{|c|}{ Number of Samples } & 5 & \\
\hline
\end{tabular}

Table 9.4-17: 50 wt\% Thermocarb TC300 / Vectra A950RX LCP

\begin{tabular}{|c|c|c|c|}
\hline Test Date & Sample Number & Through-Plane Thermal Conductivity (W/mK) & Temperature $\left({ }^{\circ} \mathrm{C}\right)$ \\
\hline $3 / 14 / 2005$ & EBV50-TC-21 & 1.122 & 55 \\
\hline $3 / 14 / 2005$ & EBV50-TC-13 & 1.141 & 55 \\
\hline $3 / 14 / 2005$ & EBV50-TC-18 & 1.102 & 55 \\
\hline $3 / 14 / 2005$ & EBV50-TC-16 & 1.068 & 55 \\
\hline \multicolumn{2}{|c|}{ Average } & 1.108 & \\
\cline { 1 - 2 } Standard Deviation & 0.031 & \\
\hline \multicolumn{2}{|c|}{ Number of Samples } & 4 & \\
\hline
\end{tabular}


Table 9.4-18: 55 wt \% Thermocarb TC300 / Vectra A950RX LCP

\begin{tabular}{|c|c|c|c|}
\hline Test Date & Sample Number & Through-Plane Thermal Conductivity (W/mK) & Temperature $\left({ }^{\circ} \mathrm{C}\right)$ \\
\hline $3 / 14 / 2005$ & EBV55-TC-13 & 1.287 & 55 \\
\hline $3 / 14 / 2005$ & EBV55-TC-21 & 1.314 & 55 \\
\hline $3 / 14 / 2005$ & EBV55-TC-19 & 1.291 & 55 \\
\hline $3 / 14 / 2005$ & EBV55-TC-30 & 1.249 & 55 \\
\hline \multicolumn{2}{|c|}{ Average } & 1.285 & \\
\cline { 1 - 2 } Standard Deviation & 0.027 & \\
\hline \multicolumn{2}{|c|}{ Number of Samples } & 4 & \\
\hline
\end{tabular}

Table 9.4-19: 60 wt \% Thermocarb TC300 / Vectra A950RX LCP

\begin{tabular}{|c|c|c|c|}
\hline Test Date & Sample Number & Through-Plane Thermal Conductivity (W/mK) & Temperature $\left({ }^{\circ} \mathrm{C}\right)$ \\
\hline $3 / 14 / 2005$ & EBV60-TC-25 & 1.608 & 55 \\
\hline $3 / 14 / 2005$ & EBV60-TC-28 & 1.561 & 55 \\
\hline $3 / 14 / 2005$ & EBV60-TC-31 & 1.625 & 55 \\
\hline $3 / 15 / 2005$ & EBV60-TC-14 & 1.518 & 55 \\
\hline $3 / 15 / 2005$ & EBV60-TC-22 & 1.446 & 55 \\
\hline $3 / 15 / 2005$ & EBV60-TC-31 & 1.498 & 55 \\
\hline $3 / 15 / 2005$ & EBV60-TC-28 & 1.539 & 55 \\
\hline $3 / 15 / 2005$ & EBV60-TC-25 & 1.673 & 55 \\
\hline \multicolumn{2}{|c|}{ Average } & 1.559 & \\
\hline \multicolumn{2}{|c|}{ Standard Deviation } & 0.074 & \\
\hline \multicolumn{2}{|c|}{ Number of Samples } & 8 & \\
\hline
\end{tabular}

\section{Table 9.4-20: 65 wt\% Thermocarb TC300 / Vectra A950RX LCP}

\begin{tabular}{|c|c|c|c|}
\hline Test Date & Sample Number & Through-Plane Thermal Conductivity (W/mK) & Temperature $\left({ }^{\circ} \mathrm{C}\right)$ \\
\hline $3 / 15 / 2005$ & EBV65-TC-20 & 2.106 & 55 \\
\hline $3 / 15 / 2005$ & EBV65-TC-22 & 2.025 & 55 \\
\hline $3 / 15 / 2005$ & EBV65-TC-16 & 1.833 & 55 \\
\hline $3 / 15 / 2005$ & EBV65-TC-24 & 1.809 & 55 \\
\hline $3 / 15 / 2005$ & EBV65-TC-25 & 1.923 & 55 \\
\hline $3 / 16 / 2005$ & EBV65-TC-31 & 1.870 & 55 \\
\hline $3 / 16 / 2005$ & EBV65-TC-18 & 2.033 & 55 \\
\hline \multicolumn{2}{|c|}{ Average } & 1.943 & \\
\cline { 1 - 2 } Standard Deviation & 0.113 & \\
\hline \multicolumn{2}{|c|}{ Number of Samples } & 7 & \\
\hline
\end{tabular}


Table 9.4-21: 70 wt\% Thermocarb TC300 / Vectra A950RX LCP

\begin{tabular}{|c|c|c|c|}
\hline Test Date & Sample Number & Through-Plane Thermal Conductivity (W/mK) & Temperature $\left({ }^{\circ} \mathrm{C}\right)$ \\
\hline $3 / 16 / 2005$ & EBV70-TC-25 & 2.246 & 55 \\
\hline $3 / 16 / 2005$ & EBV70-TC-24 & 2.342 & 55 \\
\hline $3 / 16 / 2005$ & EBV70-TC-31 & 2.464 & 55 \\
\hline $3 / 17 / 2005$ & EBV70-TC-28 & 2.254 & 55 \\
\hline $3 / 17 / 2005$ & EBV70-TC-20 & 2.398 & 55 \\
\hline $3 / 17 / 2005$ & EBV70-TC-16 & 2.312 & 55 \\
\hline $3 / 17 / 2005$ & EBV70-TC-19 & 2.242 & 55 \\
\hline \multicolumn{2}{|c|}{ Average } & 2.323 & \\
\cline { 1 - 2 } Standard Deviation & 0.085 & \\
\cline { 1 - 2 } Number of Samples & 7 & \\
\hline
\end{tabular}

Table 9.4-22: 75 wt\% Thermocarb TC300 / Vectra A950RX LCP

\begin{tabular}{|c|c|c|c|}
\hline Test Date & Sample Number & Through-Plane Thermal Conductivity (W/mK) & Temperature $\left({ }^{\circ} \mathrm{C}\right)$ \\
\hline $3 / 18 / 2005$ & EBV75-TC-13 & 2.779 & 55 \\
\hline $3 / 18 / 2005$ & EBV75-TC-15 & 2.629 & 55 \\
\hline $3 / 18 / 2005$ & EBV75-TC-21 & 2.614 & 55 \\
\hline $3 / 18 / 2005$ & EBV75-TC-14 & 2.513 & 55 \\
\hline $3 / 18 / 2005$ & EBV75-TC-33 & 2.591 & 55 \\
\hline \multicolumn{2}{|r|}{ Average } & 2.625 & \\
\hline \multicolumn{2}{|c|}{ Standard Deviation } & 0.097 & \\
\hline \multicolumn{2}{|c|}{ Number of Samples } & 5 & \\
\hline
\end{tabular}


Table 9.4-23: 40 wt\% Asbury Synthetic Graphite 4012 / Vectra A950RX LCP

\begin{tabular}{|c|c|c|c|}
\hline Test Date & $\begin{array}{c}\text { Sample } \\
\text { Number }\end{array}$ & $\begin{array}{c}\text { Through-Plane Thermal Conductivity } \\
(\mathrm{W} / \mathrm{mK})\end{array}$ & $\begin{array}{c}\text { Temperature } \\
\left({ }^{\circ} \mathrm{C}\right)\end{array}$ \\
\hline $6 / 9 / 2004$ & ECV40-TC-11 & 0.610 & 55 \\
\hline $6 / 9 / 2004$ & ECV40-TC-13 & 0.628 & 55 \\
\hline $6 / 10 / 2004$ & ECV40-TC-23 & 0.610 & 55 \\
\hline $11 / 19 / 2004$ & ECV40-TC-21 & 0.610 & 55 \\
\hline \multicolumn{2}{|r|}{ Average } & 0.615 & \\
\cline { 1 - 2 } Standard Deviation & 0.009 & \\
\hline \multicolumn{2}{|r|}{ Number of Samples } & 4 & \\
\hline
\end{tabular}

Table 9.4-24: 60 wt\% Asbury Synthetic Graphite 4012 / Vectra A950RX LCP

\begin{tabular}{|c|c|c|c|}
\hline Test Date & $\begin{array}{c}\text { Sample } \\
\text { Number }\end{array}$ & $\begin{array}{c}\text { Through-Plane Thermal Conductivity } \\
(\mathrm{W} / \mathrm{mK})\end{array}$ & $\begin{array}{c}\text { Temperature } \\
\left({ }^{\circ} \mathrm{C}\right)\end{array}$ \\
\hline $6 / 14 / 2004$ & ECV60-TC-16 & 1.517 & 55 \\
\hline $6 / 14 / 2004$ & ECV60-TC-21 & 1.407 & 55 \\
\hline $11 / 11 / 2004$ & ECV60-TC-20 & 1.503 & 55 \\
\hline $11 / 29 / 2004$ & ECV60-TC-29 & 1.434 & 55 \\
\hline \multicolumn{2}{|c|}{ Average } & 1.465 & \\
\hline \multicolumn{2}{|c|}{ Standard Deviation } & 0.053 & \\
\hline \multicolumn{2}{|c|}{ Number of Samples } & 4 & \\
\hline
\end{tabular}

Table 9.4-25: 70 wt\% Asbury Synthetic Graphite 4012 / Vectra A950RX LCP

\begin{tabular}{|c|c|c|c|} 
Test Date & $\begin{array}{c}\text { Sample } \\
\text { Number }\end{array}$ & $\begin{array}{c}\text { Through-Plane Thermal Conductivity } \\
(\mathrm{W} / \mathrm{mK})\end{array}$ & $\begin{array}{c}\text { Temperature } \\
\left({ }^{\circ} \mathrm{C}\right)\end{array}$ \\
\hline $6 / 14 / 2004$ & ECV70-TC-12 & 1.954 & 55 \\
\hline $6 / 14 / 2004$ & ECV70-TC-15 & 2.087 & 55 \\
\hline $6 / 15 / 2004$ & ECV70-TC-17 & 1.931 & 55 \\
\hline $11 / 28 / 2004$ & ECV70-TC-20 & 2.203 & 55 \\
\hline \multicolumn{2}{|c|}{ Average } & 2.044 & \\
\hline \multicolumn{2}{|c|}{ Standard Deviation } & 0.126 & \\
\hline \multicolumn{2}{|c|}{ Number of Samples } & 4 & \\
\hline
\end{tabular}


Table 9.4-26: 40 wt\% Asbury 3160 Natural Flake Graphite / Vectra A950RX LCP

\begin{tabular}{|c|c|c|c|}
\hline Test Date & $\begin{array}{c}\text { Sample } \\
\text { Number }\end{array}$ & $\begin{array}{c}\text { Through-Plane Thermal Conductivity } \\
(\mathrm{W} / \mathrm{mK})\end{array}$ & $\begin{array}{c}\text { Temperature } \\
\left({ }^{\circ} \mathrm{C}\right)\end{array}$ \\
\hline $10 / 7 / 2004$ & EDV40-TC-18 & 0.604 & 55 \\
\hline $10 / 7 / 2004$ & EDV40-TC-20 & 0.571 & 55 \\
\hline $10 / 7 / 2004$ & EDV40-TC-23 & 0.596 & 55 \\
\hline $11 / 16 / 2004$ & EDV40-TC-29 & 0.599 & 55 \\
\hline \multicolumn{2}{|r|}{ Average } & 0.593 & \\
\cline { 1 - 2 } Standard Deviation & 0.015 & \\
\hline \multicolumn{2}{|c|}{ Number of Samples } & 4 & \\
\hline
\end{tabular}

Table 9.4-27: 60 wt\% Asbury 3160 Natural Flake Graphite / Vectra A950RX LCP

\begin{tabular}{|c|c|c|c|}
\hline Test Date & $\begin{array}{c}\text { Sample } \\
\text { Number }\end{array}$ & $\begin{array}{c}\text { Through-Plane Thermal Conductivity } \\
(\mathrm{W} / \mathrm{mK})\end{array}$ & $\begin{array}{c}\text { Temperature } \\
\left({ }^{\circ} \mathrm{C}\right)\end{array}$ \\
\hline $10 / 5 / 2004$ & EDV60-TC-21 & 1.417 & 55 \\
\hline $10 / 5 / 2004$ & EDV60-TC-23 & 1.328 & 55 \\
\hline $10 / 5 / 2004$ & EDV60-TC-31 & 1.327 & 55 \\
\hline $11 / 29 / 2004$ & EDV60-TC-24 & 1.436 & 55 \\
\hline \multicolumn{2}{|c|}{ Average } & 1.377 & \\
\hline \multicolumn{2}{|c|}{ Standard Deviation } & 0.058 & \\
\hline \multicolumn{2}{|c|}{ Number of Samples } & 4 & \\
\hline
\end{tabular}

Table 9.4-28: 70 wt\% Asbury 3160 Natural Flake Graphite / Vectra A950RX LCP

\begin{tabular}{|c|c|c|c|}
\hline Test Date & $\begin{array}{c}\text { Sample } \\
\text { Number }\end{array}$ & $\begin{array}{c}\text { Through-Plane Thermal Conductivity } \\
(\mathrm{W} / \mathrm{mK})\end{array}$ & $\begin{array}{c}\text { Temperature } \\
\left({ }^{\circ} \mathrm{C}\right)\end{array}$ \\
\hline $10 / 5 / 2004$ & EDV70-TC-12 & 1.947 & 55 \\
\hline $10 / 5 / 2004$ & EDV70-TC-27 & 2.075 & 55 \\
\hline $10 / 5 / 2004$ & EDV70-TC-16 & 1.921 & 55 \\
\hline $11 / 18 / 2004$ & EDV70-TC-25 & 1.844 & 55 \\
\hline \multicolumn{2}{|r|}{ Average } & 1.946 & \\
\hline \multicolumn{2}{|r|}{ Standard Deviation } & 0.096 & \\
\hline \multicolumn{2}{|r|}{ Number of Samples } & 4 & \\
\hline
\end{tabular}


Table 9.4-29: 40 wt\% Asbury F108A CNC / Vectra A950RX LCP

\begin{tabular}{|c|c|c|c|}
\hline Test Date & $\begin{array}{c}\text { Sample } \\
\text { Number }\end{array}$ & $\begin{array}{c}\text { Through-Plane Thermal Conductivity } \\
(\mathrm{W} / \mathrm{mK})\end{array}$ & $\begin{array}{c}\text { Temperature } \\
\left({ }^{\circ} \mathrm{C}\right)\end{array}$ \\
\hline $9 / 30 / 2004$ & EEV40-TC-12 & 0.483 & 55 \\
\hline $9 / 30 / 2004$ & EEV40-TC-16 & 0.477 & 55 \\
\hline $9 / 30 / 2004$ & EEV40-TC-28 & 0.444 & 55 \\
\hline $11 / 16 / 2004$ & EEV40-TC-23 & 0.504 & 55 \\
\hline \multicolumn{2}{|r|}{ Average } & 0.477 & \\
\cline { 1 - 2 } Standard Deviation & 0.025 & \\
\hline \multicolumn{2}{|c|}{ Number of Samples } & 4 & \\
\hline
\end{tabular}

Table 9.4-30: 60 wt\% Asbury F108A CNC / Vectra A950RX LCP

\begin{tabular}{|c|c|c|c|}
\hline Test Date & $\begin{array}{c}\text { Sample } \\
\text { Number }\end{array}$ & $\begin{array}{c}\text { Through-Plane Thermal Conductivity } \\
(\mathrm{W} / \mathrm{mK})\end{array}$ & $\begin{array}{c}\text { Temperature } \\
\left({ }^{\circ} \mathrm{C}\right)\end{array}$ \\
\hline $9 / 30 / 2004$ & EEV60-TC-18 & 0.730 & 55 \\
\hline $9 / 30 / 2004$ & EEV60-TC-20 & 0.712 & 55 \\
\hline $9 / 30 / 2004$ & EEV60-TC-24 & 0.749 & 55 \\
\hline $11 / 18 / 2004$ & EEV60-TC-6 & 0.652 & 55 \\
\hline \multicolumn{2}{|c|}{ Average } & 0.711 & \\
\hline \multicolumn{2}{|c|}{ Standard Deviation } & 0.042 & \\
\hline \multicolumn{2}{|c|}{ Number of Samples } & 4 & \\
\hline
\end{tabular}

Table 9.4-31: 70 wt\% Asbury F108A CNC / Vectra A950RX LCP

\begin{tabular}{|c|c|c|c|}
\hline Test Date & $\begin{array}{c}\text { Sample } \\
\text { Number }\end{array}$ & $\begin{array}{c}\text { Through-Plane Thermal Conductivity } \\
(\mathrm{W} / \mathrm{mK})\end{array}$ & $\begin{array}{c}\text { Temperature } \\
\left({ }^{\circ} \mathrm{C}\right)\end{array}$ \\
\hline $10 / 5 / 2004$ & EEV70-TC-14 & 0.979 & 55 \\
\hline $10 / 5 / 2004$ & EEV70-TC-21 & 0.933 & 55 \\
\hline $10 / 5 / 2004$ & EEV70-TC-23 & 0.975 & 55 \\
\hline $11 / 18 / 2004$ & EEV70-TC-4 & 0.976 & 55 \\
\hline \multicolumn{2}{|r|}{ Average } & 0.966 & \\
\hline \multicolumn{2}{|r|}{ Standard Deviation } & 0.022 & \\
\hline \multicolumn{2}{|r|}{ Number of Samples } & 4 & \\
\hline
\end{tabular}


Table 9.4-32: 5 wt\% Fortafil 243 / Vectra A950RX LCP

\begin{tabular}{|c|c|c|c|}
\hline Test Date & Sample Number & Through-Plane Thermal Conductivity (W/mK) & Temperature $\left({ }^{\circ} \mathrm{C}\right)$ \\
\hline $1 / 10 / 2006$ & EHV5-TC-15 & 0.242 & 55 \\
\hline $1 / 10 / 2006$ & EHV5-TC-18 & 0.233 & 55 \\
\hline $1 / 10 / 2006$ & EHV5-TC-21 & 0.231 & 55 \\
\hline $1 / 10 / 2006$ & EHV5-TC-24 & 0.234 & 55 \\
\hline $1 / 10 / 2006$ & EHV5-TC-27 & 0.247 & 55 \\
\hline $1 / 10 / 2006$ & EHV5-TC-30 & 0.235 & 55 \\
\hline \multicolumn{2}{|c|}{ Average } & 0.237 & \\
\cline { 1 - 2 } Standard Deviation & 0.006 & \\
\hline \multicolumn{2}{|c|}{ Number of Samples } & 6 & \\
\hline
\end{tabular}

Table 9.4-33: 7.5 wt \% Fortafil 243 / Vectra A950RX LCP

\begin{tabular}{|c|c|c|c|}
\hline Test Date & Sample Number & Through-Plane Thermal Conductivity (W/mK) & Temperature $\left({ }^{\circ} \mathrm{C}\right)$ \\
\hline $1 / 10 / 2006$ & EHV7.5-TC-15 & 0.252 & 55 \\
\hline $1 / 10 / 2006$ & EHV7.5-TC-18 & 0.253 & 55 \\
\hline $1 / 10 / 2006$ & EHV7.5-TC-21 & 0.260 & 55 \\
\hline $1 / 10 / 2006$ & EHV7.5-TC-24 & 0.254 & 55 \\
\hline $1 / 10 / 2006$ & EHV7.5-TC-27 & 0.260 & 55 \\
\hline $1 / 10 / 2006$ & EHV7.5-TC-30 & 0.255 & 55 \\
\cline { 1 - 2 } & Average & 0.256 & \\
\cline { 1 - 2 } Standard Deviation & 0.004 & \\
\cline { 1 - 2 } Number of Samples & 6 & \\
\hline
\end{tabular}

\section{Table 9.4-34: 10 wt \% Fortafil 243 / Vectra A950RX LCP}

\begin{tabular}{|c|c|c|c|}
\hline Test Date & Sample Number & Through-Plane Thermal Conductivity (W/mK) & Temperature $\left({ }^{\circ} \mathrm{C}\right)$ \\
\hline $1 / 11 / 2006$ & EHV10-TC-12 & 0.265 & 55 \\
\hline $1 / 11 / 2006$ & EHV10-TC-15 & 0.266 & 55 \\
\hline $1 / 11 / 2006$ & EHV10-TC-18 & 0.278 & 55 \\
\hline $1 / 11 / 2006$ & EHV10-TC-21 & 0.271 & 55 \\
\hline $1 / 11 / 2006$ & EHV10-TC-24 & 0.271 & 55 \\
\hline $1 / 11 / 2006$ & EHV10-TC-27 & 0.279 & 55 \\
\hline \multicolumn{2}{|c|}{ Average } & 0.272 & \\
\hline \multicolumn{2}{|c|}{ Standard Deviation } & 0.006 & \\
\hline \multicolumn{2}{|c|}{ Number of Samples } & 6 & \\
\hline
\end{tabular}


Table 9.4-35: 15 wt\% Fortafil 243 / Vectra A950RX LCP

\begin{tabular}{|c|c|c|c|}
\hline Test Date & Sample Number & Through-Plane Thermal Conductivity (W/mK) & Temperature $\left({ }^{\circ} \mathrm{C}\right)$ \\
\hline $1 / 11 / 2006$ & EHV15-TC-15 & 0.281 & 55 \\
\hline $1 / 11 / 2006$ & EHV15-TC-18 & 0.295 & 55 \\
\hline $1 / 11 / 2006$ & EHV15-TC-21 & 0.286 & 55 \\
\hline $1 / 11 / 2006$ & EHV15-TC-24 & 0.282 & 55 \\
\hline $1 / 11 / 2006$ & EHV15-TC-27 & 0.273 & 55 \\
\hline $1 / 11 / 2006$ & EHV15-TC-30 & 0.275 & 55 \\
\hline \multicolumn{2}{|c|}{ Average } & 0.282 & \\
\cline { 1 - 2 } Standard Deviation & 0.008 & \\
\hline \multicolumn{2}{|c|}{ Number of Samples } & 6 & \\
\hline
\end{tabular}

Table 9.4-36: 20 wt\% Fortafil 243 / Vectra A950RX LCP

\begin{tabular}{|c|c|c|c|}
\hline Test Date & Sample Number & Through-Plane Thermal Conductivity (W/mK) & Temperature $\left({ }^{\circ} \mathrm{C}\right)$ \\
\hline $1 / 12 / 2006$ & EHV20-TC-12 & 0.304 & 55 \\
\hline $1 / 12 / 2006$ & EHV20-TC-15 & 0.322 & 55 \\
\hline $1 / 12 / 2006$ & EHV20-TC-18 & 0.325 & 55 \\
\hline $1 / 12 / 2006$ & EHV20-TC-21 & 0.317 & 55 \\
\hline $1 / 12 / 2006$ & EHV20-TC-24 & 0.314 & 55 \\
\hline $1 / 12 / 2006$ & EHV20-TC-27 & 0.313 & 55 \\
\hline \multicolumn{2}{|c|}{ Average } & 0.316 & \\
\hline \multicolumn{2}{|c|}{ Standard Deviation } & 0.007 & \\
\hline \multicolumn{2}{|c|}{ Number of Samples } & 6 & \\
\hline
\end{tabular}

\section{Table 9.4-37: 25 wt\% Fortafil 243 / Vectra A950RX LCP}

\begin{tabular}{|c|c|c|c|}
\hline Test Date & Sample Number & Through-Plane Thermal Conductivity (W/mK) & Temperature $\left({ }^{\circ} \mathrm{C}\right)$ \\
\hline $1 / 12 / 2006$ & EHV25-TC-15 & 0.354 & 55 \\
\hline $1 / 12 / 2006$ & EHV25-TC-18 & 0.340 & 55 \\
\hline $1 / 12 / 2006$ & EHV25-TC-21 & 0.358 & 55 \\
\hline $1 / 12 / 2006$ & EHV25-TC-24 & 0.354 & 55 \\
\hline $1 / 12 / 2006$ & EHV25-TC-27 & 0.355 & 55 \\
\hline $1 / 12 / 2006$ & EHV25-TC-30 & 0.354 & 55 \\
\hline \multicolumn{2}{|c|}{ Average } & 0.352 & \\
\hline \multicolumn{2}{|c|}{ Standard Deviation } & 0.006 & \\
\hline \multicolumn{2}{|c|}{ Number of Samples } & 6 & \\
\hline
\end{tabular}


Table 9.4-38: 30 wt\% Fortafil 243 / Vectra A950RX LCP

\begin{tabular}{|c|c|c|c|}
\hline Test Date & Sample Number & Through-Plane Thermal Conductivity $(\mathrm{W} / \mathrm{mK})$ & Temperature $\left({ }^{\circ} \mathrm{C}\right)$ \\
\hline $1 / 16 / 2006$ & EHV30-TC-15 & 0.370 & 55 \\
\hline $1 / 16 / 2006$ & EHV30-TC-21 & 0.376 & 55 \\
\hline $1 / 16 / 2006$ & EHV30-TC-24 & 0.370 & 55 \\
\hline $1 / 16 / 2006$ & EHV30-TC-27 & 0.355 & 55 \\
\hline $1 / 16 / 2006$ & EHV30-TC-30 & 0.359 & 55 \\
\hline \multicolumn{2}{|c|}{ Average } & 0.366 & \\
\cline { 1 - 2 } Standard Deviation & 0.009 & \\
\hline \multicolumn{2}{|c|}{ Number of Samples } & 5 & \\
\hline
\end{tabular}

Table 9.4-39: 35 wt\% Fortafil 243 / Vectra A950RX LCP

\begin{tabular}{|c|c|c|c|}
\hline Test Date & Sample Number & Through-Plane Thermal Conductivity (W/mK) & Temperature $\left({ }^{\circ} \mathrm{C}\right)$ \\
\hline $1 / 16 / 2006$ & EHV35-TC-15 & 0.391 & 55 \\
\hline $1 / 16 / 2006$ & EHV35-TC-18 & 0.419 & 55 \\
\hline $1 / 16 / 2006$ & EHV35-TC-21 & 0.456 & 55 \\
\hline $1 / 16 / 2006$ & EHV35-TC-24 & 0.439 & 55 \\
\hline $1 / 16 / 2006$ & EHV35-TC-27 & 0.421 & 55 \\
\hline $1 / 16 / 2006$ & EHV35-TC-30 & 0.456 & 55 \\
\hline \multicolumn{2}{|c|}{ Average } & 0.430 & \\
\hline \multicolumn{2}{|c|}{ Standard Deviation } & 0.025 & \\
\hline \multicolumn{2}{|c|}{ Number of Samples } & 6 & \\
\hline
\end{tabular}

Table 9.4-40: 40 wt\% Fortafil 243 / Vectra A950RX LCP

\begin{tabular}{|c|c|c|c|}
\hline Test Date & Sample Number & Through-Plane Thermal Conductivity (W/mK) & Temperature $\left({ }^{\circ} \mathrm{C}\right)$ \\
\hline $1 / 17 / 2006$ & EHV40-TC-15 & 0.530 & 55 \\
\hline $1 / 17 / 2006$ & EHV40-TC-18 & 0.532 & 55 \\
\hline $1 / 17 / 2006$ & EHV40-TC-21 & 0.502 & 55 \\
\hline $1 / 17 / 2006$ & EHV40-TC-24 & 0.544 & 55 \\
\hline $1 / 17 / 2006$ & EHV40-TC-27 & 0.528 & 55 \\
\hline $1 / 17 / 2006$ & EHV40-TC-30 & 0.525 & 55 \\
\hline \multicolumn{2}{|c|}{ Average } & 0.527 & \\
\hline \multicolumn{2}{|c|}{ Standard Deviation } & 0.014 & \\
\hline \multicolumn{2}{|c|}{ Number of Samples } & 6 & \\
\hline
\end{tabular}


Table 9.4-41: 45 wt\% Fortafil 243 / Vectra A950RX LCP

\begin{tabular}{|c|c|c|c|}
\hline Test Date & Sample Number & Through-Plane Thermal Conductivity $(\mathrm{W} / \mathrm{mK})$ & Temperature $\left({ }^{\circ} \mathrm{C}\right)$ \\
\hline $1 / 18 / 2006$ & EHV45-TC-15 & 0.613 & 55 \\
\hline $1 / 18 / 2006$ & EHV45-TC-18 & 0.633 & 55 \\
\hline $1 / 18 / 2006$ & EHV45-TC-21 & 0.563 & 55 \\
\hline $1 / 18 / 2006$ & EHV45-TC-24 & 0.627 & 55 \\
\hline $1 / 18 / 2006$ & EHV45-TC-27 & 0.554 & 55 \\
\hline $1 / 18 / 2006$ & EHV45-TC-30 & 0.601 & 55 \\
\hline \multicolumn{2}{|c|}{ Average } & 0.599 & \\
\cline { 1 - 2 } Standard Deviation & 0.033 & \\
\hline \multicolumn{2}{|c|}{ Number of Samples } & 6 & \\
\hline
\end{tabular}

Table 9.4-42: 50 wt\% Fortafil 243 / Vectra A950RX LCP

\begin{tabular}{|c|c|c|c|}
\hline Test Date & Sample Number & Through-Plane Thermal Conductivity (W/mK) & Temperature $\left({ }^{\circ} \mathrm{C}\right)$ \\
\hline $1 / 18 / 2006$ & EHV50R-TC-15 & 0.728 & 55 \\
\hline $1 / 18 / 2006$ & EHV50R-TC-18 & 0.702 & 55 \\
\hline $1 / 18 / 2006$ & EHV50R-TC-24 & 0.650 & 55 \\
\hline $1 / 18 / 2006$ & EHV50R-TC-27 & 0.671 & 55 \\
\hline \multicolumn{2}{|c|}{ Average } & 0.687 & \\
\cline { 1 - 2 } Standard Deviation & 0.034 & \\
\hline \multicolumn{2}{|c|}{ Number of Samples } & 4 & \\
\hline
\end{tabular}

Table 9.4-43: 55 wt\% Fortafil 243 / Vectra A950RX LCP

\begin{tabular}{|c|c|c|c|}
\hline Test Date & Sample Number & Through-Plane Thermal Conductivity (W/mK) & Temperature $\left({ }^{\circ} \mathrm{C}\right)$ \\
\hline $1 / 18 / 2006$ & EHV55-TC-15 & 0.889 & 55 \\
\hline $1 / 18 / 2006$ & EHV55-TC-18 & 0.782 & 55 \\
\hline $1 / 18 / 2006$ & EHV55-TC-21 & 0.882 & 55 \\
\hline $1 / 18 / 2006$ & EHV55-TC-27 & 0.835 & 55 \\
\hline $1 / 18 / 2006$ & EHV55-TC-30 & 0.793 & 55 \\
\hline \multicolumn{2}{|c|}{ Average } & 0.836 & \\
\cline { 1 - 2 } Standard Deviation & 0.050 & \\
\cline { 1 - 2 } Number of Samples & 5 & \\
\hline
\end{tabular}


Table 9.4-44: 60 wt\% Fortafil 243 / Vectra A950RX LCP

\begin{tabular}{|c|c|c|c|}
\hline Test Date & Sample Number & Through-Plane Thermal Conductivity $(\mathrm{W} / \mathrm{mK})$ & Temperature $\left({ }^{\circ} \mathrm{C}\right)$ \\
\hline $1 / 18 / 2006$ & EHV60R-TC-18 & 1.039 & 55 \\
\hline $1 / 18 / 2006$ & EHV60R-TC-21 & 1.042 & 55 \\
\hline $1 / 18 / 2006$ & EHV60R-TC-24 & 1.012 & 55 \\
\hline $1 / 18 / 2006$ & EHV60R-TC-27 & 1.038 & 55 \\
\hline $1 / 18 / 2006$ & EHV60R-TC-30 & 1.062 & 55 \\
\hline \multicolumn{2}{|c|}{ Average } & 1.039 & \\
\hline \multicolumn{2}{|c|}{ Standard Deviation } & 0.018 & \\
\hline \multicolumn{2}{|c|}{ Number of Samples } & 5 & \\
\hline
\end{tabular}




\section{Section 9.5: Specific Heat Data}

\section{Table 9.5-1: Vectra A950RX LCP}

\begin{tabular}{|c|c|c|}
\hline Test Date & Sample Number & Specific Heat $(\mathrm{J} / \mathrm{kgK})$ \\
\hline $6 / 27 / 2005$ & EVR-TC-17 & 1002.9 \\
\hline $6 / 27 / 2005$ & EVR-TC-17 & 1049.3 \\
\hline $6 / 27 / 2005$ & EVR-TC-17 & 1067.8 \\
\hline $6 / 27 / 2005$ & EVR-TC-17 & 1075.3 \\
\hline $6 / 27 / 2005$ & EVR-TC-17 & 1077.5 \\
\hline & Average & 1054.6 \\
\cline { 2 - 3 } & Standard Deviation & 30.9 \\
\cline { 2 - 3 } & Number of Samples & 5 \\
\hline
\end{tabular}

Table 9.5-2: 10 wt\% Thermocarb TC300 / Vectra A950RX LCP

\begin{tabular}{|c|c|c|}
\hline Test Date & Sample Number & Specific Heat (J/kgK) \\
\hline $6 / 28 / 2005$ & EBV10-TC-15 & 1020.0 \\
\hline $7 / 13 / 2005$ & EBV10-TC-15 & 1030.3 \\
\hline $6 / 28 / 2005$ & EBV10-TC-15 & 1034.8 \\
\hline $6 / 29 / 2005$ & EBV10-TC-15 & 1062.8 \\
\hline & Average & 1037.0 \\
\cline { 2 - 3 } & Standard Deviation & 18.3 \\
\cline { 2 - 3 } & Number of Samples & 4 \\
\hline
\end{tabular}

Table 9.5-3: 15 wt\% Thermocarb TC300 / Vectra A950RX LCP

\begin{tabular}{|c|c|c|}
\hline Test Date & Sample Number & Specific Heat (J/kgK) \\
\hline $6 / 28 / 2005$ & EBV15-TC-13 & 1005.6 \\
\hline $7 / 21 / 2005$ & EBV15-TC-13 & 1012.7 \\
\hline $6 / 29 / 2005$ & EBV15-TC-13 & 1037.4 \\
\hline $6 / 29 / 2008$ & EBV15-TC-22 & 1064.2 \\
\hline $7 / 13 / 2005$ & EBV15-TC-22 & 1054.1 \\
\hline & Average & 1034.8 \\
\cline { 2 - 3 } & Standard Deviation & 25.4 \\
\cline { 2 - 3 } & Number of Samples & 5 \\
\hline
\end{tabular}


Table 9.5-4: 20 wt\% Thermocarb TC300 / Vectra A950RX LCP

\begin{tabular}{|c|c|c|}
\hline Test Date & Sample Number & Specific Heat (J/kgK) \\
\hline $6 / 30 / 2005$ & EBV20-TC-11 & 990.3 \\
\hline $6 / 29 / 2005$ & EBV20-TC-11 & 1000.3 \\
\hline $6 / 29 / 2005$ & EBV20-TC-17 & 996.7 \\
\hline $7 / 12 / 2005$ & EBV20-TC-17 & 1011.8 \\
\hline $6 / 29 / 2005$ & EBV20-TC-21 & 985.1 \\
\hline $7 / 13 / 2005$ & EBV20-TC-21 & 992.9 \\
\hline & Average & 996.2 \\
\cline { 2 - 3 } & Standard Deviation & 9.3 \\
\cline { 2 - 3 } & Number of Samples & 6 \\
\hline
\end{tabular}

Table 9.5-5: 30 wt\% Thermocarb TC300 / Vectra A950RX LCP

\begin{tabular}{|c|c|c|}
\hline Test Date & Sample Number & Specific Heat $(\mathrm{J} / \mathrm{kgK})$ \\
\hline $6 / 30 / 2005$ & EBV30-TC-16 & 979.8 \\
\hline $6 / 30 / 2005$ & EBV30-TC-16 & 1007.1 \\
\hline $6 / 30 / 2005$ & EBV30-TC-18 & 973.4 \\
\hline $6 / 30 / 2005$ & EBV30-TC-18 & 977.4 \\
\hline $6 / 30 / 2005$ & EBV30-TC-22 & 974.1 \\
\hline $7 / 13 / 2005$ & EBV30-TC-22 & 1014.5 \\
\hline & Average & 987.7 \\
\cline { 2 - 3 } & Standard Deviation & 18.2 \\
\cline { 2 - 3 } & Number of Samples & 6 \\
\hline
\end{tabular}

Table 9.5-6: 30 wt\% Thermocarb TC300 / Vectra A950RX LCP

\begin{tabular}{|c|c|c|}
\hline Test Date & Sample Number & Specific Heat (J/kgK) \\
\hline $6 / 27 / 2005$ & EBV40-TC-10 & 972.2 \\
\hline $6 / 14 / 2005$ & EBV40-TC-12 & 929.5 \\
\hline $6 / 14 / 2005$ & EBV40-TC-12 & 949.4 \\
\hline $6 / 9 / 2005$ & EBV40-TC-12 & 974.5 \\
\hline $6 / 9 / 2005$ & EBV40-TC-12 & 976.8 \\
\hline $6 / 10 / 2005$ & EBV40-TC-12 & 981.6 \\
\hline $6 / 13 / 2005$ & EBV40-TC-12 & 985.7 \\
\hline $6 / 10 / 2005$ & EBV40-TC-14 & 960.0 \\
\hline $6 / 9 / 2005$ & EBV40-TC-14 & 970.2 \\
\hline $6 / 13 / 2005$ & EBV40-TC-14 & 976.1 \\
\hline & Average & 967.6 \\
\cline { 2 - 3 } & Standard Deviation & 17.0 \\
\cline { 2 - 3 } & Number of Samples & 10 \\
\hline
\end{tabular}


Table 9.5-7: 50 wt\% Thermocarb TC300 / Vectra A950RX LCP

\begin{tabular}{|c|c|c|}
\hline Test Date & Sample Number & Specific Heat (J/kgK) \\
\hline $7 / 5 / 2005$ & EBV50-TC-11 & 894.6 \\
\hline $7 / 5 / 2005$ & EBV50-TC-11 & 895.5 \\
\hline $7 / 5 / 2005$ & EBV50-TC-17 & 898.8 \\
\hline $7 / 12 / 2005$ & EBV50-TC-17 & 974.7 \\
\hline $7 / 5 / 2005$ & EBV50-TC-22 & 897.2 \\
\hline $7 / 12 / 2005$ & EBV50-TC-22 & 958.1 \\
\hline & Average & 919.8 \\
\cline { 2 - 3 } & Standard Deviation & 36.5 \\
\cline { 2 - 3 } & Number of Samples & 6 \\
\hline
\end{tabular}

Table 9.5-8: 55 wt\% Thermocarb TC300 / Vectra A950RX LCP

\begin{tabular}{|c|c|c|}
\hline Test Date & Sample Number & Specific Heat (J/kgK) \\
\hline $7 / 5 / 2005$ & EBV55-TC-11 & 902.9 \\
\hline $7 / 7 / 2005$ & EBV55-TC-11 & 921.8 \\
\hline $7 / 5 / 2005$ & EBV55-TC-16 & 874.4 \\
\hline $7 / 6 / 2005$ & EBV55-TC-16 & 902.8 \\
\hline $7 / 6 / 2005$ & EBV55-TC-28 & 909.1 \\
\hline & Average & 902.2 \\
\cline { 2 - 3 } & Standard Deviation & 17.4 \\
\cline { 2 - 3 } & Number of Samples & 5 \\
\hline
\end{tabular}

Table 9.5-9: 60 wt\% Thermocarb TC300 / Vectra A950RX LCP

\begin{tabular}{|c|c|c|}
\hline Test Date & Sample Number & Specific Heat (J/kgK) \\
\hline $6 / 15 / 2005$ & EBV60-TC-11 & 853.4 \\
\hline $6 / 14 / 2005$ & EBV60-TC-11 & 865.5 \\
\hline $6 / 16 / 2005$ & EBV60-TC-11 & 878.2 \\
\hline $6 / 14 / 2005$ & EBV60-TC-13 & 821.9 \\
\hline $6 / 15 / 2005$ & EBV60-TC-13 & 888.3 \\
\hline $6 / 15 / 2005$ & EBV60-TC-13 & 898.4 \\
\hline & Average & 867.6 \\
\cline { 2 - 3 } & Standard Deviation & 27.5 \\
\cline { 2 - 3 } & Number of Samples & 6 \\
\hline
\end{tabular}


Table 9.5-10: 65 wt\% Thermocarb TC300 / Vectra A950RX LCP

\begin{tabular}{|c|c|c|}
\hline Test Date & Sample Number & Specific Heat (J/kgK) \\
\hline $7 / 6 / 2005$ & EBV65-TC-17 & 852.7 \\
\hline $7 / 7 / 2005$ & EBV65-TC-17 & 859.6 \\
\hline $7 / 6 / 2005$ & EBV65-TC-21 & 875.2 \\
\hline $7 / 6 / 2005$ & EBV65-TC-26 & 849.3 \\
\hline $7 / 21 / 2005$ & EBV65-TC-26 & 867.1 \\
\hline & Average & 860.8 \\
\cline { 2 - 3 } & Standard Deviation & 10.6 \\
\cline { 2 - 3 } & Number of Samples & 5 \\
\hline
\end{tabular}

Table 9.5-11: 70 wt\% Thermocarb TC300 / Vectra A950RX LCP

\begin{tabular}{|c|c|c|}
\hline Test Date & Sample Number & Specific Heat $(\mathrm{J} / \mathrm{kgK})$ \\
\hline $7 / 7 / 2005$ & EBV70-TC-11 & 846.2 \\
\hline $7 / 11 / 2005$ & EBV70-TC-18 & 875.3 \\
\hline $7 / 11 / 2005$ & EBV70-TC-27 & 858.8 \\
\hline & Average & 860.1 \\
\cline { 2 - 3 } & Standard Deviation & 14.6 \\
\cline { 2 - 3 } & Number of Samples & 3 \\
\hline
\end{tabular}

Table 9.5-12: 75 wt\% Thermocarb TC300 / Vectra A950RX LCP

\begin{tabular}{|c|c|c|}
\hline Test Date & Sample Number & Specific Heat (J/kgK) \\
\hline $7 / 21 / 2005$ & EBV75-TC-9 & 852.2 \\
\hline $7 / 11 / 2005$ & EBV75-TC-9 & 855.8 \\
\hline $7 / 12 / 2005$ & EBV75-TC-9 & 879.7 \\
\hline $7 / 21 / 2005$ & EBV75-TC-10 & 797.6 \\
\hline $7 / 12 / 2005$ & EBV75-TC-10 & 843.5 \\
\hline $7 / 13 / 2005$ & EBV75-TC-10 & 857.7 \\
\hline $7 / 12 / 2005$ & EBV75-TC-10 & 863.7 \\
\hline & Average & 850.0 \\
\cline { 2 - 3 } & Standard Deviation & 25.7 \\
\cline { 2 - 3 } & Number of Samples & 7 \\
\hline
\end{tabular}


Table 9.5-13: 40 wt\% Asbury Synthetic Graphite 4012 / Vectra A950RX LCP

\begin{tabular}{|c|c|c|}
\hline Test Date & Sample Number & Specific Heat (J/kgK) \\
\hline $6 / 17 / 2005$ & ECV40-TC-11 & 905.9 \\
\hline $6 / 17 / 2005$ & ECV40-TC-11 & 921.7 \\
\hline $6 / 16 / 2005$ & ECV40-TC-11 & 933.2 \\
\hline $6 / 16 / 2005$ & ECV40-TC-11 & 955.1 \\
\hline $6 / 16 / 2005$ & ECV40-TC-16 & 897.4 \\
\hline $6 / 16 / 2005$ & ECV40-TC-16 & 903.6 \\
\hline $6 / 16 / 2005$ & ECV40-TC-16 & 904.1 \\
\hline & Average & 917.3 \\
\cline { 2 - 3 } & Standard Deviation & 20.8 \\
\cline { 2 - 3 } & Number of Samples & 7 \\
\hline
\end{tabular}

Table 9.5-14: 60 wt\% Asbury Synthetic Graphite 4012 / Vectra A950RX LCP

\begin{tabular}{|c|c|c|}
\hline Test Date & Sample Number & Specific Heat (J/kgK) \\
\hline $6 / 20 / 2005$ & ECV60-TC-14 & 852.1 \\
\hline $6 / 17 / 2005$ & ECV60-TC-14 & 879.4 \\
\hline $6 / 17 / 2005$ & ECV60-TC-14 & 888.7 \\
\hline $6 / 20 / 2005$ & ECV60-TC-19 & 853.3 \\
\hline $6 / 17 / 2005$ & ECV60-TC-19 & 855.9 \\
\hline $6 / 20 / 2005$ & ECV60-TC-19 & 867.2 \\
\hline & Average & 866.1 \\
\cline { 2 - 3 } & Standard Deviation & 15.2 \\
\cline { 2 - 3 } & Number of Samples & 6 \\
\hline
\end{tabular}

Table 9.5-15: 70 wt\% Asbury Synthetic Graphite 4012 / Vectra A950RX LCP

\begin{tabular}{|c|c|c|}
\hline Test Date & Sample Number & Specific Heat (J/kgK) \\
\hline $6 / 20 / 2005$ & ECV70-TC-11 & 789.6 \\
\hline $6 / 20 / 2005$ & ECV70-TC-11 & 793.2 \\
\hline $6 / 21 / 2005$ & ECV70-TC-11 & 834.0 \\
\hline $6 / 23 / 2005$ & ECV70-TC-11 & 838.8 \\
\hline $6 / 21 / 2005$ & ECV70-TC-13 & 853.7 \\
\hline $6 / 21 / 2005$ & ECV70-TC-13 & 856.8 \\
\hline & Average & 827.7 \\
\cline { 2 - 3 } & Standard Deviation & 29.4 \\
\cline { 2 - 3 } & Number of Samples & 6 \\
\hline
\end{tabular}


Table 9.5-16: 40 wt\% Asbury 3160 Natural Flake Graphite / Vectra A950RX LCP

\begin{tabular}{|c|c|c|}
\hline Test Date & Sample Number & Specific Heat (J/kgK) \\
\hline $8 / 29 / 2005$ & EDV40-TC-13 & 972.6 \\
\hline $8 / 29 / 2005$ & EDV40-TC-17 & 1016.9 \\
\hline $8 / 29 / 2005$ & EDV40-TC-25 & 988.7 \\
\hline 9/1/2005 & EDV40-TC-25 & 1010.0 \\
\hline & Average & 997.0 \\
\cline { 2 - 3 } & Standard Deviation & 20.2 \\
\cline { 2 - 3 } & Number of Samples & 4 \\
\hline
\end{tabular}

Table 9.5-17: 60 wt\% Asbury 3160 Natural Flake Graphite / Vectra A950RX LCP

\begin{tabular}{|c|c|c|}
\hline Test Date & Sample Number & Specific Heat $(\mathrm{J} / \mathrm{kgK})$ \\
\hline $8 / 30 / 2005$ & EDV60-TC-11 & 878.8 \\
\hline $8 / 30 / 2005$ & EDV60-TC-11 & 888.3 \\
\hline $8 / 30 / 2005$ & EDV60-TC-14 & 888.2 \\
\hline 9/1/2005 & EDV60-TC-14 & 932.1 \\
\hline $8 / 30 / 2005$ & EDV60-TC-20 & 861.5 \\
\hline $8 / 30 / 2005$ & EDV60-TC-20 & 870.9 \\
\hline & Average & 886.6 \\
\cline { 2 - 3 } & Standard Deviation & 24.5 \\
\cline { 2 - 3 } & Number of Samples & 6 \\
\hline
\end{tabular}

Table 9.5-18: 70 wt\% Asbury 3160 Natural Flake Graphite / Vectra A950RX LCP

\begin{tabular}{|c|c|c|}
\hline Test Date & Sample Number & Specific Heat (J/kgK) \\
\hline $8 / 31 / 2005$ & EDV70-TC-14 & 856.6 \\
\hline $8 / 31 / 2005$ & EDV70-TC-17 & 855.6 \\
\hline $8 / 31 / 2005$ & EDV70-TC-17 & 869.6 \\
\hline $8 / 31 / 2005$ & EDV70-TC-22 & 870.1 \\
\hline $8 / 31 / 2005$ & EDV70-TC-22 & 956.1 \\
\hline 9/1/2005 & EDV70-TC-28 & 882.8 \\
\hline 9/1/2005 & EDV70-TC-28 & 900.9 \\
\hline & Average & 884.5 \\
\cline { 2 - 3 } & Standard Deviation & 35.2 \\
\cline { 2 - 3 } & Number of Samples & 7 \\
\hline
\end{tabular}


Table 9.5-19: 40 wt\% Asbury F108A CNC / Vectra A950RX LCP

\begin{tabular}{|c|c|c|}
\hline Test Date & Sample Number & Specific Heat $(\mathrm{J} / \mathrm{kgK})$ \\
\hline 9/2/2005 & EEV40-TC-17 & 784.3 \\
\hline 9/2/2005 & EEV40-TC-21 & 779.3 \\
\hline 9/2/2005 & EEV40-TC-21 & 771.2 \\
\hline & Average & 778.3 \\
\cline { 2 - 3 } & Standard Deviation & 6.6 \\
\cline { 2 - 3 } & Number of Samples & 3 \\
\hline
\end{tabular}

Table 9.5-20: 60 wt\% Asbury F108A CNC / Vectra A950RX LCP

\begin{tabular}{|c|c|c|}
\hline Test Date & Sample Number & Specific Heat (J/kgK) \\
\hline 9/3/2005 & EEV60-TC-17 & 763.2 \\
\hline 9/3/2005 & EEV60-TC-21 & 751.2 \\
\hline 9/3/2005 & EEV60-TC-21 & 784.7 \\
\hline & Average & 766.4 \\
\cline { 2 - 3 } & Standard Deviation & 17.0 \\
\cline { 2 - 3 } & Number of Samples & 3 \\
\hline
\end{tabular}

Table 9.5-21: 70 wt\% Asbury F108A CNC / Vectra A950RX LCP

\begin{tabular}{|c|c|c|}
\hline Test Date & Sample Number & Specific Heat (J/kgK) \\
\hline 9/4/2005 & EEV70-TC-18 & 746.6 \\
\hline 9/4/2005 & EEV70-TC-34 & 778.4 \\
\hline 9/4/2005 & EEV70-TC-34 & 754.9 \\
\hline & Average & 760.0 \\
\cline { 2 - 3 } & Standard Deviation & 16.5 \\
\cline { 2 - 3 } & Number of Samples & 3 \\
\hline
\end{tabular}


Table 9.5-22: 5 wt\% Fortafil 243 / Vectra A950RX LCP

\begin{tabular}{|c|c|c|}
\hline Test Date & Sample Number & Specific Heat (J/kgK) \\
\hline $3 / 27 / 2006$ & EHV5-TC-14 & 1050.3 \\
\hline $3 / 27 / 2006$ & EHV5-TC-29 & 1042.2 \\
\hline & Average & 1046.3 \\
\cline { 2 - 3 } & Standard Deviation & 5.8 \\
\cline { 2 - 3 } & Number of Samples & 2 \\
\hline & Theory Value & 1048.3 \\
\hline
\end{tabular}

Table 9.5-23: 7.5 wt\% Fortafil 243 / Vectra A950RX LCP

\begin{tabular}{|c|c|c|}
\hline Test Date & Sample Number & Specific Heat (J/kgK) \\
\hline $3 / 28 / 2006$ & EHV7.5-TC-14 & 1041.7 \\
\hline $3 / 28 / 2006$ & EHV7.5-TC-19 & 1036.2 \\
\hline & Average & 1039.0 \\
\cline { 2 - 3 } & Standard Deviation & 3.9 \\
\cline { 2 - 3 } & Number of Samples & 2 \\
\hline & Theory Value & 1045.0 \\
\hline
\end{tabular}

Table 9.5-24: 10 wt\% Fortafil 243 / Vectra A950RX LCP

\begin{tabular}{|c|c|c|}
\hline Test Date & Sample Number & Specific Heat (J/kgK) \\
\hline $3 / 29 / 2006$ & EHV10-TC-19 & 1006.4 \\
\hline $3 / 29 / 2006$ & EHV10-TC-29 & 1037.1 \\
\hline & Average & 1021.7 \\
\cline { 2 - 3 } & Standard Deviation & 21.6 \\
\cline { 2 - 3 } & Number of Samples & 2 \\
\hline & Theory Value & 1041.6 \\
\hline
\end{tabular}


Table 9.5-25: 15 wt\% Fortafil 243 / Vectra A950RX LCP

\begin{tabular}{|c|c|c|}
\hline Test Date & Sample Number & Specific Heat $(\mathrm{J} / \mathrm{kgK})$ \\
\hline $3 / 29 / 2006$ & EHV15-TC-14 & 1016.4 \\
\hline $3 / 29 / 2006$ & EHV15-TC-19 & 1019.2 \\
\hline $3 / 29 / 2006$ & EHV15-TC-29 & 1021.2 \\
\hline & Average & 1018.9 \\
\cline { 2 - 3 } & Standard Deviation & 2.4 \\
\cline { 2 - 3 } & Number of Samples & 3 \\
\hline & Theory Value & 1034.9 \\
\hline
\end{tabular}

Table 9.5-26: 20 wt\% Fortafil 243 / Vectra A950RX LCP

\begin{tabular}{|c|c|c|}
\hline Test Date & Sample Number & Specific Heat (J/kgK) \\
\hline $4 / 1 / 2006$ & EHV20-TC-14 & 1024.8 \\
\hline $4 / 1 / 2006$ & EHV20-TC-19 & 1014.5 \\
\hline $4 / 1 / 2006$ & EHV20-TC-29 & 1023.5 \\
\hline & Average & 1020.9 \\
\cline { 2 - 3 } & Standard Deviation & 5.6 \\
\cline { 2 - 3 } & Number of Samples & 3 \\
\hline & Theory Value & 1028.2 \\
\hline
\end{tabular}

Table 9.5-27: 30 wt\% Fortafil 243 / Vectra A950RX LCP

\begin{tabular}{|c|c|c|}
\hline Test Date & Sample Number & Specific Heat (J/kgK) \\
\hline $4 / 2 / 2006$ & EHV30-TC-19 & 1011.8 \\
\hline $4 / 2 / 2006$ & EHV30-TC-29 & 1007.9 \\
\hline & Average & 1009.9 \\
\cline { 2 - 3 } & Standard Deviation & 2.8 \\
\cline { 2 - 3 } & Number of Samples & 2 \\
\hline & Theory Value & 1014.8 \\
\hline
\end{tabular}


Table 9.5-28: 35 wt\% Fortafil 243 / Vectra A950RX LCP

\begin{tabular}{|c|c|c|}
\hline Test Date & Sample Number & Specific Heat (J/kgK) \\
\hline $4 / 3 / 2006$ & EHV35-TC-14 & 988.9 \\
\hline $4 / 3 / 2006$ & EHV35-TC-29 & 1003.7 \\
\hline & Average & 996.3 \\
\cline { 2 - 3 } & Standard Deviation & 10.5 \\
\cline { 2 - 3 } & Number of Samples & 2 \\
\hline & Theory Value & 1008.1 \\
\hline
\end{tabular}

Table 9.5-29: Theoretical Values for Fortafil 243 / Vectra Composites

\begin{tabular}{|c|c|}
\hline Sample Number & Specific Heat $(\mathrm{J} / \mathrm{kgK})$ \\
\hline EHV5 & 1048.3 \\
\hline EHV7.5 & 1045.0 \\
\hline EHV10 & 1041.6 \\
\hline EHV15 & 1034.9 \\
\hline EHV20 & 1028.2 \\
\hline EHV25 & 1021.5 \\
\hline EHV30 & 1014.8 \\
\hline EHV35 & 1008.1 \\
\hline EHV40 & 1001.4 \\
\hline EHV45 & 994.7 \\
\hline EHV50R & 988.0 \\
\hline EHV55 & 981.3 \\
\hline EHV60R & 974.6 \\
\hline
\end{tabular}

The results in Table E.29 were derived from the following formula:

$$
\sum_{i=1}^{2} M_{i}{ }^{*} C p_{i}
$$

In this equation, $M$ is the mass fraction of the material, $C p$ is the specific heat of the material, $i=1$ denotes the Vectra and $i=2$ denotes the Fortafil 243 carbon fiber. Values used for $C p$ were $1055 \mathrm{~J} /(\mathrm{kgK})$ for the Vectra and $921 \mathrm{~J} /(\mathrm{kgK})$ for the Fortafil 243 carbon fiber. As shown above in Tables 9.5-22 - 9.5-28, the formula results showed good agreement with experimental data. 
Section 9.6: Hot Disk Thermal Conductivity Data

\section{Table 9.6-1: 10 wt\% Thermocarb TC300 / Vectra A950RX LCP}

\begin{tabular}{|c|c|c|c|c|c|}
\hline Test Date & $\begin{array}{c}\text { Disk } \\
\text { Numbers }\end{array}$ & $\begin{array}{c}\text { Axial Thermal } \\
\text { Conductivity }(\mathrm{W} / \mathrm{mK})\end{array}$ & $\begin{array}{c}\text { Radial Thermal } \\
\text { Conductivity }(\mathrm{W} / \mathrm{mK})\end{array}$ & $\begin{array}{l}\text { Power } \\
\text { (W) }\end{array}$ & $\begin{array}{c}\text { Time } \\
(\mathrm{s})\end{array}$ \\
\hline $1 / 20 / 2006$ & $14,13,12,11$ & 0.2835 & 1.4224 & 0.030 & 40 \\
\hline $1 / 20 / 2006$ & $29,27,22,20$ & 0.2858 & 1.3828 & 0.030 & 40 \\
\hline $1 / 20 / 2006$ & $22,11,20,12$ & 0.2836 & 1.4717 & 0.040 & 40 \\
\hline \multicolumn{2}{|c|}{ Average } & 0.2843 & 1.4256 & & \\
\hline \multicolumn{2}{|c|}{ Standard Deviation } & 0.0013 & 0.0445 & & \\
\hline \multicolumn{2}{|c|}{ Number of Samples } & 3 & 3 & & \\
\hline
\end{tabular}

Table 9.6-2: 15 wt\% Thermocarb TC300 / Vectra A950RX LCP

\begin{tabular}{|c|c|c|c|c|c|}
\hline Test Date & $\begin{array}{c}\text { Disk } \\
\text { Numbers }\end{array}$ & $\begin{array}{c}\text { Axial Thermal } \\
\text { Conductivity (W/mK) }\end{array}$ & $\begin{array}{c}\text { Radial Thermal } \\
\text { Conductivity (W/mK) }\end{array}$ & $\begin{array}{l}\text { Power } \\
\text { (W) }\end{array}$ & $\begin{array}{c}\text { Time } \\
\text { (s) }\end{array}$ \\
\hline $1 / 19 / 2006$ & $11,20,27,15$ & 0.3238 & 1.8154 & 0.035 & 40 \\
\hline $1 / 19 / 2006$ & $12,24,26,27$ & 0.3223 & 1.8339 & 0.050 & 40 \\
\hline $1 / 19 / 2006$ & $24,18,17,26$ & 0.3239 & 1.9101 & 0.040 & 40 \\
\hline \multicolumn{2}{|c|}{ Average } & 0.3233 & 1.8531 & & \\
\hline \multicolumn{2}{|c|}{ Standard Deviation } & 0.0009 & 0.0502 & & \\
\hline \multicolumn{2}{|c|}{ Number of Samples } & 3 & 3 & & \\
\hline
\end{tabular}

Table 9.6-3: 20 wt\% Thermocarb TC300 / Vectra A950RX LCP

\begin{tabular}{|c|c|c|c|c|c|}
\hline Test Date & $\begin{array}{c}\text { Disk } \\
\text { Numbers }\end{array}$ & $\begin{array}{c}\text { Axial Thermal } \\
\text { Conductivity }(\mathrm{W} / \mathrm{mK})\end{array}$ & $\begin{array}{c}\text { Radial Thermal } \\
\text { Conductivity (W/mK) }\end{array}$ & $\begin{array}{l}\text { Power } \\
\text { (W) }\end{array}$ & $\begin{array}{l}\text { Time } \\
(\mathrm{s})\end{array}$ \\
\hline $12 / 19 / 2005$ & $09,13,16,26$ & 0.3905 & 1.9969 & 0.180 & 40 \\
\hline $12 / 19 / 2005$ & $10,14,18,27$ & 0.3899 & 2.0915 & 0.180 & 40 \\
\hline $12 / 19 / 2005$ & $08,12,15,23$ & 0.3736 & 1.9971 & 0.180 & 40 \\
\hline \multicolumn{2}{|c|}{ Average } & 0.3847 & 2.0285 & & \\
\hline \multicolumn{2}{|c|}{ Standard Deviation } & 0.0096 & 0.0546 & & \\
\hline \multicolumn{2}{|c|}{ Number of Samples } & 3 & 3 & & \\
\hline
\end{tabular}


Table 9.6-4: 25 wt\% Thermocarb TC300 / Vectra A950RX LCP

\begin{tabular}{|c|c|c|c|c|c|}
\hline Test Date & $\begin{array}{c}\text { Disk } \\
\text { Numbers }\end{array}$ & $\begin{array}{c}\text { Axial Thermal } \\
\text { Conductivity (W/mK) }\end{array}$ & $\begin{array}{c}\text { Radial Thermal } \\
\text { Conductivity (W/mK) }\end{array}$ & $\begin{array}{l}\text { Power } \\
\text { (W) }\end{array}$ & $\begin{array}{c}\text { Time } \\
(\mathrm{s})\end{array}$ \\
\hline $12 / 15 / 2005$ & $25,28,16,29$ & 0.4837 & 2.2703 & 0.210 & 40 \\
\hline $12 / 15 / 2005$ & $14,23,17,12$ & 0.4409 & 2.5213 & 0.220 & 40 \\
\hline $12 / 15 / 2005$ & $19,32,22,11$ & 0.4519 & 2.5092 & 0.220 & 40 \\
\hline \multicolumn{2}{|c|}{ Average } & 0.4588 & 2.4336 & & \\
\hline \multicolumn{2}{|c|}{ Standard Deviation } & 0.0222 & 0.1416 & & \\
\hline \multicolumn{2}{|c|}{ Number of Samples } & 3 & 3 & & \\
\hline
\end{tabular}

Table 9.6-5: 30 wt\% Thermocarb TC300 / Vectra A950RX LCP

\begin{tabular}{|c|c|c|c|c|c|}
\hline Test Date & $\begin{array}{c}\text { Disk } \\
\text { Numbers }\end{array}$ & $\begin{array}{c}\text { Axial Thermal } \\
\text { Conductivity (W/mK) }\end{array}$ & $\begin{array}{c}\text { Radial Thermal } \\
\text { Conductivity (W/mK) }\end{array}$ & $\begin{array}{l}\text { Power } \\
\text { (W) }\end{array}$ & $\begin{array}{c}\text { Time } \\
(\mathrm{s})\end{array}$ \\
\hline $12 / 15 / 2005$ & $13,21,12,23$ & 0.5621 & 2.9000 & 0.200 & 40 \\
\hline $12 / 15 / 2005$ & $27,26,20,11$ & 0.5345 & 2.9032 & 0.200 & 40 \\
\hline $12 / 15 / 2005$ & $21,15,13,14$ & 0.5379 & 3.0119 & 0.210 & 40 \\
\hline \multicolumn{2}{|c|}{ Average } & 0.5448 & 2.9384 & & \\
\hline \multicolumn{2}{|c|}{ Standard Deviation } & 0.0151 & 0.0637 & & \\
\hline \multicolumn{2}{|c|}{ Number of Samples } & 3 & 3 & & \\
\hline
\end{tabular}

Table 9.6-6: 35 wt\% Thermocarb TC300 / Vectra A950RX LCP

\begin{tabular}{|c|c|c|c|c|c|}
\hline Test Date & $\begin{array}{l}\text { Disk } \\
\text { Numbers }\end{array}$ & $\begin{array}{c}\text { Axial Thermal } \\
\text { Conductivity }(\mathrm{W} / \mathrm{mK})\end{array}$ & $\begin{array}{c}\text { Radial Thermal } \\
\text { Conductivity (W/mK) }\end{array}$ & $\begin{array}{l}\text { Power } \\
\text { (W) }\end{array}$ & $\begin{array}{l}\text { Time } \\
(\mathrm{s})\end{array}$ \\
\hline $12 / 15 / 2005$ & $14,17,16,25$ & 0.6244 & 4.3845 & 0.190 & 20 \\
\hline $12 / 15 / 2005$ & $14,28,12,33$ & 0.6596 & 4.3850 & 0.195 & 20 \\
\hline $12 / 15 / 2005$ & $26,17,25,16$ & 0.6220 & 4.4439 & 0.200 & 20 \\
\hline \multicolumn{2}{|c|}{ Average } & 0.6353 & 4.4045 & & \\
\hline \multicolumn{2}{|c|}{ Standard Deviation } & 0.0210 & 0.0342 & & \\
\hline \multicolumn{2}{|c|}{ Number of Samples } & 3 & 3 & & \\
\hline
\end{tabular}


Table 9.6-7: 40 wt\% Fortafil 243 Carbon Fiber / Vectra A950RX LCP

\begin{tabular}{|c|c|c|c|c|c|}
\hline $\begin{array}{c}\text { Test } \\
\text { Date }\end{array}$ & $\begin{array}{c}\text { Disk } \\
\text { Numbers }\end{array}$ & $\begin{array}{c}\text { Axial Thermal Conductivity } \\
(\mathrm{W} / \mathrm{mK})\end{array}$ & $\begin{array}{c}\text { Radial Thermal } \\
\text { Conductivity (W/mK) }\end{array}$ & $\begin{array}{c}\text { Power } \\
\text { (W) }\end{array}$ & $\begin{array}{c}\text { Time } \\
\text { (s) }\end{array}$ \\
\hline $9 / 1 / 2005$ & 13,15 & 0.7750 & 5.0466 & 0.050 & 5 \\
\hline $9 / 1 / 2005$ & 21,24 & 0.6425 & 6.4717 & 0.050 & 5 \\
\hline $9 / 1 / 2005$ & 25,13 & 0.5981 & 6.6101 & 0.050 & 5 \\
\hline $9 / 1 / 2005$ & 15,21 & 0.7703 & 5.6035 & 0.050 & 5 \\
\hline $9 / 1 / 2005$ & 24,25 & 0.7232 & 5.6712 & 0.050 & 5 \\
\hline \multicolumn{2}{|c|}{ Average } & 0.7018 & 5.8806 & & \\
\hline \multicolumn{2}{|c|}{ Standard Deviation } & 0.0787 & 0.6515 & & \\
\hline \multicolumn{2}{|c|}{ Number of Samples } & 5 & 5 & & \\
\hline
\end{tabular}

Table 9.6-8: 45 wt\% Thermocarb TC300 / Vectra A950RX LCP

\begin{tabular}{|c|c|c|c|c|c|}
\hline Test Date & $\begin{array}{c}\text { Disk } \\
\text { Numbers }\end{array}$ & $\begin{array}{c}\text { Axial Thermal } \\
\text { Conductivity (W/mK) }\end{array}$ & $\begin{array}{c}\text { Radial Thermal } \\
\text { Conductivity (W/mK) }\end{array}$ & $\begin{array}{l}\text { Power } \\
\text { (W) }\end{array}$ & $\begin{array}{c}\text { Time } \\
(\mathrm{s})\end{array}$ \\
\hline $12 / 15 / 2005$ & $16,26,19,11$ & 0.8668 & 6.2507 & 0.700 & 10 \\
\hline $12 / 15 / 2005$ & $31,22,23,12$ & 0.8795 & 6.7666 & 0.700 & 10 \\
\hline $12 / 15 / 2005$ & $33,14,17,25$ & 0.8728 & 6.3041 & 0.700 & 10 \\
\hline \multicolumn{2}{|c|}{ Average } & 0.8730 & 6.4405 & & \\
\hline \multicolumn{2}{|c|}{ Standard Deviation } & 0.0064 & 0.2837 & & \\
\hline \multicolumn{2}{|c|}{ Number of Samples } & 3 & 3 & & \\
\hline
\end{tabular}

Table 9.6-9: 50 wt\% Thermocarb TC300 / Vectra A950RX LCP

\begin{tabular}{|c|c|c|c|c|c|}
\hline Test Date & $\begin{array}{c}\text { Disk } \\
\text { Numbers }\end{array}$ & $\begin{array}{c}\text { Axial Thermal } \\
\text { Conductivity (W/mK) }\end{array}$ & $\begin{array}{c}\text { Radial Thermal } \\
\text { Conductivity (W/mK) }\end{array}$ & $\begin{array}{l}\text { Power } \\
\text { (W) }\end{array}$ & $\begin{array}{c}\text { Time } \\
(\mathrm{s})\end{array}$ \\
\hline $12 / 12 / 2005$ & $14,25,26,12$ & 1.1010 & 9.0403 & 0.270 & 10 \\
\hline $12 / 12 / 2005$ & $15,19,28,24$ & 1.1110 & 8.9916 & 0.260 & 10 \\
\hline $12 / 12 / 2005$ & $25,14,12,26$ & 1.0898 & 9.0273 & 0.250 & 10 \\
\hline \multicolumn{2}{|c|}{ Average } & 1.1006 & 9.0198 & & \\
\hline \multicolumn{2}{|c|}{ Standard Deviation } & 0.0106 & 0.0252 & & \\
\hline \multicolumn{2}{|c|}{ Number of Samples } & 3 & 3 & & \\
\hline
\end{tabular}


Table 9.6-10: 55 wt\% Thermocarb TC300 / Vectra A950RX LCP

\begin{tabular}{|c|c|c|c|c|c|}
\hline Test Date & $\begin{array}{c}\text { Disk } \\
\text { Numbers }\end{array}$ & $\begin{array}{c}\text { Axial Thermal } \\
\text { Conductivity (W/mK) }\end{array}$ & $\begin{array}{c}\text { Radial Thermal } \\
\text { Conductivity (W/mK) }\end{array}$ & $\begin{array}{l}\text { Power } \\
\text { (W) }\end{array}$ & $\begin{array}{c}\text { Time } \\
(\mathrm{s})\end{array}$ \\
\hline $12 / 12 / 2005$ & $20,15,17,24$ & 1.2751 & 12.3004 & 0.290 & 10 \\
\hline $12 / 12 / 2005$ & $20,15,32,12$ & 1.2546 & 13.4946 & 0.290 & 10 \\
\hline $12 / 12 / 2005$ & $31,29,32,12$ & 1.2659 & 12.5972 & 0.300 & 10 \\
\hline \multicolumn{2}{|c|}{ Average } & 1.2652 & 12.7974 & & \\
\hline \multicolumn{2}{|c|}{ Standard Deviation } & 0.0103 & 0.6217 & & \\
\hline \multicolumn{2}{|c|}{ Number of Samples } & 3 & 3 & & \\
\hline
\end{tabular}

Table 9.6-11: 60 wt\% Thermocarb TC300 / Vectra A950RX LCP

\begin{tabular}{|c|c|c|c|c|c|}
\hline Test Date & $\begin{array}{c}\text { Disk } \\
\text { Numbers }\end{array}$ & $\begin{array}{c}\text { Axial Thermal } \\
\text { Conductivity (W/mK) }\end{array}$ & $\begin{array}{c}\text { Radial Thermal } \\
\text { Conductivity (W/mK) }\end{array}$ & $\begin{array}{l}\text { Power } \\
\text { (W) }\end{array}$ & $\begin{array}{c}\text { Time } \\
(\mathrm{s})\end{array}$ \\
\hline $12 / 15 / 2005$ & $29,12,18,30$ & 1.5639 & 15.7023 & 0.310 & 10 \\
\hline $12 / 15 / 2005$ & $16,24,19,26$ & 1.4953 & 16.2898 & 0.310 & 10 \\
\hline $12 / 15 / 2005$ & $19,30,16,24$ & 1.5771 & 16.1134 & 0.300 & 10 \\
\hline \multicolumn{2}{|c|}{ Average } & 1.5454 & 16.0351 & & \\
\hline \multicolumn{2}{|c|}{ Standard Deviation } & 0.0439 & 0.3015 & & \\
\hline \multicolumn{2}{|c|}{ Number of Samples } & 3 & 3 & & \\
\hline
\end{tabular}

Table 9.6-12: 65 wt \% Thermocarb TC300 / Vectra A950RX LCP

\begin{tabular}{|c|c|c|c|c|c|}
\hline Test Date & $\begin{array}{c}\text { Disk } \\
\text { Numbers }\end{array}$ & $\begin{array}{c}\text { Axial Thermal } \\
\text { Conductivity }(\mathrm{W} / \mathrm{mK})\end{array}$ & $\begin{array}{c}\text { Radial Thermal } \\
\text { Conductivity }(\mathrm{W} / \mathrm{mK})\end{array}$ & $\begin{array}{l}\text { Power } \\
\text { (W) }\end{array}$ & $\begin{array}{c}\text { Time } \\
\text { (s) }\end{array}$ \\
\hline $12 / 15 / 2005$ & $10,27,12,15$ & 1.9250 & 21.0332 & 0.405 & 2.5 \\
\hline $12 / 15 / 2005$ & $27,10,15,12$ & 2.0259 & 22.2389 & 0.410 & 2.5 \\
\hline $12 / 15 / 2005$ & $10,9,11,15$ & 1.9950 & 21.5280 & 0.425 & 2.5 \\
\hline \multicolumn{2}{|c|}{ Average } & 1.9820 & 21.6000 & & \\
\hline \multicolumn{2}{|c|}{ Standard Deviation } & 0.0517 & 0.6061 & & \\
\hline \multicolumn{2}{|c|}{ Number of Samples } & 3 & 3 & & \\
\hline
\end{tabular}


Table 9.6-13: 70 wt\% Thermocarb TC300 / Vectra A950RX LCP

\begin{tabular}{|c|c|c|c|c|c|}
\hline Test Date & $\begin{array}{c}\text { Disk } \\
\text { Numbers }\end{array}$ & $\begin{array}{c}\text { Axial Thermal } \\
\text { Conductivity (W/mK) }\end{array}$ & $\begin{array}{c}\text { Radial Thermal } \\
\text { Conductivity (W/mK) }\end{array}$ & $\begin{array}{l}\text { Power } \\
\text { (W) }\end{array}$ & $\begin{array}{l}\text { Time } \\
\text { (s) }\end{array}$ \\
\hline $1 / 17 / 2006$ & $12,15,29,23$ & 2.3369 & 32.0626 & 0.500 & 2.5 \\
\hline $1 / 18 / 2006$ & $12,29,30,23$ & 2.2631 & 31.6455 & 1.240 & 2.5 \\
\hline $1 / 18 / 2006$ & $29,12,23,30$ & 2.3556 & 33.9381 & 1.210 & 2.5 \\
\hline \multicolumn{2}{|c|}{ Average } & 2.3186 & 32.5488 & & \\
\hline \multicolumn{2}{|c|}{ Standard Deviation } & 0.0489 & 1.2212 & & \\
\hline \multicolumn{2}{|c|}{ Number of Samples } & 3 & 3 & & \\
\hline
\end{tabular}

Table 9.6-14: 75 wt\% Thermocarb TC300 / Vectra A950RX LCP

\begin{tabular}{|c|c|c|c|c|c|}
\hline Test Date & $\begin{array}{c}\text { Disk } \\
\text { Numbers }\end{array}$ & $\begin{array}{l}\text { Axial Thermal Conductivity } \\
(\mathrm{W} / \mathrm{mK})\end{array}$ & $\begin{array}{c}\text { Radial Thermal } \\
\text { Conductivity (W/mK) }\end{array}$ & $\begin{array}{l}\text { Power } \\
\text { (W) }\end{array}$ & $\begin{array}{c}\text { Time } \\
(\mathrm{s})\end{array}$ \\
\hline $1 / 18 / 2006$ & $5,12,11,6$ & 2.6282 & 50.1980 & 1.250 & 2.5 \\
\hline $1 / 18 / 2006$ & $5,10,8,12$ & 2.6983 & 47.1954 & 1.250 & 2.5 \\
\hline $1 / 18 / 2006$ & $11,12,5,6$ & 2.5460 & 46.8229 & 1.250 & 2.5 \\
\hline \multicolumn{2}{|c|}{ Average } & 2.6242 & 48.0721 & & \\
\hline \multicolumn{2}{|c|}{ Standard Deviation } & 0.0762 & 1.8505 & & \\
\hline \multicolumn{2}{|c|}{ Number of Samples } & 3 & 3 & & \\
\hline
\end{tabular}

Table 9.6-15: 40 wt\% Asbury Synthetic Graphite 4012 / Vectra A950RX LCP

\begin{tabular}{|c|c|c|c|c|c|}
\hline Test Date & Disk Numbers & $\begin{array}{c}\text { Axial Thermal } \\
\text { Conductivity } \\
\text { (W/mK) }\end{array}$ & $\begin{array}{l}\text { Radial Thermal } \\
\text { Conductivity } \\
\text { (W/mK) }\end{array}$ & Power (W) & Time (s) \\
\hline $10 / 11 / 2005$ & $15-25$ & 0.5860 & 3.4907 & 0.050 & 5 \\
\hline 10/11/2005 & $17-19$ & 0.5746 & 3.9981 & 0.050 & 5 \\
\hline 10/11/2005 & $18-23$ & 0.6590 & 3.3976 & 0.050 & 5 \\
\hline $10 / 11 / 2005$ & $13-22$ & 0.6358 & 3.5570 & 0.050 & 5 \\
\hline 10/11/2005 & $14-27$ & 0.6756 & 3.3010 & 0.050 & 5 \\
\hline \multicolumn{2}{|c|}{ Average } & 0.6262 & 3.5489 & & \\
\hline \multicolumn{2}{|c|}{ Standard Deviation } & 0.0444 & 0.2691 & & \\
\hline \multicolumn{2}{|c|}{ Number of Samples } & 5 & 5 & & \\
\hline
\end{tabular}


Table 9.6-16: 60 wt\% Asbury Synthetic Graphite 4012 / Vectra A950RX LCP

\begin{tabular}{|c|c|c|c|c|c|}
\hline Test Date & $\begin{array}{c}\text { Disk } \\
\text { Numbers }\end{array}$ & $\begin{array}{l}\text { Axial Thermal Conductivity } \\
(\mathrm{W} / \mathrm{mK})\end{array}$ & $\begin{array}{c}\text { Radial Thermal } \\
\text { Conductivity (W/mK) }\end{array}$ & $\begin{array}{l}\text { Power } \\
\text { (W) }\end{array}$ & $\begin{array}{c}\text { Time } \\
(\mathrm{s})\end{array}$ \\
\hline $9 / 27 / 2005$ & $13-16$ & 1.4956 & 11.8618 & 1.500 & 2.5 \\
\hline $9 / 27 / 2005$ & $14-27$ & 1.5120 & 12.7100 & 0.100 & 10 \\
\hline $9 / 27 / 2005$ & $25-28$ & 1.4648 & 13.1632 & 1.500 & 2.5 \\
\hline $9 / 27 / 2005$ & $30-31$ & 1.3850 & 12.7209 & 1.500 & 2.5 \\
\hline $9 / 27 / 2005$ & $32-33$ & 1.4457 & 14.5137 & 1.500 & 2.5 \\
\hline \multicolumn{2}{|c|}{ Average } & 1.4606 & 12.9939 & & \\
\hline \multicolumn{2}{|c|}{ Standard Deviation } & 0.0496 & 0.9715 & & \\
\hline \multicolumn{2}{|c|}{ Number of Samples } & 5 & 5 & & \\
\hline
\end{tabular}

Table 9.6-17: 70 wt\% Asbury Synthetic Graphite 4012 / Vectra A950RX LCP

\begin{tabular}{|c|c|c|c|c|c|}
\hline Test Date & $\begin{array}{c}\text { Disk } \\
\text { Numbers }\end{array}$ & $\begin{array}{c}\text { Axial Thermal Conductivity } \\
\text { (W/mK) }\end{array}$ & $\begin{array}{c}\text { Radial Thermal } \\
\text { Conductivity (W/mK) }\end{array}$ & $\begin{array}{c}\text { Power } \\
\text { (W) }\end{array}$ & $\begin{array}{c}\text { Time } \\
\text { (s) }\end{array}$ \\
\hline $9 / 30 / 2005$ & $10-14$ & 2.0567 & 28.2574 & 2.000 & 2.5 \\
\hline $9 / 30 / 2005$ & $6-7$ & 2.0525 & 28.4006 & 2.000 & 2.5 \\
\hline $9 / 30 / 2005$ & $10-14$ & 2.0980 & 26.6300 & 2.000 & 2.5 \\
\hline $9 / 30 / 2005$ & $6-10$ & 2.0874 & 27.5018 & 2.000 & 2.5 \\
\hline $9 / 30 / 2005$ & $7-14$ & 2.0478 & 28.7163 & 2.000 & 2.5 \\
\hline \multicolumn{2}{|r|}{ Average } & 2.0685 & 27.9012 & & \\
\cline { 1 - 2 } Standard Deviation & 0.0226 & 0.8391 & & \\
\hline \multicolumn{2}{|r|}{ Number of Samples } & 5 & 5 & & \\
\hline
\end{tabular}

Table 9.6-18: 40 wt\% Asbury 3160 Natural Flake Graphite / Vectra A950RX LCP

\begin{tabular}{|c|c|c|c|c|c|}
\hline Test Date & $\begin{array}{c}\text { Disk } \\
\text { Numbers }\end{array}$ & $\begin{array}{c}\text { Axial Thermal Conductivity } \\
\text { (W/mK) }\end{array}$ & $\begin{array}{c}\text { Radial Thermal } \\
\text { Conductivity (W/mK) }\end{array}$ & $\begin{array}{c}\text { Power } \\
\text { (W) }\end{array}$ & $\begin{array}{c}\text { Time } \\
\text { (s) }\end{array}$ \\
\hline $9 / 26 / 2005$ & $11-13$ & 0.5696 & 6.5730 & 0.050 & 5 \\
\hline $9 / 26 / 2005$ & $16-19$ & 0.6060 & 6.4663 & 0.050 & 5 \\
\hline $9 / 26 / 2005$ & $28-32$ & 0.6000 & 6.9260 & 0.050 & 5 \\
\hline $9 / 26 / 2005$ & $26-27$ & 0.5956 & 7.6353 & 0.050 & 5 \\
\cline { 1 - 3 } $9 / 26 / 2005$ & $28-32$ & 0.6036 & 6.9499 & 0.050 & 5 \\
\cline { 1 - 2 } Average & 0.5950 & 6.9101 & & \\
\hline \multicolumn{2}{|c|}{ Standard Deviation } & 0.0147 & 0.4578 & & \\
\hline \multicolumn{2}{|c|}{ Number of Samples } & 5 & 5 & \\
\hline
\end{tabular}


Table 9.6-19: 60 wt\% Asbury 3160 Natural Flake Graphite / Vectra A950RX LCP

\begin{tabular}{|c|c|c|c|c|c|}
\hline Test Date & $\begin{array}{c}\text { Disk } \\
\text { Numbers }\end{array}$ & $\begin{array}{c}\text { Axial Thermal Conductivity } \\
(\mathrm{W} / \mathrm{mK})\end{array}$ & $\begin{array}{c}\text { Radial Thermal } \\
\text { Conductivity (W/mK) }\end{array}$ & $\begin{array}{c}\text { Power } \\
(\mathrm{W})\end{array}$ & $\begin{array}{c}\text { Time } \\
(\mathrm{s})\end{array}$ \\
\hline $10 / 3 / 2005$ & $12-13$ & 1.3561 & 1.3561 & 0.120 & 10 \\
\hline $10 / 3 / 2005$ & $13-32$ & 1.3300 & 1.3300 & 0.100 & 10 \\
\hline $10 / 3 / 2005$ & $16-18$ & 1.4283 & 1.4283 & 0.070 & 10 \\
\hline $10 / 3 / 2005$ & $27-29$ & 1.3723 & 1.3723 & 0.200 & 10 \\
\hline $10 / 3 / 2005$ & $16-27$ & 1.3170 & 1.3170 & 0.055 & 10 \\
\hline \multicolumn{2}{|c|}{ Average } & 1.3607 & 1.3607 & & \\
\hline \multicolumn{2}{|c|}{ Standard Deviation } & 0.0435 & 0.0435 & & \\
\hline \multicolumn{2}{|c|}{ Number of Samples } & 5 & 5 & & \\
\hline
\end{tabular}

Table 9.6-20: 70 wt\% Asbury 3160 Natural Flake Graphite / Vectra A950RX LCP

\begin{tabular}{|c|c|c|c|c|c|}
\hline Test Date & $\begin{array}{c}\text { Disk } \\
\text { Numbers }\end{array}$ & $\begin{array}{c}\text { Axial Thermal } \\
\text { Conductivity (W/mK) }\end{array}$ & $\begin{array}{c}\text { Radial Thermal } \\
\text { Conductivity (W/mK) }\end{array}$ & $\begin{array}{c}\text { Power } \\
\text { (W) }\end{array}$ & $\begin{array}{c}\text { Time } \\
(\mathrm{s})\end{array}$ \\
\hline $9 / 29 / 2005$ & $11-13$ & 1.8961 & 35.5461 & 0.500 & 5 \\
\hline $10 / 13 / 2005$ & $20-24$ & 1.7630 & 34.8700 & 0.300 & 5 \\
\hline $9 / 29 / 2005$ & $20-24$ & 2.0762 & 33.7310 & 0.250 & 5 \\
\hline $10 / 13 / 2005$ & $20-24$ & 1.8708 & 34.2274 & 0.300 & 10 \\
\hline $9 / 29 / 2005$ & $13-15$ & 1.8714 & 35.1012 & 0.500 & 5 \\
\hline \multicolumn{2}{|c|}{ Average } & 1.8955 & 34.6951 & & \\
\cline { 1 - 2 } Standard Deviation & 0.1134 & 0.7190 & & \\
\hline \multicolumn{2}{c|}{ Number of Samples } & 5 & 5 &
\end{tabular}

\section{Table 9.6-21: 5wt\% Fortafil 243 Carbon Fiber / Vectra A950RX LCP}

\begin{tabular}{|c|c|c|c|c|c|}
\hline $\begin{array}{c}\text { Test } \\
\text { Date }\end{array}$ & $\begin{array}{c}\text { Disk } \\
\text { Numbers }\end{array}$ & $\begin{array}{c}\text { Axial Thermal Conductivity } \\
(\mathrm{W} / \mathrm{mK})\end{array}$ & $\begin{array}{c}\text { Radial Thermal } \\
\text { Conductivity (W/mK) }\end{array}$ & $\begin{array}{c}\text { Power } \\
\text { (W) }\end{array}$ & $\begin{array}{c}\text { Time } \\
\text { (s) }\end{array}$ \\
\hline $03 / 22 / 06$ & $23,28,17,16$ & 0.2366 & 1.1510 & 0.25 & 40 \\
\hline $03 / 22 / 06$ & $26,8,10,31$ & 0.2364 & 1.1810 & 0.25 & 40 \\
\hline $03 / 29 / 06$ & $31,26,16,23$ & 0.2365 & 1.1010 & 0.25 & 40 \\
\hline $03 / 29 / 06$ & $28,11,22,17$ & 0.2411 & 1.1450 & 0.4 & 40 \\
\hline $03 / 29 / 06$ & $10,23,16,12$ & 0.2405 & 1.1640 & 0.4 & 40 \\
\hline \multicolumn{2}{|c|}{ Average } & 0.2382 & 1.1484 & & \\
\cline { 1 - 2 } Standard Deviation & 0.0024 & 0.0299 & & \\
\hline \multicolumn{2}{|c|}{ Number of Samples } & 5 & 5 & & \\
\hline
\end{tabular}


Table 9.6-22: 7.5wt\% Fortafil 243 Carbon Fiber / Vectra A950RX LCP

\begin{tabular}{|c|c|c|c|c|c|}
\hline $\begin{array}{c}\text { Test } \\
\text { Date }\end{array}$ & $\begin{array}{c}\text { Disk } \\
\text { Numbers }\end{array}$ & $\begin{array}{c}\text { Axial Thermal Conductivity } \\
\text { (W/mK) }\end{array}$ & $\begin{array}{c}\text { Radial Thermal } \\
\text { Conductivity (W/mK) }\end{array}$ & $\begin{array}{c}\text { Power } \\
\text { (W) }\end{array}$ & $\begin{array}{c}\text { Time } \\
\text { (s) }\end{array}$ \\
\hline $03 / 22 / 06$ & $25,31,23,26$ & 0.2522 & 1.2440 & 0.4 & 20 \\
\hline $03 / 22 / 06$ & $11,22,16,13$ & 0.2553 & 1.2330 & 0.4 & 20 \\
\hline $03 / 30 / 06$ & $17,28,25,22$ & 0.2562 & 1.1950 & 0.4 & 20 \\
\hline $03 / 29 / 06$ & $13,28,17,12$ & 0.2586 & 1.2090 & 0.4 & 20 \\
\hline $03 / 29 / 06$ & $23,26,22,11$ & 0.2546 & 1.1580 & 0.4 & 20 \\
\hline \multicolumn{2}{|c|}{ Average } & 0.2554 & 1.2078 & & \\
\hline \multicolumn{2}{|c|}{ Standard Deviation } & 0.0023 & 0.0339 & & \\
\hline \multicolumn{2}{|c|}{ Number of Samples } & 5 & 5 & & \\
\hline
\end{tabular}

Table 9.6-23: 10wt\% Fortafil 243 Carbon Fiber / Vectra A950RX LCP

\begin{tabular}{|c|c|c|c|c|c|}
\hline $\begin{array}{l}\text { Test } \\
\text { Date }\end{array}$ & $\begin{array}{c}\text { Disk } \\
\text { Numbers }\end{array}$ & $\begin{array}{l}\text { Axial Thermal Conductivity } \\
(\mathrm{W} / \mathrm{mK})\end{array}$ & $\begin{array}{c}\text { Radial Thermal } \\
\text { Conductivity (W/mK) }\end{array}$ & $\begin{array}{l}\text { Power } \\
\text { (W) }\end{array}$ & $\begin{array}{c}\text { Time } \\
(\mathrm{s})\end{array}$ \\
\hline $03 / 22 / 06$ & $2,25,13,1$ & 0.2662 & 1.1650 & 0.4 & 20 \\
\hline $03 / 29 / 06$ & $16,10,13,25$ & 0.2761 & 1.2110 & 0.4 & 20 \\
\hline $03 / 29 / 06$ & $16,11,17,22$ & 0.2673 & 1.2430 & 0.4 & 20 \\
\hline 03/29/06 & $25,13,28,20$ & 0.2755 & 1.3060 & 0.4 & 20 \\
\hline 03/29/06 & $8,26,10,9$ & 0.2690 & 1.2430 & 0.4 & 20 \\
\hline \multicolumn{2}{|c|}{ Average } & 0.2708 & 1.2336 & & \\
\hline \multicolumn{2}{|c|}{ Standard Deviation } & 0.0047 & 0.0516 & & \\
\hline \multicolumn{2}{|c|}{ Number of Samples } & 5 & 5 & & \\
\hline
\end{tabular}

Table 9.6-24: 15wt\% Fortafil 243 Carbon Fiber / Vectra A950RX LCP

\begin{tabular}{|c|c|c|c|c|c|}
\hline $\begin{array}{c}\text { Test } \\
\text { Date }\end{array}$ & $\begin{array}{c}\text { Disk } \\
\text { Numbers }\end{array}$ & $\begin{array}{c}\text { Axial Thermal Conductivity } \\
(\mathrm{W} / \mathrm{mK})\end{array}$ & $\begin{array}{c}\text { Radial Thermal } \\
\text { Conductivity (W/mK) }\end{array}$ & $\begin{array}{c}\text { Power } \\
(\mathrm{W})\end{array}$ & $\begin{array}{c}\text { Time } \\
(\mathrm{s})\end{array}$ \\
\cline { 1 - 3 } $03 / 22 / 06$ & $12,28,26,17$ & 0.2831 & 1.3970 & 0.4 & 20 \\
\hline $03 / 22 / 06$ & $11,32,31,22$ & 0.2832 & 1.3950 & 0.4 & 20 \\
\hline $03 / 29 / 06$ & $17,28,10,26$ & 0.2775 & 1.4080 & 0.4 & 20 \\
\hline $03 / 29 / 06$ & $13,23,20,16$ & 0.2873 & 1.4260 & 0.4 & 20 \\
\cline { 1 - 2 } $03 / 29 / 06$ & $28,22,20,32$ & 0.2812 & 1.4090 & 0.4 & 20 \\
\hline \multicolumn{2}{|c|}{ Average } & 0.2825 & 1.4070 & & \\
\hline \multicolumn{2}{|c|}{ Standard Deviation } & 0.0036 & 0.0123 & & \\
\hline \multicolumn{2}{|c|}{ Number of Samples } & 5 & 5 & & \\
\hline
\end{tabular}


Table 9.6-25: 20wt\% Fortafil 243 Carbon Fiber / Vectra A950RX LCP

\begin{tabular}{|c|c|c|c|c|c|}
\hline $\begin{array}{c}\text { Test } \\
\text { Date }\end{array}$ & $\begin{array}{c}\text { Disk } \\
\text { Numbers }\end{array}$ & $\begin{array}{c}\text { Axial Thermal Conductivity } \\
(\mathrm{W} / \mathrm{mK})\end{array}$ & $\begin{array}{c}\text { Radial Thermal } \\
\text { Conductivity (W/mK) }\end{array}$ & $\begin{array}{c}\text { Power } \\
\text { (W) }\end{array}$ & $\begin{array}{c}\text { Time } \\
(\mathrm{s})\end{array}$ \\
\hline $03 / 22 / 06$ & $32,28,10,13$ & 0.3162 & 1.5540 & 0.4 & 20 \\
\hline $03 / 22 / 06$ & $16,20,22,35$ & 0.3151 & 1.5650 & 0.4 & 20 \\
\hline $03 / 29 / 06$ & $26,31,11,25$ & 0.3220 & 1.5380 & 0.4 & 20 \\
\hline $03 / 29 / 06$ & $17,28,32,16$ & 0.3235 & 1.5080 & 0.4 & 20 \\
\hline $03 / 29 / 06$ & $28,13,32,22$ & 0.3210 & 1.5730 & 0.4 & 20 \\
\hline \multicolumn{2}{|c|}{ Average } & 0.3196 & 1.5476 & & \\
\hline \multicolumn{2}{|c|}{ Standard Deviation } & 0.0037 & 0.0257 & & \\
\hline \multicolumn{2}{|c|}{ Number of Samples } & 5 & 5 & \\
\hline
\end{tabular}

Table 9.6-26: 25wt\% Fortafil 243 Carbon Fiber / Vectra A950RX LCP

\begin{tabular}{|c|c|c|c|c|c|}
\hline $\begin{array}{l}\text { Test } \\
\text { Date }\end{array}$ & $\begin{array}{c}\text { Disk } \\
\text { Numbers }\end{array}$ & $\begin{array}{l}\text { Axial Thermal Conductivity } \\
(\mathrm{W} / \mathrm{mK})\end{array}$ & $\begin{array}{c}\text { Radial Thermal } \\
\text { Conductivity }(\mathrm{W} / \mathrm{mK})\end{array}$ & $\begin{array}{l}\text { Power } \\
\text { (W) }\end{array}$ & $\begin{array}{c}\text { Time } \\
(\mathrm{s})\end{array}$ \\
\hline $03 / 24 / 06$ & $26,22,12,32$ & 0.3541 & 1.6430 & 0.45 & 10 \\
\hline $03 / 24 / 06$ & $31,13,16,23$ & 0.3526 & 1.6820 & 0.45 & 10 \\
\hline $03 / 24 / 06$ & $32,28,20,12$ & 0.3523 & 1.6720 & 0.45 & 10 \\
\hline $03 / 24 / 06$ & $20,32,31,25$ & 0.3516 & 1.7160 & 0.45 & 10 \\
\hline $03 / 24 / 06$ & $28,33,17,22$ & 0.3522 & 1.6880 & 0.45 & 10 \\
\hline \multicolumn{2}{|c|}{ Average } & 0.3526 & 1.6802 & & \\
\hline \multicolumn{2}{|c|}{ Standard Deviation } & 0.0009 & 0.0264 & & \\
\hline \multicolumn{2}{|c|}{ Number of Samples } & 5 & 5 & & \\
\hline
\end{tabular}

\section{Table 9.6-27: 30wt\% Fortafil 243 Carbon Fiber / Vectra A950RX LCP}

\begin{tabular}{|c|c|c|c|c|c|}
\hline $\begin{array}{c}\text { Test } \\
\text { Date }\end{array}$ & $\begin{array}{c}\text { Disk } \\
\text { Numbers }\end{array}$ & $\begin{array}{c}\text { Axial Thermal Conductivity } \\
(\mathrm{W} / \mathrm{mK})\end{array}$ & $\begin{array}{c}\text { Radial Thermal } \\
\text { Conductivity (W/mK) }\end{array}$ & $\begin{array}{c}\text { Power } \\
(\mathrm{W})\end{array}$ & $\begin{array}{c}\text { Time } \\
\text { (s) }\end{array}$ \\
\hline $03 / 30 / 06$ & $8,10,17,22$ & 0.3650 & 1.8870 & 0.43 & 10 \\
\hline $03 / 30 / 06$ & $2,7,20,31$ & 0.3708 & 1.8680 & 0.43 & 10 \\
\hline $03 / 30 / 06$ & $26,22,13,25$ & 0.3641 & 1.8560 & 0.3 & 10 \\
\hline $03 / 30 / 06$ & $31,22,20,25$ & 0.3619 & 1.8610 & 0.3 & 10 \\
\hline $03 / 30 / 06$ & $13,20,12,22$ & 0.3652 & 1.8120 & 0.4 & 10 \\
\hline \multicolumn{2}{|c|}{ Average } & 0.3654 & 1.8568 & & \\
\hline \multicolumn{2}{|c|}{ Standard Deviation } & 0.0033 & 0.0277 & & \\
\hline \multicolumn{2}{|c|}{ Number of Samples } & 5 & 5 & \\
\hline
\end{tabular}


Table 9.6-28: 35wt\% Fortafil 243 Carbon Fiber / Vectra A950RX LCP

\begin{tabular}{|c|c|c|c|c|c|}
\hline $\begin{array}{c}\text { Test } \\
\text { Date }\end{array}$ & $\begin{array}{c}\text { Disk } \\
\text { Numbers }\end{array}$ & $\begin{array}{c}\text { Axial Thermal Conductivity } \\
(\mathrm{W} / \mathrm{mK})\end{array}$ & $\begin{array}{c}\text { Radial Thermal } \\
\text { Conductivity (W/mK) }\end{array}$ & $\begin{array}{c}\text { Power } \\
(\mathrm{W})\end{array}$ & $\begin{array}{c}\text { Time } \\
(\mathrm{s})\end{array}$ \\
\hline $03 / 27 / 06$ & $31,32,23,25$ & 0.4285 & 1.9920 & 0.4 & 10 \\
\hline $03 / 27 / 06$ & $32,31,13,20$ & 0.4303 & 2.0030 & 0.4 & 10 \\
\hline $03 / 27 / 06$ & $26,17,20,16$ & 0.4304 & 1.9950 & 0.4 & 10 \\
\hline $03 / 27 / 06$ & $23,28,32,10$ & 0.4314 & 1.9970 & 0.4 & 10 \\
\hline $03 / 27 / 06$ & $26,17,16,20$ & 0.4386 & 1.9910 & 0.4 & 10 \\
\hline \multicolumn{2}{|c|}{ Average } & 0.4318 & 1.9956 & & \\
\hline \multicolumn{2}{|c|}{ Standard Deviation } & 0.0039 & 0.0048 & & \\
\hline \multicolumn{2}{|c|}{ Number of Samples } & 5 & 5 & & \\
\hline
\end{tabular}

Table 9.6-29: 40wt\% Fortafil 243 Carbon Fiber / Vectra A950RX LCP

\begin{tabular}{|c|c|c|c|c|c|}
\hline $\begin{array}{l}\text { Test } \\
\text { Date }\end{array}$ & $\begin{array}{c}\text { Disk } \\
\text { Numbers }\end{array}$ & $\begin{array}{l}\text { Axial Thermal Conductivity } \\
(\mathrm{W} / \mathrm{mK})\end{array}$ & $\begin{array}{c}\text { Radial Thermal } \\
\text { Conductivity }(\mathrm{W} / \mathrm{mK})\end{array}$ & $\begin{array}{l}\text { Power } \\
\text { (W) }\end{array}$ & $\begin{array}{c}\text { Time } \\
(\mathrm{s})\end{array}$ \\
\hline $03 / 22 / 06$ & $20,28,31,22$ & 0.5315 & 2.1060 & 0.5 & 10 \\
\hline $03 / 22 / 06$ & $32,25,11,26$ & 0.5234 & 2.0250 & 0.5 & 10 \\
\hline $03 / 24 / 06$ & $13,20,22,31$ & 0.5266 & 2.0350 & 0.5 & 10 \\
\hline $03 / 29 / 06$ & $17,16,28,12$ & 0.5263 & 2.0650 & 0.5 & 10 \\
\hline $03 / 24 / 06$ & $28,26,32,13$ & 0.5249 & 2.0200 & 0.5 & 10 \\
\hline \multicolumn{2}{|c|}{ Average } & 0.5265 & 2.0502 & & \\
\hline \multicolumn{2}{|c|}{ Standard Deviation } & 0.0031 & 0.0357 & & \\
\hline \multicolumn{2}{|c|}{ Number of Samples } & 5 & 5 & & \\
\hline
\end{tabular}

Table 9.6-30: 45wt\% Fortafil 243 Carbon Fiber / Vectra A950RX LCP

\begin{tabular}{|c|c|c|c|c|c|}
\hline $\begin{array}{l}\text { Test } \\
\text { Date } \\
\end{array}$ & $\begin{array}{c}\text { Disk } \\
\text { Numbers } \\
\end{array}$ & $\begin{array}{l}\text { Axial Thermal Conductivity } \\
(\mathrm{W} / \mathrm{mK})\end{array}$ & $\begin{array}{c}\text { Radial Thermal } \\
\text { Conductivity }(\mathrm{W} / \mathrm{mK}) \\
\end{array}$ & $\begin{array}{c}\text { Power } \\
\text { (W) }\end{array}$ & $\begin{array}{c}\text { Time } \\
(\mathrm{s})\end{array}$ \\
\hline $03 / 24 / 06$ & $12,22,23,32$ & 0.5957 & 2.128 & 0.6 & 10 \\
\hline $03 / 24 / 06$ & $26,13,20,28$ & 0.5965 & 2.095 & 0.6 & 10 \\
\hline $03 / 24 / 06$ & $25,17,16,31$ & 0.6074 & 2.106 & 0.55 & 10 \\
\hline 03/29/06 & $9,17,26,11$ & 0.6037 & 2.122 & 0.6 & 10 \\
\hline $03 / 29 / 06$ & $26,22,11,20$ & 0.6065 & 2.096 & 0.6 & 10 \\
\hline \multicolumn{2}{|c|}{ Average } & 0.6020 & 2.1094 & & \\
\hline \multicolumn{2}{|c|}{ Standard Deviation } & 0.0055 & 0.0150 & & \\
\hline \multicolumn{2}{|c|}{ Number of Samples } & 5 & 5 & & \\
\hline
\end{tabular}


Table 9.6-31: 50wt\% Fortafil 243 Carbon Fiber / Vectra A950RX LCP

\begin{tabular}{|c|c|c|c|c|c|}
\hline $\begin{array}{c}\text { Test } \\
\text { Date }\end{array}$ & $\begin{array}{c}\text { Disk } \\
\text { Numbers }\end{array}$ & $\begin{array}{c}\text { Axial Thermal Conductivity } \\
(\mathrm{W} / \mathrm{mK})\end{array}$ & $\begin{array}{c}\text { Radial Thermal } \\
\text { Conductivity (W/mK) }\end{array}$ & $\begin{array}{c}\text { Power } \\
(\mathrm{W})\end{array}$ & $\begin{array}{c}\text { Time } \\
(\mathrm{s})\end{array}$ \\
\hline $04 / 18 / 06$ & $25,23,28,36$ & 0.6900 & 2.275 & 0.65 & 10 \\
\hline $04 / 18 / 06$ & $28,11,37,26$ & 0.6882 & 2.268 & 0.65 & 10 \\
\hline $04 / 18 / 06$ & $7,10,31,25$ & 0.6920 & 2.192 & 0.62 & 10 \\
\hline $04 / 18 / 06$ & $7,26,10,31$ & 0.6808 & 2.208 & 0.62 & 10 \\
\hline $04 / 18 / 06$ & $11,12,36,9$ & 0.6886 & 2.251 & 0.62 & 10 \\
\hline \multicolumn{2}{|c|}{ Average } & 0.6879 & 2.239 & & \\
\hline \multicolumn{2}{|c|}{ Standard Deviation } & 0.0042 & 0.037 & & \\
\hline \multicolumn{2}{|c|}{ Number of Samples } & 5 & 5 & & \\
\hline
\end{tabular}

Table 9.6-32: 55wt\% Fortafil 243 Carbon Fiber / Vectra A950RX LCP

\begin{tabular}{|c|c|c|c|c|c|}
\hline $\begin{array}{c}\text { Test } \\
\text { Date }\end{array}$ & $\begin{array}{c}\text { Disk } \\
\text { Numbers }\end{array}$ & $\begin{array}{c}\text { Axial Thermal Conductivity } \\
(\mathrm{W} / \mathrm{mK})\end{array}$ & $\begin{array}{c}\text { Radial Thermal } \\
\text { Conductivity (W/mK) }\end{array}$ & $\begin{array}{c}\text { Power } \\
(\mathrm{W})\end{array}$ & $\begin{array}{c}\text { Time } \\
(\mathrm{s})\end{array}$ \\
\hline $04 / 19 / 06$ & $17,12,16,26$ & 0.8361 & 2.247 & 0.65 & 10 \\
\hline $04 / 19 / 06$ & $32,13,25,28$ & 0.8361 & 2.406 & 0.65 & 10 \\
\hline $04 / 19 / 06$ & $10,26,22,8$ & 0.8430 & 2.418 & 0.70 & 5 \\
\hline $04 / 19 / 06$ & $17,28,11,32$ & 0.8290 & 2.222 & 0.70 & 5 \\
\hline $04 / 19 / 06$ & $28,13,22,33$ & 0.8411 & 2.375 & 0.70 & 5 \\
\hline $04 / 19 / 06$ & $25,20,28,31$ & 0.8349 & 2.345 & 0.70 & 5 \\
\hline $04 / 19 / 06$ & $26,31,33,13$ & 0.8537 & 2.301 & 0.70 & 5 \\
\hline $04 / 19 / 06$ & $32,17,23,12$ & 0.8359 & 2.296 & 0.65 & 10 \\
\hline $04 / 19 / 06$ & $28,25,13,32$ & 0.8362 & 2.254 & 0.65 & 5 \\
\hline $04 / 19 / 06$ & $7,8,23,17$ & 0.8485 & 2.262 & 0.70 & 5 \\
\hline $04 / 19 / 06$ & $4,20,16,32$ & 0.8427 & 2.355 & 0.70 & 5 \\
\hline $04 / 19 / 06$ & $5,10,26,6$ & 0.8474 & 2.242 & 0.70 & 5 \\
\hline $04 / 19 / 06$ & $23,17,20,4$ & 0.8312 & 2.420 & 0.70 & 5 \\
\hline $04 / 19 / 06$ & $16,32,13,3$ & 0.8415 & 2.383 & 0.70 & 5 \\
\hline $04 / 19 / 06$ & $7,12,28,8$ & 0.8436 & 2.222 & 0.70 & 5 \\
\hline $04 / 19 / 06$ & $6,11,9,17$ & 0.8337 & 2.384 & 0.70 & 5 \\
\hline $04 / 19 / 06$ & $32,13,20,4$ & 0.8201 & 2.420 & 0.70 & 5 \\
\hline $04 / 19 / 06$ & $25,22,33,5$ & 0.8233 & 2.284 & 0.70 & 5 \\
\hline $04 / 19 / 06$ & $31,10,12,7$ & 0.8513 & 2.296 & 0.70 & 5 \\
\hline $04 / 19 / 06$ & $28,8,11,6$ & 0.8264 & 2.340 & 0.70 & 5 \\
\hline \multicolumn{2}{|c|}{ Average } & 0.8378 & 2.324 & & \\
\hline \multicolumn{2}{|c|}{ Standard Deviation } & 0.0091 & 0.069 & & \\
\hline Number of Samples & 20 & 20 & & \\
\hline
\end{tabular}


Table 9.6-33: 60wt\% Fortafil 243 Carbon Fiber / Vectra A950RX LCP

\begin{tabular}{|c|c|c|c|c|c|}
\hline $\begin{array}{l}\text { Test } \\
\text { Date }\end{array}$ & $\begin{array}{c}\text { Disk } \\
\text { Numbers }\end{array}$ & $\begin{array}{l}\text { Axial Thermal Conductivity } \\
(\mathrm{W} / \mathrm{mK})\end{array}$ & $\begin{array}{c}\text { Radial Thermal } \\
\text { Conductivity (W/mK) }\end{array}$ & $\begin{array}{l}\text { Power } \\
\text { (W) }\end{array}$ & $\begin{array}{c}\text { Time } \\
(\mathrm{s})\end{array}$ \\
\hline $04 / 20 / 06$ & $8,28,23,3$ & 1.016 & 2.376 & 0.80 & 10 \\
\hline $04 / 20 / 06$ & $28,13,26,32$ & 1.038 & 2.403 & 0.75 & 10 \\
\hline 04/20/06 & $8,28,23,3$ & 1.036 & 2.410 & 0.80 & 10 \\
\hline $04 / 20 / 06$ & $13,20,32,6$ & 1.028 & 2.437 & 0.80 & 10 \\
\hline $04 / 20 / 06$ & $11,32,13,20$ & 1.054 & 2.451 & 0.80 & 5 \\
\hline $04 / 20 / 06$ & $28,10,17,25$ & 1.017 & 2.464 & 0.80 & 5 \\
\hline 04/20/06 & $31,22,11,32$ & 0.980 & 2.476 & 0.80 & 5 \\
\hline $04 / 20 / 06$ & $6,13,32,17$ & 1.056 & 2.478 & 0.80 & 10 \\
\hline 04/20/06 & $8,13,17,16$ & 1.051 & 2.541 & 0.80 & 5 \\
\hline $04 / 20 / 06$ & $20,13,32,6$ & 1.021 & 2.554 & 0.80 & 10 \\
\hline \multicolumn{2}{|c|}{ Average } & 1.0297 & 2.4590 & & \\
\hline \multicolumn{2}{|c|}{ Standard Deviation } & 0.0230 & 0.0572 & & \\
\hline \multicolumn{2}{|c|}{ Number of Samples } & 10 & 10 & & \\
\hline
\end{tabular}




\section{Section 9.7: Density Data}

\section{Table 9.7-1: Vectra A950RX LCP}

\begin{tabular}{|c|c|c|c|}
\hline Test Date & Sample Number & Theoretical Density $(\mathrm{g} / \mathrm{mL})$ & Measured Density $(\mathrm{g} / \mathrm{mL})$ \\
\hline $7 / 27 / 2004$ & EVR-TC-15 & 1.400 & 1.395 \\
\hline $7 / 27 / 2004$ & EVR-TC-17 & 1.400 & 1.396 \\
\hline $7 / 27 / 2004$ & EVR-TC-19 & 1.400 & 1.395 \\
\hline $7 / 27 / 2004$ & EVR-TC-26 & 1.400 & 1.400 \\
\hline $7 / 27 / 2004$ & EVR-TC-16 & 1.400 & 1.396 \\
\hline & & Average & 1.396 \\
\cline { 3 - 4 } & & Standard Deviation & 0.002 \\
\cline { 3 - 4 } & & Number of Samples & 5 \\
\hline
\end{tabular}

Table 9.7-2: 2.5 wt \% Ketjenblack EC600 JD / Vectra A950RX LCP

\begin{tabular}{|c|c|c|c|}
\hline Test Date & Sample Number & Theoretical Density $(\mathrm{g} / \mathrm{mL})$ & Measured Density $(\mathrm{g} / \mathrm{mL})$ \\
\hline $7 / 27 / 2004$ & EAV2.5-TC-15 & 1.408 & 1.400 \\
\hline $7 / 27 / 2004$ & EAV2.5-TC-21 & 1.408 & 1.401 \\
\hline $7 / 27 / 2004$ & EAV2.5-TC-23 & 1.408 & 1.399 \\
\hline $7 / 27 / 2004$ & EAV2.5-TC-25 & 1.408 & 1.396 \\
\hline $7 / 27 / 2004$ & EAV2.5-TC-28 & 1.408 & 1.403 \\
\hline & Average & 1.400 \\
\cline { 3 - 4 } & & Standard Deviation & 0.003 \\
\cline { 3 - 4 } & & Number of Samples & 5 \\
\hline
\end{tabular}

\section{Table 9.7-3: 4 wt\% Ketjenblack EC600 JD / Vectra A950RX LCP}

\begin{tabular}{|c|c|c|c|}
\hline Test Date & Sample Number & Theoretical Density $(\mathrm{g} / \mathrm{mL})$ & Measured Density $(\mathrm{g} / \mathrm{mL})$ \\
\hline $7 / 27 / 2004$ & EAV4R-TC-20 & 1.413 & 1.409 \\
\hline $7 / 27 / 2004$ & EAV4R-TC-23 & 1.413 & 1.411 \\
\hline $7 / 27 / 2004$ & EAV4R-TC-26 & 1.413 & 1.413 \\
\hline $7 / 27 / 2004$ & EAV4R-TC-29 & 1.413 & 1.412 \\
\hline $7 / 27 / 2004$ & EAV4R-TC-32 & 1.413 & 1.413 \\
\hline & & Average & 1.412 \\
\cline { 3 - 4 } & & Standard Deviation & 0.002 \\
\cline { 3 - 4 } & & Number of Samples & 5 \\
\hline
\end{tabular}


Table 9.7-4: 5 wt\% Ketjenblack EC600 JD / Vectra A950RX LCP

\begin{tabular}{|c|c|c|c|}
\hline Test Date & Sample Number & Theoretical Density $(\mathrm{g} / \mathrm{mL})$ & Measured Density $(\mathrm{g} / \mathrm{mL})$ \\
\hline $7 / 27 / 2004$ & EAV5R-TC-16 & 1.416 & 1.415 \\
\hline $7 / 27 / 2004$ & EAV5R-TC-23 & 1.416 & 1.416 \\
\hline $7 / 27 / 2004$ & EAV5R-TC-24 & 1.416 & 1.416 \\
\hline $7 / 27 / 2004$ & EAV5R-TC-25 & 1.416 & 1.414 \\
\hline $7 / 27 / 2004$ & EAV5R-TC-29 & 1.416 & 1.415 \\
\hline & & Average & 1.415 \\
\cline { 3 - 4 } & & Standard Deviation & 0.001 \\
\cline { 3 - 4 } & & Number of Samples & 5 \\
\hline
\end{tabular}

Table 9.7-5: 6 wt\% Ketjenblack EC600 JD / Vectra A950RX LCP

\begin{tabular}{|c|c|c|c|} 
Test Date & Sample Number & Theoretical Density $(\mathrm{g} / \mathrm{mL})$ & Measured Density $(\mathrm{g} / \mathrm{mL})$ \\
\hline $7 / 27 / 2004$ & EAV6-TC-17 & 1.419 & 1.420 \\
\hline $7 / 27 / 2004$ & EAV6-TC-20 & 1.419 & 1.422 \\
\hline $7 / 27 / 2004$ & EAV6-TC-24 & 1.419 & 1.418 \\
\hline $7 / 27 / 2004$ & EAV6-TC-25 & 1.419 & 1.417 \\
\hline $7 / 27 / 2004$ & EAV6-TC-18 & 1.419 & 1.424 \\
\hline & & Average & 1.420 \\
\cline { 3 - 4 } & & Standard Deviation & 0.003 \\
\cline { 3 - 4 } & & Number of Samples & 5 \\
\hline
\end{tabular}

Table 9.7-6: 7.5 wt\% Ketjenblack EC600 JD / Vectra A950RX LCP

\begin{tabular}{|c|c|c|c|}
\hline Test Date & Sample Number & Theoretical Density $(\mathrm{g} / \mathrm{mL})$ & Measured Density $(\mathrm{g} / \mathrm{mL})$ \\
\hline $7 / 27 / 2004$ & EAV7.5-TC-17 & 1.424 & 1.428 \\
\hline $7 / 27 / 2004$ & EAV7.5-TC-19 & 1.424 & 1.428 \\
\hline $7 / 27 / 2004$ & EAV7.5-TC-21 & 1.424 & 1.428 \\
\hline $7 / 27 / 2004$ & EAV7.5-TC-24 & 1.424 & 1.428 \\
\hline $7 / 27 / 2004$ & EAV7.5-TC-28 & 1.424 & 1.428 \\
\hline & & Average & 1.428 \\
\cline { 3 - 4 } & & Standard Deviation & 0.000 \\
\cline { 3 - 4 } & & Number of Samples & 5 \\
\hline
\end{tabular}


Table 9.7-7: 10 wt\% Ketjenblack EC600 JD / Vectra A950RX LCP

\begin{tabular}{|c|c|c|c|}
\hline Test Date & Sample Number & Theoretical Density $(\mathrm{g} / \mathrm{mL})$ & Measured Density $(\mathrm{g} / \mathrm{mL})$ \\
\hline $7 / 27 / 2004$ & EAV10-TC-13 & 1.432 & 1.437 \\
\hline $7 / 27 / 2004$ & EAV10-TC-14 & 1.432 & 1.438 \\
\hline $7 / 27 / 2004$ & EAV10-TC-26 & 1.432 & 1.437 \\
\hline $7 / 27 / 2004$ & EAV10-TC-31 & 1.432 & 1.437 \\
\hline $7 / 27 / 2004$ & EAV10-TC-33 & 1.432 & 1.438 \\
\hline & & Average & 1.437 \\
\cline { 3 - 4 } & & Standard Deviation & 0.000 \\
\cline { 3 - 4 } & & Number of Samples & 5 \\
\hline
\end{tabular}

Table 9.7-8: 15 wt\% Ketjenblack EC600 JD / Vectra A950RX LCP

\begin{tabular}{|c|c|c|c|}
\hline Test Date & Sample Number & Theoretical Density $(\mathrm{g} / \mathrm{mL})$ & Measured Density $(\mathrm{g} / \mathrm{mL})$ \\
\hline $7 / 27 / 2004$ & EAV15-TC-13 & 1.448 & 1.457 \\
\hline $7 / 27 / 2004$ & EAV15-TC-18 & 1.448 & 1.457 \\
\hline $7 / 27 / 2004$ & EAV15-TC-20 & 1.448 & 1.456 \\
\hline $7 / 27 / 2004$ & EAV15-TC-21 & 1.448 & 1.457 \\
\hline $7 / 27 / 2004$ & EAV15-TC-24 & 1.448 & 1.456 \\
\hline & Average & 1.457 \\
\cline { 3 - 4 } & & Standard Deviation & 0.000 \\
\cline { 3 - 4 } & & Number of Samples & 5 \\
\hline
\end{tabular}

Table 9.7-9: 10 wt\% Thermocarb TC300 / Vectra A950RX LCP

\begin{tabular}{|c|c|c|c|}
\hline Test Date & Sample Number & Theoretical Density $(\mathrm{g} / \mathrm{mL})$ & Measured Density $(\mathrm{g} / \mathrm{mL})$ \\
\hline $3 / 9 / 2005$ & EBV10-TC-26 & 1.455 & 1.442 \\
\hline $3 / 9 / 2005$ & EBV10-TC-27 & 1.455 & 1.450 \\
\hline $3 / 9 / 2005$ & EBV10-TC-16 & 1.455 & 1.445 \\
\hline & Average & 1.446 \\
\cline { 3 - 4 } & & Standard Deviation & 0.004 \\
\cline { 3 - 4 } & & Number of Samples & 3 \\
\hline
\end{tabular}


Table 9.7-10: 15 wt\% Thermocarb TC300 / Vectra A950RX LCP

\begin{tabular}{|c|c|c|c|}
\hline Test Date & Sample Number & Theoretical Density $(\mathrm{g} / \mathrm{mL})$ & Measured Density $(\mathrm{g} / \mathrm{mL})$ \\
\hline $3 / 9 / 2005$ & EBV15-TC-26 & 1.483 & 1.476 \\
\hline $3 / 9 / 2005$ & EBV15-TC-32 & 1.483 & 1.474 \\
\hline $3 / 9 / 2005$ & EBV15-TC-14 & 1.483 & 1.474 \\
\hline & Average & 1.475 \\
\cline { 3 - 4 } & & Standard Deviation & 0.001 \\
\cline { 3 - 4 } & & Number of Samples & 3 \\
\hline
\end{tabular}

Table 9.7-11: 20 wt\% Thermocarb TC300 / Vectra A950RX LCP

\begin{tabular}{|c|c|c|c|}
\hline Test Date & Sample Number & Theoretical Density $(\mathrm{g} / \mathrm{mL})$ & Measured Density $(\mathrm{g} / \mathrm{mL})$ \\
\hline $3 / 9 / 2005$ & EBV20-TC-23 & 1.514 & 1.490 \\
\hline $3 / 9 / 2005$ & EBV20-TC-27 & 1.514 & 1.507 \\
\hline $3 / 9 / 2005$ & EBV20-TC-16 & 1.514 & 1.507 \\
\hline & Average & 1.501 \\
\cline { 3 - 4 } & & Standard Deviation & 0.010 \\
\cline { 3 - 4 } & & Number of Samples & 3 \\
\hline
\end{tabular}

Table 9.7-12: 25 wt\% Thermocarb TC300 / Vectra A950RX LCP

\begin{tabular}{|c|c|c|c|}
\hline Test Date & Sample Number & Theoretical Density $(\mathrm{g} / \mathrm{mL})$ & Measured Density $(\mathrm{g} / \mathrm{mL})$ \\
\hline & EBV25-TC-12 & 1.548 & 1.546 \\
\hline & EBV25-TC-17 & 1.548 & 1.542 \\
\hline & EBV25-TC-22 & 1.548 & 1.540 \\
\hline \multirow{2}{*}{} & Average & 1.543 \\
\cline { 3 - 4 } & & Standard Deviation & 0.003 \\
\cline { 2 - 4 } & & Number of Samples & 3 \\
\hline
\end{tabular}


Table 9.7-13: 30 wt\% Thermocarb TC300 / Vectra A950RX LCP

\begin{tabular}{|c|c|c|c|}
\hline Test Date & Sample Number & Theoretical Density $(\mathrm{g} / \mathrm{mL})$ & Measured Density $(\mathrm{g} / \mathrm{mL})$ \\
\hline $3 / 9 / 2005$ & EBV30-TC-21 & 1.578 & 1.567 \\
\hline $3 / 9 / 2005$ & EBV30-TC-26 & 1.578 & 1.567 \\
\hline $3 / 9 / 2005$ & EBV30-TC-14 & 1.578 & 1.568 \\
\hline $3 / 9 / 2005$ & EBV30-TC-16 & 1.578 & 1.567 \\
\hline $3 / 9 / 2005$ & EBV30-TC-21 & 1.578 & 1.567 \\
\hline $3 / 9 / 2005$ & EBV30-TC-26 & 1.578 & 1.568 \\
\hline $3 / 9 / 2005$ & EBV30-TC-15 & 1.578 & 1.571 \\
\hline $3 / 9 / 2005$ & EBV30-TC-22 & 1.578 & 1.568 \\
\hline $3 / 9 / 2005$ & EBV30-TC-27 & 1.578 & 1.570 \\
\hline & & Average & 1.568 \\
\cline { 3 - 4 } & & Standard Deviation & 0.002 \\
\cline { 3 - 4 } & & Number of Samples & 9 \\
\hline
\end{tabular}

Table 9.7-14: 35 wt\% Thermocarb TC300 / Vectra A950RX LCP

\begin{tabular}{|c|c|c|c|}
\hline Test Date & Sample Number & Theoretical Density $(\mathrm{g} / \mathrm{mL})$ & Measured Density $(\mathrm{g} / \mathrm{mL})$ \\
\hline 9/22/2005 & EBV35-TC-12 & 1.6115 & 1.602 \\
\hline 9/22/2005 & EBV35-TC-17 & 1.6115 & 1.599 \\
\hline 9/22/2005 & EBV35-TC-22 & 1.6115 & 1.602 \\
\hline & Average & 1.601 \\
\cline { 3 - 4 } & & Standard Deviation & 0.002 \\
\cline { 3 - 4 } & & Number of Samples & 3 \\
\hline
\end{tabular}

Table 9.7-15: 40 wt\% Thermocarb TC300 / Vectra A950RX LCP

\begin{tabular}{|c|c|c|c|}
\hline Test Date & Sample Number & Theoretical Density $(\mathrm{g} / \mathrm{mL})$ & Measured Density $(\mathrm{g} / \mathrm{mL})$ \\
\hline $5 / 27 / 2004$ & EBV40-TC-17 & 1.647 & 1.640 \\
\hline $5 / 27 / 2004$ & EBV40-TC-19 & 1.647 & 1.641 \\
\hline $5 / 27 / 2004$ & EBV40-TC-21 & 1.647 & 1.640 \\
\hline $5 / 27 / 2004$ & EBV40-TC-23 & 1.647 & 1.640 \\
\hline $5 / 27 / 2004$ & EBV40-TC-24 & 1.647 & 1.641 \\
\hline & & Average & 1.640 \\
\cline { 3 - 4 } & & Standard Deviation & 0.000 \\
\cline { 3 - 4 } & & Number of Samples & 5 \\
\hline
\end{tabular}


Table 9.7-16: 45 wt\% Thermocarb TC300 / Vectra A950RX LCP

\begin{tabular}{|c|c|c|c|}
\hline Test Date & Sample Number & Theoretical Density $(\mathrm{g} / \mathrm{mL})$ & Measured Density $(\mathrm{g} / \mathrm{mL})$ \\
\hline 9/22/2005 & EBV45-TC-12 & 1.6842 & 1.674 \\
\hline 9/22/2005 & EBV45-TC-17 & 1.6842 & 1.674 \\
\hline 9/22/2055 & EBV45-TC-22 & 1.6842 & 1.668 \\
\hline & Average & 1.672 \\
\cline { 3 - 4 } & & Standard Deviation & 0.003 \\
\cline { 3 - 4 } & & Number of Samples & 3 \\
\hline
\end{tabular}

Table 9.7-17: 50 wt \% Thermocarb TC300 / Vectra A950RX LCP

\begin{tabular}{|c|c|c|c|}
\hline Test Date & Sample Number & Theoretical Density $(\mathrm{g} / \mathrm{mL})$ & Measured Density $(\mathrm{g} / \mathrm{mL})$ \\
\hline $3 / 9 / 2005$ & EBV50-TC-19 & 1.723 & 1.714 \\
\hline $3 / 9 / 2005$ & EBV50-TC-23 & 1.723 & 1.720 \\
\hline $3 / 9 / 2005$ & EBV50-TC-15 & 1.723 & 1.714 \\
\hline & Average & 1.716 \\
\cline { 3 - 4 } & & Standard Deviation & 0.003 \\
\cline { 3 - 4 } & & Number of Samples & 3 \\
\hline
\end{tabular}

Table 9.7-18: 55 wt \% Thermocarb TC300 / Vectra A950RX LCP

\begin{tabular}{|c|c|c|c|}
\hline Test Date & Sample Number & Theoretical Density $(\mathrm{g} / \mathrm{mL})$ & Measured Density $(\mathrm{g} / \mathrm{mL})$ \\
\hline $3 / 9 / 2005$ & EBV55-TC-27 & 1.764 & 1.738 \\
\hline $3 / 9 / 2005$ & EBV55-TC-33 & 1.764 & 1.756 \\
\hline $3 / 9 / 2005$ & EBV55-TC-11 & 1.764 & 1.792 \\
\hline $3 / 9 / 2005$ & EBV55-TC-15 & 1.764 & 1.738 \\
\hline $3 / 9 / 2005$ & EBV55-TC-27 & 1.764 & 1.756 \\
\hline $3 / 9 / 2005$ & EBV55-TC-33 & 1.764 & 1.792 \\
\hline $3 / 9 / 2005$ & EBV55-TC-17 & 1.764 & 1.756 \\
\hline $3 / 9 / 2005$ & EBV55-TC-26 & 1.764 & 1.753 \\
\hline $3 / 9 / 2005$ & EBV55-TC-32 & 1.764 & 1.756 \\
\hline & & Average & 1.760 \\
\cline { 3 - 4 } & & Standard Deviation & 0.020 \\
\cline { 3 - 4 } & & Number of Samples & 9 \\
\hline
\end{tabular}


Table 9.7-19: 60 wt \% Thermocarb TC300 / Vectra A950RX LCP

\begin{tabular}{|c|c|c|c|}
\hline Test Date & Sample Number & Theoretical Density $(\mathrm{g} / \mathrm{mL})$ & Measured Density $(\mathrm{g} / \mathrm{mL})$ \\
\hline $5 / 27 / 2004$ & EBV60-TC-18 & 1.807 & 1.807 \\
\hline $5 / 27 / 2004$ & EBV60-TC-21 & 1.807 & 1.807 \\
\hline $5 / 27 / 2004$ & EBV60-TC-24 & 1.807 & 1.807 \\
\hline $5 / 27 / 2004$ & EBV60-TC-31 & 1.807 & 1.807 \\
\hline & & Average & 1.807 \\
\cline { 3 - 4 } & & Standard Deviation & 0.000 \\
\cline { 3 - 4 } & & Number of Samples & 4 \\
\hline
\end{tabular}

Table 9.7-20: 65 wt\% Thermocarb TC300 / Vectra A950RX LCP

\begin{tabular}{|c|c|c|c|}
\hline Test Date & Sample Number & Theoretical Density $(\mathrm{g} / \mathrm{mL})$ & Measured Density $(\mathrm{g} / \mathrm{mL})$ \\
\hline $3 / 9 / 2005$ & EBV65-TC-19 & 1.851 & 1.823 \\
\hline $3 / 9 / 2005$ & EBV65-TC-26 & 1.851 & 1.862 \\
\hline $3 / 9 / 2005$ & EBV65-TC-15 & 1.851 & 1.845 \\
\hline $3 / 9 / 2005$ & EBV65-TC-11 & 1.851 & 1.823 \\
\hline $3 / 9 / 2005$ & EBV65-TC-19 & 1.851 & 1.862 \\
\hline $3 / 9 / 2005$ & EBV65-TC-26 & 1.851 & 1.845 \\
\hline $3 / 9 / 2005$ & EBV65-TC-12 & 1.851 & 1.841 \\
\hline $3 / 9 / 2005$ & EBV65-TC-17 & 1.851 & 1.845 \\
\hline $3 / 9 / 2005$ & EBV65-TC-21 & 1.851 & 1.843 \\
\hline & & Average & 1.843 \\
\cline { 3 - 4 } & & Standard Deviation & 0.014 \\
\cline { 3 - 4 } & & Number of Samples & 9 \\
\hline
\end{tabular}

Table 9.7-21: 70 wt \% Thermocarb TC300 / Vectra A950RX LCP

\begin{tabular}{|c|c|c|c|}
\hline Test Date & Sample Number & Theoretical Density $(\mathrm{g} / \mathrm{mL})$ & Measured Density $(\mathrm{g} / \mathrm{mL})$ \\
\hline $3 / 9 / 2005$ & EBV70-TC-27 & 1.898 & 1.906 \\
\hline $3 / 9 / 2005$ & EBV70-TC-30 & 1.898 & 1.901 \\
\hline $3 / 9 / 2005$ & EBV70-TC-10 & 1.898 & 1.903 \\
\hline & Average & 1.903 \\
\cline { 3 - 4 } & & Standard Deviation & 0.003 \\
\cline { 3 - 4 } & & Number of Samples & 3 \\
\hline
\end{tabular}


Table 9.7-22: 75 wt\% Thermocarb TC300 / Vectra A950RX LCP

\begin{tabular}{|c|c|c|c|}
\hline Test Date & Sample Number & Theoretical Density $(\mathrm{g} / \mathrm{mL})$ & Measured Density $(\mathrm{g} / \mathrm{mL})$ \\
\hline $3 / 9 / 2005$ & EBV75-TC-11 & 1.948 & 1.950 \\
\hline $3 / 9 / 2005$ & EBV75-TC-12 & 1.948 & 1.954 \\
\hline $3 / 9 / 2005$ & EBV75-TC-11 & 1.948 & 1.946 \\
\hline & Average & 1.950 \\
\cline { 3 - 4 } & & Standard Deviation & 0.004 \\
\cline { 3 - 4 } & & Number of Samples & 3 \\
\hline
\end{tabular}

Table 9.7-23: 40 wt\% Asbury Synthetic Graphite 4012 / Vectra A950RX LCP

\begin{tabular}{|c|c|c|c|}
\hline Test Date & Sample Number & Theoretical Density $(\mathrm{g} / \mathrm{mL})$ & Measured Density $(\mathrm{g} / \mathrm{mL})$ \\
\hline $5 / 27 / 2004$ & ECV40-TC-14 & 1.647 & 1.642 \\
\hline $5 / 27 / 2004$ & ECV40-TC-21 & 1.647 & 1.641 \\
\hline $5 / 27 / 2004$ & ECV40-TC-24 & 1.647 & 1.639 \\
\hline $5 / 27 / 2004$ & ECV40-TC-26 & 1.647 & 1.639 \\
\hline $5 / 27 / 2004$ & ECV40-TC-27 & 1.647 & 1.640 \\
\hline & & Average & 1.640 \\
\cline { 3 - 4 } & & Standard Deviation & 0.001 \\
\cline { 3 - 4 } & & Number of Samples & 5 \\
\hline
\end{tabular}

Table 9.7-24: 60 wt\% Asbury Synthetic Graphite 4012 / Vectra A950RX LCP

\begin{tabular}{|c|c|c|c|}
\hline Test Date & Sample Number & Theoretical Density $(\mathrm{g} / \mathrm{mL})$ & Measured Density $(\mathrm{g} / \mathrm{mL})$ \\
\hline $5 / 27 / 2004$ & ECV60-TC-15 & 1.807 & 1.804 \\
\hline $5 / 27 / 2004$ & ECV60-TC-17 & 1.807 & 1.804 \\
\hline $5 / 27 / 2004$ & ECV60-TC-18 & 1.807 & 1.803 \\
\hline $5 / 27 / 2004$ & ECV60-TC-22 & 1.807 & 1.805 \\
\hline $5 / 27 / 2004$ & ECV60-TC-28 & 1.807 & 1.804 \\
\hline $5 / 27 / 2004$ & ECV60-TC-35 & 1.807 & 1.804 \\
\hline & & Average & 1.804 \\
\cline { 3 - 4 } & & Standard Deviation & 0.001 \\
\cline { 3 - 4 } & & Number of Samples & 6 \\
\hline
\end{tabular}


Table 9.7-25: 70 wt\% Asbury Synthetic Graphite 4012 / Vectra A950RX LCP

\begin{tabular}{|c|c|c|c|}
\hline Test Date & Sample Number & Theoretical Density $(\mathrm{g} / \mathrm{mL})$ & Measured Density $(\mathrm{g} / \mathrm{mL})$ \\
\hline $5 / 27 / 2004$ & ECV70-TC-14 & 1.898 & 1.896 \\
\hline $5 / 27 / 2004$ & ECV70-TC-16 & 1.898 & 1.897 \\
\hline $5 / 27 / 2004$ & ECV70-TC-18 & 1.898 & 1.896 \\
\hline $5 / 27 / 2004$ & ECV70-TC-19 & 1.898 & 1.897 \\
\hline $5 / 27 / 2004$ & ECV70-TC-20 & 1.898 & 1.897 \\
\hline & & Average & 1.897 \\
\cline { 3 - 4 } & & Standard Deviation & 0.000 \\
\cline { 3 - 4 } & & Number of Samples & 5 \\
\hline
\end{tabular}

Table 9.7-26: 40 wt\% Asbury 3160 Natural Flake Graphite / Vectra A950RX LCP

\begin{tabular}{|c|c|c|c|}
\hline Test Date & Sample Number & Theoretical Density $(\mathrm{g} / \mathrm{mL})$ & Measured Density $(\mathrm{g} / \mathrm{mL})$ \\
\hline $7 / 27 / 2004$ & EDV40-TC-14 & 1.647 & 1.643 \\
\hline $7 / 27 / 2004$ & EDV40-TC-17 & 1.647 & 1.643 \\
\hline $7 / 27 / 2004$ & EDV40-TC-21 & 1.647 & 1.644 \\
\hline $7 / 27 / 2004$ & EDV40-TC-26 & 1.647 & 1.643 \\
\hline $7 / 27 / 2004$ & EDV40-TC-29 & 1.647 & 1.645 \\
\hline & & Average & 1.644 \\
\cline { 3 - 4 } & & Standard Deviation & 0.001 \\
\cline { 3 - 4 } & & Number of Samples & 5 \\
\hline
\end{tabular}

Table 9.7-27: 60 wt\% Asbury 3160 Natural Flake Graphite / Vectra A950RX LCP

\begin{tabular}{|c|c|c|c|}
\hline Test Date & Sample Number & Theoretical Density $(\mathrm{g} / \mathrm{mL})$ & Measured Density $(\mathrm{g} / \mathrm{mL})$ \\
\hline $7 / 27 / 2004$ & EDV60-TC-11 & 1.807 & 1.808 \\
\hline $7 / 27 / 2004$ & EDV60-TC-12 & 1.807 & 1.809 \\
\hline $7 / 27 / 2004$ & EDV60-TC-22 & 1.807 & 1.808 \\
\hline $7 / 27 / 2004$ & EDV60-TC-28 & 1.807 & 1.810 \\
\hline $7 / 27 / 2004$ & EDV60-TC-30 & 1.807 & 1.807 \\
\hline & & Average & 1.808 \\
\cline { 3 - 4 } & & Standard Deviation & 0.001 \\
\cline { 3 - 4 } & & Number of Samples & 5 \\
\hline
\end{tabular}


Table 9.7-28: 70 wt\% Asbury 3160 Natural Flake Graphite / Vectra A950RX LCP

\begin{tabular}{|c|c|c|c|}
\hline Test Date & Sample Number & Theoretical Density $(\mathrm{g} / \mathrm{mL})$ & Measured Density $(\mathrm{g} / \mathrm{mL})$ \\
\hline $7 / 27 / 2004$ & EDV70-TC-17 & 1.898 & 1.904 \\
\hline $7 / 27 / 2004$ & EDV70-TC-20 & 1.898 & 1.901 \\
\hline $7 / 27 / 2004$ & EDV70-TC-22 & 1.898 & 1.901 \\
\hline $7 / 27 / 2004$ & EDV70-TC-23 & 1.898 & 1.900 \\
\hline $7 / 27 / 2004$ & EDV70-TC-26 & 1.898 & 1.902 \\
\hline & & Average & 1.901 \\
\cline { 3 - 4 } & & Standard Deviation & 0.001 \\
\cline { 3 - 4 } & & Number of Samples & 5 \\
\hline
\end{tabular}

Table 9.7-29: 40 wt\% Asbury F108A CNC / Vectra A950RX LCP

\begin{tabular}{|c|c|c|c|}
\hline Test Date & Sample Number & Theoretical Density $(\mathrm{g} / \mathrm{mL})$ & Measured Density $(\mathrm{g} / \mathrm{mL})$ \\
\hline $7 / 27 / 2004$ & EEV40-TC-14 & 1.615 & 1.616 \\
\hline $7 / 27 / 2004$ & EEV40-TC-15 & 1.615 & 1.618 \\
\hline $7 / 27 / 2004$ & EEV40-TC-22 & 1.615 & 1.620 \\
\hline $7 / 27 / 2004$ & EEV40-TC-26 & 1.615 & 1.617 \\
\hline $7 / 27 / 2004$ & EEV40-TC-27 & 1.615 & 1.620 \\
\hline & & Average & 1.618 \\
\cline { 3 - 4 } & & Standard Deviation & 0.002 \\
\cline { 3 - 4 } & & Number of Samples & 5 \\
\hline
\end{tabular}

Table 9.7-30: 60 wt\% Asbury F108A CNC / Vectra A950RX LCP

\begin{tabular}{|c|c|c|c|}
\hline Test Date & Sample Number & Theoretical Density $(\mathrm{g} / \mathrm{mL})$ & Measured Density $(\mathrm{g} / \mathrm{mL})$ \\
\hline $7 / 27 / 2004$ & EEV60-TC-19 & 1.750 & 1.747 \\
\hline $7 / 27 / 2004$ & EEV60-TC-25 & 1.750 & 1.759 \\
\hline $7 / 27 / 2004$ & EEV60-TC-26 & 1.750 & 1.760 \\
\hline $7 / 27 / 2004$ & EEV60-TC-27 & 1.750 & 1.757 \\
\hline $7 / 27 / 2004$ & EEV60-TC-31 & 1.750 & 1.760 \\
\hline & & Average & 1.757 \\
\cline { 3 - 4 } & & Standard Deviation & 0.005 \\
\cline { 3 - 4 } & & Number of Samples & 5 \\
\hline
\end{tabular}


Table 9.7-31: 70 wt\% Asbury F108A CNC / Vectra A950RX LCP

\begin{tabular}{|c|c|c|c|}
\hline Test Date & Sample Number & Theoretical Density $(\mathrm{g} / \mathrm{mL})$ & Measured Density $(\mathrm{g} / \mathrm{mL})$ \\
\hline $7 / 27 / 2004$ & EEV70-TC-11 & 1.826 & 1.840 \\
\hline $7 / 27 / 2004$ & EEV70-TC-26 & 1.826 & 1.842 \\
\hline $7 / 27 / 2004$ & EEV70-TC-27 & 1.826 & 1.840 \\
\hline $7 / 27 / 2004$ & EEV70-TC-33 & 1.826 & 1.842 \\
\hline $7 / 27 / 2004$ & EEV70-TC-35 & 1.826 & 1.842 \\
\hline & & Average & 1.841 \\
\cline { 3 - 4 } & & Standard Deviation & 0.001 \\
\cline { 3 - 4 } & & Number of Samples & 5 \\
\hline
\end{tabular}

Table 9.7-32: 5 wt\% Fortafil 243 / Vectra A950RX LCP

\begin{tabular}{|c|c|c|c|}
\hline Test Date & Sample Number & Theoretical Density $(\mathrm{g} / \mathrm{mL})$ & Measured Density $(\mathrm{g} / \mathrm{mL})$ \\
\hline $1 / 10 / 2006$ & EHV5-TC-2 & 1.414 & 1.408 \\
\hline $1 / 10 / 2006$ & EHV5-TC-10 & 1.414 & 1.407 \\
\hline $1 / 10 / 2006$ & EHV5-TC-12 & 1.414 & 1.406 \\
\hline $1 / 10 / 2006$ & EHV5-TC-22 & 1.414 & 1.407 \\
\hline & & Average & 1.407 \\
\cline { 3 - 4 } & & Standard Deviation & 0.001 \\
\cline { 3 - 4 } & & Number of Samples & 4 \\
\hline
\end{tabular}

Table 9.7-33: 7.5 wt\% Fortafil 243 / Vectra A950RX LCP

\begin{tabular}{|c|c|c|c|}
\hline Test Date & Sample Number & Theoretical Density $(\mathrm{g} / \mathrm{mL})$ & Measured Density $(\mathrm{g} / \mathrm{mL})$ \\
\hline $1 / 10 / 2006$ & EHV7.5-TC-2 & 1.421 & 1.414 \\
\hline $1 / 10 / 2006$ & EHV7.5-TC-10 & 1.421 & 1.422 \\
\hline $1 / 10 / 2006$ & EHV7.5-TC-12 & 1.421 & 1.419 \\
\hline $1 / 10 / 2006$ & EHV7.5-TC-22 & 1.421 & 1.417 \\
\hline \multirow{2}{*}{} & Average & 1.418 \\
\cline { 3 - 4 } & & Standard Deviation & 0.003 \\
\cline { 3 - 4 } & & Number of Samples & 4 \\
\hline
\end{tabular}


Table 9.7-34: 10 wt\% Fortafil 243 / Vectra A950RX LCP

\begin{tabular}{|c|c|c|c|}
\hline Test Date & Sample Number & Theoretical Density $(\mathrm{g} / \mathrm{mL})$ & Measured Density $(\mathrm{g} / \mathrm{mL})$ \\
\hline $1 / 10 / 2006$ & EHV10-TC-2 & 1.428 & 1.422 \\
\hline $1 / 10 / 2006$ & EHV10-TC-10 & 1.428 & 1.425 \\
\hline $1 / 10 / 2006$ & EHV10-TC-12 & 1.428 & 1.423 \\
\hline $1 / 10 / 2006$ & EHV10-TC-22 & 1.428 & 1.424 \\
\hline & & Average & 1.424 \\
\cline { 3 - 4 } & & Standard Deviation & 0.001 \\
\cline { 3 - 4 } & & Number of Samples & 4 \\
\hline
\end{tabular}

Table 9.7-35: 15 wt\% Fortafil 243 / Vectra A950RX LCP

\begin{tabular}{|c|c|c|c|}
\hline Test Date & Sample Number & Theoretical Density $(\mathrm{g} / \mathrm{mL})$ & Measured Density $(\mathrm{g} / \mathrm{mL})$ \\
\hline $1 / 10 / 2006$ & EHV15-TC-2 & 1.442 & 1.437 \\
\hline $1 / 10 / 2006$ & EHV15-TC-10 & 1.442 & 1.437 \\
\hline $1 / 10 / 2006$ & EHV15-TC-12 & 1.442 & 1.439 \\
\hline $1 / 10 / 2006$ & EHV15-TC-22 & 1.442 & 1.437 \\
\hline \multirow{2}{*}{} & Average & 1.438 \\
\cline { 3 - 4 } & & Standard Deviation & 0.001 \\
\cline { 3 - 4 } & & Number of Samples & 4 \\
\hline
\end{tabular}

Table 9.7-36: 20 wt\% Fortafil 243 / Vectra A950RX LCP

\begin{tabular}{|c|c|c|c|}
\hline Test Date & Sample Number & Theoretical Density $(\mathrm{g} / \mathrm{mL})$ & Measured Density $(\mathrm{g} / \mathrm{mL})$ \\
\hline $1 / 10 / 2006$ & EHV20-TC-2 & 1.457 & 1.451 \\
\hline $1 / 10 / 2006$ & EHV20-TC-10 & 1.457 & 1.453 \\
\hline $1 / 10 / 2006$ & EHV20-TC-13 & 1.457 & 1.452 \\
\hline $1 / 10 / 2006$ & EHV20-TC-22 & 1.457 & 1.459 \\
\hline \multirow{2}{*}{} & Average & 1.454 \\
\cline { 3 - 4 } & & Standard Deviation & 0.004 \\
\cline { 3 - 4 } & & Number of Samples & 4 \\
\hline
\end{tabular}


Table 9.7-37: 25 wt\% Fortafil 243 / Vectra A950RX LCP

\begin{tabular}{|c|c|c|c|}
\hline Test Date & Sample Number & Theoretical Density $(\mathrm{g} / \mathrm{mL})$ & Measured Density $(\mathrm{g} / \mathrm{mL})$ \\
\hline $1 / 10 / 2006$ & EHV25-TC-2 & 1.472 & 1.470 \\
\hline $1 / 10 / 2006$ & EHV25-TC-10 & 1.472 & 1.468 \\
\hline $1 / 10 / 2006$ & EHV25-TC-12 & 1.472 & 1.468 \\
\hline $1 / 10 / 2006$ & EHV25-TC-22 & 1.472 & 1.474 \\
\hline & & Average & 1.470 \\
\cline { 3 - 4 } & & Standard Deviation & 0.003 \\
\cline { 3 - 4 } & & Number of Samples & 4 \\
\hline
\end{tabular}

Table 9.7-38: 30 wt\% Fortafil 243 / Vectra A950RX LCP

\begin{tabular}{|c|c|c|c|}
\hline Test Date & Sample Number & Theoretical Density $(\mathrm{g} / \mathrm{mL})$ & Measured Density $(\mathrm{g} / \mathrm{mL})$ \\
\hline $1 / 10 / 2006$ & EHV30-TC-2 & 1.487 & 1.484 \\
\hline $1 / 10 / 2006$ & EHV30-TC-10 & 1.487 & 1.484 \\
\hline $1 / 10 / 2006$ & EHV30-TC-12 & 1.487 & 1.485 \\
\hline $1 / 10 / 2006$ & EHV30-TC-22 & 1.487 & 1.484 \\
\hline & & Average & 1.484 \\
\cline { 3 - 4 } & & Standard Deviation & 0.000 \\
\cline { 3 - 4 } & & Number of Samples & 4 \\
\hline
\end{tabular}

Table 9.7-39: 35 wt\% Fortafil 243 / Vectra A950RX LCP

\begin{tabular}{|c|c|c|c|}
\hline Test Date & Sample Number & Theoretical Density $(\mathrm{g} / \mathrm{mL})$ & Measured Density $(\mathrm{g} / \mathrm{mL})$ \\
\hline $1 / 10 / 2006$ & EHV35-TC-2 & 1.503 & 1.499 \\
\hline $1 / 10 / 2006$ & EHV35-TC-10 & 1.503 & 1.499 \\
\hline $1 / 10 / 2006$ & EHV35-TC-12 & 1.503 & 1.500 \\
\hline $1 / 10 / 2006$ & EHV35-TC-22 & 1.503 & 1.500 \\
\hline & Average & 1.500 \\
\cline { 3 - 4 } & & Standard Deviation & 0.001 \\
\cline { 3 - 4 } & & Number of Samples & 4 \\
\hline
\end{tabular}


Table 9.7-40: 40 wt\% Fortafil 243 / Vectra A950RX LCP

\begin{tabular}{|c|c|c|c|}
\hline Test Date & Sample Number & Theoretical Density $(\mathrm{g} / \mathrm{mL})$ & Measured Density $(\mathrm{g} / \mathrm{mL})$ \\
\hline $1 / 10 / 2006$ & EHV40-TC-2 & 1.519 & 1.515 \\
\hline $1 / 10 / 2006$ & EHV40-TC-10 & 1.519 & 1.515 \\
\hline $1 / 10 / 2006$ & EHV40-TC-12 & 1.519 & 1.516 \\
\hline $1 / 10 / 2006$ & EHV40-TC-22 & 1.519 & 1.517 \\
\hline & & Average & 1.516 \\
\cline { 3 - 4 } & & Standard Deviation & 0.001 \\
\cline { 3 - 4 } & & Number of Samples & 4 \\
\hline
\end{tabular}

Table 9.7-41: 45 wt\% Fortafil 243 / Vectra A950RX LCP

\begin{tabular}{|c|c|c|c|}
\hline Test Date & Sample Number & Theoretical Density $(\mathrm{g} / \mathrm{mL})$ & Measured Density $(\mathrm{g} / \mathrm{mL})$ \\
\hline $1 / 10 / 2006$ & EHV45-TC-2 & 1.535 & 1.532 \\
\hline $1 / 10 / 2006$ & EHV45-TC-10 & 1.535 & 1.534 \\
\hline $1 / 10 / 2006$ & EHV45-TC-12 & 1.535 & 1.533 \\
\hline $1 / 10 / 2006$ & EHV45-TC-22 & 1.535 & 1.532 \\
\hline \multirow{2}{*}{} & Average & 1.533 \\
\cline { 3 - 4 } & & Standard Deviation & 0.001 \\
\cline { 3 - 4 } & & Number of Samples & 4 \\
\hline
\end{tabular}

\section{Table 9.7-42: 50 wt\% Fortafil 243 / Vectra A950RX LCP}

\begin{tabular}{|c|c|c|c|}
\hline Test Date & Sample Number & Theoretical Density $(\mathrm{g} / \mathrm{mL})$ & Measured Density $(\mathrm{g} / \mathrm{mL})$ \\
\hline $3 / 1 / 2006$ & EHV50R-TC-13 & 1.552 & 1.556 \\
\hline $3 / 1 / 2006$ & EHV50R-TC-23 & 1.552 & 1.552 \\
\hline $3 / 1 / 2006$ & EHV50R-TC-28 & 1.552 & 1.551 \\
\hline & & Average & 1.553 \\
\cline { 3 - 4 } & & Standard Deviation & 0.002 \\
\cline { 3 - 4 } & & Number of Samples & 3 \\
\hline
\end{tabular}


Table 9.7-43: 55 wt\% Fortafil 243 / Vectra A950RX LCP

\begin{tabular}{|c|c|c|c|}
\hline Test Date & Sample Number & Theoretical Density $(\mathrm{g} / \mathrm{mL})$ & Measured Density $(\mathrm{g} / \mathrm{mL})$ \\
\hline $3 / 1 / 2006$ & EHV55-TC-13 & 1.569 & 1.570 \\
\hline $3 / 1 / 2006$ & EHV55-TC-23 & 1.569 & 1.570 \\
\hline $3 / 1 / 2006$ & EHV55-TC-28 & 1.569 & 1.569 \\
\hline & & Average & 1.570 \\
\cline { 3 - 4 } & & Standard Deviation & 0.000 \\
\cline { 3 - 4 } & & Number of Samples & 3 \\
\hline
\end{tabular}

Table 9.7-44: 60 wt\% Fortafil 243 / Vectra A950RX LCP

\begin{tabular}{|c|c|c|c|}
\hline Test Date & Sample Number & Theoretical Density $(\mathrm{g} / \mathrm{mL})$ & Measured Density $(\mathrm{g} / \mathrm{mL})$ \\
\hline $3 / 1 / 2006$ & EHV60R-TC-13 & 1.586 & 1.584 \\
\hline $3 / 1 / 2006$ & EHV60R-TC-23 & 1.586 & 1.587 \\
\hline $3 / 1 / 2006$ & EHV60R-TC-28 & 1.586 & 1.584 \\
\hline & & Average & 1.585 \\
\cline { 3 - 4 } & & Standard Deviation & 0.002 \\
\cline { 3 - 4 } & & Number of Samples & 3 \\
\hline
\end{tabular}




\section{Section 9.8: Orientation Data}

Table 9.8-1: Thermocarb TC300 / Vectra A950RX LCP (In-Plane)

\begin{tabular}{|c|c|c|c|}
\hline Sample & Average (degrees) & Standard Deviation (degrees) & Number of Data Points \\
\hline EBV40 & 19.90 & 21.16 & 1690 \\
\hline EBV60 & 23.84 & 22.10 & 650 \\
\hline EBV70 & 28.38 & 25.43 & 1064 \\
\hline
\end{tabular}

Table 9.8-2: Thermocarb TC300 / Vectra A950RX LCP (Through-Plane)

\begin{tabular}{|c|c|c|c|}
\hline Sample & Average (degrees) & Standard Deviation (degrees) & Number of Data Points \\
\hline EBV40 & 51.92 & 31.09 & 571 \\
\hline EBV60 & 52.71 & 30.22 & 1564 \\
\hline EBV70 & 44.38 & 29.71 & 1422 \\
\hline
\end{tabular}

Table 9.8-3: Asbury Synthetic Graphite 4012 / Vectra A950RX LCP (In-Plane)

\begin{tabular}{|c|c|c|c|}
\hline Sample & Average (degrees) & Standard Deviation (degrees) & Number of Data Points \\
\hline ECV40 & 23.56 & 21.01 & 621 \\
\hline ECV60 & 29.16 & 25.27 & 1657 \\
\hline ECV70 & 34.60 & 26.05 & 595 \\
\hline
\end{tabular}

Table 9.8-4: Asbury Synthetic Graphite 4012 / Vectra A950RX LCP (ThroughPlane)

\begin{tabular}{|c|c|c|c|}
\hline Sample & Average (degrees) & Standard Deviation (degrees) & Number of Data Points \\
\hline ECV40 & 53.25 & 29.90 & 1169 \\
\hline ECV60 & 46.80 & 29.46 & 1664 \\
\hline ECV70 & 40.26 & 27.46 & 1458 \\
\hline
\end{tabular}


Table 9.8-5: Asbury 3160 Natural Flake Graphite / Vectra A950RX LCP (In-Plane)

\begin{tabular}{|c|c|c|c|}
\hline Sample & Average (degrees) & Standard Deviation (degrees) & Number of Data Points \\
\hline EDV40 & 13.89 & 16.00 & 1577 \\
\hline EDV60 & 27.68 & 24.78 & 408 \\
\hline EDV70 & 39.26 & 30.18 & 373 \\
\hline
\end{tabular}

Table 9.8-6: Asbury 3160 Natural Flake Graphite / Vectra A950RX LCP (ThroughPlane)

\begin{tabular}{|c|c|c|c|}
\hline Sample & Average (degrees) & Standard Deviation (degrees) & Number of Data Points \\
\hline EDV40 & 50.15 & 28.80 & 2094 \\
\hline EDV60 & 40.17 & 28.25 & 1811 \\
\hline EDV70 & 38.18 & 25.00 & 1851 \\
\hline
\end{tabular}

Table 9.8-7: Asbury F108A CNC / Vectra A950RX LCP (In-Plane)

\begin{tabular}{|c|c|c|c|}
\hline Sample & Average (degrees) & Standard Deviation (degrees) & Number of Data Points \\
\hline EEV40 & 23.43 & 22.21 & 585 \\
\hline EEV60 & 32.02 & 25.81 & 1469 \\
\hline EEV70 & 31.07 & 27.44 & 769 \\
\hline
\end{tabular}

Table 9.8-8: Asbury F108A CNC / Vectra A950RX LCP (Through-Plane)

\begin{tabular}{|c|c|c|c|}
\hline Sample & Average (degrees) & Standard Deviation (degrees) & Number of Data Points \\
\hline EEV40 & 51.57 & 29.51 & 884 \\
\hline EEV60 & 48.59 & 29.21 & 595 \\
\hline EEV70 & 44.95 & 28.26 & 756 \\
\hline
\end{tabular}


Table 9.8-9: Fortafil 243 Carbon Fiber / Vectra A950RX LCP (In-Plane)

\begin{tabular}{|c|c|c|c|}
\hline Sample & Average (degrees) & Standard Deviation (degrees) & Number of Data Points \\
\hline EHV10 & 33.42 & 24.09 & 545 \\
\hline EHV20 & 36.50 & 26.53 & 2620 \\
\hline EHV40 & 14.36 & 17.44 & 2373 \\
\hline EHV60 & 17.93 & 19.56 & 4225 \\
\hline
\end{tabular}

Table 9.8-10: Fortafil 243 Carbon Fiber / Vectra A950RX LCP (Through-Plane)

\begin{tabular}{|c|c|c|c|}
\hline Sample & Average (degrees) & Standard Deviation (degrees) & Number of Data Points \\
\hline EHV10 & 61.49 & 31.40 & 2693 \\
\hline EHV20 & 62.23 & 28.88 & 989 \\
\hline EHV40 & 59.89 & 27.17 & 1294 \\
\hline EHV60 & 62.16 & 24.01 & 386 \\
\hline
\end{tabular}




\section{Section 9.9: Through-Plane Micrographs}

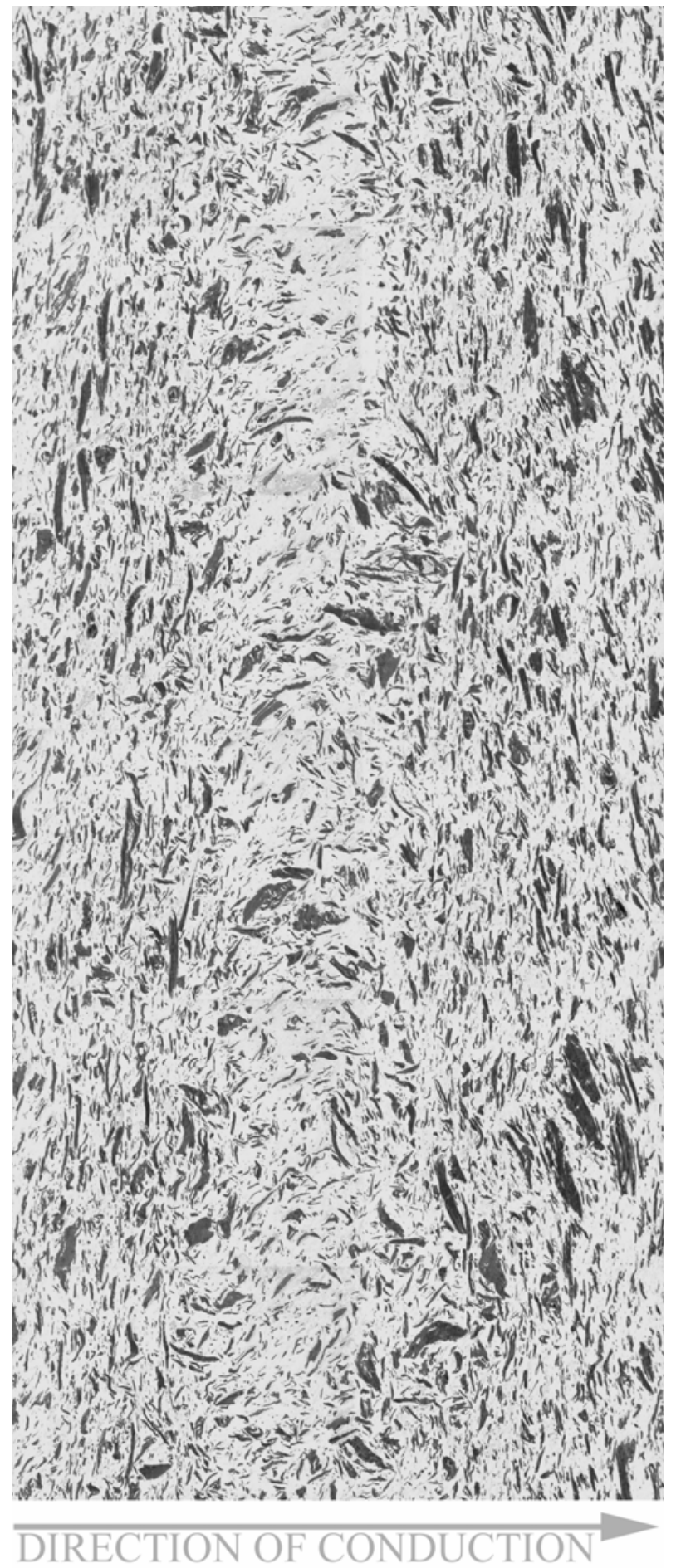

Figure 9.9-1: Optical Micrograph by reflected light of a through-plane thermal conductivity sample containing 40 wt \% Thermocarb TC-300 synthetic graphite in Vectra A950RX LCP at 100x magnification. 


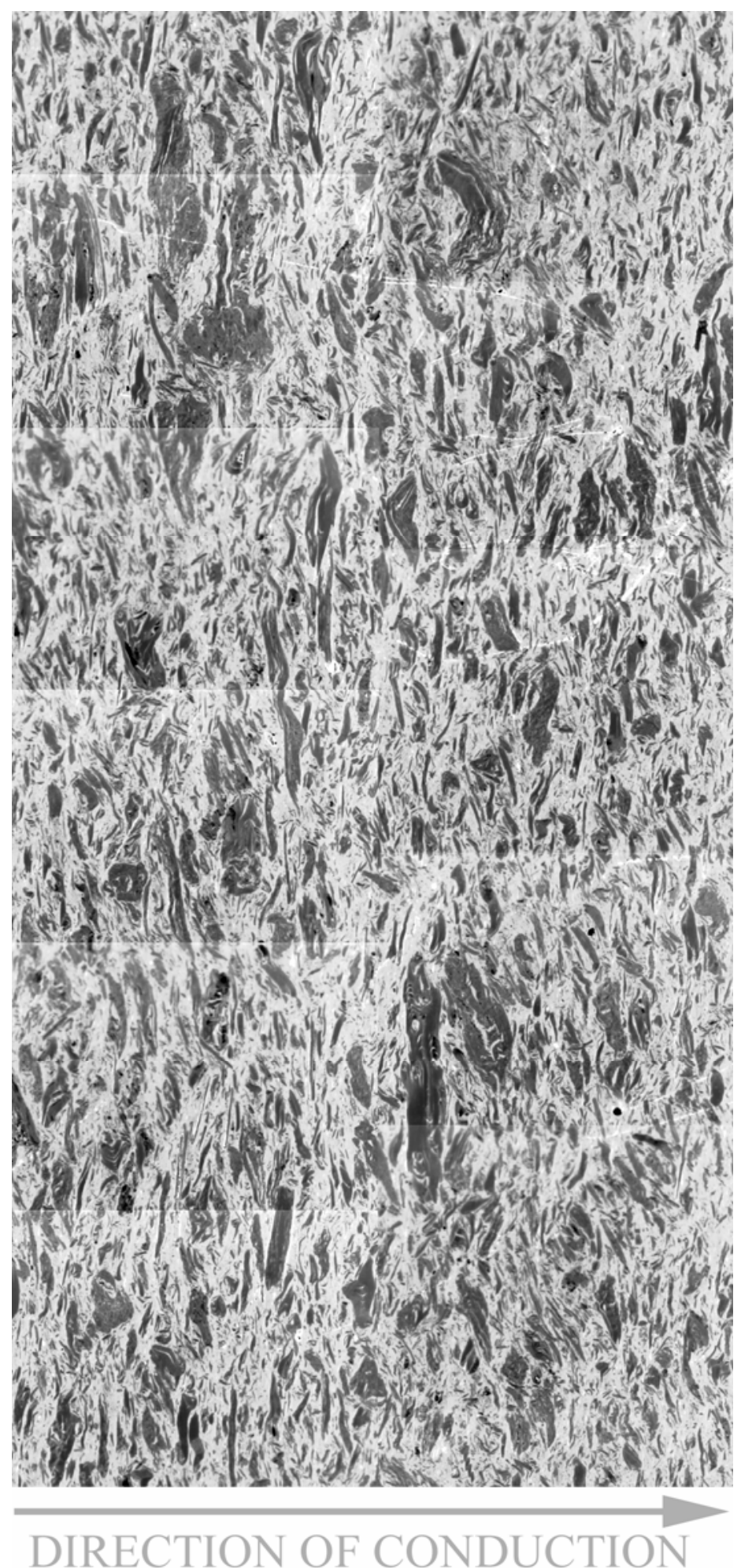

Figure 9.9-2: Optical Micrograph by reflected light of a through-plane thermal conductivity sample containing 60 wt $\%$ Thermocarb TC-300 synthetic graphite in Vectra A950RX LCP at 200x magnification. 


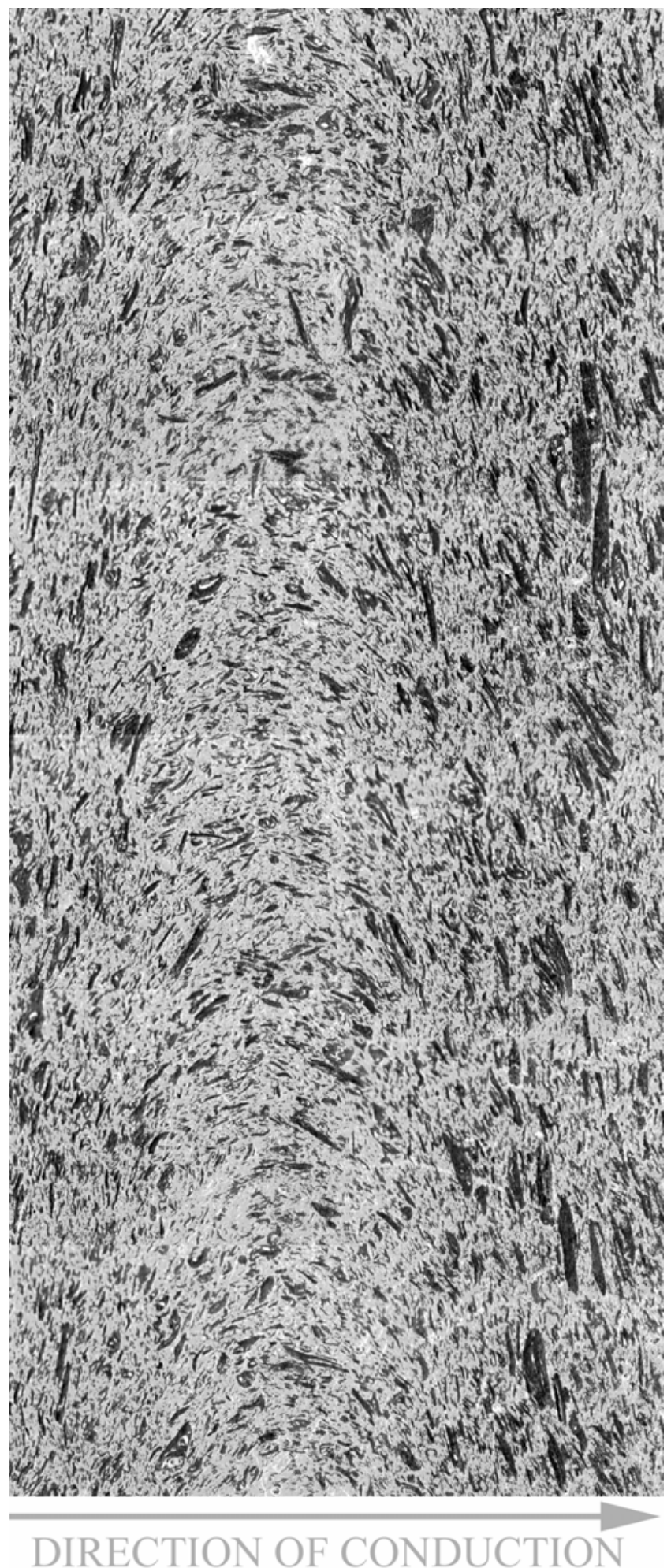

Figure 9.9-3: Optical Micrograph by reflected light of a through-plane thermal conductivity sample containing 70 wt \% Thermocarb TC-300 synthetic graphite in Vectra A950RX LCP at 100x magnification. 


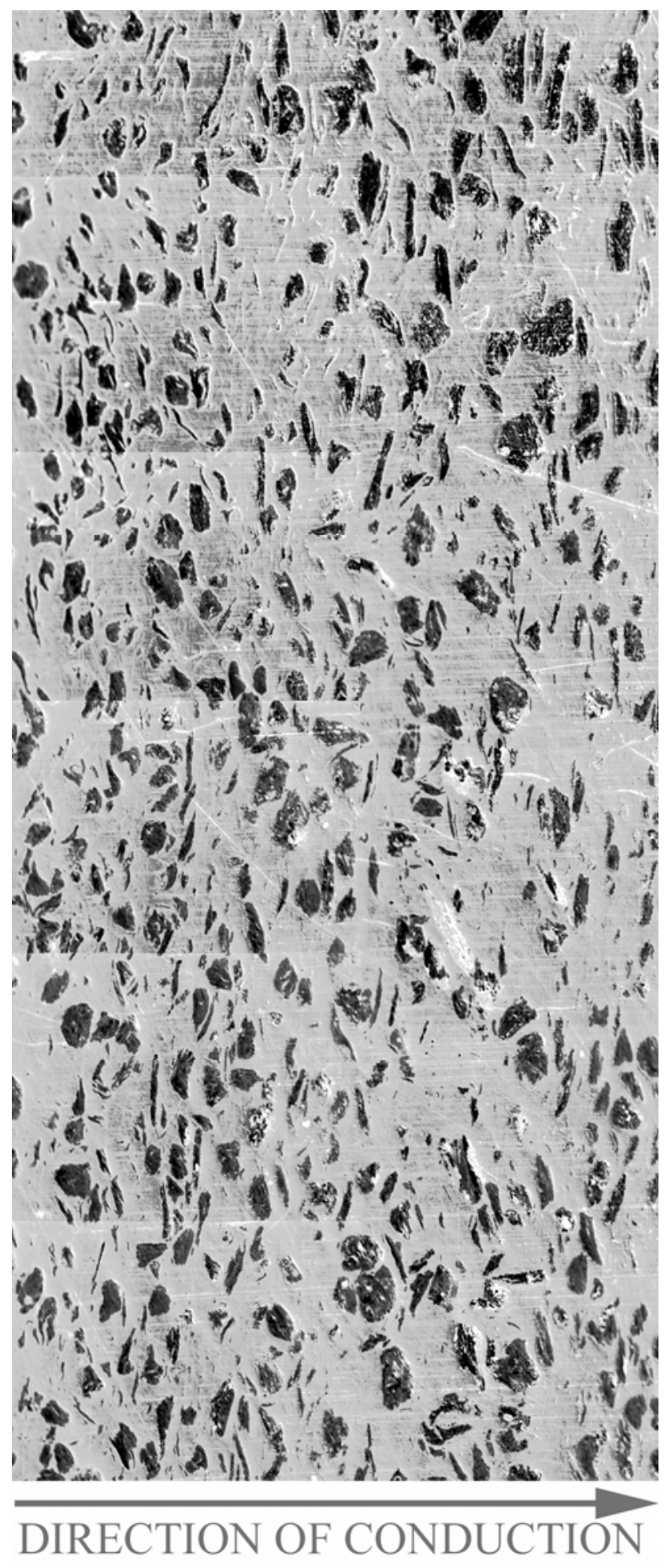

Figure 9.9-4: Optical Micrograph by reflected light of a through-plane thermal conductivity sample containing 40 wt \% Asbury 4012 synthetic graphite in Vectra A950RX LCP at 100x magnification. 


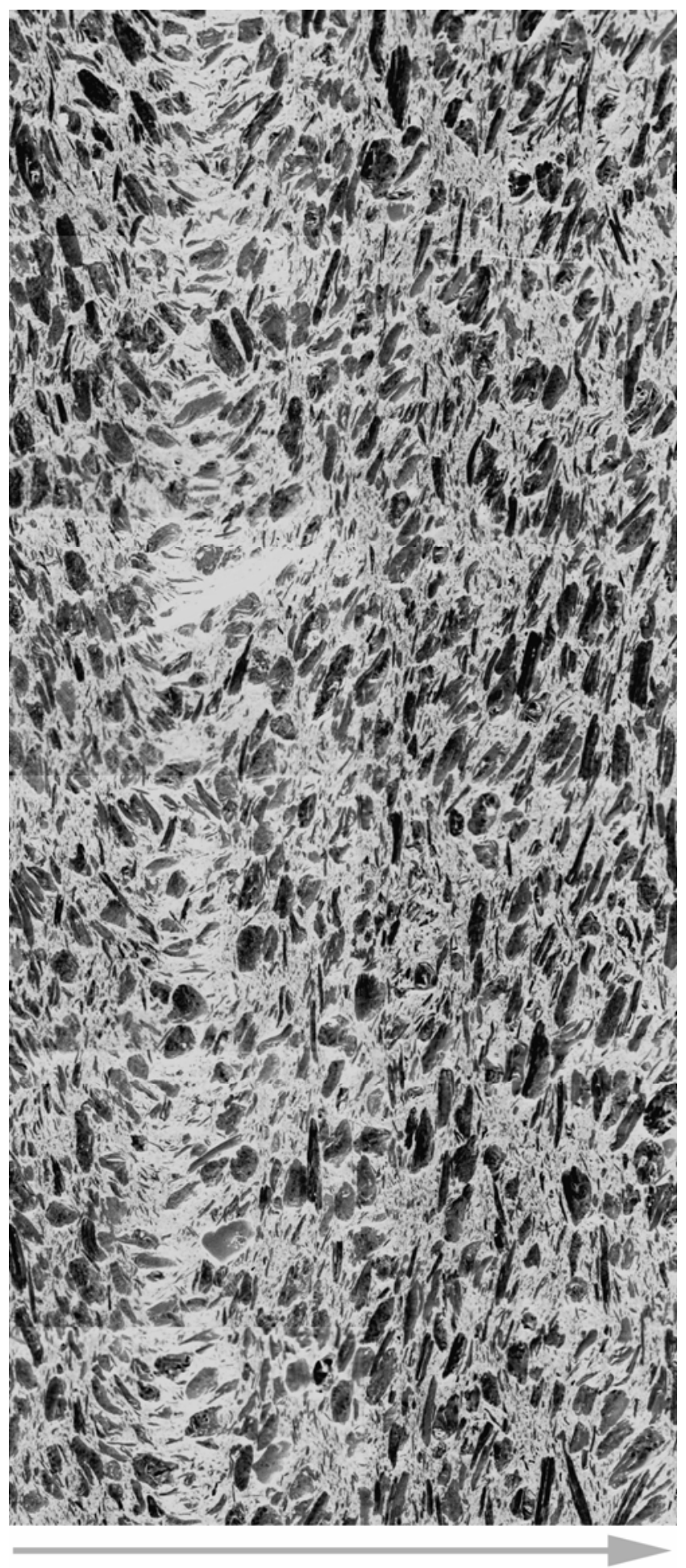

DIRECTION OF CONDUCTION

Figure 9.9-5: Optical Micrograph by reflected light of a through-plane thermal conductivity sample containing 60 wt \% Asbury 4012 synthetic graphite in Vectra A950RX LCP at 100x magnification. 


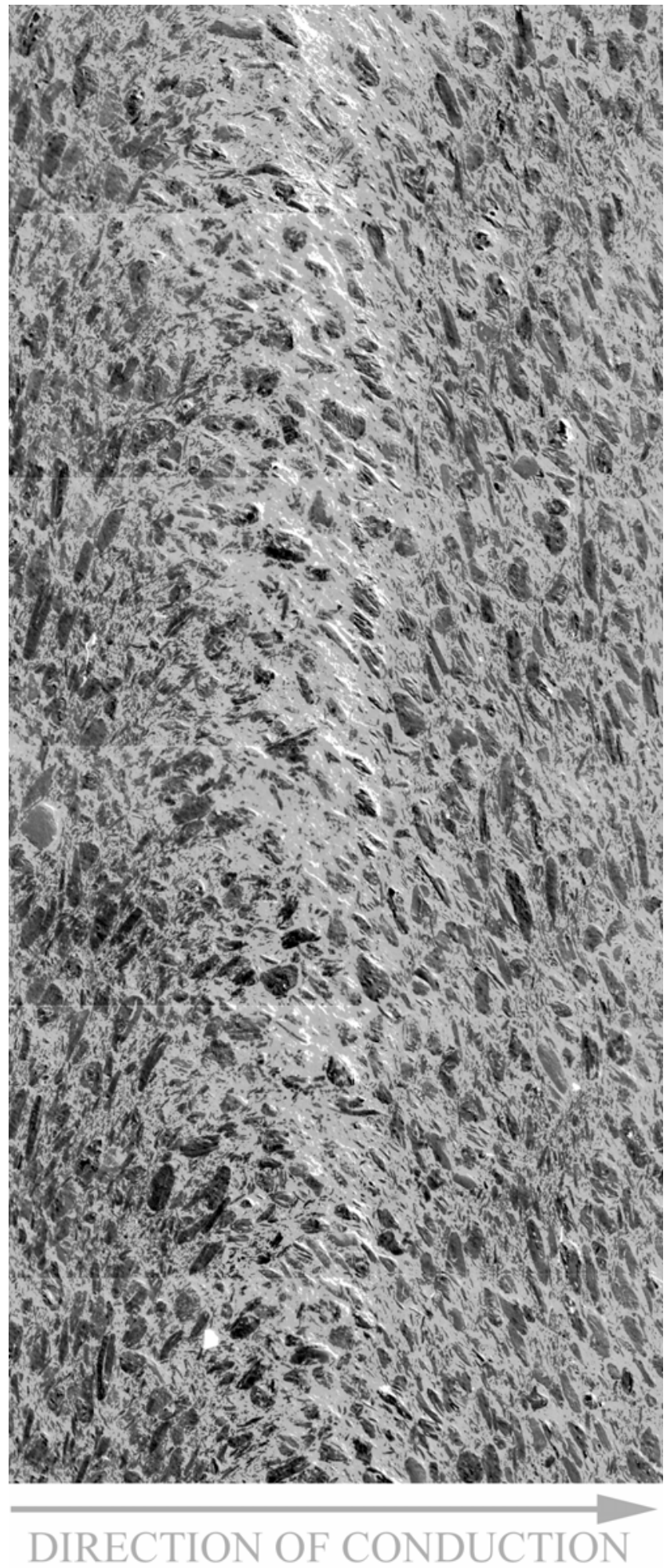

Figure 9.9-6: Optical Micrograph by reflected light of a through-plane thermal conductivity sample containing 70 wt \% Asbury 4012 synthetic graphite in Vectra A950RX LCP at 100x magnification. 


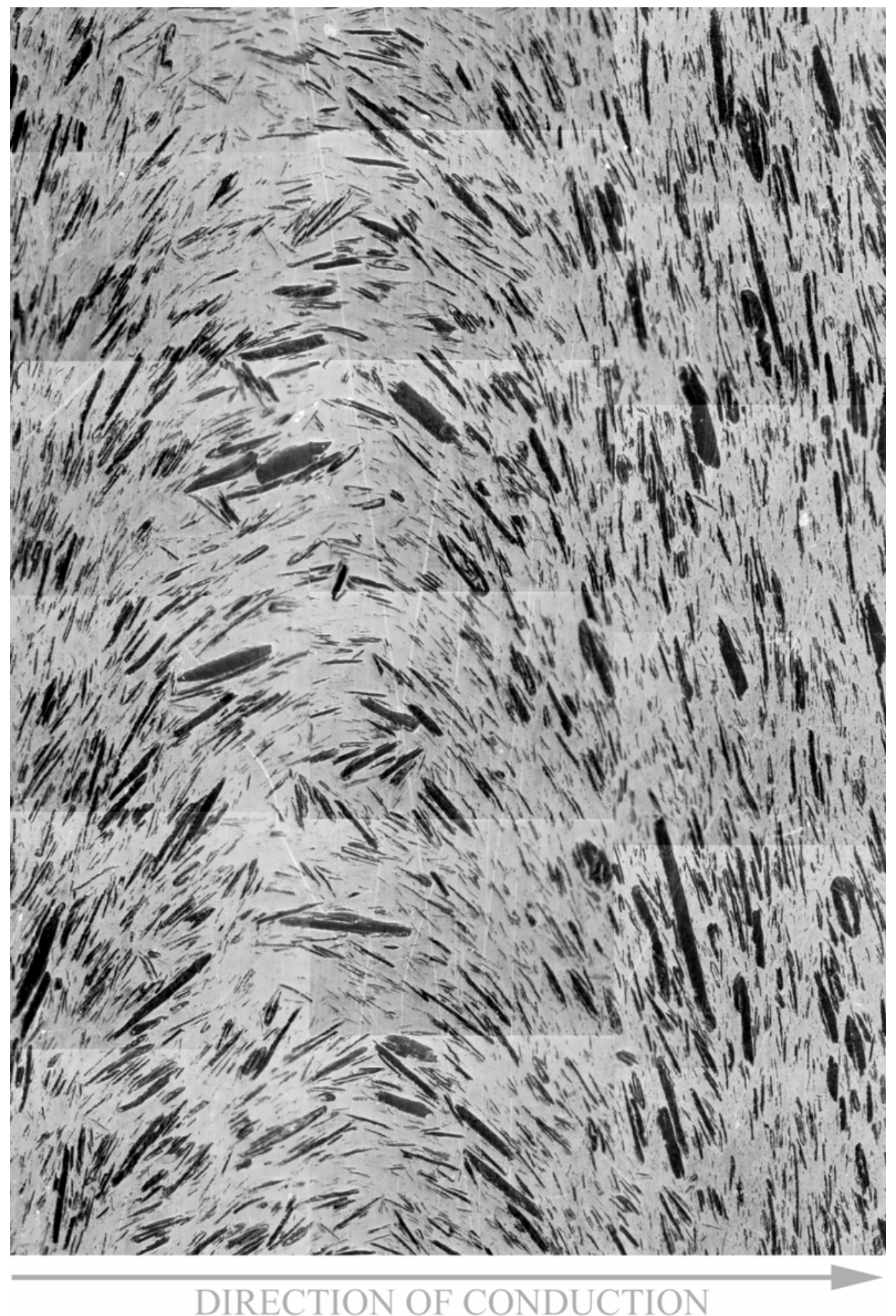

Figure 9.9-7: Optical Micrograph by reflected light of a through-plane thermal conductivity sample containing 40 wt\% Asbury 3160 natural flake graphite in Vectra A950RX LCP at 200x magnification. 


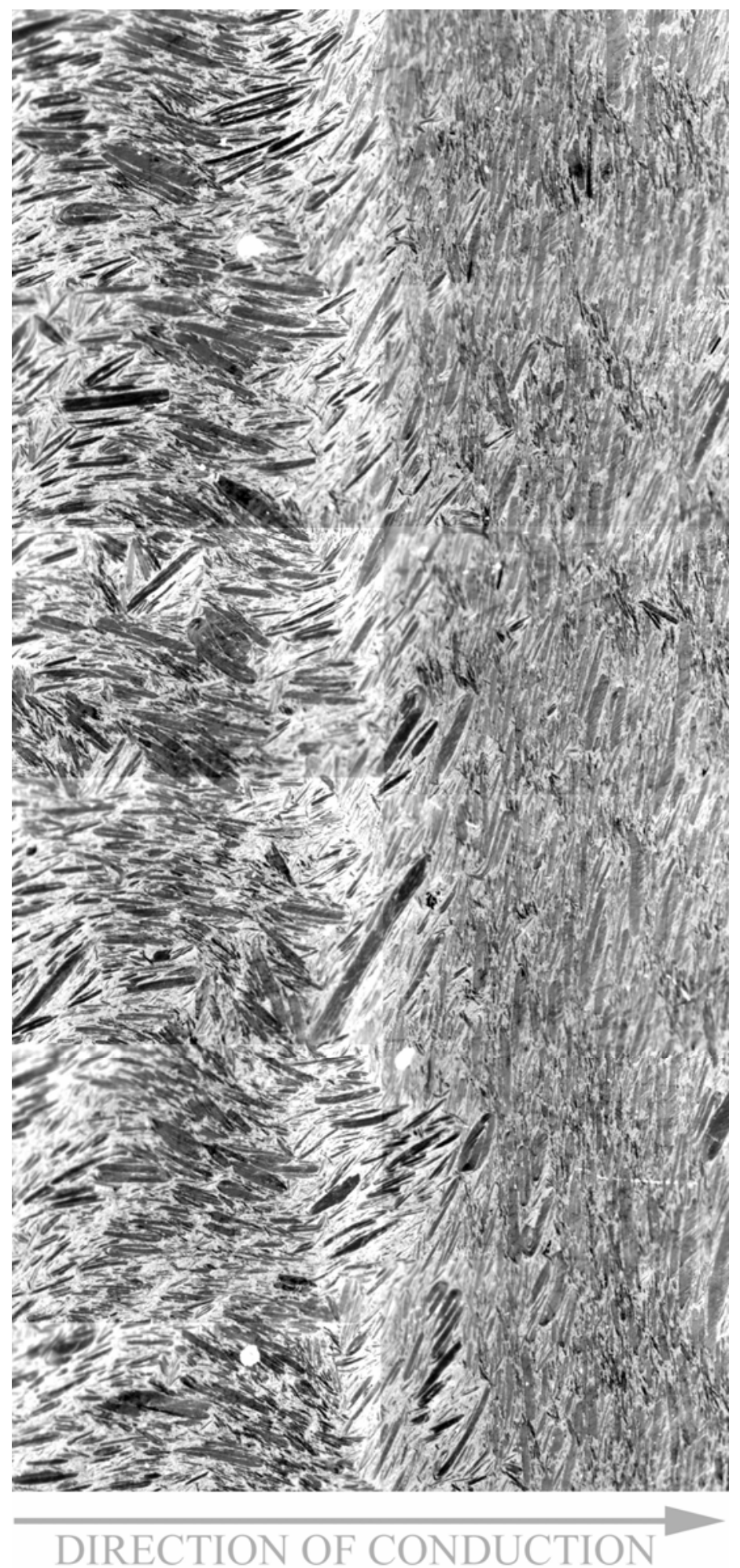

Figure 9.9-8: Optical Micrograph by reflected light of a through-plane thermal conductivity sample containing $60 \mathrm{wt} \%$ Asbury 3160 natural flake graphite in Vectra A950RX LCP at 200x magnification. 


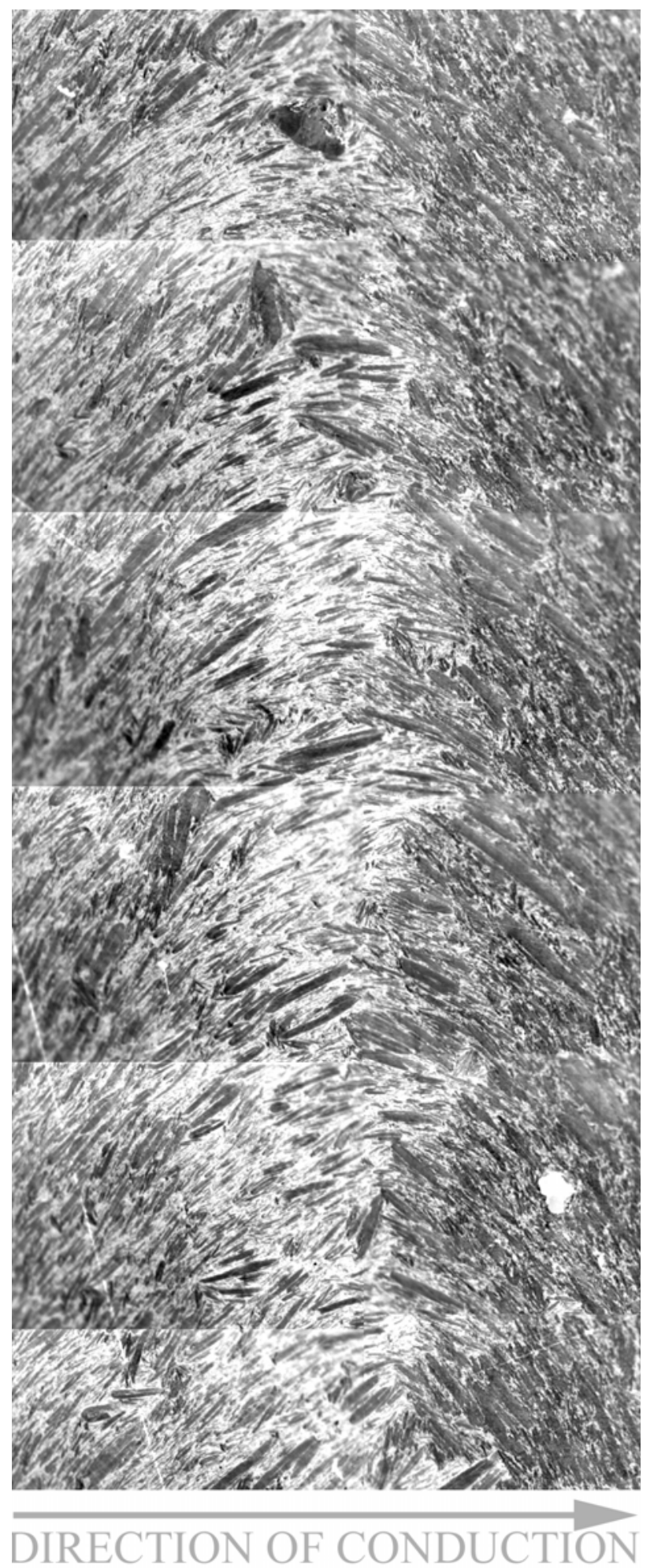

Figure 9.9-9: Optical Micrograph by reflected light of a through-plane thermal conductivity sample containing $70 \mathrm{wt} \%$ Asbury 3160 natural flake graphite in Vectra A950RX LCP at 200x magnification. 


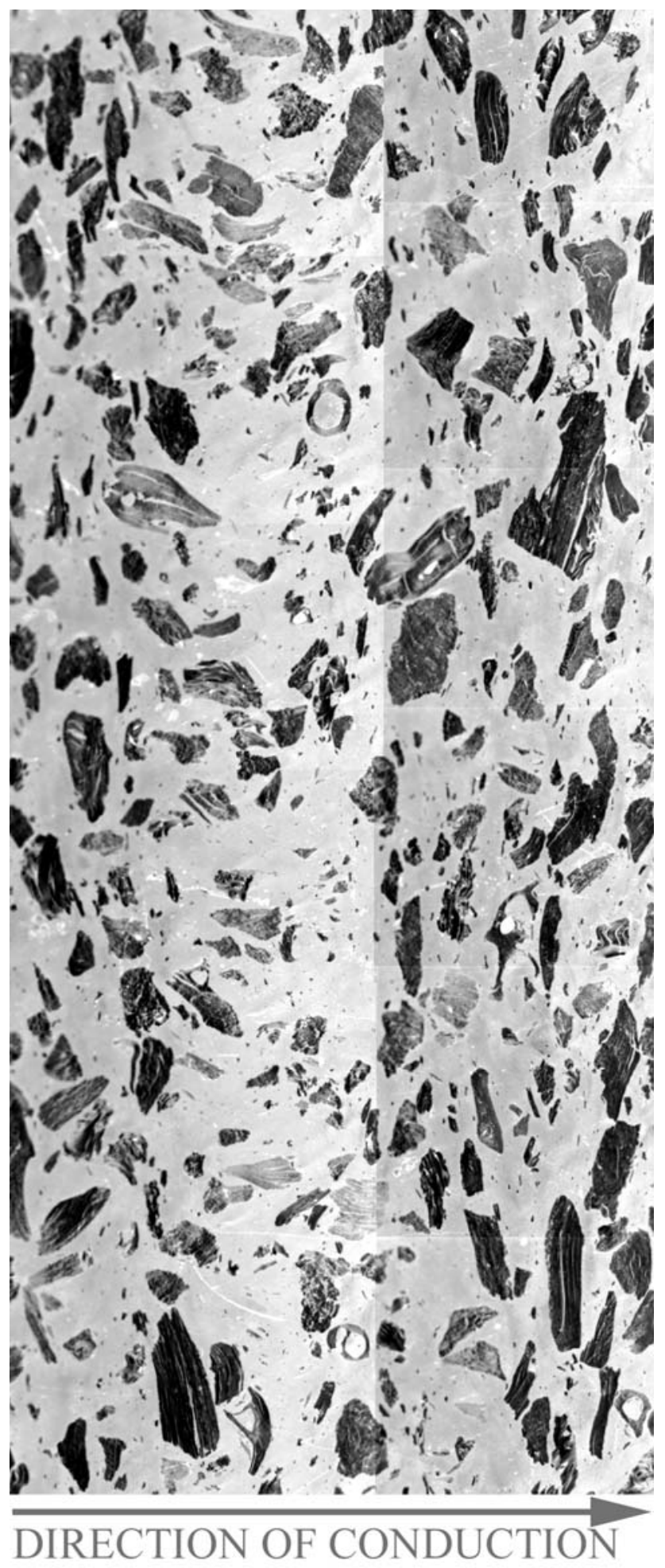

Figure 9.9-10: Optical Micrograph by reflected light of a through-plane thermal conductivity sample containing 40 wt\% Asbury F108A CNC in Vectra A950RX LCP at 100x magnification. 


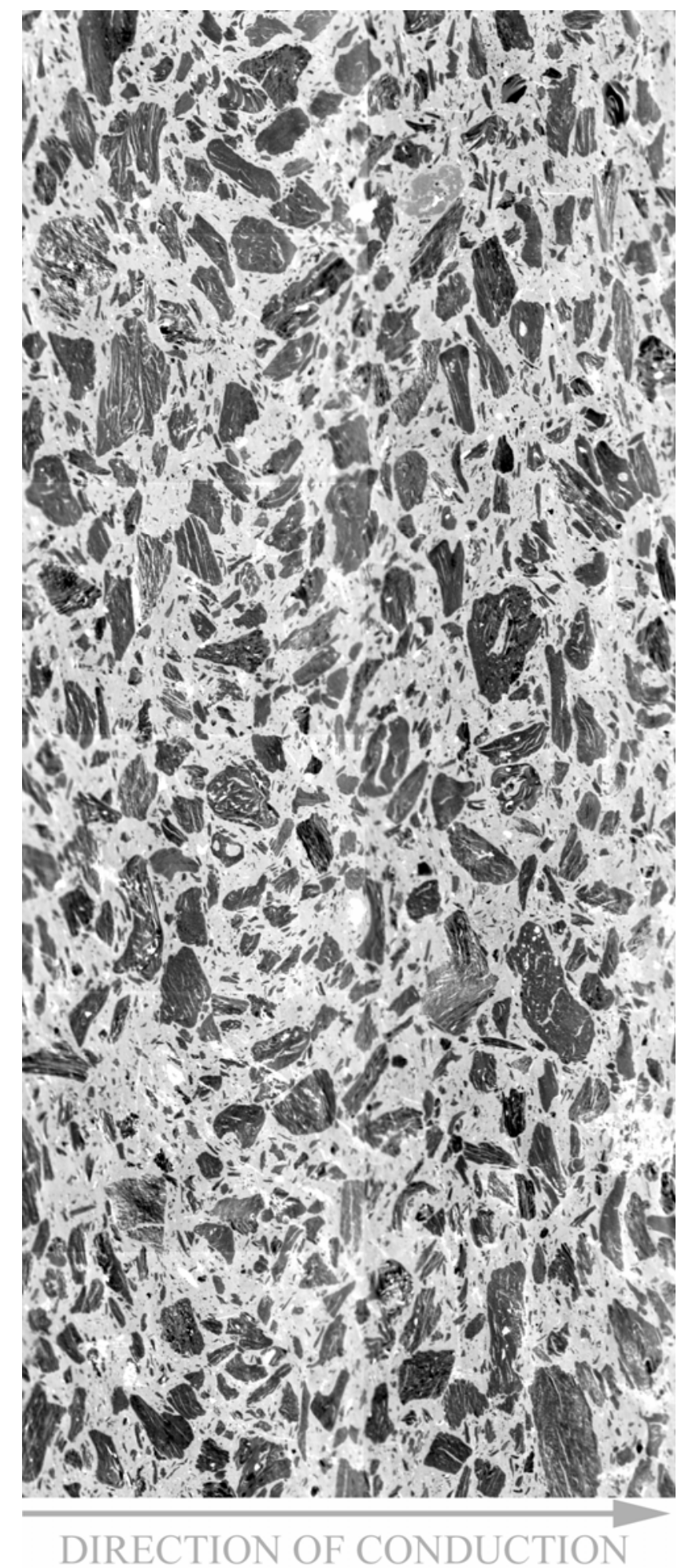

Figure 9.9-11: Optical Micrograph by reflected light of a through-plane thermal conductivity sample containing 60 wt \% Asbury F108A CNC in Vectra A950RX LCP at 100x magnification. 


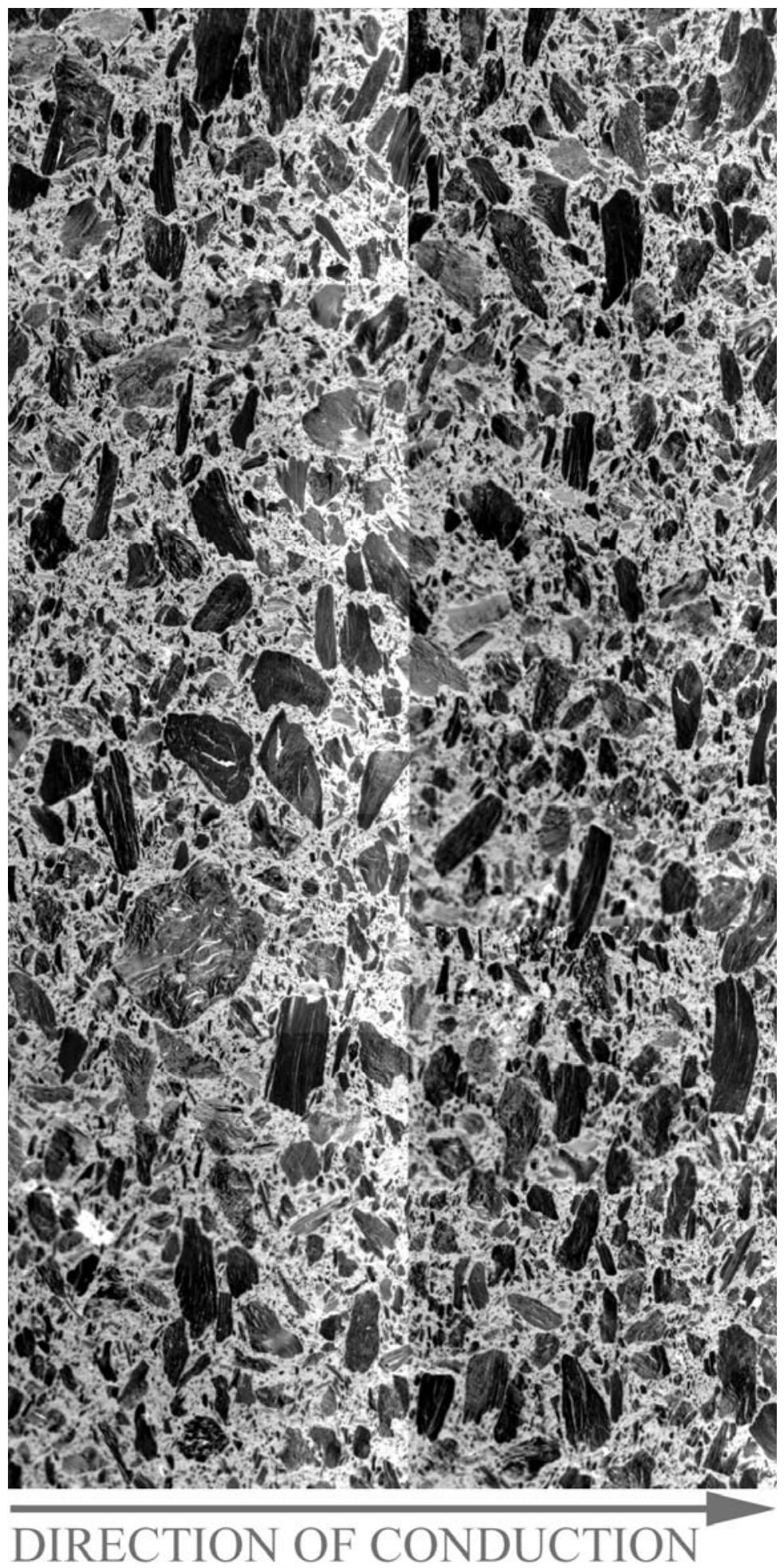

Figure 9.9-12: Optical Micrograph by reflected light of a through-plane thermal conductivity sample containing 70 wt\% Asbury F108A CNC in Vectra A950RX LCP at 100x magnification. 


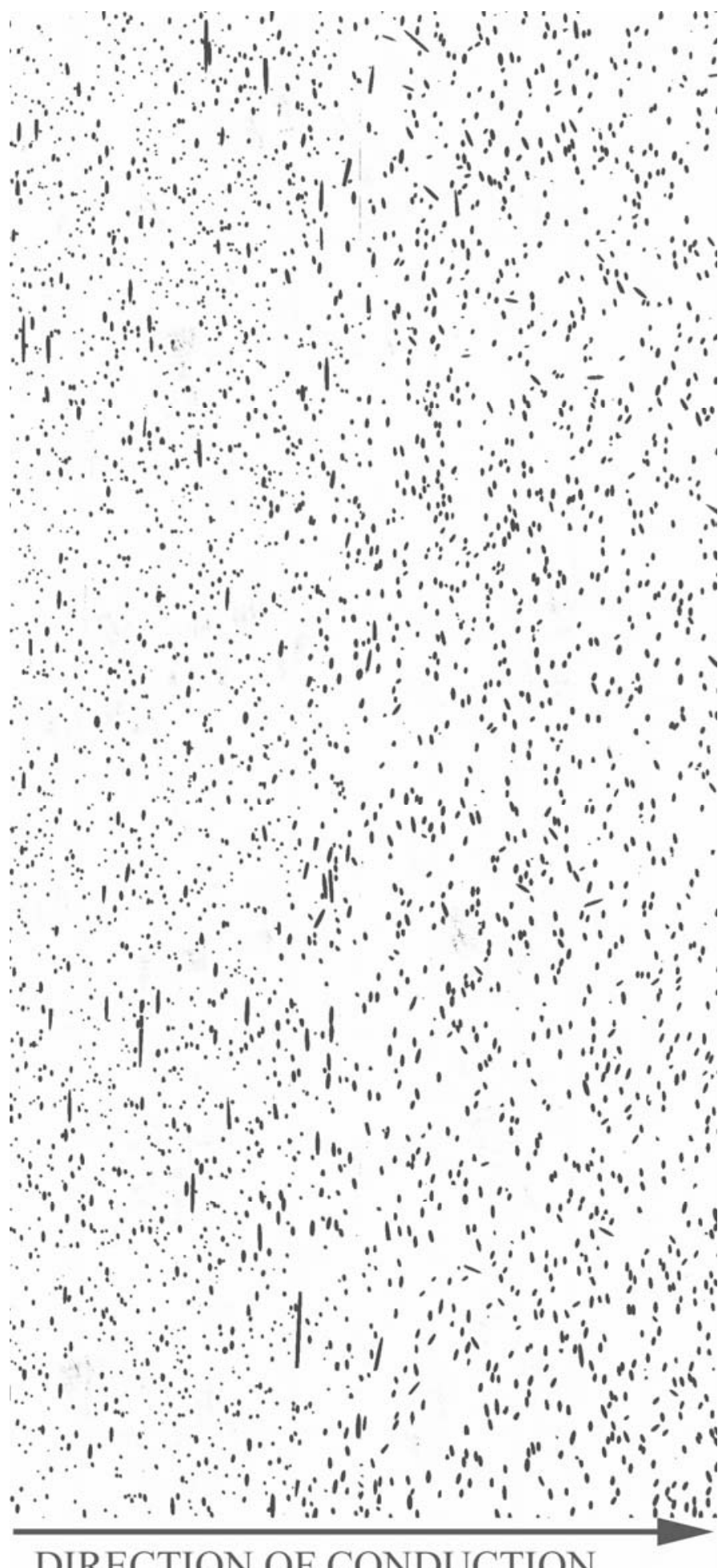

DIRECTION OF CONDUCTION

Figure 9.9-13: Optical Micrograph by reflected light of a through-plane thermal conductivity sample containing 10 wt \% Fortafil 243 carbon fiber in Vectra A950RX LCP at 100x magnification. 


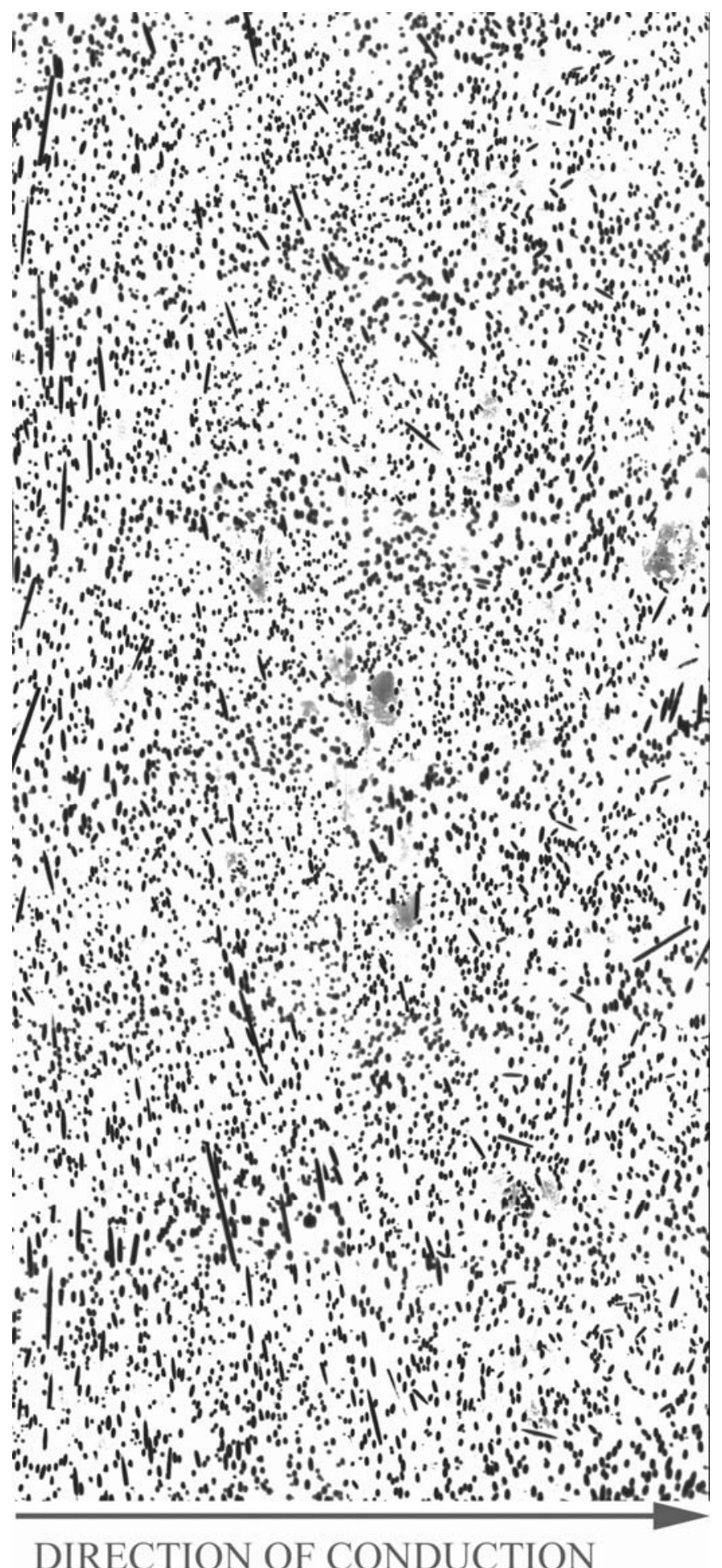

Figure 9.9-14: Optical Micrograph by reflected light of a through-plane thermal conductivity sample containing 20 wt\% Fortafil 243 carbon fiber in Vectra A950RX LCP at 100x magnification. 


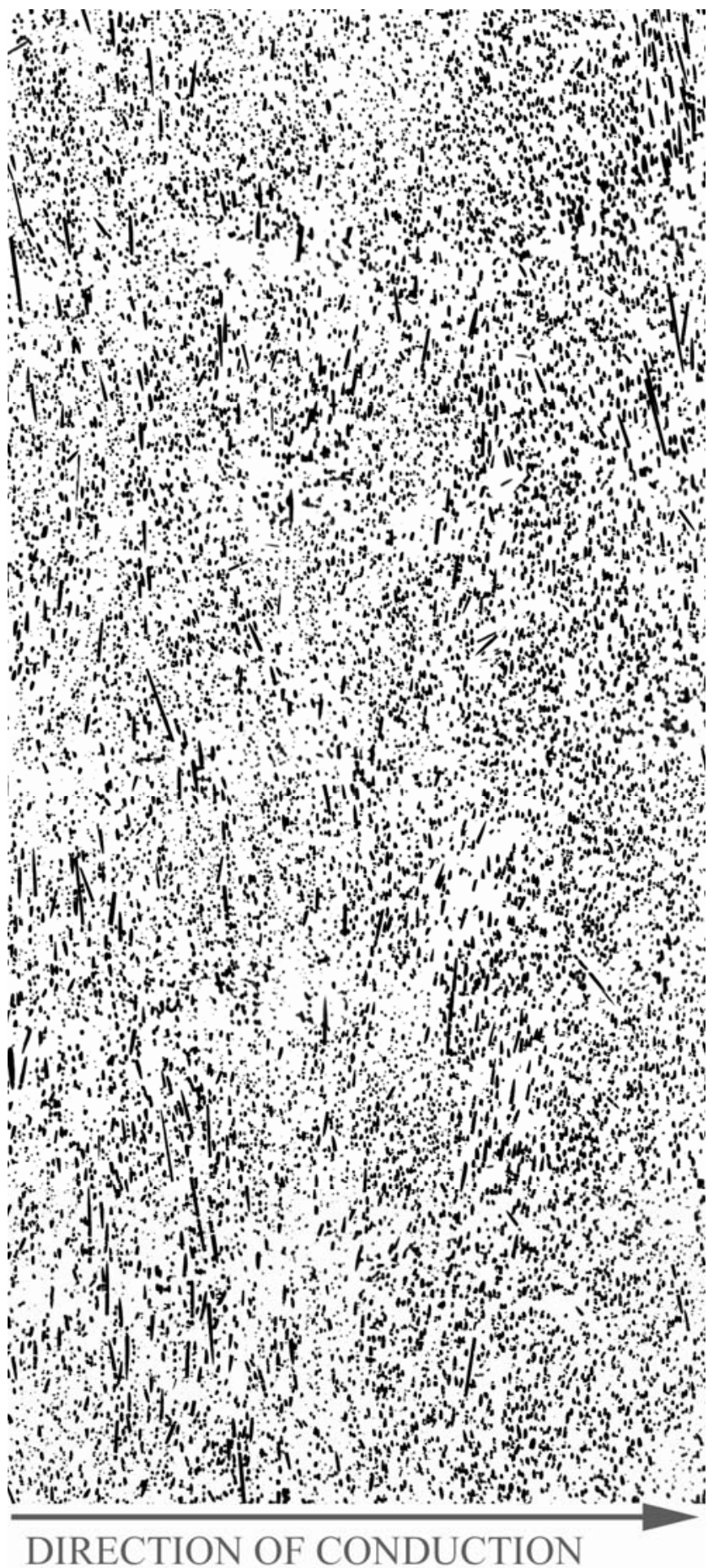

Figure 9.9-15: Optical Micrograph by reflected light of a through-plane thermal conductivity sample containing 40 wt\% Fortafil 243 carbon fiber in Vectra A950RX LCP at 100x magnification. 


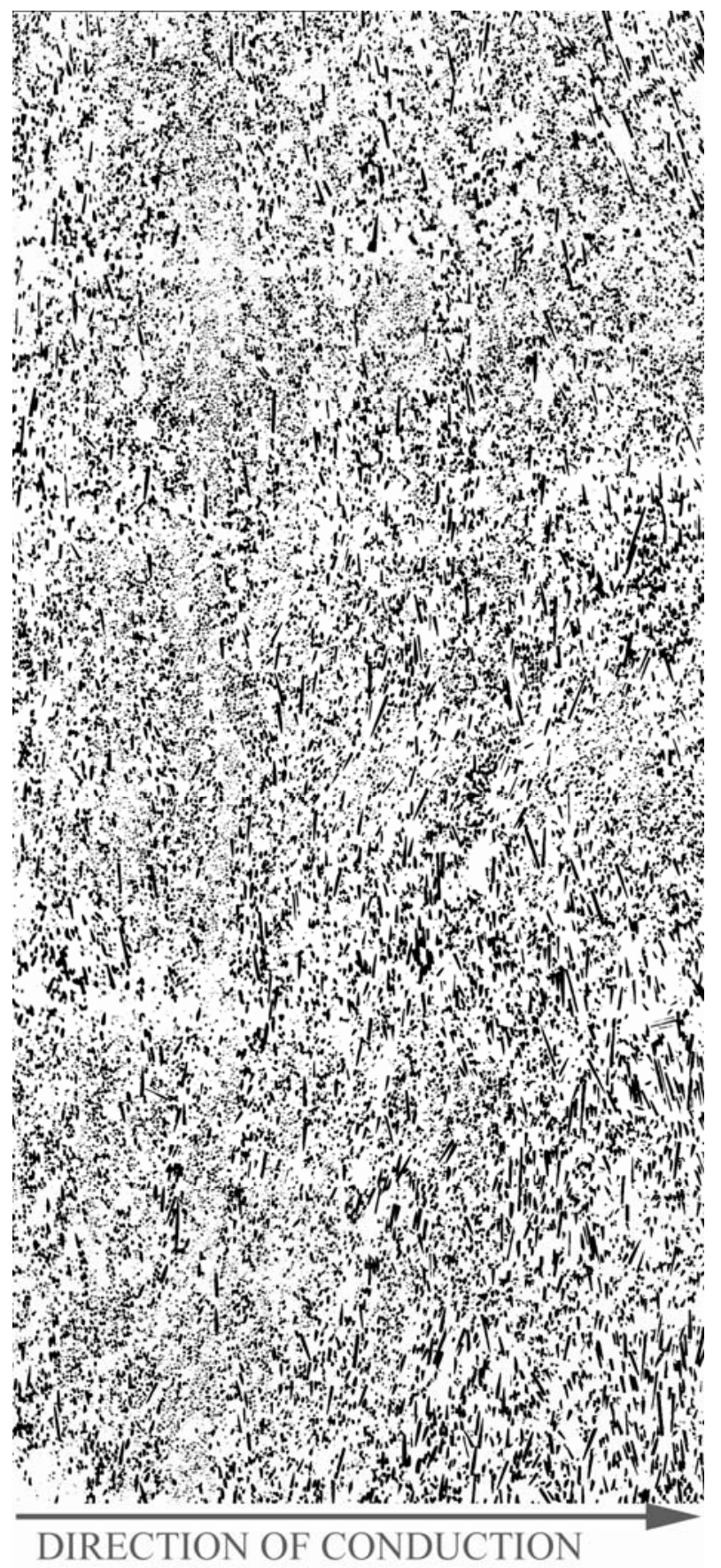

Figure 9.9-16: Optical Micrograph by reflected light of a through-plane thermal conductivity sample containing 60 wt\% Fortafil 243 carbon fiber in Vectra A950RX LCP at 100x magnification. 


\section{Section 9.10: In-Plane Micrographs}

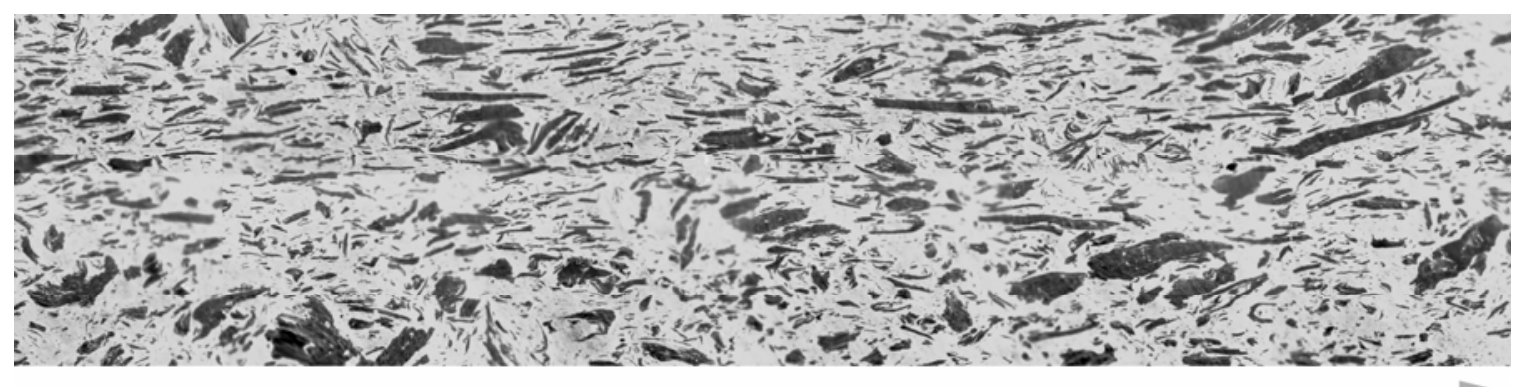

DIRECTION OF CONDUCTION

Figure 9.10-1: Optical Micrograph by reflected light of an in-plane electrical resistivity sample containing $40 \mathrm{wt} \%$ Thermocarb TC-300 synthetic graphite in Vectra A950RX LCP at 200x magnification.

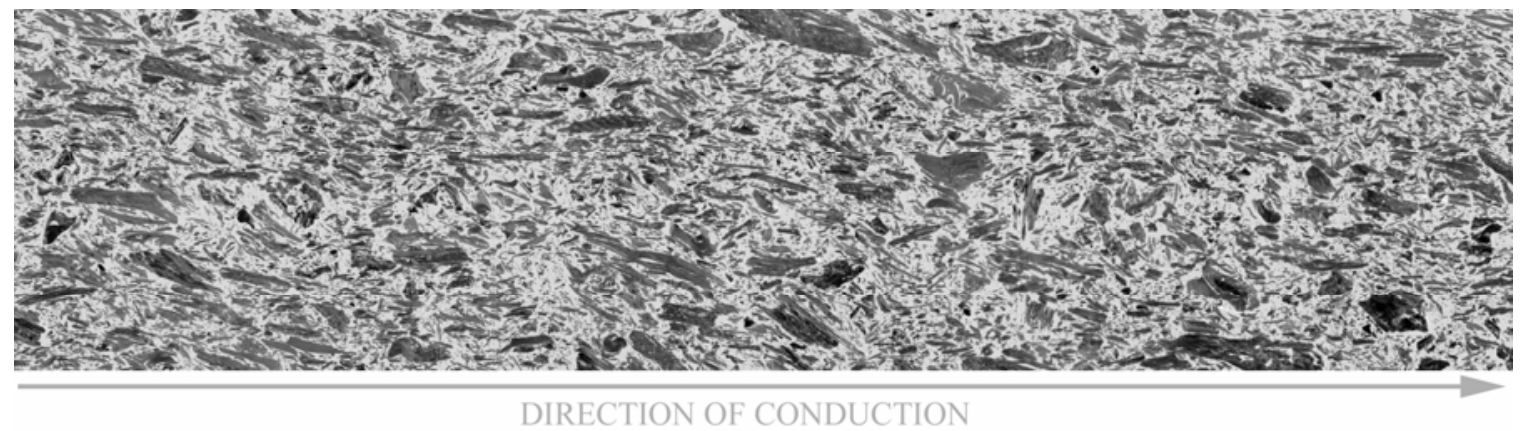

Figure 9.10-2: Optical Micrograph by reflected light of an in-plane electrical resistivity sample containing $60 \mathrm{wt} \%$ Thermocarb TC-300 synthetic graphite in Vectra A950RX LCP at 200x magnification.

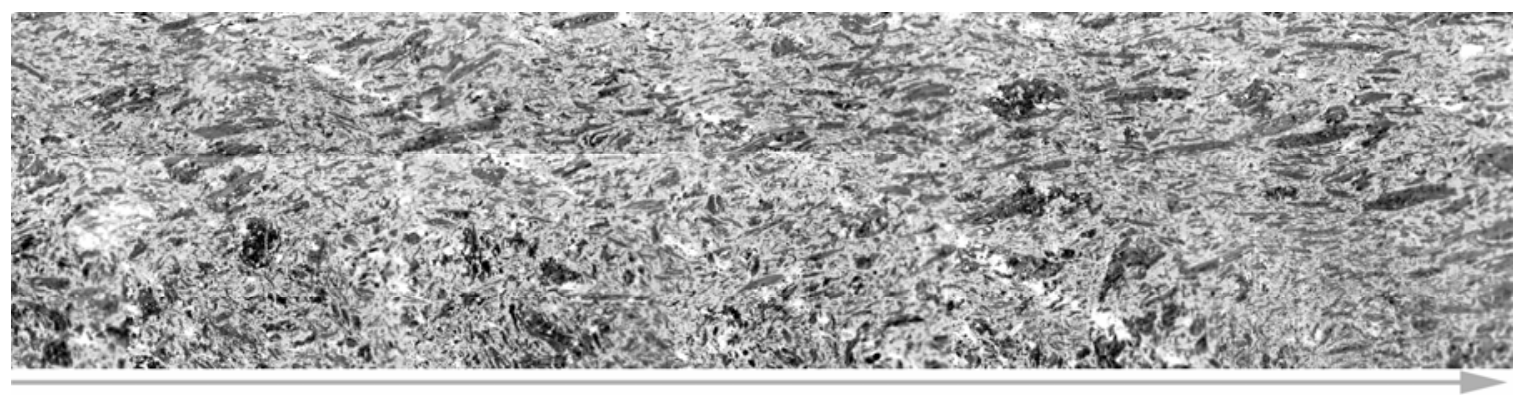

DIRECTION OF CONDUCTION

Figure 9.10-3: Optical Micrograph by reflected light of an in-plane electrical resistivity sample containing $70 \mathrm{wt} \%$ Thermocarb TC-300 synthetic graphite in Vectra A950RX LCP at 200x magnification. 


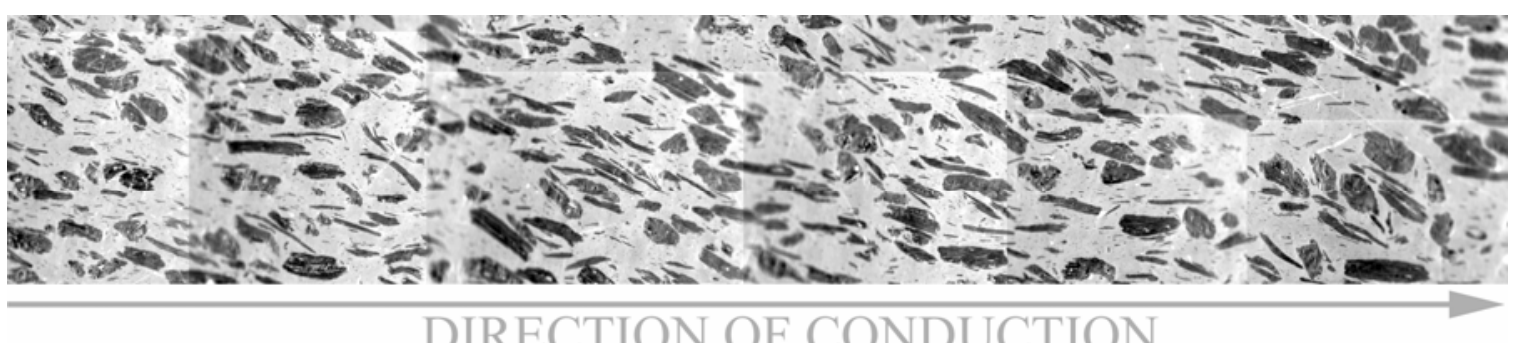

Figure 9.10-4: Optical Micrograph by reflected light of an in-plane electrical resistivity sample containing 40 wt\% Asbury 4012 synthetic graphite in Vectra A950RX LCP at 100x magnification.

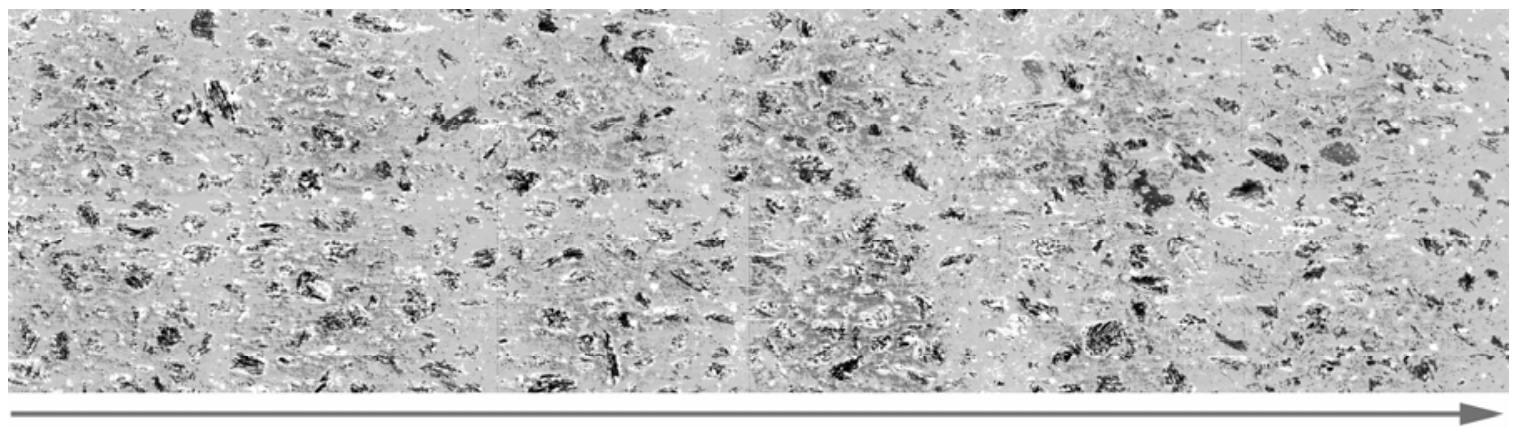

DIRECTION OF CONDUCTION

Figure 9.10-5: Optical Micrograph by reflected light of an in-plane electrical resistivity sample containing $60 \mathrm{wt} \%$ Asbury 4012 synthetic graphite in Vectra A950RX LCP at 100x magnification.

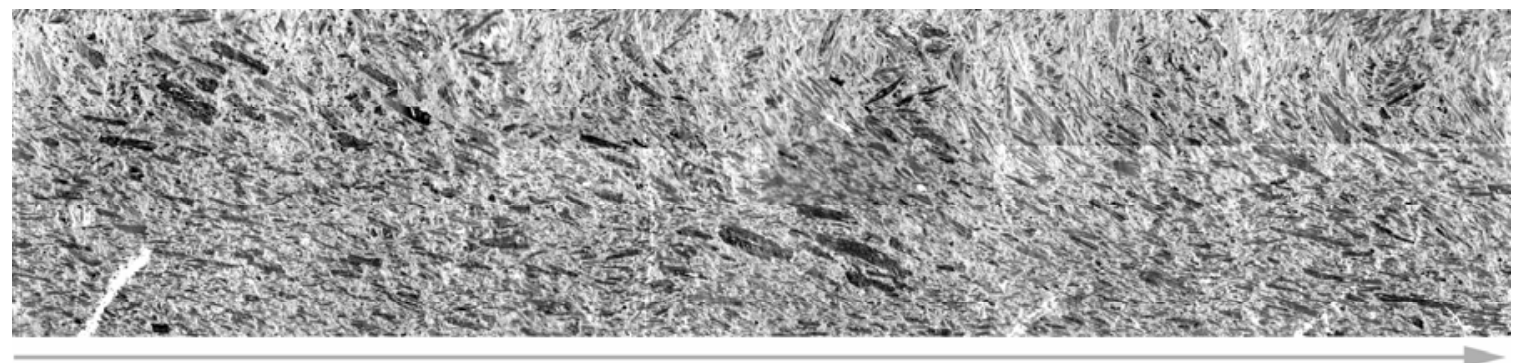

DIRECTION OF CONDUCTION

Figure 9.10-6: Optical Micrograph by reflected light of an in-plane electrical resistivity sample containing 70 wt\% Asbury 4012 synthetic graphite in Vectra A950RX LCP at 100x magnification. 


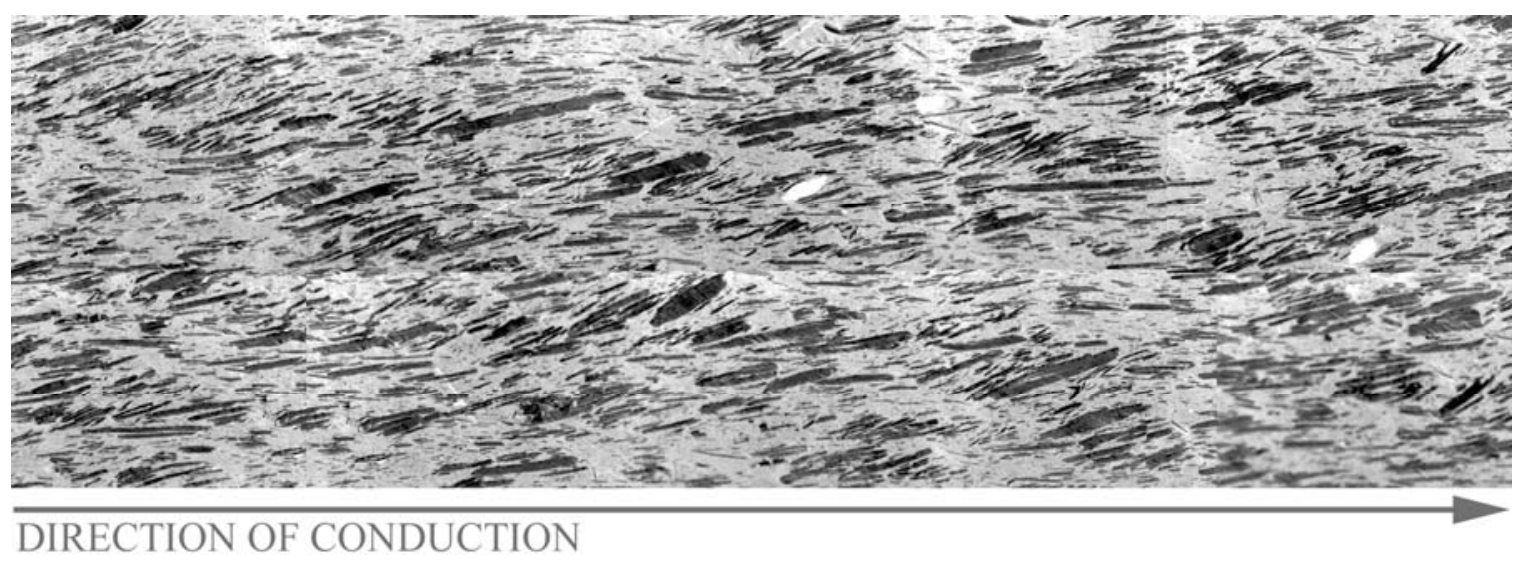

Figure 9.10-7: Optical Micrograph by reflected light of an in-plane electrical resistivity sample containing $40 \mathrm{wt} \%$ Asbury 3160 natural flake graphite in Vectra A950RX LCP at 200x magnification.

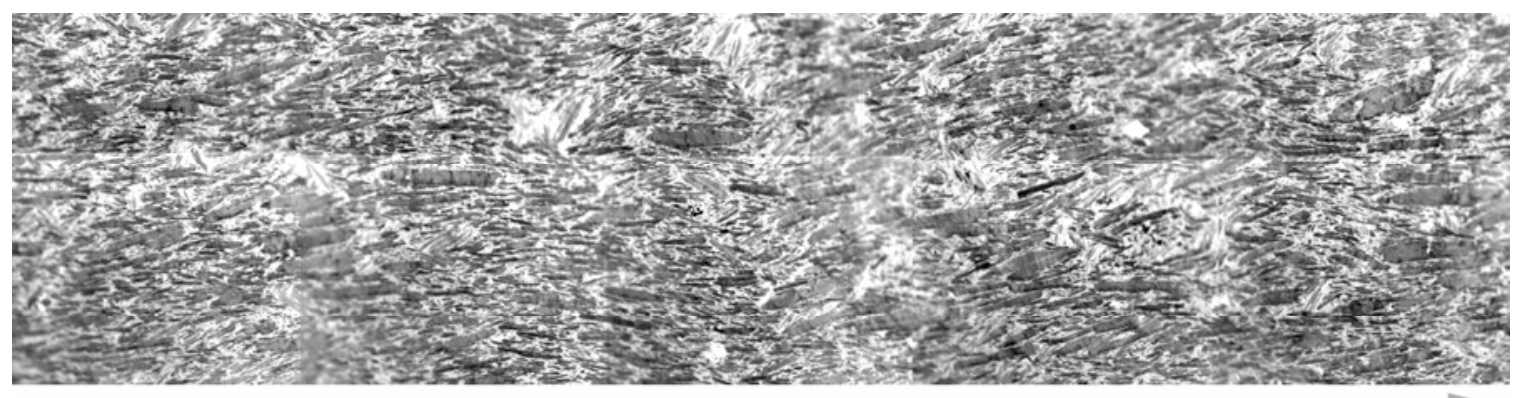

DIRECTION OF CONDUCTION

Figure 9.10-8: Optical Micrograph by reflected light of an in-plane electrical resistivity sample containing $60 \mathrm{wt} \%$ Asbury 3160 natural flake graphite in Vectra A950RX LCP at 200x magnification.

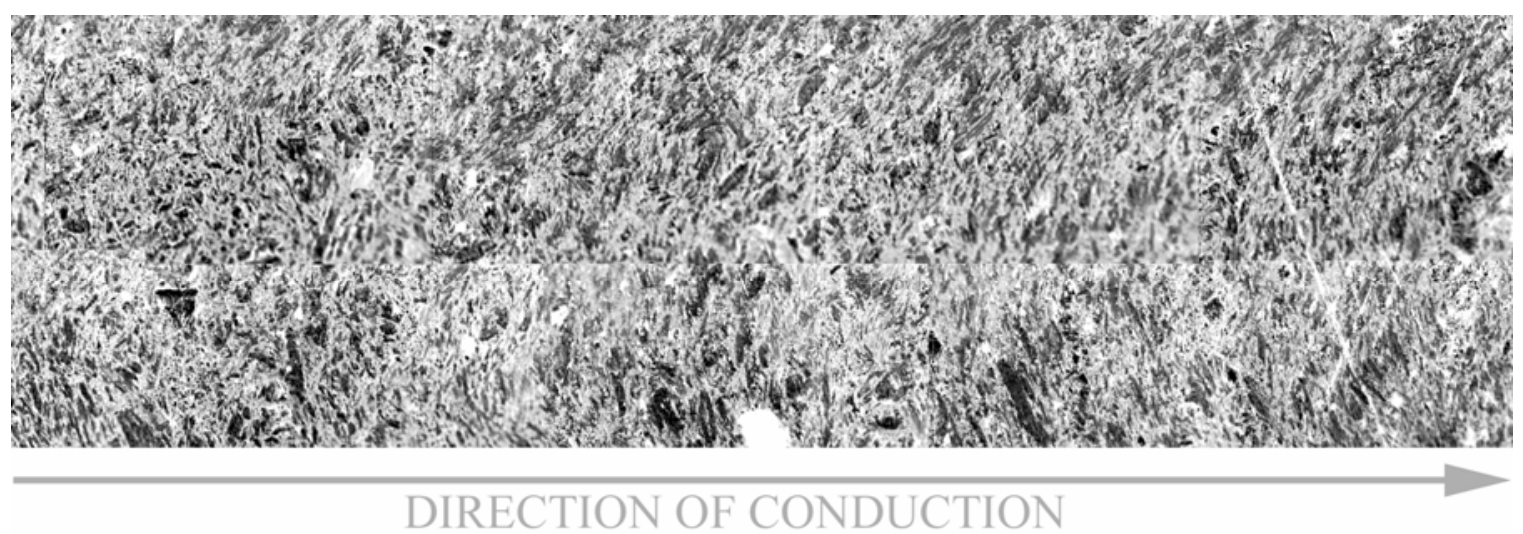

Figure 9.10-9: Optical Micrograph by reflected light of an in-plane electrical resistivity sample containing 70 wt \% Asbury 3160 natural flake graphite in Vectra A950RX LCP at 100x magnification. 


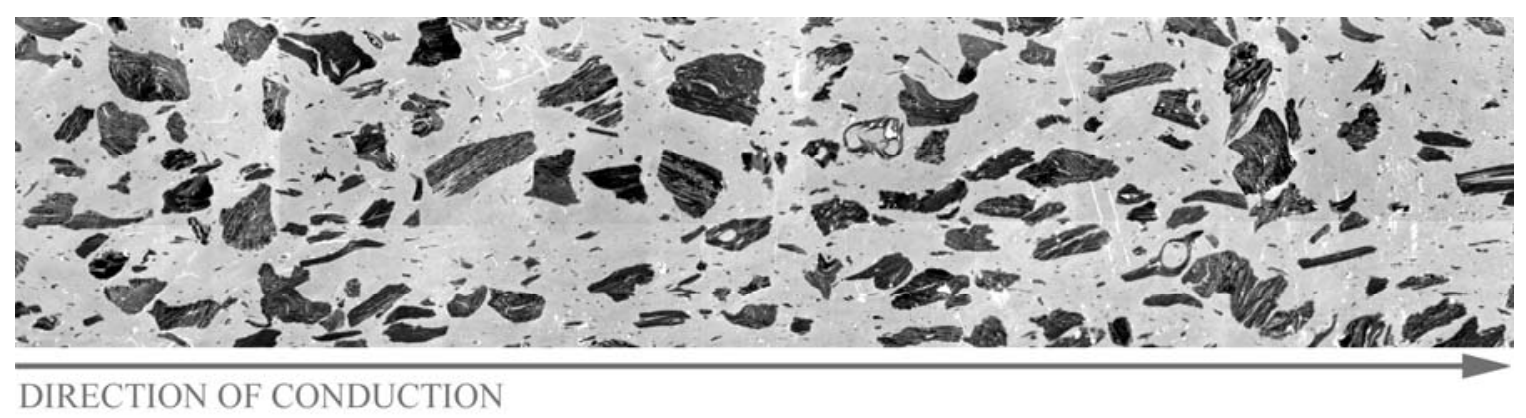

Figure 9.10-10: Optical Micrograph by reflected light of an in-plane electrical resistivity sample containing 40 wt\% Asbury F108A CNC in Vectra A950RX LCP at 100x magnification.

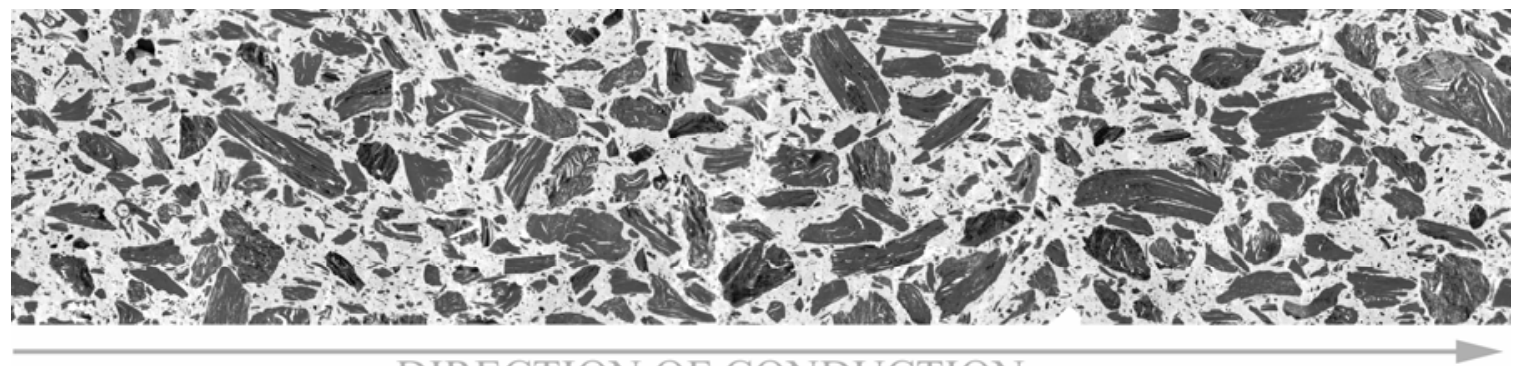

$$
\text { DIRECTION OF CONDUCTION }
$$

Figure 9.10-11: Optical Micrograph by reflected light of an in-plane electrical resistivity sample containing 60 wt\% Asbury F108A CNC in Vectra A950RX LCP at 100x magnification.

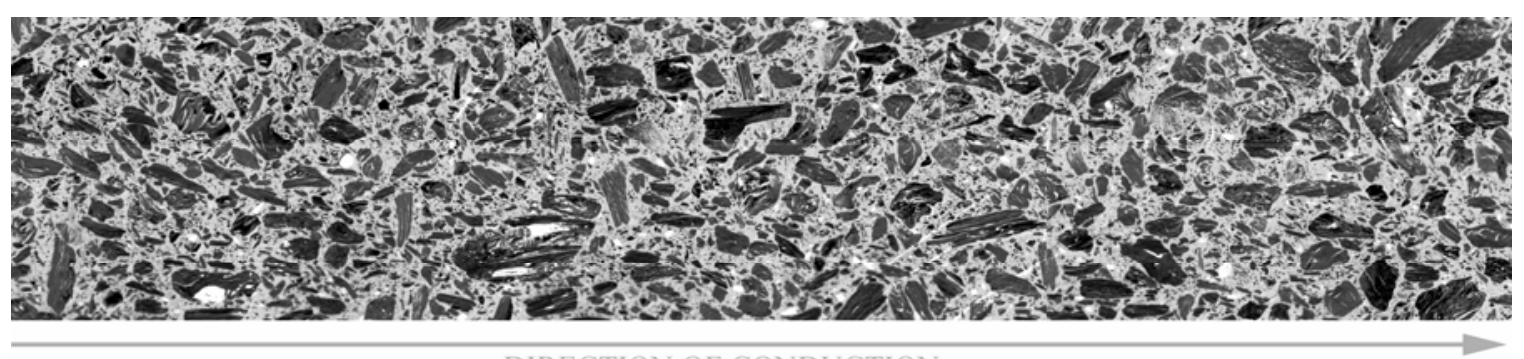

DIRECTION OF CONDUCTION

Figure 9.10-12: Optical Micrograph by reflected light of an in-plane electrical resistivity sample containing 40 wt\% Asbury F108A CNC in Vectra A950RX LCP at 100x magnification. 


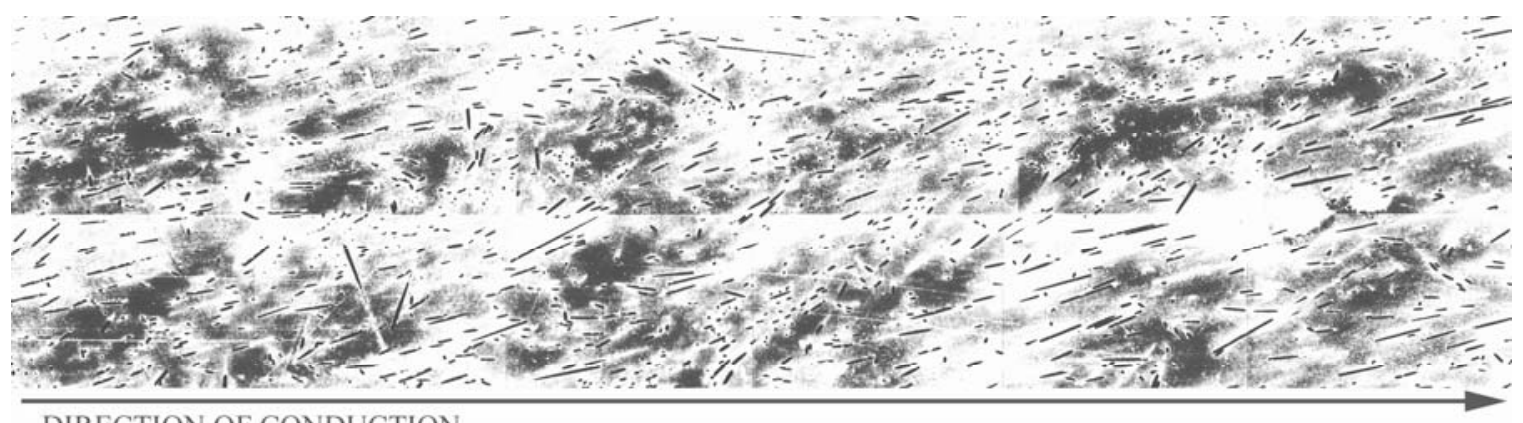

DIRECTION OF CONDUCTION

Figure 9.10-13: Optical Micrograph by reflected light of an in-plane electrical resistivity sample containing 10 wt \% Fortafil 243 carbon fiber in Vectra A950RX LCP at 100x magnification.

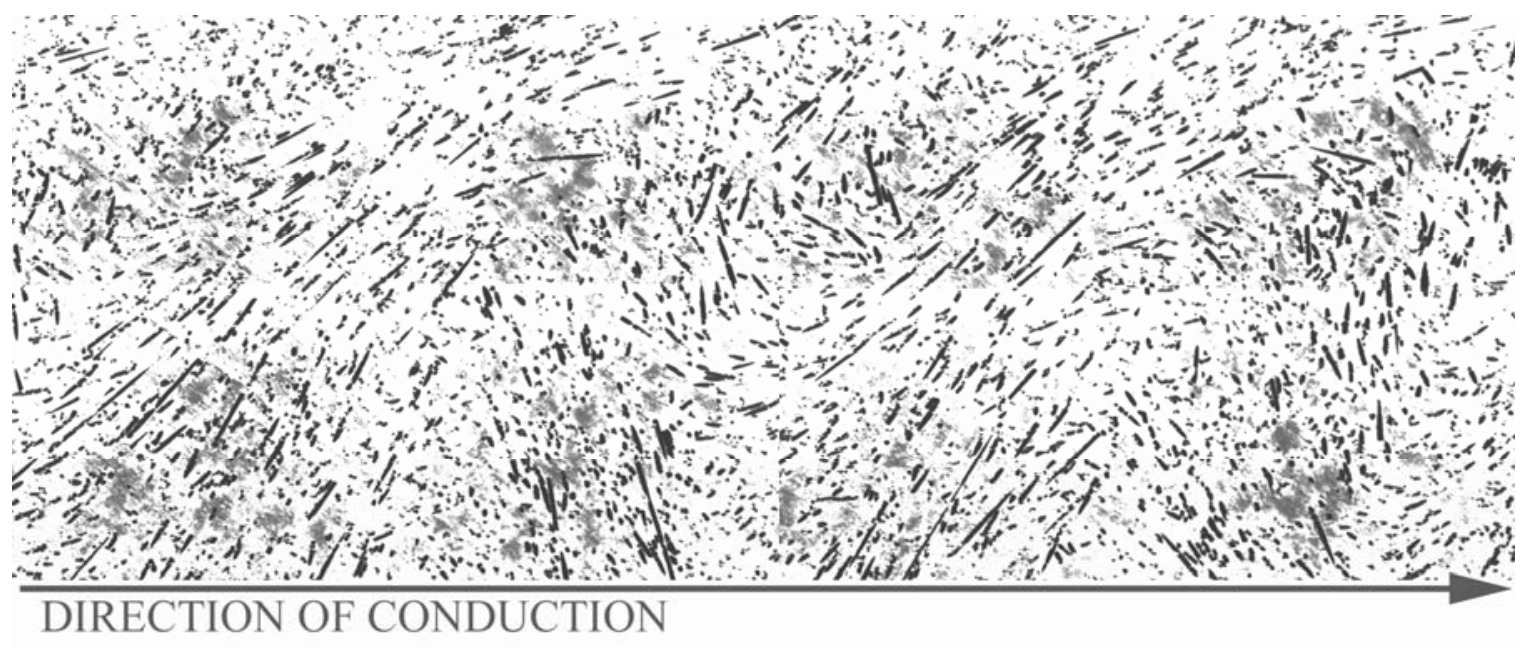

Figure 9.10-14: Optical Micrograph by reflected light of an in-plane electrical resistivity sample containing 20 wt \% Fortafil 243 carbon fiber in Vectra A950RX LCP at 100x magnification.

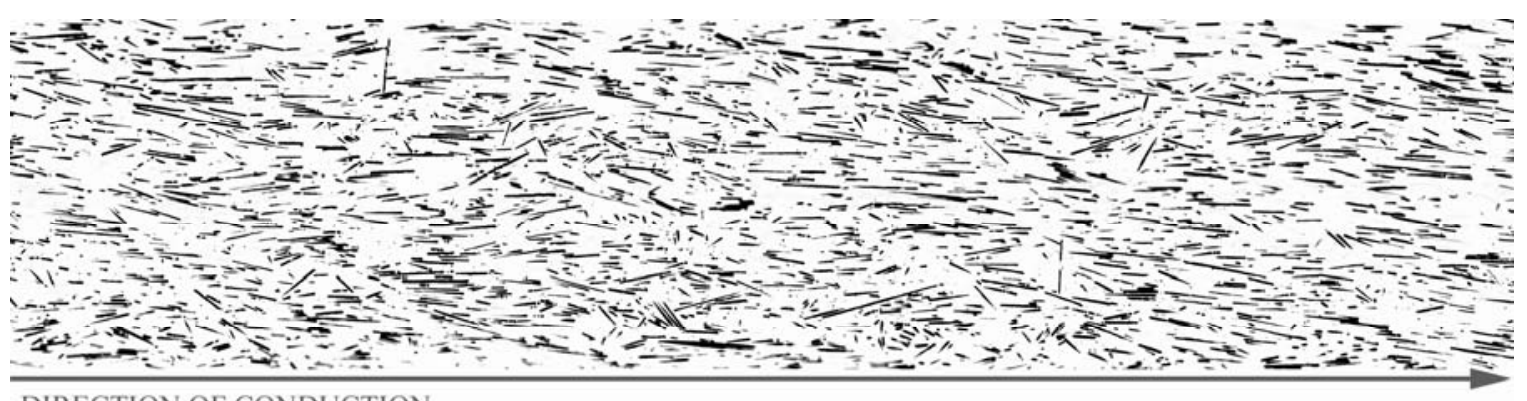

DIRECTION OF CONDUCTION

Figure 9.10-15: Optical Micrograph by reflected light of an in-plane electrical resistivity sample containing 40 wt \% Fortafil 243 carbon fiber in Vectra A950RX LCP at 100x magnification. 


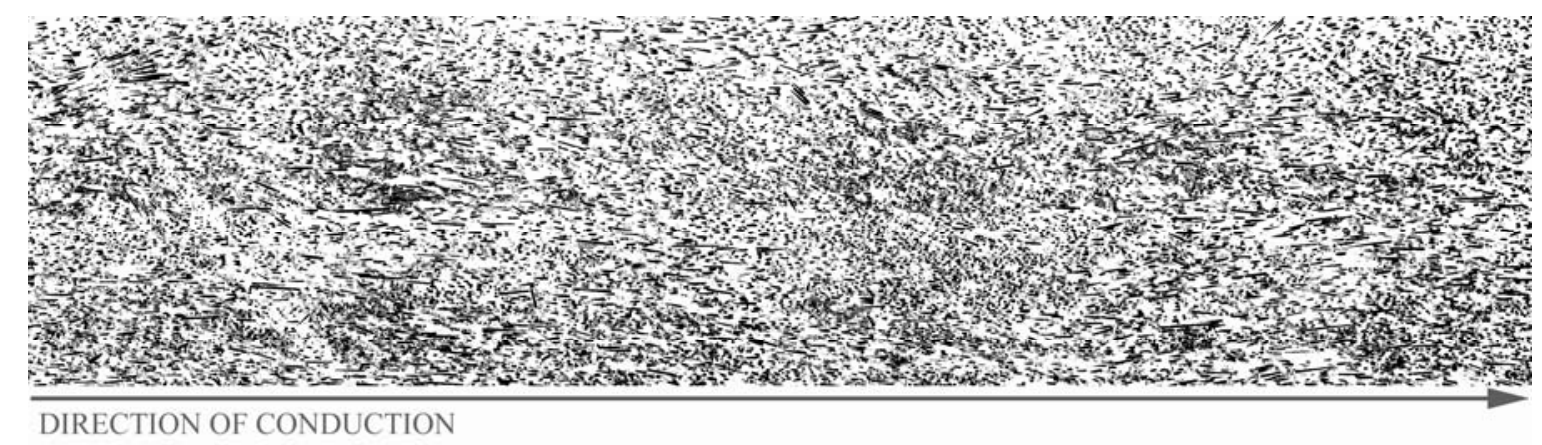

Figure 9.10-16: Optical Micrograph by reflected light of an in-plane electrical resistivity sample containing 60 wt \% Fortafil 243 carbon fiber in Vectra A950RX LCP at 100x magnification. 


\section{Section 9.11: Modeling Results}

Table 9.11-1: Rule of Mixtures, Carbon Black Composite

\begin{tabular}{|c|c|c|c|c|c|c|}
\hline \multicolumn{2}{|r|}{$\mathrm{TC}(\mathrm{W} / \mathrm{mK})$} & & & $\begin{array}{l}0.003577 \\
\text { epsilon(y) }\end{array}$ & $\begin{array}{c}0.002643 \\
\operatorname{sum}\left((y(i)-y(\bmod ))^{\wedge} 2\right)\end{array}$ & $\begin{array}{c}0.738959 \\
\operatorname{sum}\left(y(i)^{\wedge} 2\right)\end{array}$ \\
\hline Filler & 2.1 & & & & & \\
\hline & & & \multirow{2}{*}{$\begin{array}{l}\text { TC }(\mathrm{W} / \mathrm{mK}) \\
\text { Experimental }\end{array}$} & \multirow{2}{*}{$\begin{array}{l}\text { TC }(\mathrm{W} / \mathrm{mK}) \\
\text { Calculated }\end{array}$} & & \\
\hline Formulation & wt $\%$ filler & vol\% filler & & & $(y(i)-y(\bmod ))^{\wedge} 2$ & $\mathrm{y}(\mathrm{i})^{\wedge} 2$ \\
\hline EVR & 0 & 0.000 & 0.217 & 0.220 & 0.000010 & 0.047046 \\
\hline EAV2.5 & 2.5 & 0.019 & 0.242 & 0.256 & 0.000218 & 0.058419 \\
\hline EAV4R & 4 & 0.031 & 0.258 & 0.279 & 0.000438 & 0.066616 \\
\hline EAV5R & 5 & 0.039 & 0.269 & 0.294 & 0.000634 & 0.072200 \\
\hline EAV6 & 6 & 0.047 & 0.293 & 0.308 & 0.000224 & 0.086084 \\
\hline EAV7.5 & 7.5 & 0.060 & 0.322 & 0.332 & 0.000103 & 0.103491 \\
\hline EAV10 & 10 & 0.080 & 0.364 & 0.370 & 0.000043 & 0.132132 \\
\hline EAV15 & 15 & 0.121 & 0.416 & 0.447 & 0.000974 & 0.172973 \\
\hline
\end{tabular}


Table 9.11-2: Rule of Mixtures, Synthetic Graphite Composite

\begin{tabular}{|c|c|c|c|c|c|c|}
\hline \multicolumn{2}{|r|}{$\mathrm{TC}(\mathrm{W} / \mathrm{mK})$} & & & $\begin{array}{c}29846.9 \\
\text { epsilon(y) }\end{array}$ & $\begin{array}{c}714497 \\
\operatorname{sum}\left((y(i)-y(\bmod ))^{\wedge} 2\right)\end{array}$ & $\begin{array}{c}23.9387 \\
\operatorname{sum}\left(y(i)^{\wedge} 2\right)\end{array}$ \\
\hline Filler & 600 & & & & & \\
\hline & & & \multirow{2}{*}{$\begin{array}{l}\mathrm{TC}(\mathrm{W} / \mathrm{mK}) \\
\text { Experimental }\end{array}$} & \multirow{2}{*}{$\begin{array}{l}\mathrm{TC}(\mathrm{W} / \mathrm{mK}) \\
\text { Calculated }\end{array}$} & & \\
\hline Formulation & wt $\%$ filler & vol\% filler & & & $(\mathrm{y}(\mathrm{i})-\mathrm{y}(\mathrm{mod}))^{\wedge} 2$ & $y(i)^{\wedge} 2$ \\
\hline EVR & 0 & 0.000 & 0.217 & 0.220 & 0.000010 & 0.047046 \\
\hline EBV10 & 10 & 0.065 & 0.294 & 39.164 & 1510.89 & 0.086142 \\
\hline EBV15 & 15 & 0.099 & 0.349 & 59.802 & 3534.63 & 0.122080 \\
\hline EBV20 & 20 & 0.135 & 0.387 & 81.250 & 6538.89 & 0.149692 \\
\hline EBV25 & 25 & 0.172 & 0.470 & 103.382 & 10590.9 & 0.220806 \\
\hline EBV30 & 30 & 0.211 & 0.546 & 126.954 & 15978.8 & 0.298553 \\
\hline EBV35 & 35 & 0.252 & 0.611 & 151.365 & 22726.8 & 0.372832 \\
\hline EBV40 & 40 & 0.293 & 0.706 & 175.956 & 30712.3 & 0.499001 \\
\hline EBV45 & 45 & 0.338 & 0.880 & 202.946 & 40830.4 & 0.775104 \\
\hline EBV50 & 50 & 0.385 & 1.108 & 230.895 & 52802.2 & 1.22789 \\
\hline EBV55 & 55 & 0.433 & 1.285 & 259.967 & 66916.2 & 1.65148 \\
\hline EBV60 & 60 & 0.484 & 1.559 & 290.514 & 83494.9 & 2.42923 \\
\hline EBV65 & 65 & 0.537 & 1.943 & 322.422 & 102707 & 3.77369 \\
\hline EBV70 & 70 & 0.593 & 2.323 & 355.890 & 125010 & 5.39401 \\
\hline EBV75 & 75 & 0.652 & 2.625 & 391.397 & 151143 & 6.89115 \\
\hline
\end{tabular}


Table 9.11-3: Rule of Mixtures, Carbon Fiber Composite

\begin{tabular}{|c|c|c|c|c|c|c|}
\hline \multicolumn{2}{|r|}{$\mathrm{TC}(\mathrm{W} / \mathrm{mK})$} & & \multirow{2}{*}{\multicolumn{2}{|c|}{$\begin{array}{l}119.638 \\
\text { epsilon(y) }\end{array}$}} & \multirow{2}{*}{$\begin{array}{c}448.065 \\
\operatorname{sum}\left((y(i)-y(m o d))^{\wedge} 2\right)\end{array}$} & \multirow{2}{*}{$\begin{array}{c}3.74516 \\
\operatorname{sum}\left(y(i)^{\wedge} 2\right)\end{array}$} \\
\hline Vectra & 0.22 & & & & & \\
\hline \multirow{2}{*}{\multicolumn{3}{|c|}{ Filler }} & \multirow{3}{*}{$\begin{array}{l}\mathrm{TC}(\mathrm{W} / \mathrm{mK}) \\
\text { Experimental }\end{array}$} & & & \\
\hline & & & & \multirow{2}{*}{$\begin{array}{l}\mathrm{TC}(\mathrm{W} / \mathrm{mK}) \\
\text { Calculated }\end{array}$} & & \\
\hline Formulation & wt $\%$ filler & vol\% filler & & & $(y(i)-y(\bmod ))^{\wedge} 2$ & $y(i)^{\wedge} 2$ \\
\hline EVR & 0 & 0.000 & 0.217 & 0.220 & 0.000010 & 0.047046 \\
\hline EHV5 & 5 & 0.041 & 0.238 & 1.031 & 0.628817 & 0.056644 \\
\hline EHV7.5 & 7.5 & 0.061 & 0.255 & 1.427 & 1.37260 & 0.065025 \\
\hline EHV10 & 10 & 0.082 & 0.271 & 1.842 & 2.46792 & 0.073441 \\
\hline EHV15 & 15 & 0.124 & 0.282 & 2.673 & 5.71554 & 0.079524 \\
\hline EHV2O & 20 & 0.168 & 0.320 & 3.543 & 10.3880 & 0.102400 \\
\hline EHV25 & 25 & 0.212 & 0.353 & 4.413 & 16.4865 & 0.124609 \\
\hline EHV30 & 30 & 0.255 & 0.365 & 5.264 & 23.9992 & 0.133225 \\
\hline EHV35 & 35 & 0.302 & 0.432 & 6.194 & 33.1956 & 0.186624 \\
\hline EHV40 & 40 & 0.349 & 0.527 & 7.123 & 43.5101 & 0.277729 \\
\hline EHV45 & 45 & 0.397 & 0.602 & 8.073 & 55.8108 & 0.362404 \\
\hline EHV50R & 50 & 0.446 & 0.688 & 9.042 & 69.7873 & 0.473344 \\
\hline EHV55 & 55 & 0.496 & 0.838 & 10.031 & 84.5090 & 0.702244 \\
\hline EHV60R & 60 & 0.547 & 1.030 & 11.040 & 100.193 & 1.06090 \\
\hline
\end{tabular}


Table 9.11-4: Inverse Rule of Mixtures, Carbon Black Composite

\begin{tabular}{|c|c|c|c|c|c|c|}
\hline \multicolumn{2}{|r|}{$\mathrm{TC}(\mathrm{W} / \mathrm{mK})$} & & & $\begin{array}{l}0.080772 \\
\text { epsilon(y) }\end{array}$ & $\begin{array}{c}0.059687 \\
\operatorname{sum}\left((y(i)-y(m o d))^{\wedge} 2\right)\end{array}$ & $\begin{array}{c}0.738959 \\
\operatorname{sum}\left(y(i)^{\wedge} 2\right)\end{array}$ \\
\hline Filler & 2.1 & & & & & \\
\hline & & & \multirow{2}{*}{$\begin{array}{l}\mathrm{TC}(\mathrm{W} / \mathrm{mK}) \\
\text { Experimental }\end{array}$} & \multirow{2}{*}{$\begin{array}{l}\mathrm{TC}(\mathrm{W} / \mathrm{mK}) \\
\text { Calculated }\end{array}$} & & \\
\hline Formulation & wt $\%$ filler & vol\% filler & & & $(y(i)-y(m o d))^{\wedge} 2$ & $y(i)^{\wedge} 2$ \\
\hline EVR & 0 & 0.000 & 0.217 & 0.220 & 0.000010 & 0.047046 \\
\hline EAV2.5 & 2.5 & 0.019 & 0.242 & 0.224 & 0.000317 & 0.058419 \\
\hline EAV4R & 4 & 0.031 & 0.258 & 0.226 & 0.001007 & 0.066616 \\
\hline EAV5R & 5 & 0.039 & 0.269 & 0.228 & 0.001655 & 0.072200 \\
\hline EAV6 & 6 & 0.047 & 0.293 & 0.230 & 0.004062 & 0.086084 \\
\hline EAV7.5 & 7.5 & 0.060 & 0.322 & 0.232 & 0.007978 & 0.103491 \\
\hline EAV10 & 10 & 0.080 & 0.364 & 0.237 & 0.016021 & 0.132132 \\
\hline EAV15 & 15 & 0.121 & 0.416 & 0.247 & 0.028636 & 0.172973 \\
\hline
\end{tabular}


Table 9.11-5: Inverse Rule of Mixtures, Synthetic Graphite Composite

\begin{tabular}{|c|c|c|c|c|c|c|}
\hline \multicolumn{2}{|r|}{$\mathrm{TC}(\mathrm{W} / \mathrm{mK})$} & & & $\begin{array}{l}0.528627 \\
\text { epsilon(y) }\end{array}$ & $\begin{array}{c}12.6547 \\
\operatorname{sum}\left((y(i)-y(\bmod ))^{\wedge} 2\right)\end{array}$ & $\begin{array}{c}23.9387 \\
\operatorname{sum}\left(y(\mathrm{i})^{\wedge} 2\right)\end{array}$ \\
\hline Filler & 600 & & & & & \\
\hline & & & \multirow{2}{*}{$\begin{array}{l}\mathrm{TC}(\mathrm{W} / \mathrm{mK}) \\
\text { Experimental }\end{array}$} & \multirow{2}{*}{$\begin{array}{l}\mathrm{TC}(\mathrm{W} / \mathrm{mK}) \\
\text { Calculated }\end{array}$} & & \\
\hline Formulation & wt $\%$ filler & vol\% filler & & & $(y(i)-y(m o d))^{\wedge} 2$ & $y(i)^{\wedge} 2$ \\
\hline EVR & 0 & 0.000 & 0.217 & 0.220 & 0.000010 & 0.047046 \\
\hline EBV10 & 10 & 0.065 & 0.294 & 0.235 & 0.003391 & 0.086142 \\
\hline EBV15 & 15 & 0.099 & 0.349 & 0.244 & 0.011055 & 0.122080 \\
\hline EBV20 & 20 & 0.135 & 0.387 & 0.254 & 0.017569 & 0.149692 \\
\hline EBV25 & 25 & 0.172 & 0.470 & 0.266 & 0.041706 & 0.220806 \\
\hline EBV30 & 30 & 0.211 & 0.546 & 0.279 & 0.071549 & 0.298553 \\
\hline EBV35 & 35 & 0.252 & 0.611 & 0.294 & 0.100184 & 0.372832 \\
\hline EBV40 & 40 & 0.293 & 0.706 & 0.311 & 0.156241 & 0.499001 \\
\hline EBV45 & 45 & 0.338 & 0.880 & 0.332 & 0.300453 & 0.775104 \\
\hline EBV50 & 50 & 0.385 & 1.108 & 0.357 & 0.563537 & 1.22789 \\
\hline EBV55 & 55 & 0.433 & 1.285 & 0.388 & 0.804885 & 1.65148 \\
\hline EBV60 & 60 & 0.484 & 1.559 & 0.426 & 1.28231 & 2.42923 \\
\hline EBV65 & 65 & 0.537 & 1.943 & 0.475 & 2.15337 & 3.77369 \\
\hline EBV70 & 70 & 0.593 & 2.323 & 0.540 & 3.17641 & 5.39401 \\
\hline EBV75 & 75 & 0.652 & 2.625 & 0.632 & 3.97200 & 6.89115 \\
\hline
\end{tabular}


Table 9.11-6: Inverse Rule of Mixtures, Carbon Fiber Composite

\begin{tabular}{|c|c|c|c|c|c|c|}
\hline \multicolumn{2}{|r|}{$\mathrm{TC}(\mathrm{W} / \mathrm{mK})$} & & & $\begin{array}{l}0.181337 \\
\text { epsilon(y) }\end{array}$ & $\begin{array}{c}0.679135 \\
\operatorname{sum}\left((y(i)-y(\bmod ))^{\wedge} 2\right)\end{array}$ & $\begin{array}{c}3.74516 \\
\operatorname{sum}\left(y(i)^{\wedge} 2\right)\end{array}$ \\
\hline Filler & 20 & & & & & \\
\hline & & & \multirow{2}{*}{$\begin{array}{l}\mathrm{TC}(\mathrm{W} / \mathrm{mK}) \\
\text { Experimental }\end{array}$} & \multirow{2}{*}{$\begin{array}{l}\mathrm{TC}(\mathrm{W} / \mathrm{mK}) \\
\text { Calculated }\end{array}$} & & \\
\hline Formulation & wt $\%$ filler & vol $\%$ filler & & & $(y(i)-y(m o d))^{\wedge} 2$ & $y(i)^{\wedge} 2$ \\
\hline EVR & 0 & 0.000 & 0.217 & 0.220 & 0.000010 & 0.047046 \\
\hline EHV5 & 5 & 0.041 & 0.238 & 0.229 & 0.000076 & 0.056644 \\
\hline EHV7.5 & 7.5 & 0.061 & 0.255 & 0.234 & 0.000436 & 0.065025 \\
\hline EHV10 & 10 & 0.082 & 0.271 & 0.239 & 0.000998 & 0.073441 \\
\hline EHV15 & 15 & 0.124 & 0.282 & 0.251 & 0.000976 & 0.079524 \\
\hline EHV20 & 20 & 0.168 & 0.320 & 0.264 & 0.003154 & 0.102400 \\
\hline EHV25 & 25 & 0.212 & 0.353 & 0.278 & 0.005571 & 0.124609 \\
\hline EHV30 & 30 & 0.255 & 0.365 & 0.294 & 0.005013 & 0.133225 \\
\hline EHV35 & 35 & 0.302 & 0.432 & 0.314 & 0.013996 & 0.186624 \\
\hline EHV40 & 40 & 0.349 & 0.527 & 0.336 & 0.036496 & 0.277729 \\
\hline EHV45 & 45 & 0.397 & 0.602 & 0.362 & 0.057495 & 0.362404 \\
\hline EHV50R & 50 & 0.446 & 0.688 & 0.394 & 0.086656 & 0.473344 \\
\hline EHV55 & 55 & 0.496 & 0.838 & 0.432 & 0.164971 & 0.702244 \\
\hline EHV60R & 60 & 0.547 & 1.030 & 0.479 & 0.303287 & 1.06090 \\
\hline
\end{tabular}


Table 9.11-7: Geometric Rule of Mixtures, Carbon Black Composite

\begin{tabular}{|c|c|c|c|c|c|c|}
\hline \multicolumn{2}{|r|}{$\mathrm{TC}(\mathrm{W} / \mathrm{mK})$} & & & $\begin{array}{l}0.047189 \\
\text { epsilon(y) }\end{array}$ & $\begin{array}{c}0.034871 \\
\operatorname{sum}\left((y(i)-y(m o d))^{\wedge} 2\right)\end{array}$ & $\begin{array}{c}0.738959 \\
\operatorname{sum}\left(y(i)^{\wedge} 2\right)\end{array}$ \\
\hline \multirow{2}{*}{\multicolumn{3}{|c|}{ Filler }} & & & & \\
\hline & & & \multirow{2}{*}{$\begin{array}{l}\mathrm{TC}(\mathrm{W} / \mathrm{mK}) \\
\text { Experimental }\end{array}$} & \multirow{2}{*}{$\begin{array}{l}\mathrm{TC}(\mathrm{W} / \mathrm{mK}) \\
\text { Calculated }\end{array}$} & & \\
\hline Formulation & wt $\%$ filler & vol\% filler & & & $(y(i)-y(\bmod ))^{\wedge} 2$ & $y(i)^{\wedge} 2$ \\
\hline EVR & 0 & 0.000 & 0.217 & 0.220 & 0.000010 & 0.047046 \\
\hline EAV2.5 & 2.5 & 0.019 & 0.242 & 0.230 & 0.000141 & 0.058419 \\
\hline EAV4R & 4 & 0.031 & 0.258 & 0.236 & 0.000482 & 0.066616 \\
\hline EAV5R & 5 & 0.039 & 0.269 & 0.240 & 0.000801 & 0.072200 \\
\hline EAV6 & 6 & 0.047 & 0.293 & 0.245 & 0.002381 & 0.086084 \\
\hline EAV7.5 & 7.5 & 0.060 & 0.322 & 0.252 & 0.004913 & 0.103491 \\
\hline EAV10 & 10 & 0.080 & 0.364 & 0.263 & 0.010021 & 0.132132 \\
\hline EAV15 & 15 & 0.121 & 0.416 & 0.289 & 0.016123 & 0.172973 \\
\hline
\end{tabular}


Table 9.11-8: Geometric Rule of Mixtures, Synthetic Graphite Composite

\begin{tabular}{|c|c|c|c|c|c|c|}
\hline \multicolumn{2}{|r|}{$\mathrm{TC}(\mathrm{W} / \mathrm{mK})$} & & & $\begin{array}{l}85.5646 \\
\text { epsilon(y) }\end{array}$ & $\begin{array}{c}2048.31 \\
\operatorname{sum}\left((y(i)-y(m o d))^{\wedge} 2\right)\end{array}$ & $\begin{array}{c}23.9387 \\
\operatorname{sum}\left(y(\mathrm{i})^{\wedge} 2\right)\end{array}$ \\
\hline Filler & 600 & & & & & \\
\hline & & & \multirow{2}{*}{$\begin{array}{l}\mathrm{TC}(\mathrm{W} / \mathrm{mK}) \\
\text { Experimental }\end{array}$} & \multirow{2}{*}{$\begin{array}{l}\mathrm{TC}(\mathrm{W} / \mathrm{mK}) \\
\text { Calculated }\end{array}$} & & \\
\hline Formulation & wt $\%$ filler & vol\% filler & & & $(y(i)-y(m o d))^{\wedge} 2$ & $y(i)^{\wedge} 2$ \\
\hline EVR & 0 & 0.000 & 0.217 & 0.220 & 0.000010 & 0.047046 \\
\hline EBV10 & 10 & 0.065 & 0.294 & 0.368 & 0.005507 & 0.086142 \\
\hline EBV15 & 15 & 0.099 & 0.349 & 0.483 & 0.017784 & 0.122080 \\
\hline EBV20 & 20 & 0.135 & 0.387 & 0.641 & 0.064366 & 0.149692 \\
\hline EBV25 & 25 & 0.172 & 0.470 & 0.858 & 0.150439 & 0.220806 \\
\hline EBV30 & 30 & 0.211 & 0.546 & 1.171 & 0.389570 & 0.298553 \\
\hline EBV35 & 35 & 0.252 & 0.611 & 1.615 & 1.00922 & 0.372832 \\
\hline EBV40 & 40 & 0.293 & 0.706 & 2.234 & 2.33369 & 0.499001 \\
\hline EBV45 & 45 & 0.338 & 0.880 & 3.189 & 5.33114 & 0.775104 \\
\hline EBV50 & 50 & 0.385 & 1.108 & 4.611 & 12.2710 & 1.22789 \\
\hline EBV55 & 55 & 0.433 & 1.285 & 6.766 & 30.0405 & 1.65148 \\
\hline EBV60 & 60 & 0.484 & 1.559 & 10.123 & 73.3514 & 2.42923 \\
\hline EBV65 & 65 & 0.537 & 1.943 & 15.420 & 181.652 & 3.77369 \\
\hline EBV70 & 70 & 0.593 & 2.323 & 23.978 & 468.953 & 5.39401 \\
\hline EBV75 & 75 & 0.652 & 2.625 & 38.301 & 1272.74 & 6.89115 \\
\hline
\end{tabular}


Table 9.11-9: Geometric Rule of Mixtures, Carbon Fiber Composite

\begin{tabular}{|c|c|c|c|c|c|c|}
\hline \multicolumn{2}{|r|}{$\mathrm{TC}(\mathrm{W} / \mathrm{mK})$} & & & $\begin{array}{c}1.60887 \\
\text { epsilon(y) }\end{array}$ & $\begin{array}{c}6.02546 \\
\operatorname{sum}\left((y(i)-y(\bmod ))^{\wedge} 2\right)\end{array}$ & $\begin{array}{c}3.7452 \\
\operatorname{sum}\left(y(i)^{\wedge} 2\right)\end{array}$ \\
\hline Filler & 20 & & & & & \\
\hline & & & \multirow{2}{*}{$\begin{array}{l}\mathrm{TC}(\mathrm{W} / \mathrm{mK}) \\
\text { Experimental }\end{array}$} & \multirow{2}{*}{$\begin{array}{l}\mathrm{TC}(\mathrm{W} / \mathrm{mK}) \\
\text { Calculated }\end{array}$} & & \\
\hline Formulation & wt $\%$ filler & vol\% filler & & & $(y(i)-y(m o d))^{\wedge} 2$ & $y(i)^{\wedge} 2$ \\
\hline EVR & 0 & 0.000 & 0.217 & 0.220 & 0.000010 & 0.047046 \\
\hline EHV5 & 5 & 0.041 & 0.238 & 0.265 & 0.000712 & 0.056644 \\
\hline EHV7.5 & 7.5 & 0.061 & 0.255 & 0.290 & 0.001202 & 0.065025 \\
\hline EHV10 & 10 & 0.082 & 0.271 & 0.318 & 0.002251 & 0.073441 \\
\hline EHV15 & 15 & 0.124 & 0.282 & 0.385 & 0.010578 & 0.079524 \\
\hline EHV20 & 20 & 0.168 & 0.320 & 0.469 & 0.022296 & 0.102400 \\
\hline EHV25 & 25 & 0.212 & 0.353 & 0.572 & 0.048106 & 0.124609 \\
\hline EHV30 & 30 & 0.255 & 0.365 & 0.695 & 0.108776 & 0.133225 \\
\hline EHV35 & 35 & 0.302 & 0.432 & 0.859 & 0.182209 & 0.186624 \\
\hline EHV40 & 40 & 0.349 & 0.527 & 1.062 & 0.285838 & 0.277729 \\
\hline EHV45 & 45 & 0.397 & 0.602 & 1.318 & 0.512979 & 0.362404 \\
\hline EHV50R & 50 & 0.446 & 0.688 & 1.644 & 0.914368 & 0.473344 \\
\hline EHV55 & 55 & 0.496 & 0.838 & 2.060 & 1.49357 & 0.702244 \\
\hline EHV60R & 60 & 0.547 & 1.030 & 2.593 & 2.44257 & 1.0609 \\
\hline
\end{tabular}


Table 9.11-10: Nielsen’s Model, Carbon Black Composite

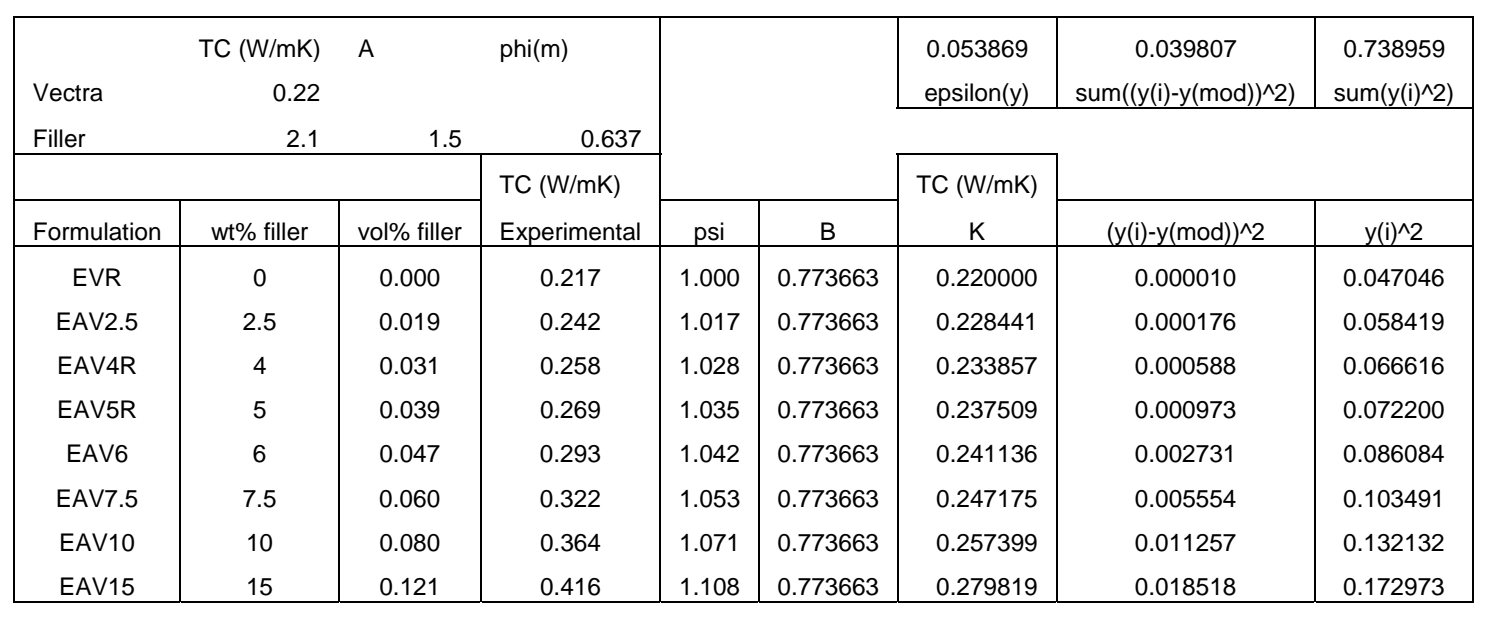


Table 9.11-11: Nielsen's Model, Synthetic Graphite Composite

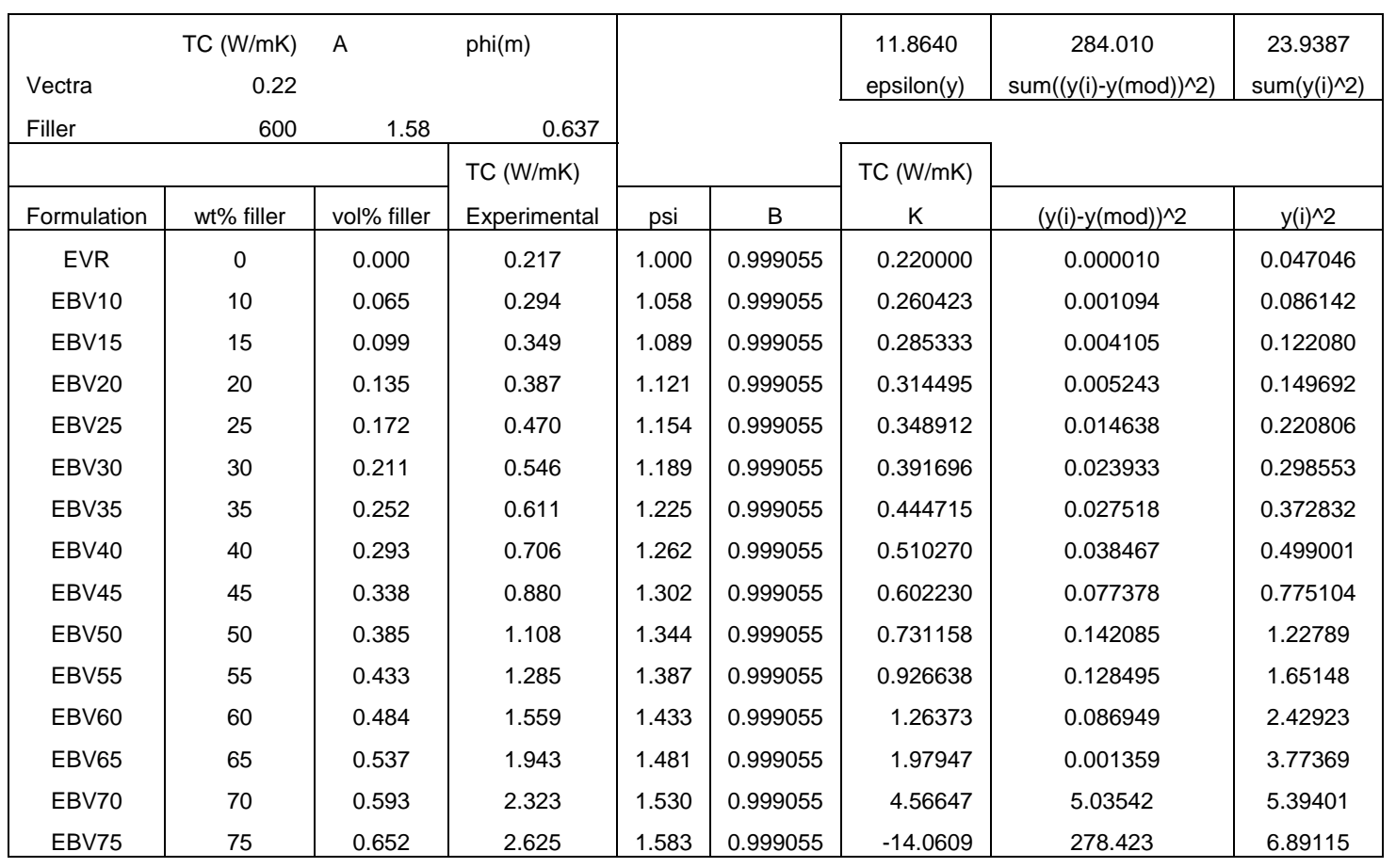


Table 9.11-12: Nielsen's Model, Carbon Fiber Composite

\begin{tabular}{|c|c|c|c|c|c|c|c|c|}
\hline Vectra & $\begin{array}{r}\mathrm{TC}(\mathrm{W} / \mathrm{mK}) \\
0.22\end{array}$ & A & phi(m) & & & \multirow[t]{2}{*}{$\begin{array}{c}431.171 \\
\text { epsilon(y) }\end{array}$} & \multirow[t]{2}{*}{$\begin{array}{c}1614.803 \\
\operatorname{sum}\left((y(i)-y(\bmod ))^{\wedge} 2\right)\end{array}$} & \multirow[t]{2}{*}{$\begin{array}{r}3.74516 \\
\operatorname{sum}\left(y(i)^{\wedge} 2\right)\end{array}$} \\
\hline Filler & 20 & 4.29 & 0.52 & & & & & \\
\hline & & & \multirow{2}{*}{$\begin{array}{l}\text { TC }(\mathrm{W} / \mathrm{mK}) \\
\text { Experimental }\end{array}$} & & & \multirow{2}{*}{$\begin{array}{c}\mathrm{TC}(\mathrm{W} / \mathrm{mK}) \\
\mathrm{K}\end{array}$} & & \\
\hline Formulation & wt $\%$ filler & vol\% filler & & psi & $\mathrm{B}$ & & $(y(i)-y(m o d))^{\wedge} 2$ & $y(i)^{\wedge} 2$ \\
\hline EVR & 0 & 0.000 & 0.217 & 1.000 & 0.944432 & 0.220000 & 0.000010 & 0.047046 \\
\hline EHV5 & 5 & 0.041 & 0.238 & 1.073 & 0.944432 & 0.267664 & 0.000880 & 0.056644 \\
\hline EHV7.5 & 7.5 & 0.061 & 0.255 & 1.108 & 0.944432 & 0.293086 & 0.001451 & 0.065025 \\
\hline EHV10 & 10 & 0.082 & 0.271 & 1.146 & 0.944432 & 0.321624 & 0.002563 & 0.073441 \\
\hline EHV15 & 15 & 0.124 & 0.282 & 1.220 & 0.944432 & 0.385630 & 0.010739 & 0.079524 \\
\hline EHV20 & 20 & 0.168 & 0.320 & 1.298 & 0.944432 & 0.465667 & 0.021219 & 0.102400 \\
\hline EHV25 & 25 & 0.212 & 0.353 & 1.376 & 0.944432 & 0.564536 & 0.044747 & 0.124609 \\
\hline EHV30 & 30 & 0.255 & 0.365 & 1.453 & 0.944432 & 0.687983 & 0.104318 & 0.133225 \\
\hline EHV35 & 35 & 0.302 & 0.432 & 1.536 & 0.944432 & 0.870634 & 0.192399 & 0.186624 \\
\hline EHV40 & 40 & 0.349 & 0.527 & 1.620 & 0.944432 & 1.13919 & 0.374778 & 0.277729 \\
\hline EHV45 & 45 & 0.397 & 0.602 & 1.705 & 0.944432 & 1.59042 & 0.976975 & 0.362404 \\
\hline EHV50R & 50 & 0.446 & 0.688 & 1.792 & 0.944432 & 2.51752 & 3.34713 & 0.473344 \\
\hline EHV55 & 55 & 0.496 & 0.838 & 1.880 & 0.944432 & 5.55864 & 22.2844 & 0.702244 \\
\hline EHV60R & 60 & 0.547 & 1.030 & 1.971 & 0.944432 & -38.8127 & 1587.441 & 1.06090 \\
\hline
\end{tabular}


Table 9.11-13: Modified Nielsen's Model, Carbon Black Composite

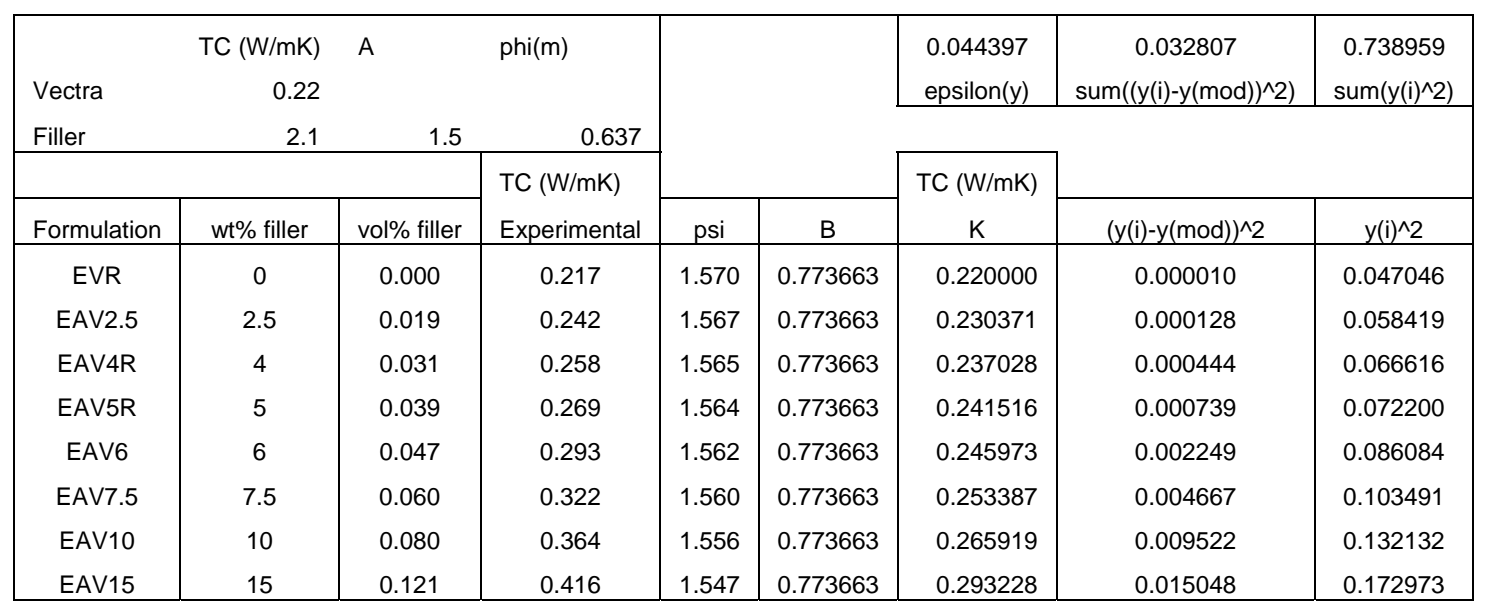


Table 9.11-14: Modified Nielsen’s Model, Synthetic Graphite Composite

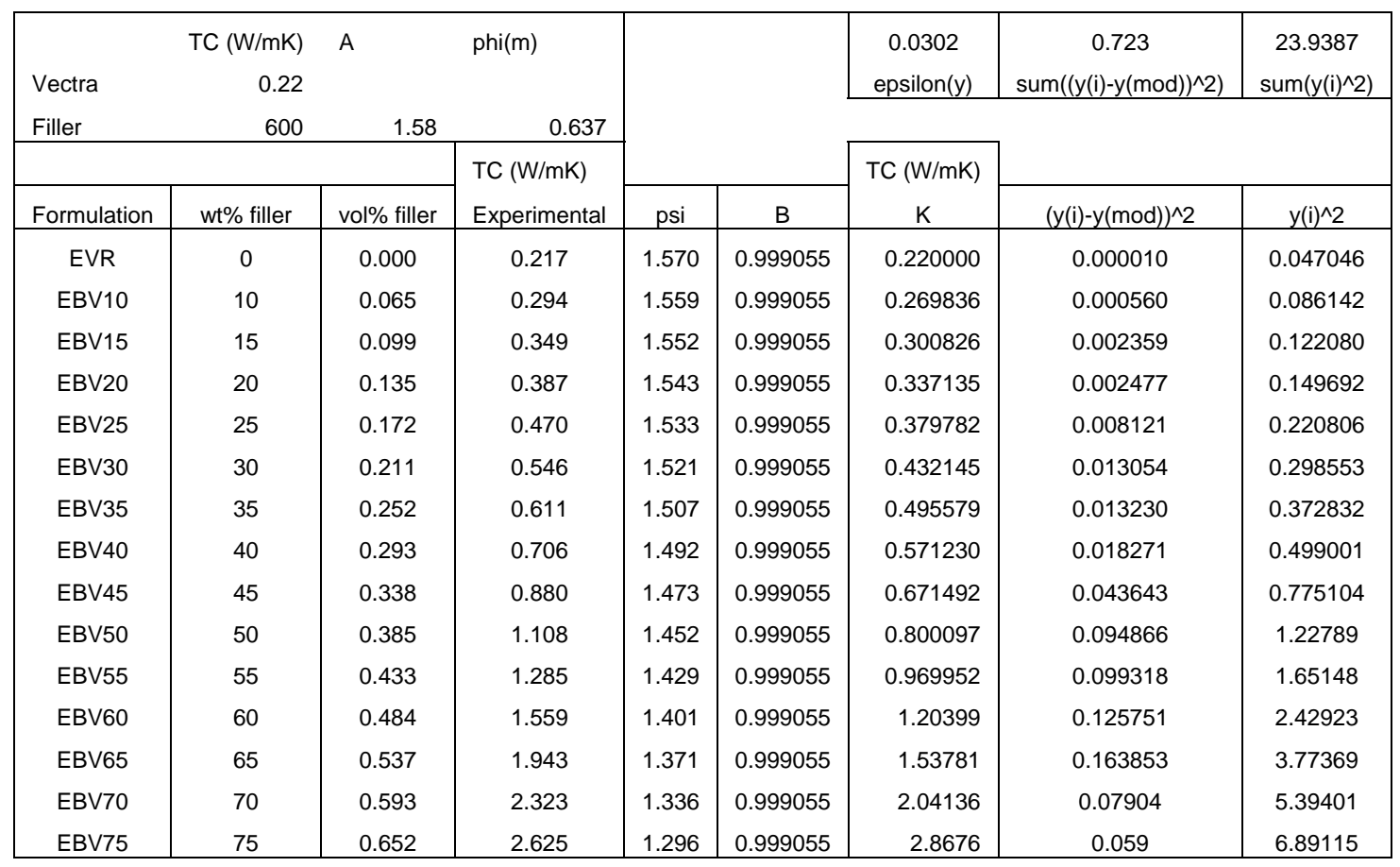


Table 9.11-15: Modified Nielsen's Model, Carbon Fiber Composite

\begin{tabular}{|c|c|c|c|c|c|c|c|c|}
\hline Vectra & $\begin{array}{r}\mathrm{TC}(\mathrm{W} / \mathrm{mK}) \\
0.22\end{array}$ & $A$ & phi(m) & & & \multirow[t]{2}{*}{$\begin{array}{c}1.974 \\
\text { epsilon(y) }\end{array}$} & $\begin{array}{c}7.392 \\
\operatorname{sum}\left((y(i)-y(\bmod ))^{\wedge} 2\right)\end{array}$ & \multirow[t]{2}{*}{$\begin{array}{c}3.74516 \\
\operatorname{sum}\left(y(i)^{\wedge} 2\right)\end{array}$} \\
\hline Filler & 20 & 4.29 & 0.52 & & & & & \\
\hline & & & TC (W/mK) & & & $\mathrm{TC}(\mathrm{W} / \mathrm{mK})$ & & \\
\hline Formulation & wt $\%$ filler & vol\% filler & Experimental & psi & $\mathrm{B}$ & $\mathrm{K}$ & $(y(i)-y(\bmod ))^{\wedge} 2$ & $y(i)^{\wedge} 2$ \\
\hline EVR & 0 & 0.000 & 0.217 & 1.923 & 0.944432 & 0.220000 & 0.000010 & 0.047046 \\
\hline EHV5 & 5 & 0.041 & 0.238 & 1.888 & 0.944432 & 0.276783 & 0.001504 & 0.056644 \\
\hline EHV7.5 & 7.5 & 0.061 & 0.255 & 1.871 & 0.944432 & 0.307523 & 0.002759 & 0.065025 \\
\hline EHV10 & 10 & 0.082 & 0.271 & 1.853 & 0.944432 & 0.342203 & 0.005070 & 0.073441 \\
\hline EHV15 & 15 & 0.124 & 0.282 & 1.817 & 0.944432 & 0.419870 & 0.019008 & 0.079524 \\
\hline EHV20 & 20 & 0.168 & 0.320 & 1.779 & 0.944432 & 0.515130 & 0.038076 & 0.102400 \\
\hline EHV25 & 25 & 0.212 & 0.353 & 1.740 & 0.944432 & 0.627664 & 0.075440 & 0.124609 \\
\hline EHV30 & 30 & 0.255 & 0.365 & 1.702 & 0.944432 & 0.758085 & 0.154516 & 0.133225 \\
\hline EHV35 & 35 & 0.302 & 0.432 & 1.661 & 0.944432 & 0.929332 & 0.247339 & 0.186624 \\
\hline EHV40 & 40 & 0.349 & 0.527 & 1.618 & 0.944432 & 1.13828 & 0.373669 & 0.277729 \\
\hline EHV45 & 45 & 0.397 & 0.602 & 1.575 & 0.944432 & 1.40153 & 0.639245 & 0.362404 \\
\hline EHV50R & 50 & 0.446 & 0.688 & 1.530 & 0.944432 & 1.73773 & 1.10194 & 0.473344 \\
\hline EHV55 & 55 & 0.496 & 0.838 & 1.484 & 0.944432 & 2.17355 & 1.7837 & 0.702244 \\
\hline EHV60R & 60 & 0.547 & 1.030 & 1.437 & 0.944432 & 2.7475 & 2.950 & 1.06090 \\
\hline
\end{tabular}


Table 9.11-16: Optimized Nielsen’s Model, Carbon Black Composite

\begin{tabular}{|c|c|c|c|c|c|c|c|c|}
\hline Vectra & $\begin{array}{r}\mathrm{TC}(\mathrm{W} / \mathrm{mK}) \\
0.22\end{array}$ & A & phi(m) & & & $\begin{array}{l}0.000948 \\
\text { epsilon(y) }\end{array}$ & $\begin{array}{c}0.000701 \\
\operatorname{sum}\left((y(i)-y(\bmod ))^{\wedge} 2\right)\end{array}$ & $\begin{array}{r}0.738959 \\
\operatorname{sum}\left(y(i)^{\wedge} 2\right) \\
\end{array}$ \\
\hline Filler & 2.1 & 47.3142 & 0.637 & & & \multirow{3}{*}{$\begin{array}{c}\mathrm{TC}(\mathrm{W} / \mathrm{mK}) \\
\mathrm{K}\end{array}$} & & \\
\hline & & & \multirow{2}{*}{$\begin{array}{l}\mathrm{TC}(\mathrm{W} / \mathrm{mK}) \\
\text { Experimental }\end{array}$} & & & & & \\
\hline Formulation & wt $\%$ filler & vol\% filler & & psi & $\mathrm{B}$ & & $(y(i)-y(m o d))^{\wedge} 2$ & $y(i)^{\wedge} 2$ \\
\hline EVR & 0 & 0.000 & 0.217 & 1.000 & 0.150290 & 0.220000 & 0.000010 & 0.047046 \\
\hline EAV2.5 & 2.5 & 0.019 & 0.242 & 1.017 & 0.150290 & 0.251094 & 0.000088 & 0.058419 \\
\hline EAV4R & 4 & 0.031 & 0.258 & 1.028 & 0.150290 & 0.270434 & 0.000152 & 0.066616 \\
\hline EAV5R & 5 & 0.039 & 0.269 & 1.035 & 0.150290 & 0.283212 & 0.000211 & 0.072200 \\
\hline EAV6 & 6 & 0.047 & 0.293 & 1.042 & 0.150290 & 0.295703 & 0.000005 & 0.086084 \\
\hline EAV7.5 & 7.5 & 0.060 & 0.322 & 1.053 & 0.150290 & 0.316058 & 0.000032 & 0.103491 \\
\hline EAV10 & 10 & 0.080 & 0.364 & 1.071 & 0.150290 & 0.349327 & 0.000201 & 0.132132 \\
\hline EAV15 & 15 & 0.121 & 0.416 & 1.108 & 0.150290 & 0.417375 & 0.000002 & 0.172973 \\
\hline
\end{tabular}


Table 9.11-17: Optimized Nielsen’s Model, Synthetic Graphite Composite

\begin{tabular}{|c|c|c|c|c|c|c|c|c|}
\hline Vectra & $\begin{array}{r}\mathrm{TC}(\mathrm{W} / \mathrm{mK}) \\
0.22\end{array}$ & A & phi(m) & & & \multirow[t]{2}{*}{$\begin{array}{c}3.83693 \\
\text { epsilon(y) }\end{array}$} & $\begin{array}{c}91.8511 \\
\operatorname{sum}\left((y(i)-y(\bmod ))^{\wedge} 2\right)\end{array}$ & \multirow[t]{2}{*}{$\begin{array}{c}23.9387 \\
\operatorname{sum}\left(y(i)^{\wedge} 2\right)\end{array}$} \\
\hline Filler & 600 & 0.0000 & 0.637 & & & & & \\
\hline & & & $\mathrm{TC}(\mathrm{W} / \mathrm{mK})$ & & & $\mathrm{TC}(\mathrm{W} / \mathrm{mK})$ & & \\
\hline Formulation & wt $\%$ filler & vol\% filler & Experimental & psi & $\mathrm{B}$ & $\mathrm{K}$ & $(y(i)-y(m o d))^{\wedge} 2$ & $y(i)^{\wedge} 2$ \\
\hline EVR & 0 & 0.000 & 0.217 & 1.000 & 0.999633 & 0.220000 & 0.000010 & 0.047046 \\
\hline EBV10 & 10 & 0.065 & 0.294 & 1.058 & 0.999633 & 0.236223 & 0.003281 & 0.086142 \\
\hline EBV15 & 15 & 0.099 & 0.349 & 1.089 & 0.999633 & 0.246672 & 0.010553 & 0.122080 \\
\hline EBV20 & 20 & 0.135 & 0.387 & 1.121 & 0.999633 & 0.259242 & 0.016297 & 0.149692 \\
\hline EBV25 & 25 & 0.172 & 0.470 & 1.154 & 0.999633 & 0.274449 & 0.038201 & 0.220806 \\
\hline EBV30 & 30 & 0.211 & 0.546 & 1.189 & 0.999633 & 0.293784 & 0.063815 & 0.298553 \\
\hline EBV35 & 35 & 0.252 & 0.611 & 1.225 & 0.999633 & 0.318240 & 0.085475 & 0.372832 \\
\hline EBV40 & 40 & 0.293 & 0.706 & 1.262 & 0.999633 & 0.349021 & 0.127720 & 0.499001 \\
\hline EBV45 & 45 & 0.338 & 0.880 & 1.302 & 0.999633 & 0.392886 & 0.237670 & 0.775104 \\
\hline EBV50 & 50 & 0.385 & 1.108 & 1.344 & 0.999633 & 0.455238 & 0.426228 & 1.22789 \\
\hline EBV55 & 55 & 0.433 & 1.285 & 1.387 & 0.999633 & 0.550869 & 0.539095 & 1.65148 \\
\hline EBV60 & 60 & 0.484 & 1.559 & 1.433 & 0.999633 & 0.71734 & 0.707722 & 2.42923 \\
\hline EBV65 & 65 & 0.537 & 1.943 & 1.481 & 0.999633 & 1.07356 & 0.755226 & 3.77369 \\
\hline EBV70 & 70 & 0.593 & 2.323 & 1.530 & 0.999633 & 2.37201 & 0.002451 & 5.39401 \\
\hline EBV75 & 75 & 0.652 & 2.625 & 1.583 & 0.999633 & -6.8003 & 88.8373 & 6.89115 \\
\hline
\end{tabular}


Table 9.11-18: Optimized Nielsen's Model, Carbon Fiber Composite

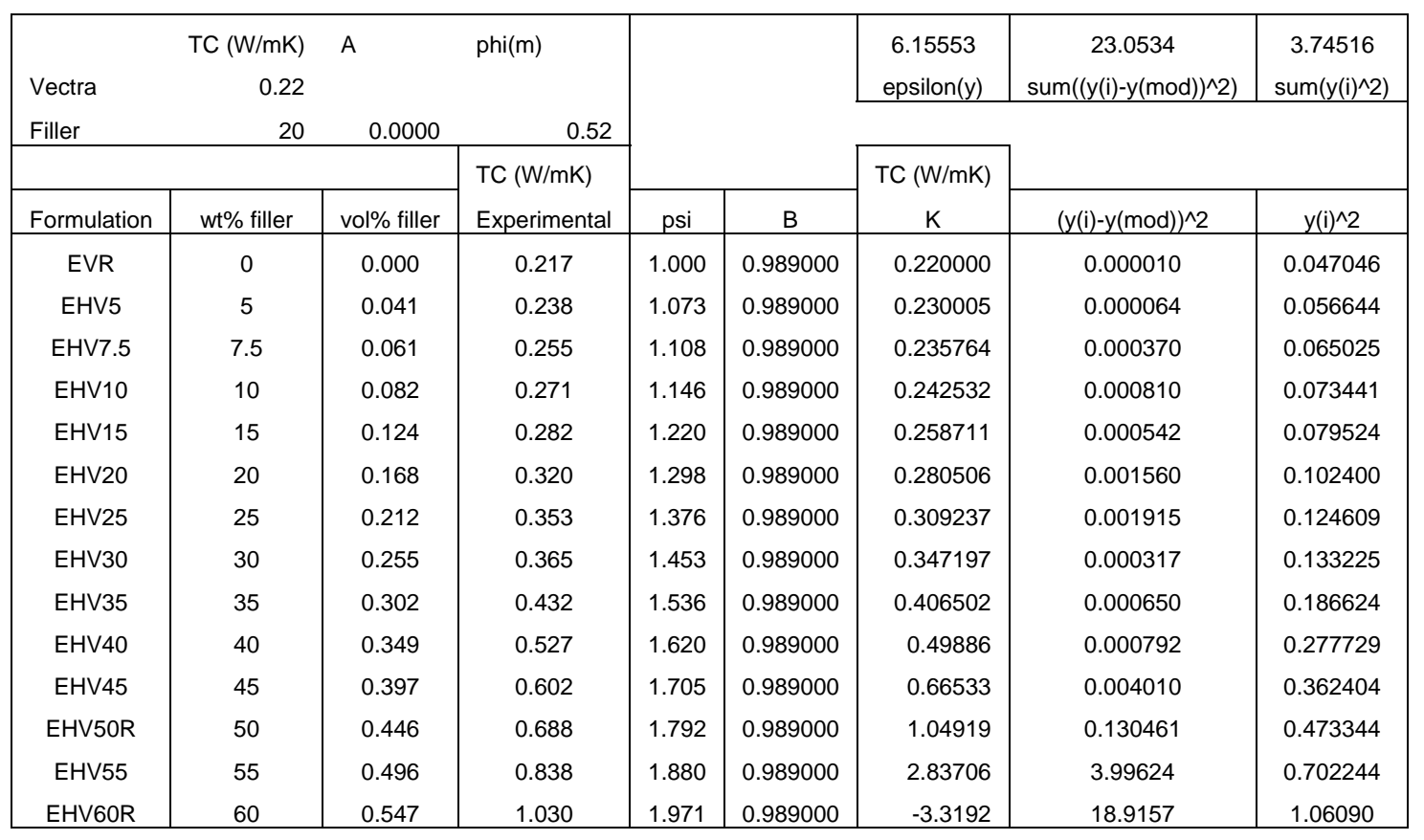


Table 9.11-19: Optimized Modified Nielsen’s Model, Carbon Black Composite

\begin{tabular}{|c|c|c|c|c|c|c|c|c|}
\hline Vectra & $\begin{array}{r}\mathrm{TC}(\mathrm{W} / \mathrm{mK}) \\
0.22\end{array}$ & A & phi(m) & & & $\begin{array}{l}0.000935 \\
\text { epsilon(y) }\end{array}$ & $\begin{array}{c}0.000691 \\
\operatorname{sum}\left((y(i)-y(\bmod ))^{\wedge} 2\right)\end{array}$ & $\begin{array}{r}0.738959 \\
\operatorname{sum}\left(y(i)^{\wedge} 2\right) \\
\end{array}$ \\
\hline Filler & 2.1 & 41.5020 & 0.637 & & & \multirow{3}{*}{$\begin{array}{c}\mathrm{TC}(\mathrm{W} / \mathrm{mK}) \\
\mathrm{K} \\
\end{array}$} & & \\
\hline & & & \multirow{2}{*}{$\begin{array}{l}\mathrm{TC}(\mathrm{W} / \mathrm{mK}) \\
\text { Experimental }\end{array}$} & & & & & \\
\hline Formulation & wt $\%$ filler & vol\% filler & & psi & $\mathrm{B}$ & & $(y(i)-y(m o d))^{\wedge} 2$ & $y(i)^{\wedge} 2$ \\
\hline EVR & 0 & 0.000 & 0.217 & 1.570 & 0.167402 & 0.220000 & 0.000010 & 0.047046 \\
\hline EAV2.5 & 2.5 & 0.019 & 0.242 & 1.567 & 0.167402 & 0.250929 & 0.000085 & 0.058419 \\
\hline EAV4R & 4 & 0.031 & 0.258 & 1.565 & 0.167402 & 0.270216 & 0.000147 & 0.066616 \\
\hline EAV5R & 5 & 0.039 & 0.269 & 1.564 & 0.167402 & 0.282979 & 0.000204 & 0.072200 \\
\hline EAV6 & 6 & 0.047 & 0.293 & 1.562 & 0.167402 & 0.295469 & 0.000004 & 0.086084 \\
\hline EAV7.5 & 7.5 & 0.060 & 0.322 & 1.560 & 0.167402 & 0.315851 & 0.000034 & 0.103491 \\
\hline EAV10 & 10 & 0.080 & 0.364 & 1.556 & 0.167402 & 0.349230 & 0.000204 & 0.132132 \\
\hline EAV15 & 15 & 0.121 & 0.416 & 1.547 & 0.167402 & 0.417702 & 0.000003 & 0.172973 \\
\hline
\end{tabular}


Table 9.11-20: Optimized Modified Nielsen’s Model, Synthetic Graphite Composite

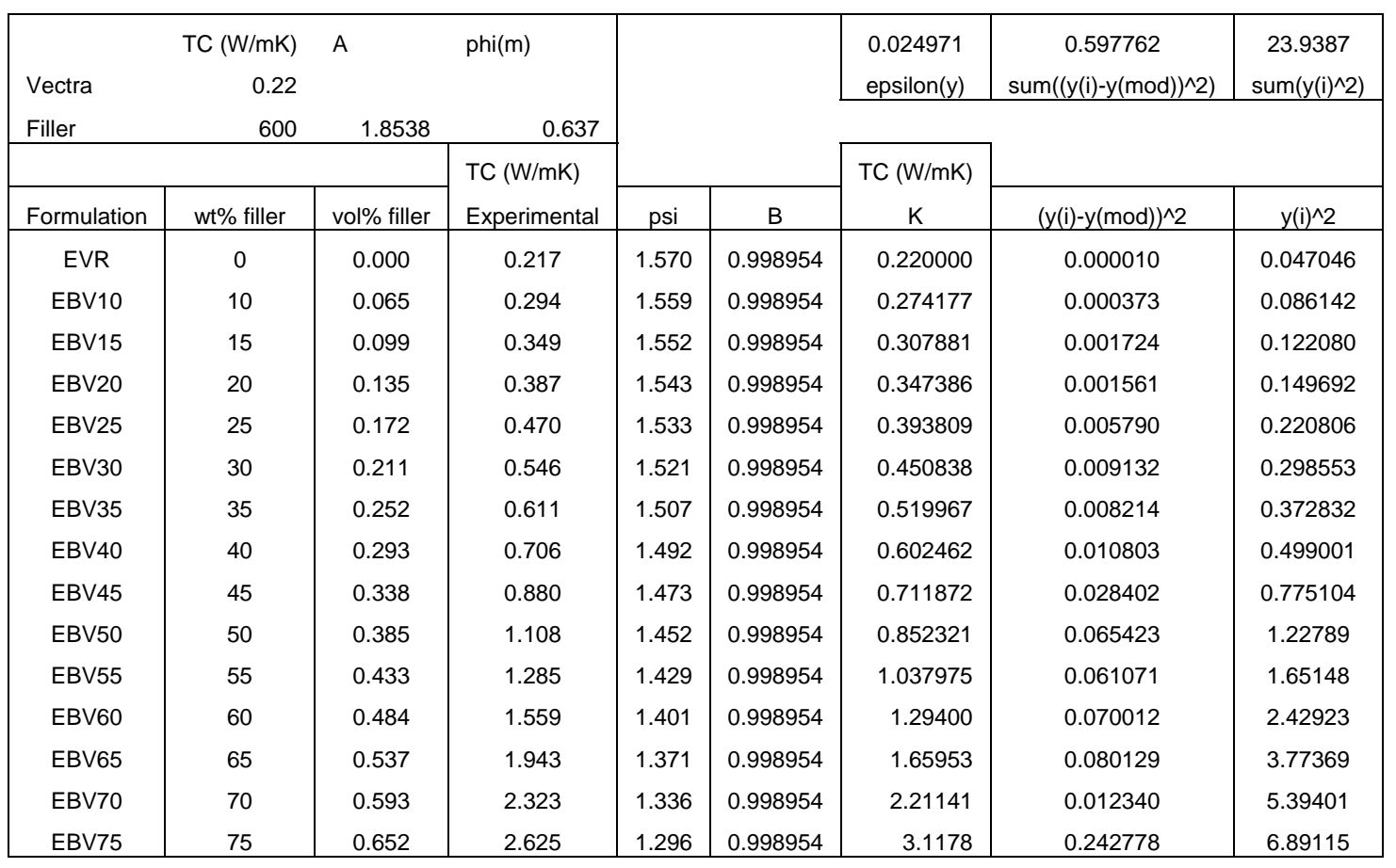


Table 9.11-21: Optimized Modified Nielsen's Model, Carbon Fiber Composite

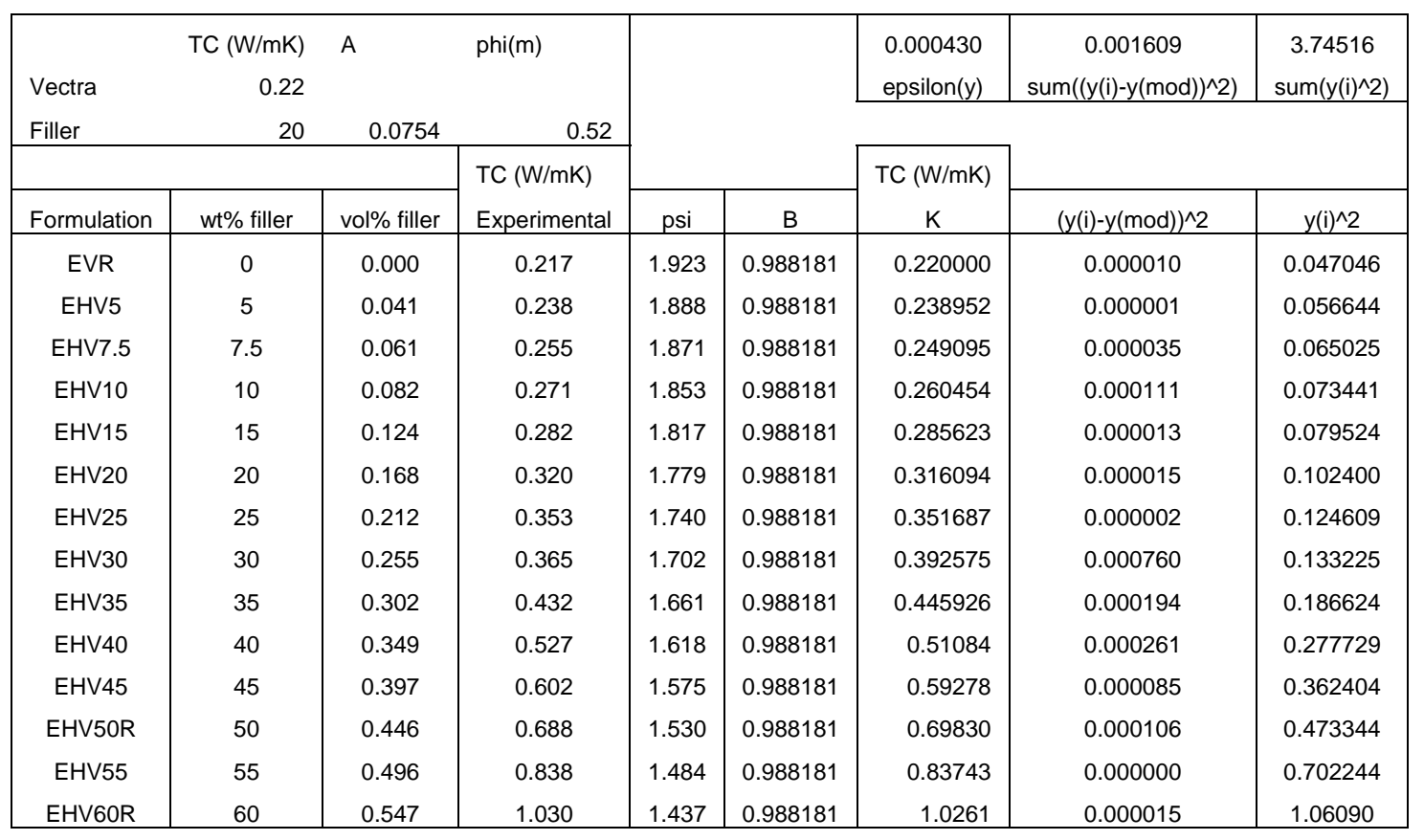

